\title{
GEOMECHANICAL PERFORMANCE OF HYDRATE-BEARING SEDIMENTS IN OFFSHORE ENVIRONMENTS
}

\author{
Phase I Topical Report
}

Authors
Stephen A. Holditch - Texas A\&M University
Tad Patzek - University of California, Berkeley
Richard Plumb - Schlumberger
Jonny Rutqvist and George Moridis - Lawrence Berkely National Labory
DOE Award Number: DE-FC26-05NT42664
CFDA Number: 81.089 (Fossil Energy Research and Development)

December 2006 


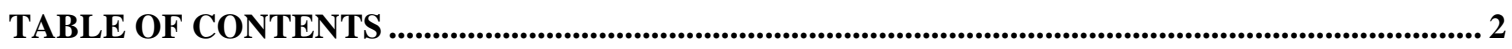

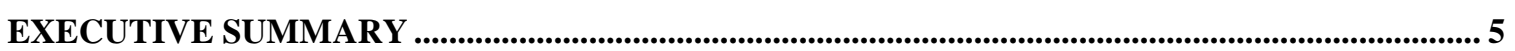

1. DEVELOPMENT OF A COUPLED GEOMECHANICAL NUMERICAL MODEL ................. 8

2. DEVELOPMENT OF INTERFACE BETWEEN PETREL AND FLAC3D ................................ 17

3. DESCRIPTION OF HYDRATE BEARING SEDIMENTS OFFSHORE INTRODUCTION .. 18

4. REVIEW OF THE GAS HYDRATE EXPERIMENTAL STUDIES IN POROUS MEDIA ..... 64

5. SYNTHETIC CORES IN THE LABORATORY FOR GAS HYDRATE TESTING ................. 86

6. ANNUAL REPORT FROM UNIVERSITY OF CALIFORNIA AT BERKELEY .....................91

7. CONCLUSIONS FROM PHASE I ................................................................................................... 92

8. REFERENCES.......................................................................................................................... 95

"This report was prepared as an account of work sponsored by an agency of the United States Government. Neither the United States Government nor any agency thereof, nor any of their employees, makes any warranty, express or implies, or assumes any legal liability or responsibility for the accuracy, completeness, or usefulness of any information, apparatus, product, or process disclosed, or represents that its use would not infringe privately owned rights. Reference herein to any specific commercial product, process, or service by trade name, trademark, manufacture, or otherwise does not necessarily constitute or imply its endorsement, recommendation, or favoring by the United States Government or any agency thereof. The views and opinions of authors expressed herein do not necessarily state or reflect those of the United States Government or any agency thereof." 


\section{LIST OF FIGURES}

Figure 1.1 - Couplings of TOUGH+HYDRATE and FLAC3D for the analysis of geomechanical behavior

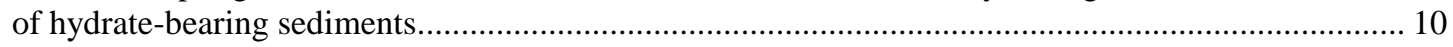

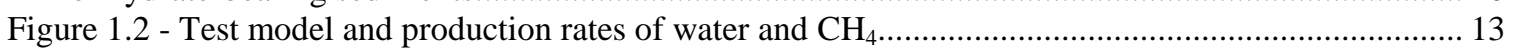

Figure 1.3 - Time dependent output from a test simulation with 15 days of production ............................... 15

Figure $1.4-\mathrm{TH}+$ /FLAC simulation output of solid saturations after 15 days of production........................... 16

Figure 1.5 - TH+/FLAC simulation output of mechanical properties after 15 days of production ............... 16

Figure 1.6 - TH+/FLAC simulation output of principal effective stresses after 15 days of production ....... 17

Figure $1.7-\mathrm{TH}+$ /FLAC simulation output of deformation after 15 days of production .............................. 17

Figure 3.1 - Different types of geometries of natural gas hydrates (Shipboard-Scientists 1996) ................. 22

Figure 3.2 - Map of the general area of gas hydrate on the basis of BSR (Shipboard-Scientists 1996) ....... 23

Figure 3.3 - Bathymetric map of the Blake Ridge region, Offshore Carolinas, USA (Shipboard-Scientists 1996).

Figure 3.4 - Summary of physical properties and thermal conductivity of the sediments from Site 994 C

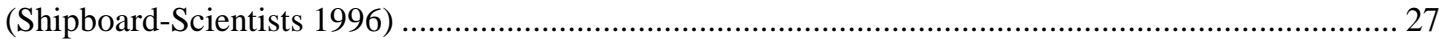

Figure 3.5 - Mineralogical variation of major sediment constituents (Shipboard-Scientists 1996).............. 28

Figure 3.6 - Physical properties and the thermal conductivity from Hole 995 A, Leg 164 (Shipboard-

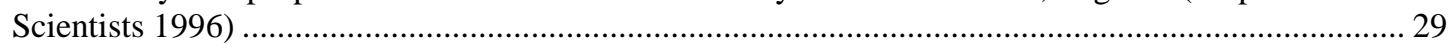

Figure 3.7 - Seismic profile of Site 996 at Blake Ridge (Shipboard-Scientists 1996)................................ 31

Figure 3.8 - Major mineral constituents of sediments based on XRD analysis and carbonate content in

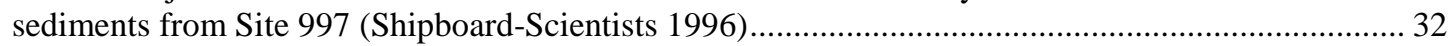

Figure 3.9 - Physical properties of sediments and their thermal conductivity from Site 997 (Shipboard-

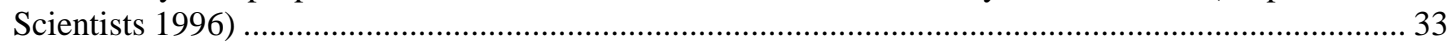

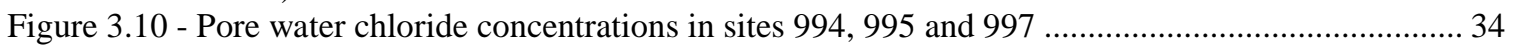

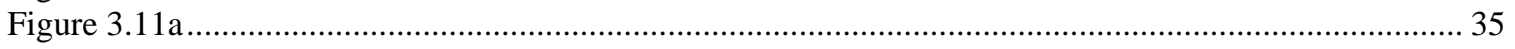

Figure 3.11c - Site 997 ................................................................................................................. 35

Figure 3.12 - Map of drilling sites at Cascadia Margin (Trehu, Torres et al. 2006) …….............................. 37

Figure 3.13 - Drilling sites during Leg 204 (Gracia, Martinez-Ruiz et al. 2006) ......................................... 38

Figure 3.14 - ODP Leg 204 Drill Sites (Trehu, Torres et al. 2006) .......................................................... 39

Figure 3.15a - Physical properties of Hole 1244 (Shipboard-Scientists 1996) ............................................ 44

Figure 3.15b - Physical properties of Hole 1249 B, C and F (Shipboard-Scientists 1996)........................... 44

Figure 3.15c - Physical properties of Hole 1251 B (Shipboard-Scientists 1996) ......................................... 45

Figure 3.16 - Grain size controls on hydrate distribution (Su, Song et al. 2006)......................................... 46

Figure 3.17 - Studied sites at Gulf of Mexico (Milkov and Sassen 2003) ................................................ 50

Figure 3.18 - Green Canyon 184/185 map (Milkov and Sassen 2003) ....................................................... 50

Figure 3.19 - Green Canyon 234/235 map (Milkov and Sassen 2003)........................................................ 51

Figure 3.20 - Garden Banks 388 map (Milkov and Sassen 2003) ........................................................... 51

Figure 3.21 - Mississippi Canyon 798/842 map (Milkov and Sassen 2003) ............................................... 52

Figure 3.22 - Green Canyon 204 map (Milkov and Sassen 2003) ............................................................ 52

Figure 3.23 - Mississippi Canyon 852/853 map (Milkov and Sassen 2003) ................................................ 53

Figure 3.24 - Atwater Valley 425 map (Milkov and Sassen 2003) ............................................................. 53

Figure 3.25 - Water content of GOM shallow sediments (Francisca, Yun et al. 2005) ................................ 54

Figure 3.26 - Water content of GOM sediments from conventional piston cores (Yun, Narsilio et al. 2007)

AT-Mound (filled circles), Atwater Valley (open circles), Keathley Canyon (cross) ............................ 55

Figure 3.27 - Geological setting of Nankai accretionary prism (He, Matsubayashi et al. 2006) .................. 57

Figure 4.1 - Uchida et al Experimental Set-up ........................................................................................ 64

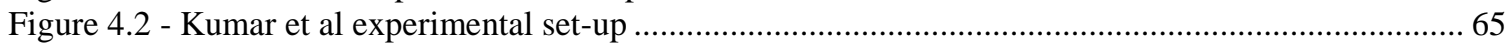

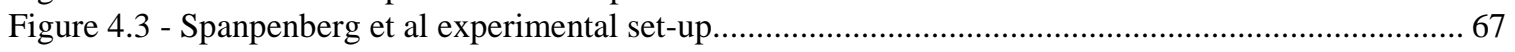

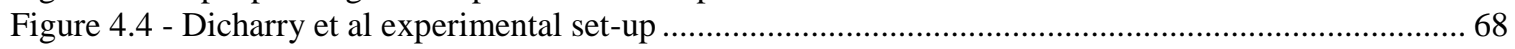

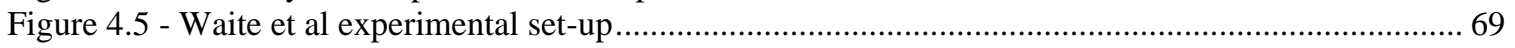

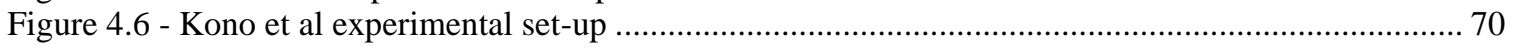

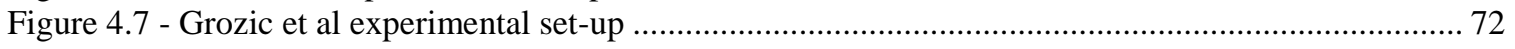

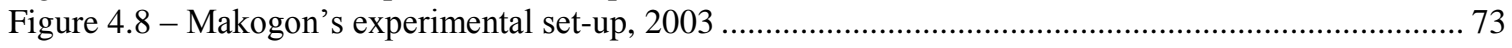

Figure 4.9 - Zatsepina and Buffett experimental set-up............................................................................... 75

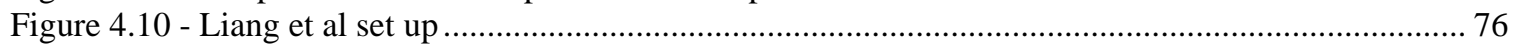


Figure 4.11 - Model for hydrate formation in wet activated carbon (Yan, Chen et al. 2005)....................... 77

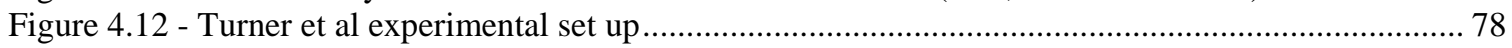

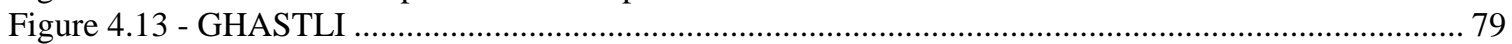

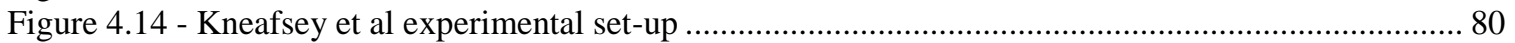

Figure 4.15 - Huang and Fang experimental set-up............................................................................ 81

Figure 4.16 - P-T trace for methane hydrate formation in pore space (Makogon 2006) ............................... 82

Figure 4.17 - Methane hydrate formation and dissociation in porous media (Makogon 2006) ..................... 83

Figure 4.18 - Capillary pressure with pore radius at different pore water pressures. .................................. 84

\section{LIST OF TABLES}

Table 3.1 - Description of gas hydrates in porous media (Shipboard-Scientists 1996) ............................... 21

Table 3.2 - Summary of water depths, penetration and formation at Blake Ridge (ODP Leg 164)............ 26

Table 3.3 - Geotechnical and physical properties of sediments from Blake Ridge (Winters 2000).............. 30

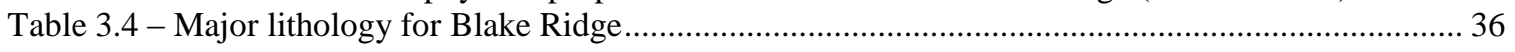

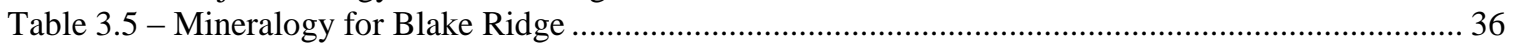

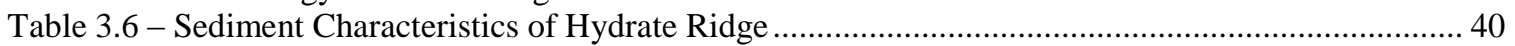

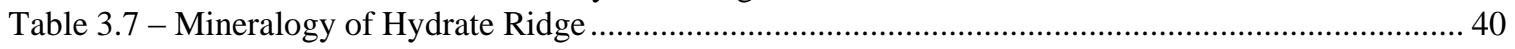

Table 3.8 - Summary of Cascadia Margin Coring Operations ...................................................................... 41

Table 3.9 - Analysis of various samples for the grain sizes in the gas hydrate stability zone ( $\mathrm{Su}$, Song et al.

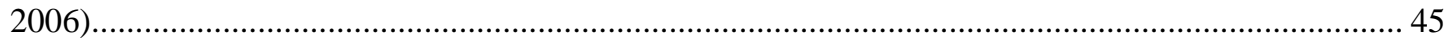

Table 3.10 - Subsurface temperatures and thermal properties at Hydrate Ridge ......................................... 47

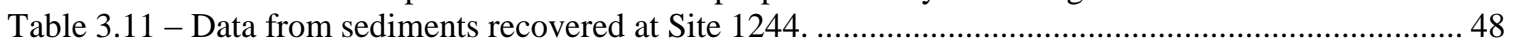

Table 3.12 - Areas in the Gulf of Mexico Studied by Sassen and Associates.............................................. 49

Table 3.13 - Sediment data from 3 Sites in the Gulf of Mexico .................................................................. 54

Table 3.14 - USGS Open-file Report 96-272 Describing Sites in the GOM ................................................. 56

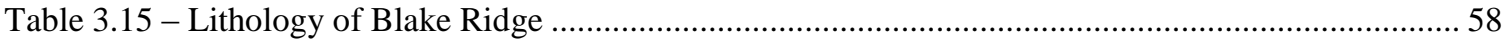

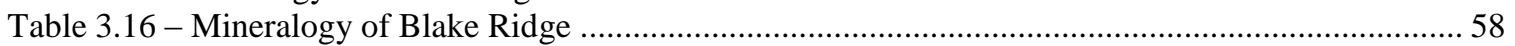

Table 3.17 - Index Properties of Sediments in Holes............................................................................... 59

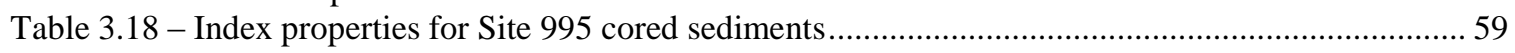

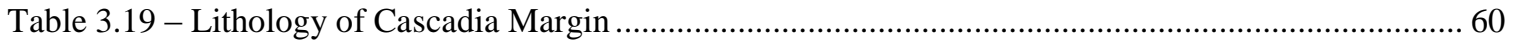

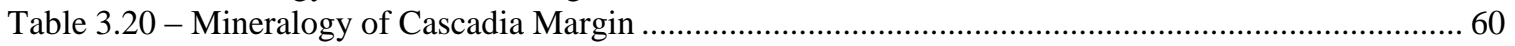

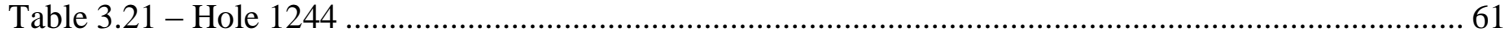

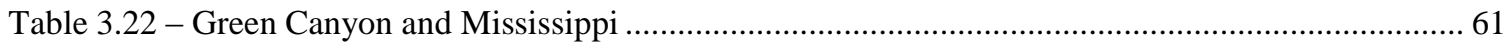

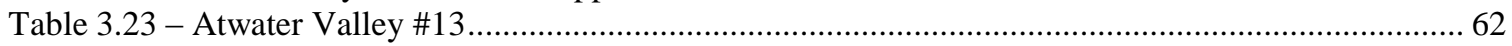

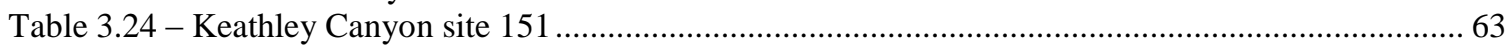

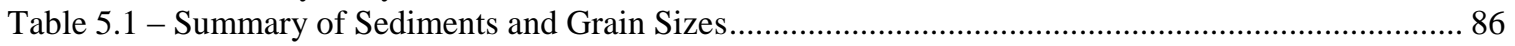




\section{Executive Summary}

The main objective of this study is to develop the necessary knowledge base and quantitative predictive capability for the description of geomechanical performance of hydratebearing sediments (hereafter referred to as HBS) in oceanic environments. The focus is on the determination of the envelope of hydrate stability under conditions typical of those related to the construction and operation of offshore platforms. To achieve this objective, we have developed a robust numerical simulator of hydrate behavior in geologic media by coupling a reservoir model with a commercial geomechanical code. To be sure our geomechanical modeling is realistic, we are also investigating the geomechanical behavior of oceanic HBS using pore-scale models (conceptual and mathematical) of fluid flow, stress analysis, and damage propagation. In Phase II of the project, we will review all published core data and generate additional core data to verify the models.

To generate data for our models, we are using data from the literature and we will be conducting laboratory studies in 2007 that generate data to (i) evaluate the conceptual pore-scale models, (ii) calibrate the mathematical models, (iii) determine dominant relations and critical parameters defining the geomechanical behavior of HBS, and (iv) establish relationships between the geomechanical status of HBS and the corresponding geophysical signature.

There are four organizations initially involved with this project. These four are Texas A\&M University (TAMU), University of California at Berkeley (UCB), Lawrence Berkeley National Laboratory (LBNL), and Schlumberger (SLB).

The milestones for Phase I of this project are given as follows:

- Literature survey on typical sediments containing gas hydrates in the ocean (TAMU)

- Recommendations on how to create typical sediments in the laboratory (TAMU)

- Demonstrate that typical sediments can be created in a repeatable manner in the laboratory and gas hydrates can be created in the pore space (TAMU)

- Develop a conceptual pore-scale model based on available data and reports (UCB)

- Test the developed pore-scale concepts on simple configurations and verify the results against known measurements and observations (UCB)

- Complete the FLAC3D routines that will be linked with the reservoir model (LBNL)

- $\quad$ Complete the TOUGH+/HYDRATE modifications and extensions (LBNL) 
- Complete the TOUGH+/FLAC3D interaction interface (LBNL)

- Integrate and test the coupled geomechanical numerical model TFxH/FLAC3D (LBNL)

- Demonstrate that Petrel can be used to develop an earth model for providing data to the TOUGH+/FLAC3D (SLB)

\section{Summary of Pore Scale Modeling by UCB}

We have developed a technique for estimating the elastic moduli of a heterogeneous grain pack by modeling mechanical interactions among the grains. Each grain is elastic, and the contact deformations are modeled using Hertz and Mindlin theories. We model the deformation of a grain pack as a sequence of static equilibrium configurations. Each configuration is sought by minimization of the potential energy of the pack. For a loose configuration, our algorithm produces a more realistic tighter pack than other methods. We capture and analyze hysteretic events, such as different loading and unloading responses or abrupt breakage of grain clusters. The computed bulk modulus estimates match experimental values reported in literature. The current progress has been presented at two conferences.

\section{Summary of TOUGH+/FLAC3D Model Development by LBNL}

We coupled the TOUGH+/HYDRATE code (developed by LBNL and used for the description of system behavior in HBS) with FLAC3D (a commercial code that is widely used in soil and rock mechanics engineering and for scientific research in academia). TOUGH+/HYDRATE allows the study of flow and transport of fluids (distributed among four phases) and heat in hydrate deposits, and accurately describes the thermodynamics of hydrates as they are distributed among fifteen possible states (i.e., phase coexistence combinations). FLAC3D has built-in constitutive mechanical models suitable for soil and rocks, including various elastoplastic models for quasi-static yield and failure analysis, and viscoplastic models for time-dependent (creep) analysis. The coupled model (hereafter referred to as the TH+/FLAC model) is the first of its kind, can be used for the joint analysis of hydraulic, thermal, flow and geomechanical behavior in HBS, and is a unique 
tool for the analysis of the effect of hydrate dissociation processes on the structural stability and possible displacement of HBS and of their overburdens.

\section{Summary of Sediment Descriptions and Recommendations by TAMU}

Texas A\&M University has done a comprehensive literature review to characterize the sediments containing hydrates that have been recovered from scientific cruises. The various regions that have been explored for gas hydrates and were reviewed in our work include Blake Ridge (Offshore South Carolina), Gulf of Mexico, Offshore Oregon (Cascadian Margin and Hydrate Ridge), Nankai Trough (Offshore Japan), Offshore Peru and various other regions explored by the Ocean Drilling Program (ODP). After analyzing all the sediments, we have recommended three sediment mixtures that we can use for mechanical properties testing in Phase II of this project. We have included recipes to make these sediments in the laboratory. We expect that TAMU and LBNL will build these sediments for testing during Phase II so that the results of the laboratory experiments at both institutions can be used seamlessly. As we gain experience in the laboratory, it is possible the 'recipes' and procedures for building the sediments may need to be improved during Phase II of the project.

\section{Summary of Petrel-FLAC3D Interface by Schlumberger}

Schlumberger has been developing a method to use Petrel as a platform for entering geologic and reservoir data into the TOUGH+-FLAC3D model when it is completed. There are two requirements for using Petrel to populate FLAC3D with geological surfaces and rock properties. One is to demonstrate that FLAC3D can import surfaces and properties from Petrel. The other is to verify that Petrel can generate the geologic structures characteristic of the hydrate zone offshore. After a series of meetings between Schlumberger and ITASKA, ITASKA has told us they can import properties and surfaces from Petrel. They have demonstrated the ability to import into FLAC3D surfaces generated in Petrel. For the second part, Schlumberger is working internally to characterize geologic structure from 2D seismic lines crossing the hydrate zone in the Gulf of Mexico. 


\section{Development of a Coupled Geomechanical Numerical Model}

\section{Introduction}

This chapter describes the LBNL activities within the framework of the larger joint project entitled "Geomechanical Performance of Hydrate-Bearing Sediments in Offshore Environments" co-authored by Texas A\&M University (TAMU), the University of California at Berkeley (UCB), and Lawrence Berkeley National Laboratory (LBNL), and in which the oil services company Schlumberger is participating. The overall objective is to develop the necessary knowledge base and quantitative predictive capability for describing the geomechanical performance of hydrate-bearing sediments (hereafter referred to as HBS).

In this chapter, we describe the development of a new numerical simulator for analyzing the geomechanical performance of the HBS. The simulator is developed by coupling a robust numerical simulator of hydrate behavior in geologic media (TOUGH+/HYDRATE) with a commercial geomechanical code (FLAC3D), thus developing a numerical simulator for the stability analysis of HBS under mechanical and thermal stresses. The objective is to build a simulator that can be used for scientific and engineering analyses of hydrate stability, including well bore and seafloor stability during gas production from oceanic hydrate formations.

The first version of the simulator is now fully operational and is currently being tested on a suite of problems related to the geomechanical behavior of the HBS.

\section{Model Development}

The starting point of our model development is the TOUGH+/HYDRATE simulator, the descendant of the earlier TOUGH+/HYDRATE code (Moridis, 2003; Moridis et al., 2004; Moridis et al., 2005). The TOUGH+/HYDRATE model is the most-advanced code currently available for simulating system behavior in geological media containing gas hydrates. This code predicts the evolution of pressure, temperature, saturation distribution, and salt concentration in hydrate-bearing systems undergoing changes through any 
combination of mechanisms that can induce hydrate dissociation or formation (e.g., changes in pressure, temperature, or inhibitor concentration).

We have now coupled TOUGH+/HYDRATE with FLAC3D (Itasca Consulting Group, 2002), a code widely used in soil and rock mechanics engineering, and for scientific research in academia. FLAC3D has built-in constitutive mechanical models suitable for soil and rocks, including various elasto-plastic models for quasistatic yield and failure analysis, and visco-plastic models for time-dependent (creep) analysis. The coupled models (hereafter referred to collectively as the TH+/FLAC model) can be used only for the joint analysis of HBS hydraulic, thermal, flow and geomechanical behavior.

Within this project, an extensive literature review has been conducted to determine the current state-of-the-knowledge regarding the geomechanical behavior of HBS. Based on this review, the coupling scheme shown in Figure 1.1 was adopted. In general, the two constituent codes in TH+/FLAC are linked through a coupled THM model of the HBS material (Figure 1.1). The coupled THM model was developed to be consistent with the existing porous media model of HBS in TOUGH+/HYDRATE, and accounts for the possible deformation of the porous media as a result of geomechanical changes. In the adopted deformable-media approach, the basic couplings between hydrological and mechanical processes are described through (1) an effective stress law, that defines how a change in pore pressure affects mechanical deformation and stress, and (2) a pore-volume model that defines how a change in stress or strain affects the fluid flow by inducing changes in the porosity, permeability and wettability properties of the medium. These are denoted as direct couplings, and are marked with solid lines in Figure 1.1. In addition, there are numerous indirect couplings, including changes in mechanical and hydrological properties (dashed arrows in Figure 1.1). The relationship between hydraulic and geomechanical properties is further complicated by couplings related to temperature changes, and the possible effects of inhibitors (occasionally used to enhance/promote hydrate dissociation). All these couplings need to be described in the coupled THM model of the HBS, and, although the corresponding processes are accounted for in TH+/FLAC, the data needed to adequately describe these processes are mostly unavailable. To that end, a 
number of laboratory experiments (planned in Task 2 of the LBNL component of the project for Fiscal Year 2007) are needed to quantify the coupling parameters.

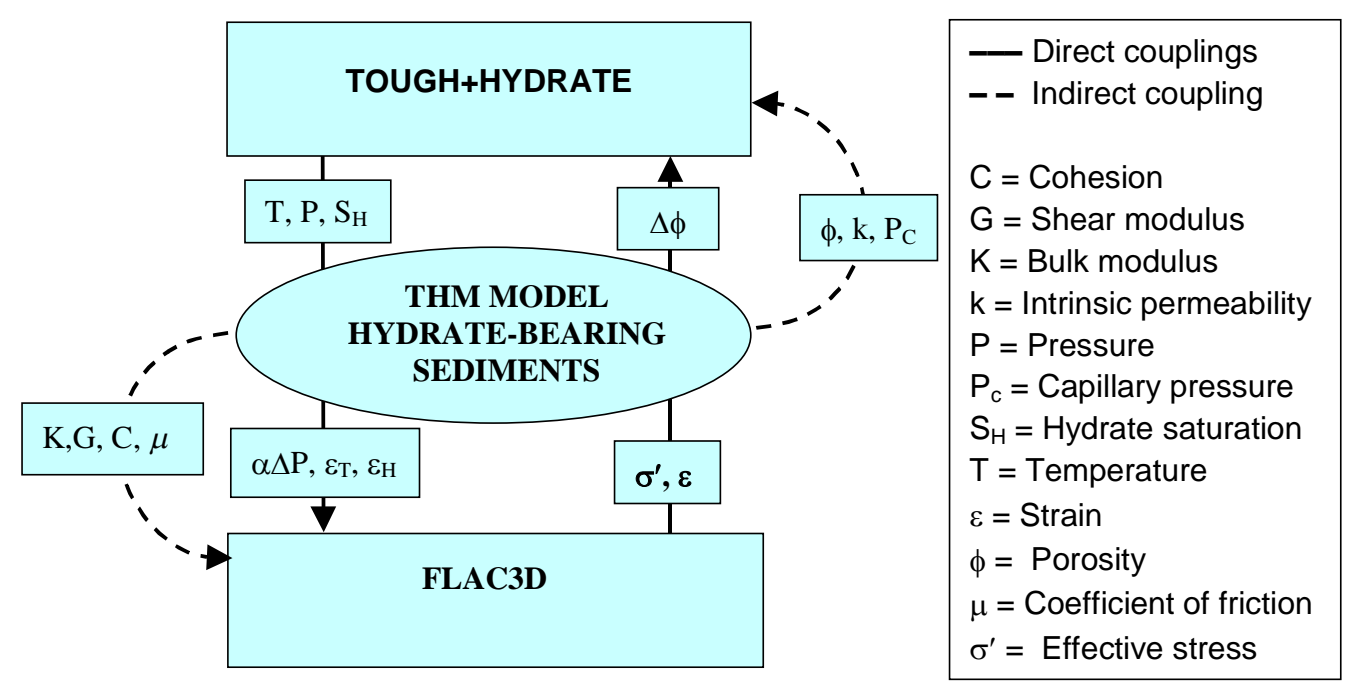

Figure 1.1 - Couplings of TOUGH+HYDRATE and FLAC3D for the analysis of geomechanical behavior of hydrate-bearing sediments

Based on the adopted coupled THM model, coupling functions have been developed that serve to pass relevant parameters between the multiphase heat and transport analysis in TOUGH+/HYDRATE and the geomechanical stress-strain analysis in FLAC3D. In addition, routines have been developed to calculate changes in hydrological and mechanical properties caused by THM interactions. These coupling routines have been developed within the framework of the object-oriented FORTRAN95 architecture of TOUGH+ and the FLAC FISH programming used in FLAC3D. We have developed and implemented functions relating changes in mechanical properties to changes in the hydrate and ice saturations, in addition to models for calculating the mechanically induced changes in porosity with associated changes in hydrological properties. Note that, to overcome the shortcoming of unavailability of data on the geomechanical properties of HBS, ice properties and parameters have been used as an analog and first-level approximation. 
Two models for mechanically induced porosity changes have been implemented:

1) A poro-elastic model that considers macroscopic stress/strain changes, as well as grain deformability.

2) An empirical model for nonlinear changes in porosity as a function of effective mean stress.

Both models calculate changes in porosity, which are then used to calculate changes in permeability and capillary pressure, using a selected porosity-permeability model.

The coupling of FLAC3D and TOUGH+/HYDRATE was conducted based on previous experience with the coupling of FLAC3D with TOUGH2, which is the predecessor of TOUGH+. The previous coupled TOUGH2 and FLAC3D simulator has been used to simulate coupled THM problems dominated by indirect hydro-mechanical couplings using loosely coupled schemes (e.g., Rutqvist et al. (2002). For coupling of TOUGH+ and FLAC3D within this project, we completely restructured the coupling architecture, allowing more tightly and rigorous coupling, in addition to higher simulation efficiency. Most notably, the geomechanical process is now invoked from TOUGH+ using a pre-selected coupling scheme. Currently, three coupling schemes are available:

1. Jacobian: The highest level of iterative coupling, in which geomechanical changes in porosity and permeability are considered in the calculation of the full Jacobian matrix within TOUGH+.

2. Iterative: The porosity and permeability are corrected for geomechanical changes once at the beginning of each iteration, based on the state at the previous iteration.

3. Time-step: The porosity and permeability are corrected once each time step.

The full Jacobian and iterative couplings belong to the category of sequentially implicit hydro-mechanical coupling schemes, whereas time-step coupling is a sequentially explicit coupling scheme. The full Jacobian coupling is necessary for simulations of problems in which so-called pore-volume (direct) coupling dominates - that is, when a mechanically induced change in porosity gives rise to an instantaneous change in pore pressure. In such a case, the full Jacobian coupling will be necessary to rigorously preserve 
the fluid mass balance. For problems in which so-called property change (indirect) couplings dominate, iterative or time-step coupling schemes might be sufficient.

The coupled TH+/FLAC simulation is prepared by first assembling two models, a thermal-hydrologic model for TOUGH+ and a mechanical one for FLAC3D. Thereafter, a number of FLAC3D FISH routines are selected and invoked in FLAC3D, which are then saved to the binary file FLAC3D.SAV. This file contains the current state of the mechanical model, including geometry, material properties, initial and boundary conditions, and the thermal-hydraulic-mechanical coupling functions necessary for the T+/FLAC simulation. In addition, a batch file called FLAC3D.INI is prepared that contains a few sequential FLAC3D commands, including commands to (a) restore FLAC3D.SAV, (b) import data from the TOUGH+/HYDRATE component of the simulation, (c) solve the equations of mechanical equilibrium, (d) export geomechanical data to TOUGH+, and (e) save the most recent (updated) data in FLAC3D.SAV. The commands in FLAC3D.INI are executed at each geomechanical call from TOUGH+.

The TH+/FLAC simulation is executed by invoking the <GEOMECHANICS> option in the TOUGH+/HYDRATE input file. This simulation runs seamlessly without user interference. The FLAC3D stages can be saved in binary files at regular intervals for later plotting, or interactive contouring may be used to monitor the geomechanical evolution on the computer screen during the simulation.

Numerical Test of HBS Mechanical Behavior During Methane Production We present a hypothetical simulation test of methane production from an HBS. Figure 1.2 presents the model geometry, boundary conditions, and initial conditions, which roughly correspond to pressure, temperature, and stress conditions in an oceanic HBS. For this test simulation, we discretized the model into 10 by 20 elements. We simulate constant production from this hydrate deposit for 15 days, inducing significant decreases in both pressure and temperature, with associated hydrate dissociation as well as formation of ice. The geomechanical properties of the HBS were taken from recent laboratory experiments on hydrate-bearing Toyora Sand (Masui et al., 2005). Based on Masui et al. 
(2005), as well as other recently published experimental data, the mechanical properties of the sediment are corrected for pore-filling solid content (hydrate and ice). At the initial conditions, with a hydrate saturation of about $50 \%$, the initial bulk and shear moduli are 375 and $343 \mathrm{MPa}$, respectively. For a Mohr-Coulomb constitutive model, the hydratedependent cohesion is initially 1.13 MPa. Moreover, based on the experimental results of Masui et al. (2005), the Mohr-Coulomb friction angle is made independent of hydrate saturation and is equal to $30^{\circ}$.
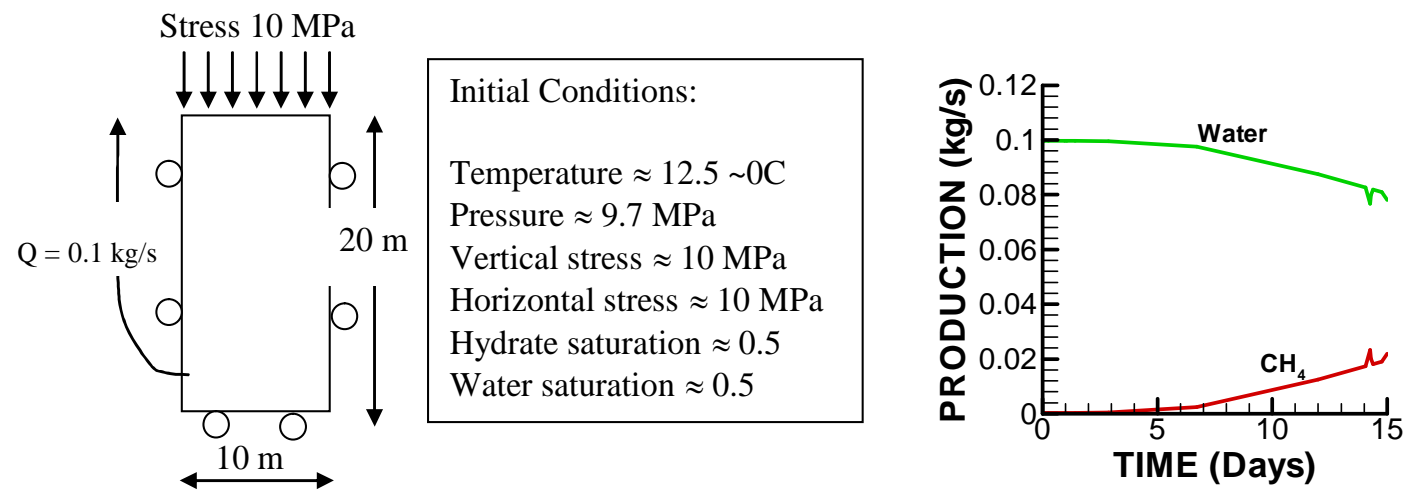

Figure 1.2 - Test model and production rates of water and $\mathrm{CH}_{4}$

Figure 1.3 presents the evolution of thermal, hydrological and mechanical parameters during the 15-day injection. Figures 1.4 to 1.7 present contour plots extracted directly from the numerical simulator. Near the production well, pressure and temperature decreases with time from 10 to $3 \mathrm{MPa}$ and from 12 to $0^{\circ} \mathrm{C}$, respectively (Figure $3 \mathrm{a}$ ). Changes in pressure and temperature cause gradual hydrate dissociation until about 15 days, when ice starts to form near the production well (Figures 1.3b and 1.4). Changes in solid saturation (hydrate + ice) have a direct impact on the mechanical properties (compare Figures 1.4 and 1.5). During the first 14 days, there is gradual softening of the sediment when hydrate is dissociated (Figure 1.3c and d). After 14 days, the mechanical properties rebound by stiffening of the bulk modulus and hardening of the strength as ice is cementing the host sediment. In general, the declining pressure and temperature result in an increasing effective stress with time and a substantial settlement (Figure1.3e and f). After 15 days of production, the stress distribution is clearly affected by the mechanical 
softening, especially near the production point (Figure 1.6). Plastic failure is induced in the system towards the end of the simulation, because the HBS strength is reduced and the principal stress field becomes more anisotropic (leading to shear failure). The $20 \mathrm{~cm}$ settlement is caused by the combined effects of pore-pressure decline and thermal cooling contraction, which in turn are affected by mechanical property changes (softening and hardening). Overall, the settlement is quite uniform, although, as expected, the greatest volumetric strain occurs near the production point (Figure 1.7).

The time-dependent data shown in Figure 1.3 were extracted from an output file of selected history parameters. The contour plots in Figures 1.4 to 1.7 were plotted using the FLAC3D built-in interactive plotting capabilities. Such plotting is designed for fast analysis of simulation results during and after simulation runs. For publishing in formal reports or scientific papers, the data can be exported and plotted using other graphics software. 


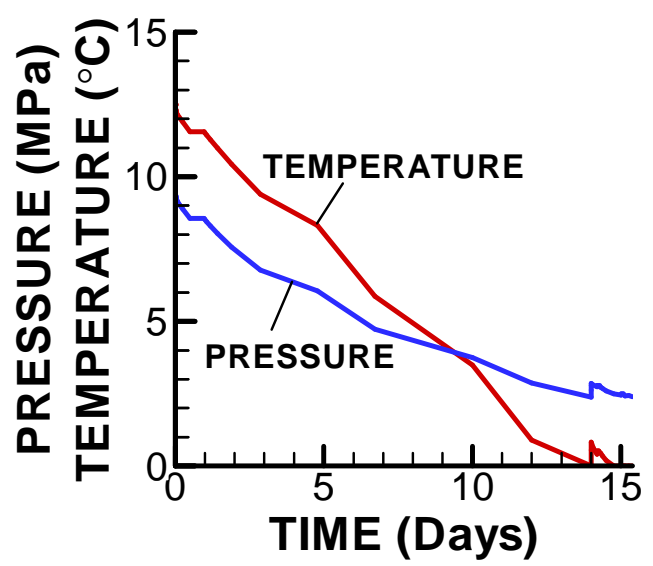

(a) Pressure and Temperature

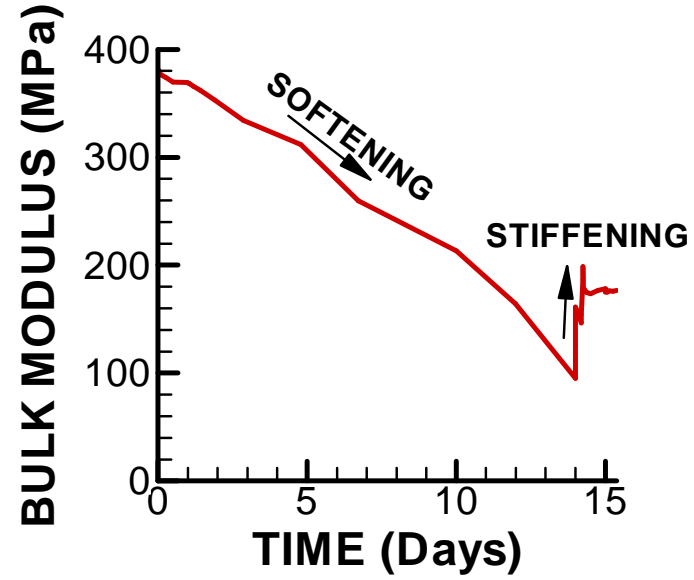

(c) Bulk Modulus

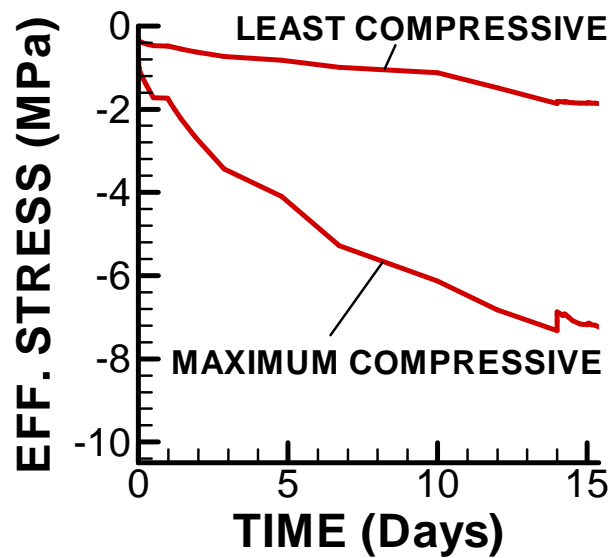

(f) Effective Principal Stresses

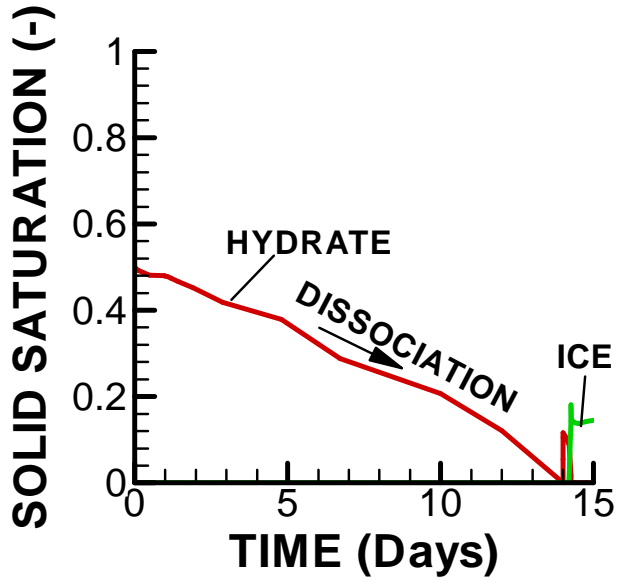

(b) Hydrate and Ice Saturation

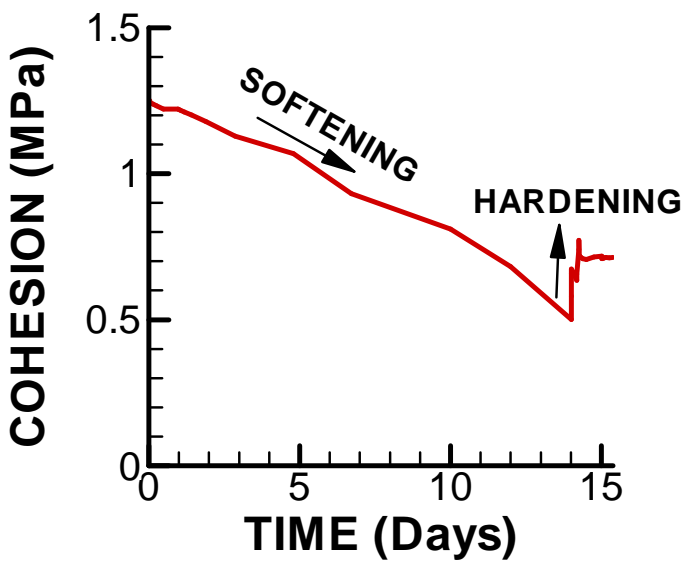

(e) Cohesion

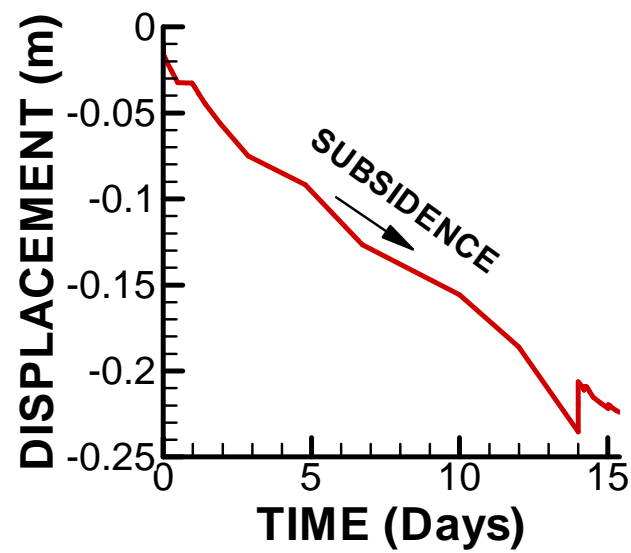

(g) Vertical Subsidence

Figure 1.3 - Time dependent output from a test simulation with 15 days of production 


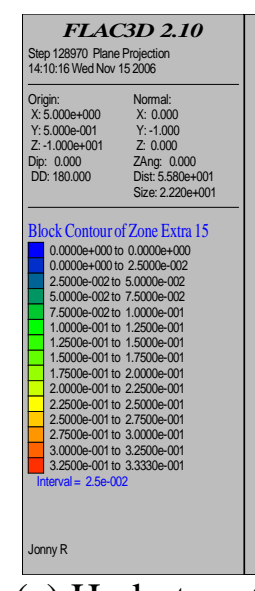

(a) Hydrate saturation

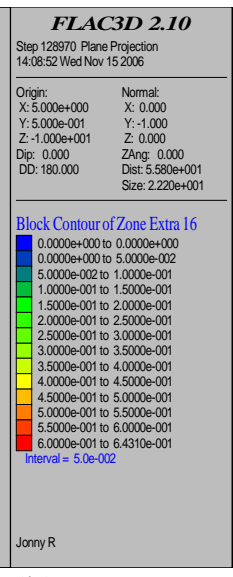

(b) Ice saturation

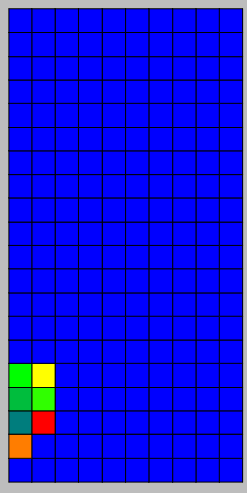

Figure 1.4 - TH+/FLAC simulation output of solid saturations after 15 days of production.

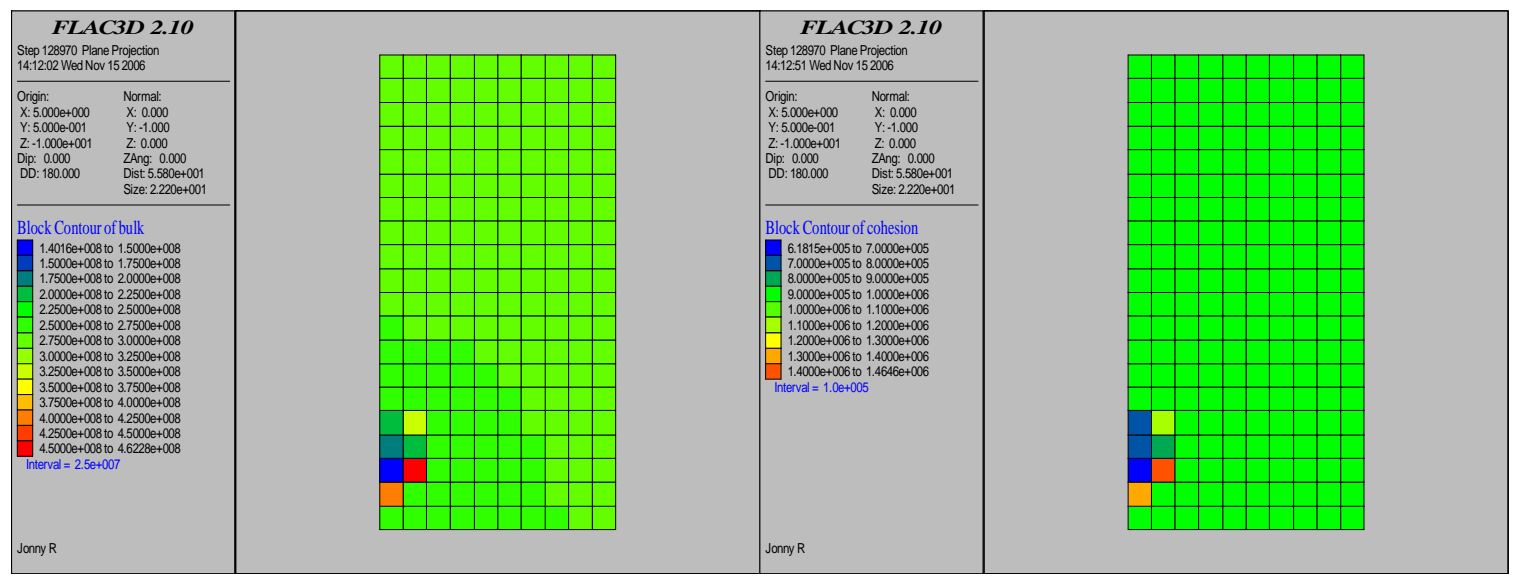

(a) Bulk modulus

(b) Cohesion

Figure 1.5 - TH+/FLAC simulation output of mechanical properties after 15 days of production 


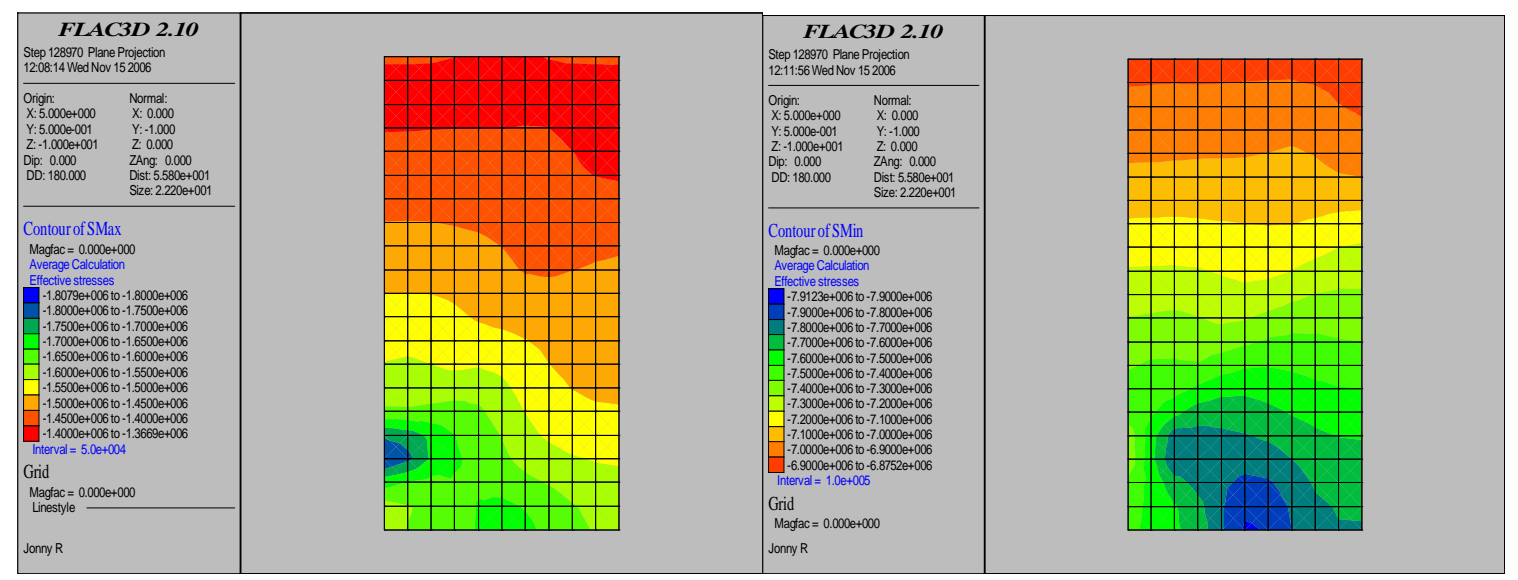

(a) Max (least compressive) stress

(b) Min (max compressive) stress

Figure 1.6 - TH+/FLAC simulation output of principal effective stresses after 15 days of production

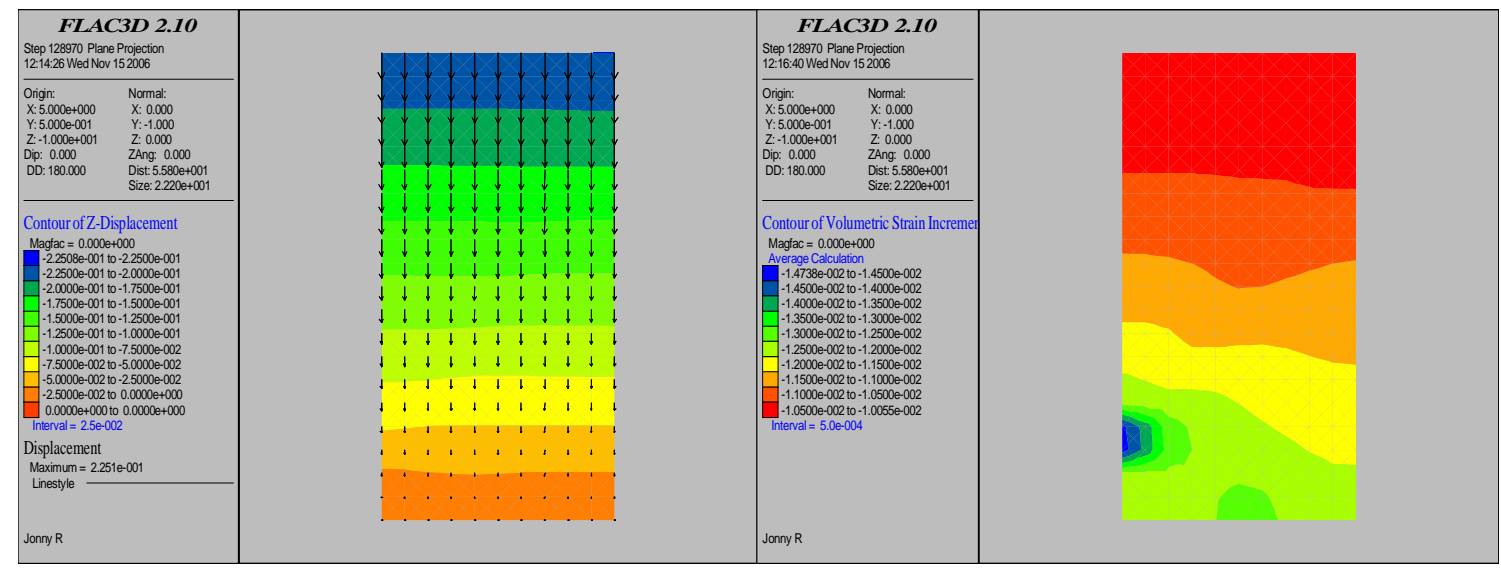

(a) Displacements

(b) Volumetric strain

Figure 1.7 - TH+/FLAC simulation output of deformation after 15 days of production

\section{Development of Interface Between Petrel and Flac3D}

Schlumberger has been developing a method to use Petrel as a platform for entering geologic and reservoir data into the TOUGH+-FLAC3D model when it is completed. There are two requirements for using Petrel to populate FLAC3D with geological surfaces and rock properties. One is to demonstrate that FLAC3D can import surfaces and properties from Petrel. The other is to verify that Petrel can generate the geologic structures characteristic of the hydrate zone offshore. After a series of meetings between Schlumberger and ITASKA, ITASKA has told us they can import properties and surfaces 
from Petrel. They have demonstrated the ability to import into FLAC3D surfaces generated in Petrel. For the second part, Schlumberger is working internally to characterize geologic structure from 2D seismic lines crossing the hydrate zone in the Gulf of Mexico.

Schlumberger is working with Itaska to develop an interface from Petrel to FLAC3D. Schlumberger sent to Itaska, several surfaces generated in Petrel. We have discussed how to specify material parameters required by FLAC3D. For example, should we read them in from Petrel, or do we populate them using FLAC "fish functions"? The models sent from Petrel appear to be more detailed than what are normally used in FLAC3D.

We have personnel in WesternGeco who will help us develop a Petrel model that we can then export to FLAC3D. We received the proposal from ITASKA to create the interface between Petrel and FLAC3D. Schlumberger approved the budget for the ITASKA proposal to create an interface linking Petrel to FLAC3D. We also held meetings with WesternGeco to identify a test data set to "demonstrate" the link. We have the go ahead for build the FLACD interface to Petrel.

The forward plan is to work with WesternGeco to build a simple but representative Petrel Model from the Gulf of Mexico, and have ITASKA import it into FLAC3D. The first pass will be to import the surfaces. If we have time, we will try to import rock properties also.

Schlumberger has also approved the donation of Petrel licenses to Texas A\&M University, University of California at Berkeley and Lawrence Berkeley National Laboratories as part of the cost sharing commitment.

\section{Description of Hydrate Bearing Sediments Offshore Introduction}

Gas hydrate is an "ice-like" crystalline material that is formed by the combination of gas and water. Gas hydrate is stable only under specific pressure and temperature conditions. Hydrates can be found in two distinct locations worldwide, offshore at or near the seafloor in deep water, and onshore in arctic permafrost regions. This study deals with the distribution of hydrates in the offshore environments. The typical gases that form the hydrates in nature are $\mathrm{C}_{1}-\mathrm{C}_{5}$ hydrocarbons, $\mathrm{CO}_{2}$ and nitrogen. A gas hydrate crystalline structure can be classified as Structure I (SI), Structure II (SII) or Structure H (SH). 
SI has a body-centered cubic lattice, SII has a diamond lattice and SH gas hydrate has a hexagonal lattice (Sloan 1998). Small guest molecules like methane and ethane form SI hydrate. Subramanian et al. (2000) found that SII can be formed for some compositions of methane and ethane. Propane and butane when present with methane in a gas composition form SII hydrate. However, $\mathrm{C}_{1}-\mathrm{C}_{5}$ gas mixtures are known to form $\mathrm{SH}$ hydrate.

There are various factors that control the distribution of gas hydrates in marine sediments. These parameters include gas composition, pore water chemistry, lithology and geothermal gradients. Gas composition controls the phase behavior of the hydratewater-gas system, and hence, the distribution of hydrate at particular sediment depths. The phase behavior is also controlled by the pore water salinity as the presence of salts alters the three phase equilibrium curve for the gas-water-hydrate system.

Lithology also plays an important role in determining the distribution of gas hydrates in the sediments in the marine subsurface (Clennell, Hovland et al. 1999). The local geothermal gradients define the base of the hydrate stability zone (HSZ), and hence, control the thickness and distribution of the hydrates.

This chapter describes the detailed lithology and mineralogy of the sediments hosting gas hydrates in nature. The various regions that have been explored for gas hydrates include Blake Ridge (Offshore South Carolina), Gulf of Mexico, Offshore Oregon (Cascadian Margin and Hydrate Ridge), Nankai Trough (Offshore Japan), Offshore Peru and various other regions explored by the Ocean Drilling Program (ODP).

Gas hydrates, when present in the marine sediments, often produce a bottom simulating reflector (BSR) which usually parallels the seafloor. This seismic BSR is assumed to be caused by the presence of free gas near the base of HSZ. The absence of a BSR, however, does not necessarily mean that hydrates are not present in the subsea sediments that are in the gas hydrate stability zone (Ecker, Dvorkin et al. 2000).

The gas forming a hydrate can either have a biogenic or thermogenic origin. Biogenic gas is produced at shallow depths and low temperatures by anaerobic bacteria acting on the organic matter in the sediments. Thermogenic gas is formed by the thermal degradation (cracking) of oil in deep subsurface. Geochemical markers and other methods are used to identify whether the gas is biogenic or thermogenic in origin. Since the composition of biogenic gas is $99 \%$ methane, it forms with water at suitable temperature 
and pressure to form methane hydrates. Thermogenic gases, which may contain significant amount of higher hydrocarbons $\left(\mathrm{C}_{2}-\mathrm{C}_{5}\right)$ can form mixed gas hydrates. These mixed gas hydrates are either SII or SH hydrates, that have different stability envelopes than SI methane hydrates. There are two potential end member sources of gases in gas hydrates i.e. autochthonous and allochthonous (Milkov 2005).

Autochthonous gases form from organic matter that is distributed in the sediments which primarily lie in the gas hydrate stability zone. These gases are formed by the microbial processes and undergo short migration paths.

Allochthonous gases are formed much deeper below the GHSZ. These gases then migrate long distances from the oil/gas accumulations along the faults through mud volcanoes and via structurally deformed beds (Milkov et al., 2005). These gases could have been formed either from microbial activity or thermogenic activity.

According to Milkov and Sassen (2001), most gas hydrate accumulations can be classified as either structural or stratigraphic. Structural accumulations are classified by high gas flux (HGF) at the sea-floor and later by low gas flux (LGF). When the allochthonous gases migrate rapidly from deeper sources into the GHSZ they form the structural hydrate deposits. This migration takes place along the faults or through permeable sand/silt layers, gas chimneys above the petroleum reservoirs, or mud volcanoes.

When there is high gas flux at the seafloor, chemosynthetic communities, seeps and authigenic carbonates will evolve at or near the seafloor. Typically, structural accumulations which form as a result of high gas flow show high gas hydrate concentrations (commonly $>5 \%$ of pores and locally up to $100 \%$ of the volume). The three-dimensional distribution of the structural accumulations is dependent upon the gas hydrate stability zone profile, salinity and migration pathways within the gas hydrate stability zone. Since the solubility of gas and temperature are lower near the seafloor, gas hydrates tend to precipitate near the seafloor (i.e. in the upper part of the gas hydrate stability zone) rather than near its base in structural accumulations. 
In the Gulf of Mexico, almost all the gas hydrate accumulations studied are structural accumulations. Stratigraphic gas hydrate accumulations occur in relatively permeable sediment layers where gas concentration locally increases as a result of slow gas migration over short distances. Diffusive-flux is the main process by which the concentration of the gas increases in the pore water to form the hydrate.

Gas hydrates can be found in the porous media in different forms as described in Table 3.1 and shown in Figure 3.1.

Table 3.1 - Description of gas hydrates in porous media (Shipboard-Scientists 1996)

\begin{tabular}{|c|c|}
\hline Geometry & Description \\
\hline Layer & $\begin{array}{l}\text { Tabular gas hydrate that transects the core conformable to bedding. Its } \\
\text { apparent thickness is typically of the order of a few centimeters }\end{array}$ \\
\hline Lens & A hydrate layer or other feature with tapering margin \\
\hline Vein & $\begin{array}{l}\text { Tabular gas hydrate feature that transects the core at an angle to the bed- } \\
\text { ding. Its apparent thickness is of the order of a few centimeters }\end{array}$ \\
\hline Veinlet & $\begin{array}{l}\text { Thin, tabular gas hydrates } \sim 1 \mathrm{~mm} \text { thick or less, commonly present adja- } \\
\text { cent to veins or layers and oriented in mutually orthogonal directions }\end{array}$ \\
\hline Nodular & Spherical to oblate features typically $1-5 \mathrm{~cm}$ in diameter. \\
\hline Disseminated & Hydrate grains less than $3 \mathrm{~mm}$ distributed throughout the sediment matrix \\
\hline Massive & $\begin{array}{l}\text { The presence of hydrate in core greater than } \sim 10 \mathrm{~cm} \text { in thickness and with } \\
\text { less than } 25 \% \text { intercalated cement }\end{array}$ \\
\hline
\end{tabular}




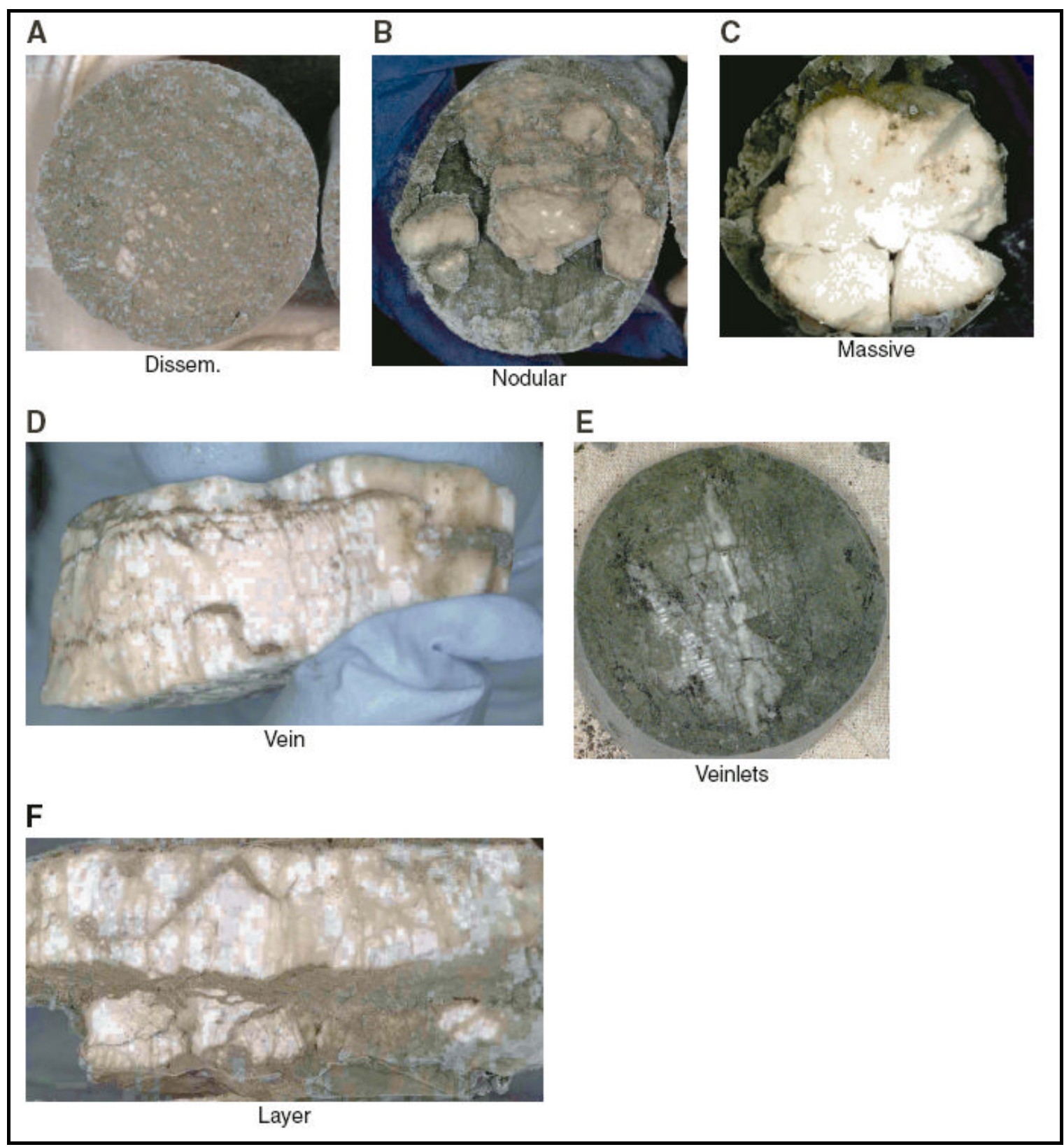

Figure 3.1 - Different types of geometries of natural gas hydrates (Shipboard-Scientists 1996)

This chapter delineates the sediment characteristics where gas hydrates have been found offshore during various exploration expeditions. These expeditions have been carried out by the Ocean Drilling Program (ODP), the Japanese Government (Nankai Trough) and the Chevron JIP/DOE (Gulf of Mexico). All the lithological and mineralogical details are reported for the hydrate bearing sediments 


\section{Blake Ridge}

\section{Geologic setting}

On the basis of Bottom Simulating Reflector (BSR), the Carolina Rise, particularly along the Blake Ridge, was one of the first areas where marine gas hydrate was first identified.

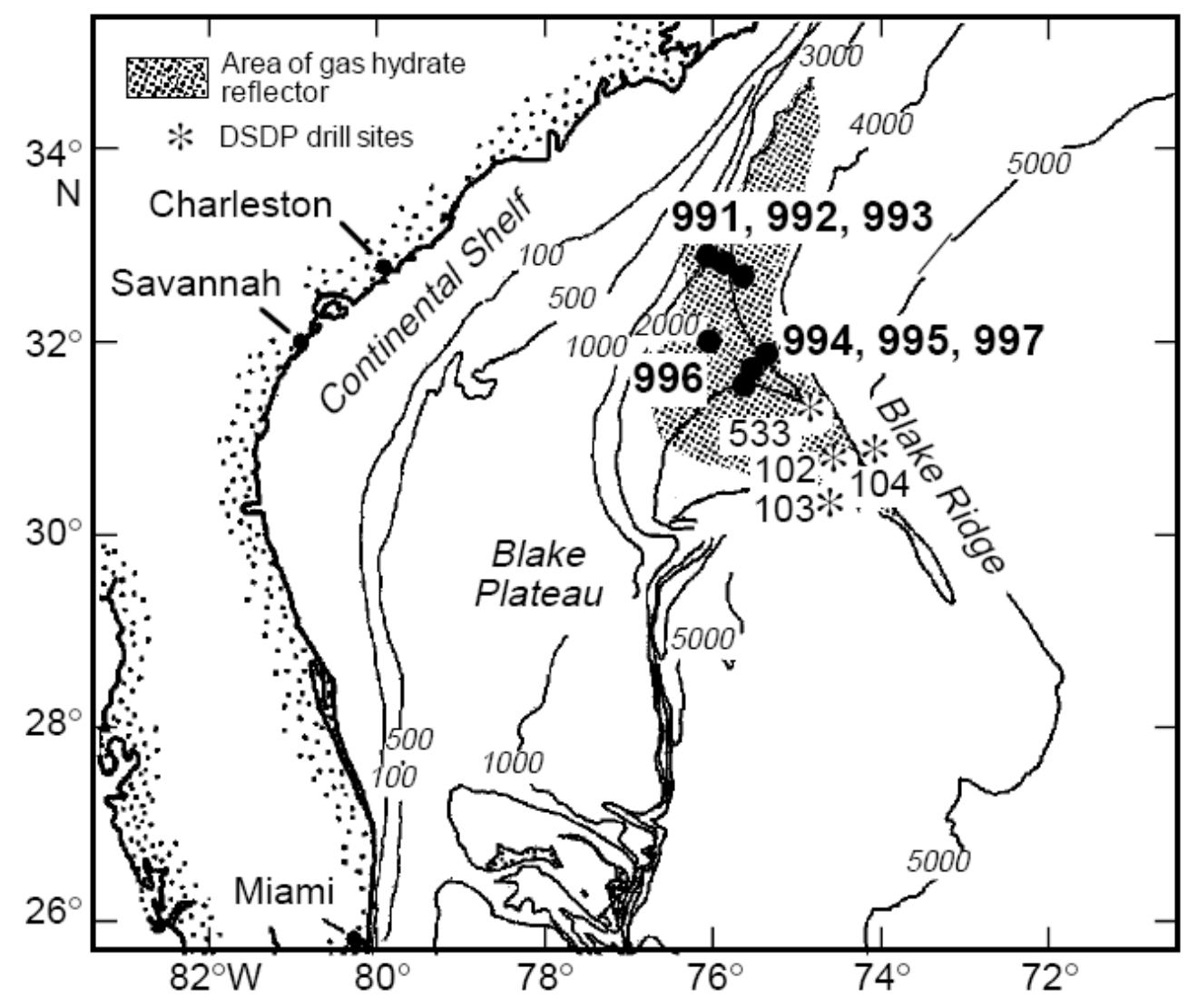

Figure 3.2 - Map of the general area of gas hydrate on the basis of BSR (Shipboard-Scientists 1996)

Figure 3.2 shows the map of the possible area of gas hydrate occurrence on the basis of where the BSR can be identified from seismic. Figure 3.3 shows the more detailed bathymetric map of Blake Ridge, drill sites for ODP Leg 164 and DSDP sites drilled. A number of large solid gas hydrates were recovered from sites 994, 996 and 997. The samples from sites 994 and 997 were either nodular or thick massive pieces of gas hydrate. X-ray computed tomography, diffraction, nuclear magnetic resonance and Raman spectroscopy gave results that indicated the gas was essentially $100 \%$ methane. Thermal 
conductivity values of hydrates from Blake Ridge range from 0.3 to $0.5 \mathrm{~W} / \mathrm{m} / \mathrm{K}$. Equilibrium dissociation indicated that the equilibrium curve is almost the same as that of pure synthetic methane hydrate. Figure 3.3 shows the data on the water depth for different drilled sites.

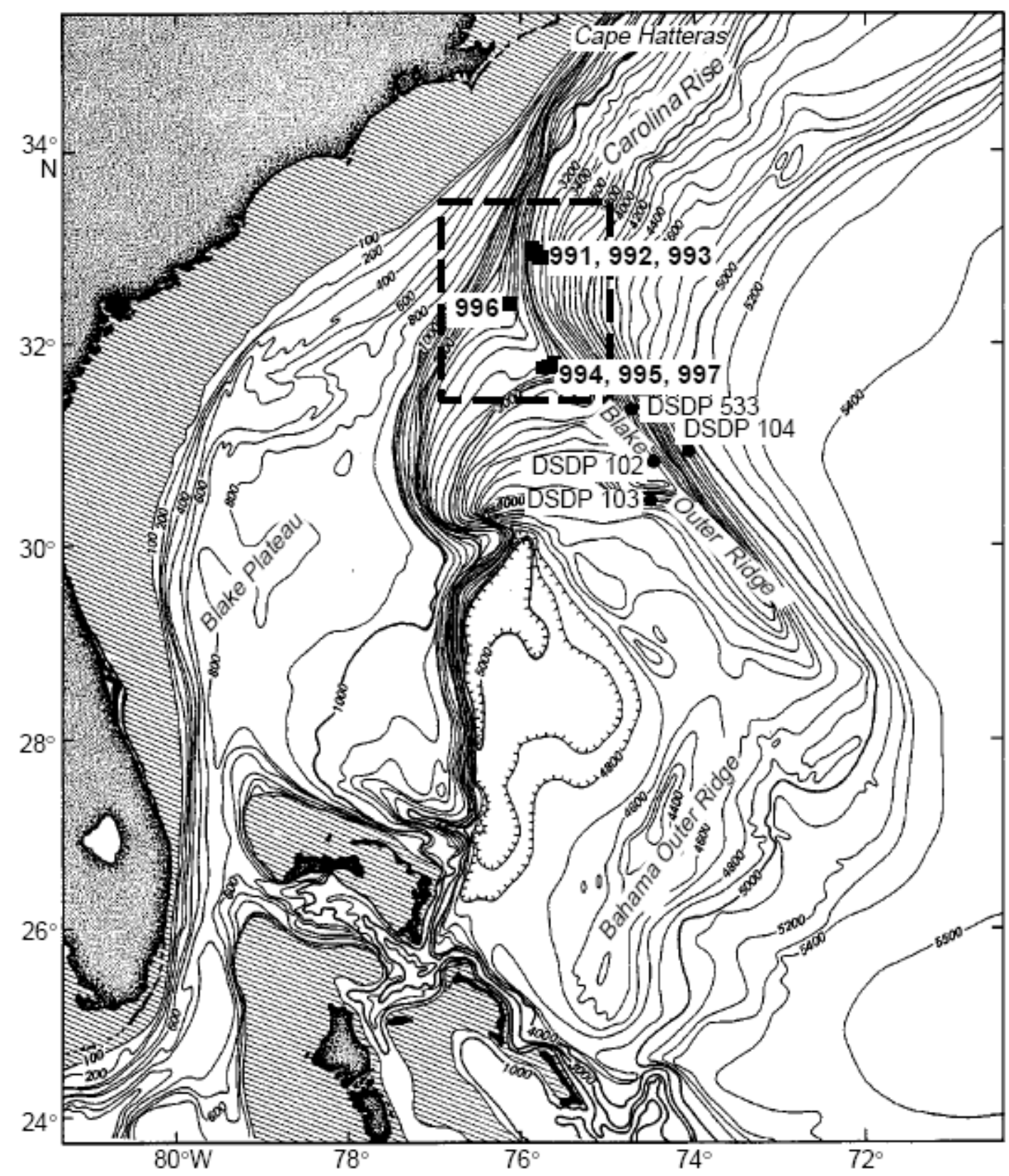

Figure 3.3 - Bathymetric map of the Blake Ridge region, Offshore Carolinas, USA (ShipboardScientists 1996) 
A large amount of microbial gas was encountered at the previous DSDP drill sites on the Blake Ridge and no indications of thermogenic hydrocarbons were noted in these holes. At site 994, the sediments were found to be very gassy. The probability of finding gas hydrate in this hole was high $(>50 \%)$ at depths from $100-450$ meters below the sea floor (mbsf) because of low chlorinity values in the pore water. The average geothermal gradient in this area was found to be $35.4{ }^{\circ} \mathrm{C} / \mathrm{km}$. The gas hydrates were recovered from nanofossil-rich clay at a sub-bottom depth of 260-330 m, about 200-120 meters above the BSR. The traditional method of core description does not work for gas hydrates because the hydrates are unstable at surface conditions. For this reason, different proxy techniques were used for the estimation of hydrate concentration in the pores. Using the chloride values, the gas hydrate concentration of some samples was as high as $14 \%$. On the average, the values of $1.3 \%, 1.8 \%$ and $2.4 \%$ of the sediment above $450 \mathrm{mbsf}$ was filled with gas hydrates at site 994, 995 and 997. Gas volumes from the Pressure Core Sampler (PCS) indicated the range of hydrate concentration to be in between $0 \%$ and $9 \%$. Seismic data from vertical seismic profiles indicate that the sediments contain at least $2 \%$ gas hydrates.

Nearly as much gas hydrates was inferred to occur at site 994 (no BSR present) as with other sites 995 and 997 (where extensive BSR was present). This demonstrates that gas hydrates may be present at a given location even if a BSR is not identified by seismic. Sites 991, 992 and 993 were the diapir sites. Shallow holes (50-60 mbsf) were drilled on the flanks and crest of the Cape Fear Diapir and Blake Ridge Diapir. The sediments from these three sites were strongly deformed.

A summary of the water depths, penetration and other data on the zones penetrated in the 12 holes drilled during ODP Leg 164 is given in Table 3.2. 
Table 3.2 - Summary of water depths, penetration and formation at Blake Ridge (ODP Leg 164)

\begin{tabular}{|c|c|c|c|}
\hline Hole & Water depth (m) & Penetration (m) & Formation \\
\hline $994 \mathrm{~A}$ & 2797.6 & 36.4 & $\begin{array}{l}\text { Unit I: 0-13.31 mbsf: Holocene to late Pleistocene; gray nannofossil-rich clay and nannofossil clay } \\
\text { Unit II: 13.3-36.4 mbsf: Late Pleistocene to late Pliocene;greenish gray nannofossil-rich clay and nannofossil clay }\end{array}$ \\
\hline 994 B & 2797.6 & 6.9 & Unit I: 0-6.9 mbsf: Holocene to late Pleistocene; gray nannofossil-rich clay and nannofossil clay \\
\hline 994 C & 2799.1 & 703.5 & $\begin{array}{l}\text { Unit I: 0-13.32 mbsf: Holocene to late Pleistocene; gray nannofossil-rich clay and nannofossil clay } \\
\text { Unit II: 13.3-160.12 mbsf: Late Pleistocene to late Pliocene;greenish gray nannofossil-rich clay and nannofossil clay } \\
\text { Unit III: 160.12-703.5 mbsf: Late Miocene; dark greenish gray diato bearing nannofossil-rich clay }\end{array}$ \\
\hline $994 \mathrm{D}$ & 2799.1 & 670 & $\begin{array}{l}\text { Unit I: 0-13.32 mbsf: Holocene to late Pleistocene; gray nannofossil-rich clay and nannofossil clay } \\
\text { Unit II: 13.3-160.12 mbsf: Late Pleistocene to late Pliocene;greenish gray nannofossil-rich clay and nannofossil clay } \\
\text { Unit III: } 160.12-670 \text { mbsf: Late Miocene; dark greenish gray diato bearing nannofossil-rich clay }\end{array}$ \\
\hline $995 \mathrm{~A}$ & 2778.5 & 704.6 & $\begin{array}{l}\text { Unit I: 0-13.4 mbsf: Holocene to late Pleistocene; light greenish gray forminifer-bearing nannofossil-rich clay and nannofossil clay } \\
\text { Unit II: } 13.4-131.9 \mathrm{mbsf} \text {; Late Pleistocene to late Pliocene; greenish gray diatom-rich nannofossil-rich clay and nannofossil-rich clay } \\
\text { Unit III: 131.9-704.6 mbsf; Late Pliocene to late Miocene;dark greenish gray diatom-bearing nannofossil-ricj clay and claystone } \\
\text { Lithology similar to } 995 \mathrm{~A}\end{array}$ \\
\hline $996 \mathrm{~A}$ & 2169.6 & 63 & $\begin{array}{l}\text { Subunit IB: } 0-0.85 \mathrm{mbsf} \text {; Late Pleistocene; greenish gray nannofossil-rich aragonite clayey silt with abundant bivalve shell fragments } \\
\text { Subunit IC: } 0.85-63 \mathrm{mbsf} \text {; Late Pleistocene to early pleistocene; greenish gray nanofossil-bearing and nannofossil-rich clay }\end{array}$ \\
\hline 996 B & 2184.1 & 3.4 & $\begin{array}{l}\text { Subunit IB: 0-1.97 mbsf; age not determined; greenish gray nannofossil-rich aragonite clayey silt with abundant bivalve shell fragments } \\
\text { Subunit IC: } 1.97-3.4 \mathrm{mbsf} \text {; age not determined; greenish gray nanofossil-bearing and nannofossil-rich clay }\end{array}$ \\
\hline $996 \mathrm{C}$ & 2184.7 & 2.6 & $\begin{array}{l}\text { Subunit IB: 0-0.95 mbsf; age not determined; greenish gray nannofossil-rich aragonite clayey silt with abundant bivalve shell fragments } \\
\text { Subunit IC: } 0.95-2.6 \mathrm{mbsf} \text {; age not determined; greenish gray nanofossil-bearing and nannofossil-rich clay +formanifers + diatoms }\end{array}$ \\
\hline 996 D & 2169.6 & 52.2 & $\begin{array}{l}\text { 0-22.6 mbsf; Very poor recovery of carbonate concretions } \\
\text { Subunit IC: 22.6-52.2 mbsf; age not determined; greenish gray nanofossil-bearing and nannofossil-rich clay +formanifers + diatoms }\end{array}$ \\
\hline $997 \mathrm{~A}$ & 2770.1 & \begin{tabular}{r|r}
434.3 \\
750.7 \\
\end{tabular} & $\begin{array}{l}\text { Unit I: 0-6.2 mbsf: Holocene to late Pleistocene; light greenish gray forminifer-bearing nannofossil-rich clay } \\
\text { Unit II: } 6.2-107.83 \mathrm{mbsf} \text { : Late Pleistocene to late Pliocene; light greenish gray forminifer-bearing nannofossil-rich clay } \\
\text { Unit III: } 107.83-434.3 \text { mbsf: Early to late Pliocene; dark greenish gray diatom-bearing nannofossil-bearing clay and claystone } \\
\text { Unit III: } 318.5-750.7 \mathrm{mbsf} \text {; Late Pliocene to late Miocene; dark greenish gray diatom-bearing nannofossil-bearing clay and claystone }\end{array}$ \\
\hline
\end{tabular}

mbsf: meters below seafloor 
Figure 3.4 is a summary of the physical properties and thermal conductivity of the sediments taken from Hole 994 C.
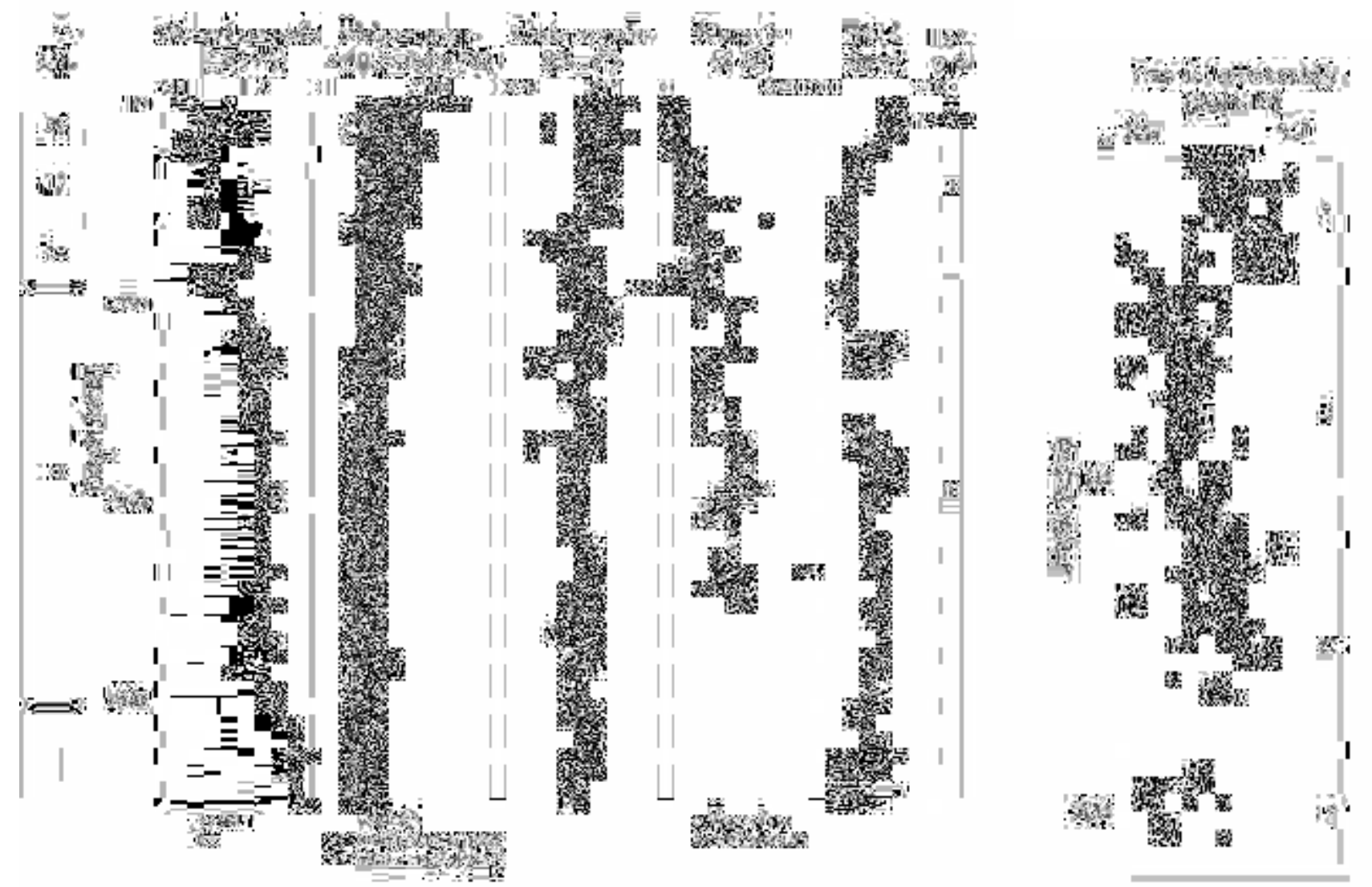

Figure 3.4 - Summary of physical properties and thermal conductivity of the sediments from Site 994 C (Shipboard-Scientists 1996) 


\section{Site 995}

Figure 3.5 describes the down hole mineralogical variation of the major sediment constituents, based on visual estimation in smear slides (Shipboard-Scientists 1996), while Figure 3.6 describes the physical properties and thermal conductivities from Site 995.

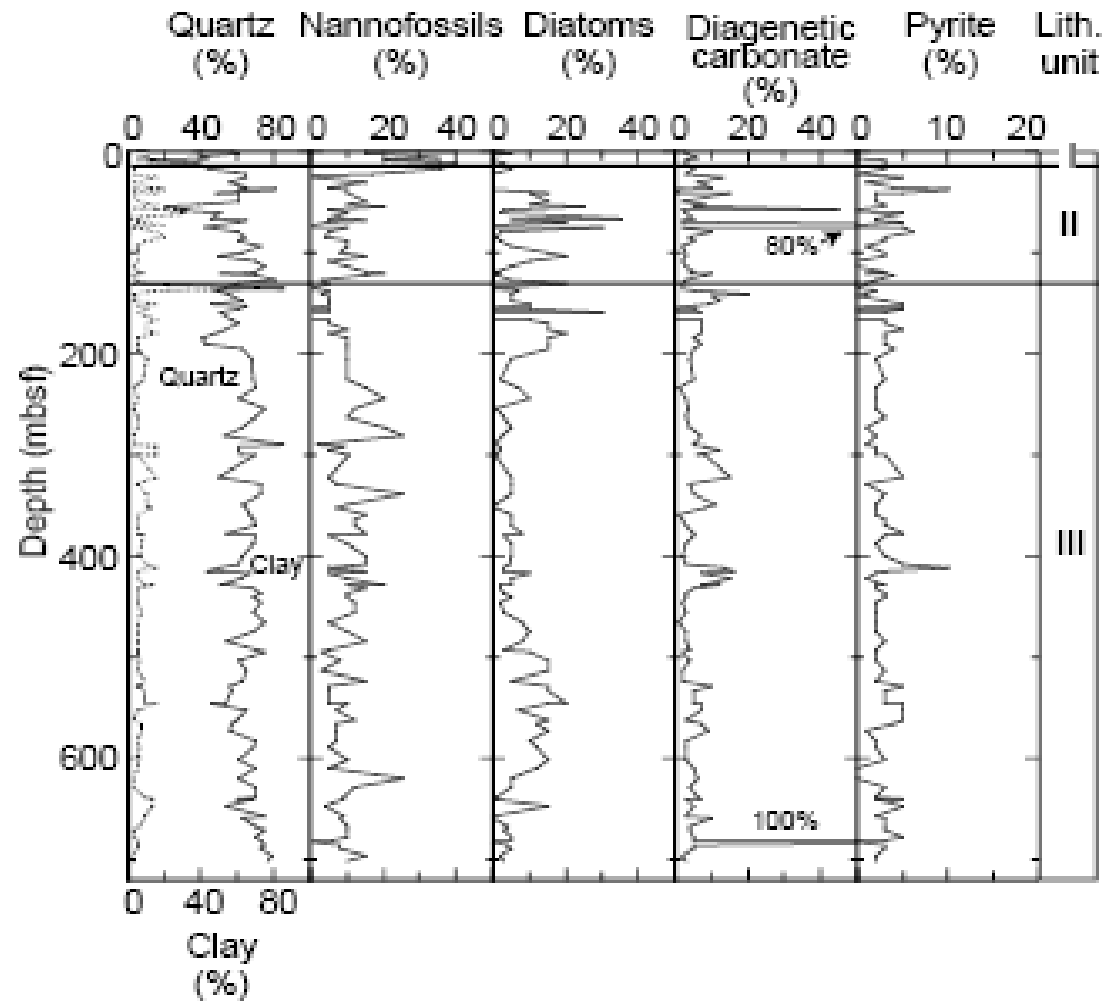

Figure 3.5 - Mineralogical variation of major sediment constituents (Shipboard-Scientists 1996) 

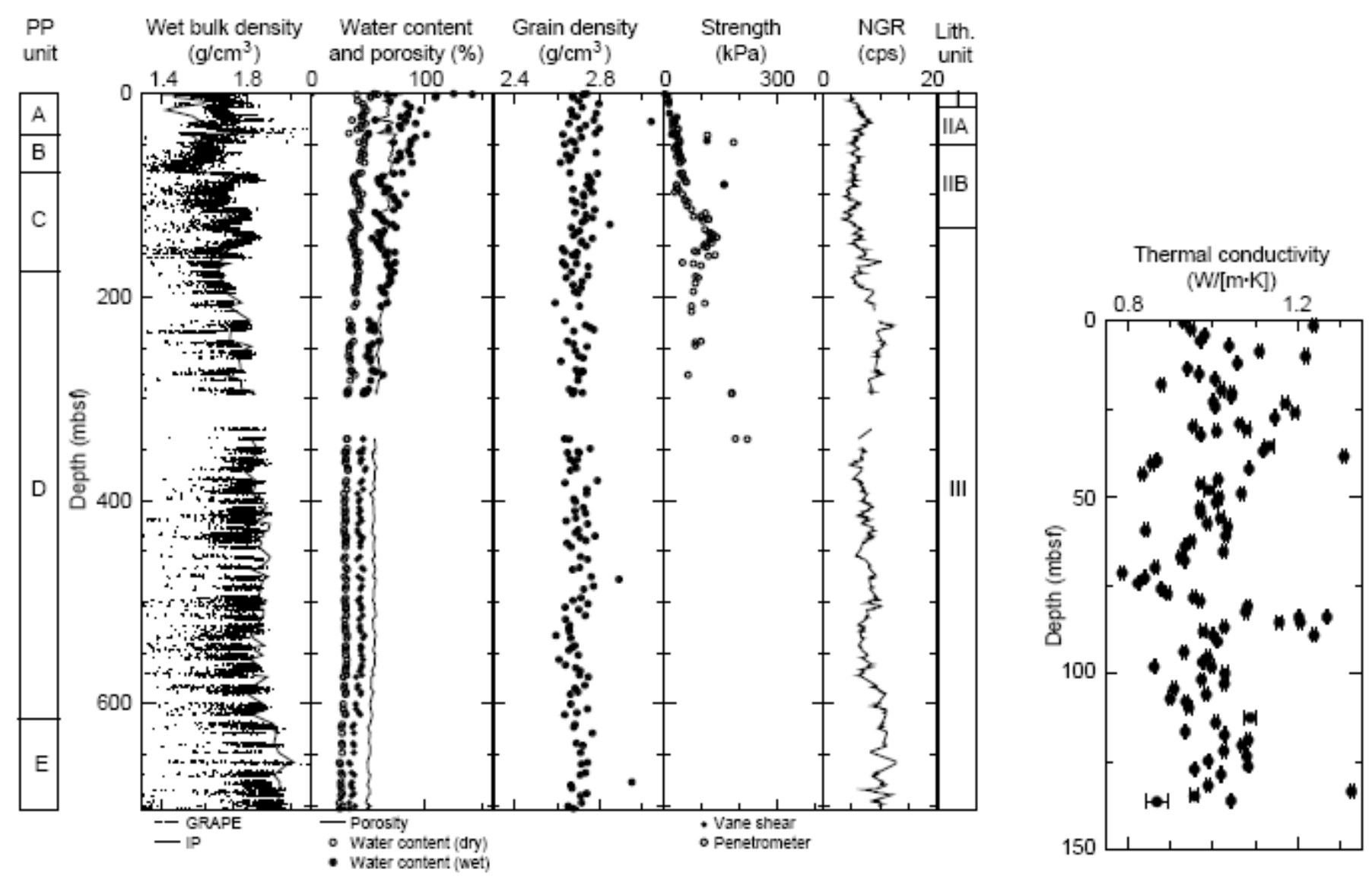

Figure 3.6 - Physical properties and the thermal conductivity from Hole 995 A, Leg 164 (Shipboard-Scientists 1996) 
Winters (2000) described the geotechnical and physical properties from Blake Ridge as follows:

Table 3.3 - Geotechnical and physical properties of sediments from Blake Ridge (Winters 2000)

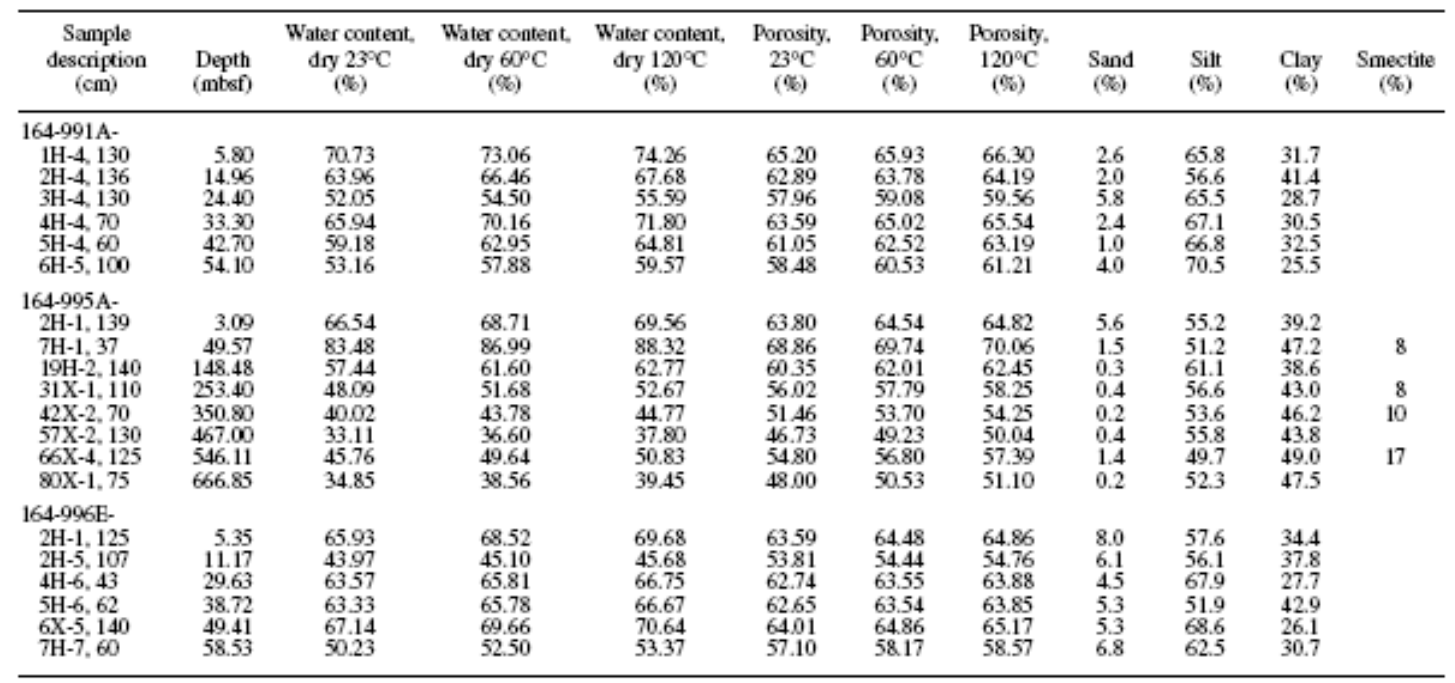

\section{Site 996}

Site 996 is located on the crest of the Blake Ridge Diapir, the southernmost diaper in a series of $\sim 20$ diapiric structures rising from deep within the Carolina Trough. The objective at this site was to investigate (1) methane migration and gas hydrate formation in a pockmarked fault zone where methane is leaking out of the continental rise, (2) the source of fluids and gases in a seafloor seep, and (3) the influence of these fluids on the host sediments. Five holes were drilled at this site in sediments overlying the Blake Ridge Diapir. Gas hydrate was recovered from all the five holes. The hydrate was white and occurred in three different forms; (1) massive pieces, cylindrical to round in shape and as much as 5-8 cm long, in sediments recovered from the uppermost $9 \mathrm{mbsf}$; (2) platy, 1- to $4 \mathrm{~mm}$ thick veins that filled wavy vertical fractures; and (3) vertically oriented rodshaped nodules $\sim 1 \mathrm{~cm}$ in diameter and 3-12 $\mathrm{cm}$ long that tapered down the core. Figure 3.7 shows the seismic profile at Site 996. 


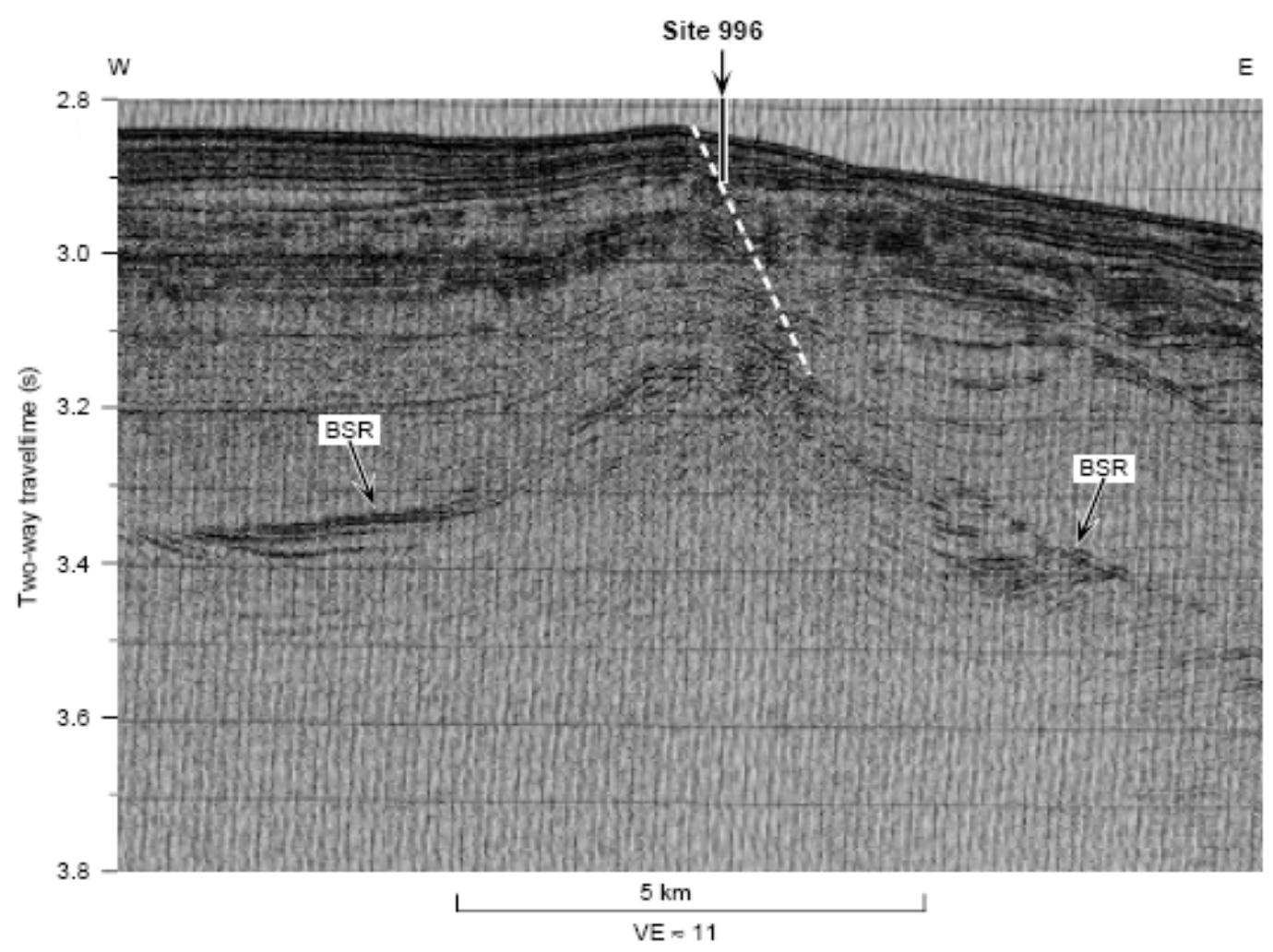

Figure 3.7 - Seismic profile of Site 996 at Blake Ridge (Shipboard-Scientists 1996)

\section{Site 997}

The presence of gas hydrate was inferred over a zone which extends from about 180 to 450 mbsf. The major mineral constituents as derived from XRD measurements from Site 997 are shown in Figure 3.8. The physical properties of the sediments and the thermal properties from the cores at Site 997 are show in Figure 3.9 

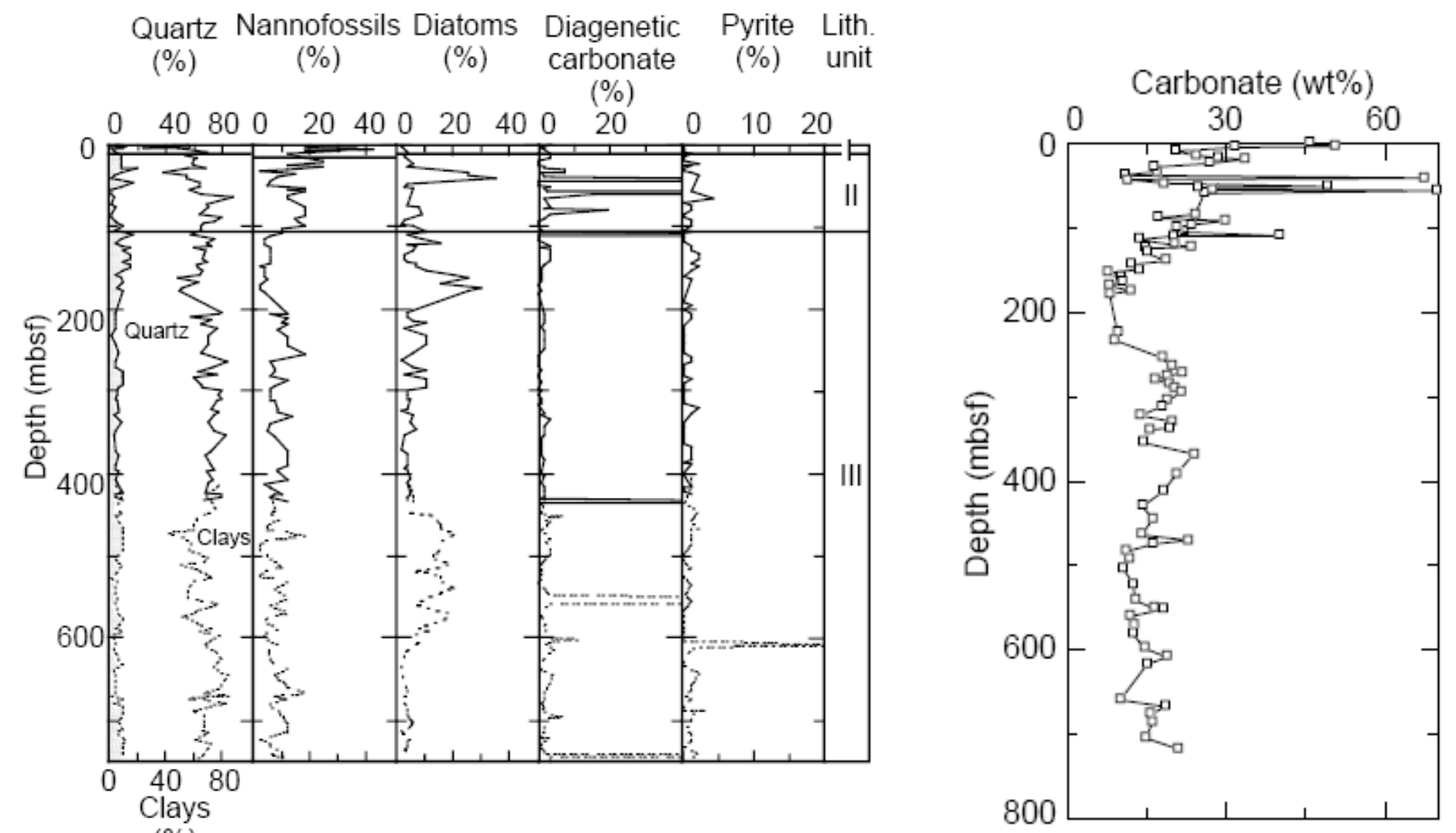

Figure 3.8 - Major mineral constituents of sediments based on XRD analysis and carbonate content in sediments from Site 997 (Shipboard-Scientists 1996) 

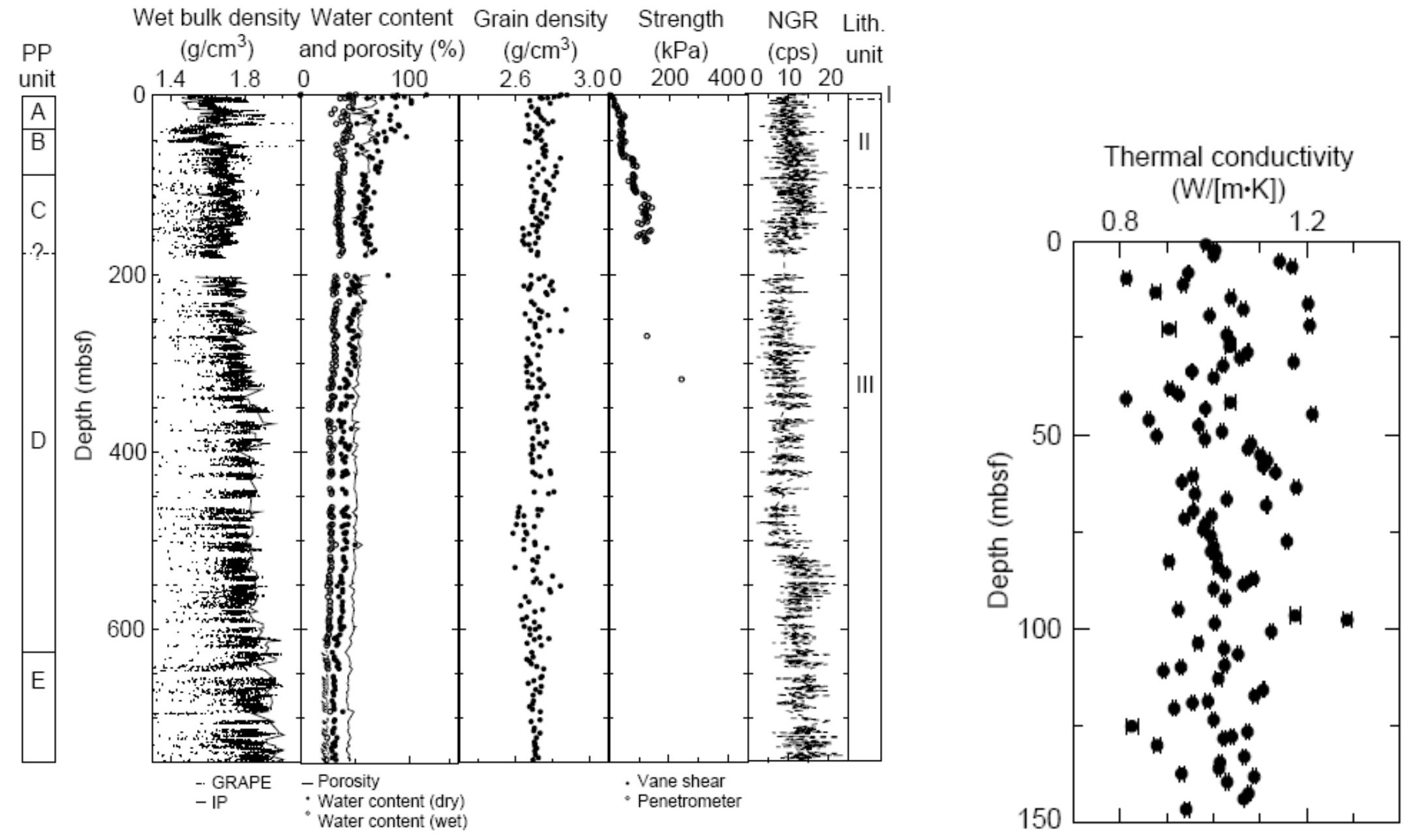

Figure 3.9 - Physical properties of sediments and their thermal conductivity from Site 997 (Shipboard-Scientists 1996) 
Pore water chloride profiles from sites 994, 995 and 997 are shown in Figure 3.10.

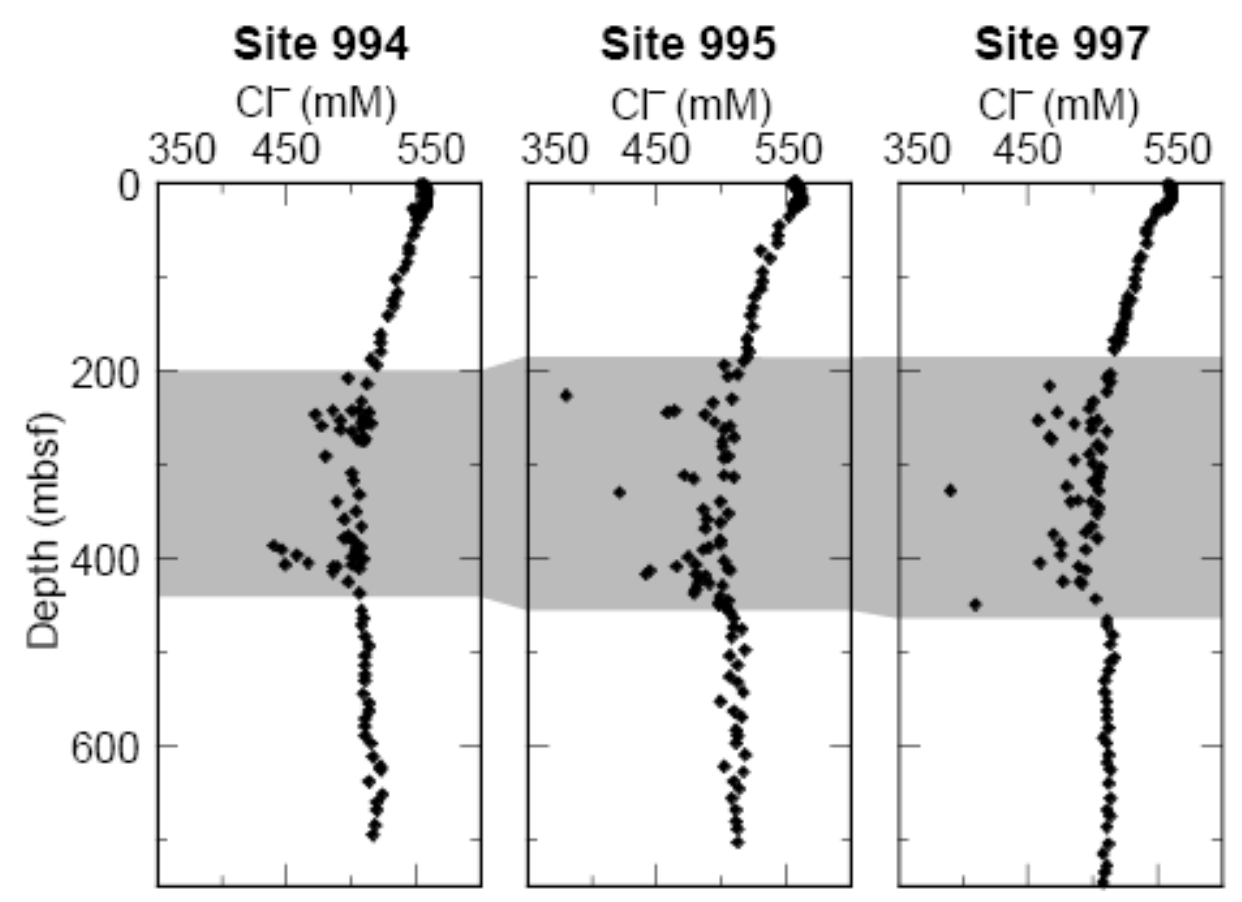

Figure 3.10 - Pore water chloride concentrations in sites 994, 995 and 997

\section{Grain-size control}

(Ginsburg et al. (2000) studied the grain size distribution at sites 994, 995 and 997 drilled at Blake Ridge during ODP Leg 164. According to 375 samples collected, the depth intervals where pore-water chlorinity anomalies occur are in relatively coarse-grained sediments. The pore-water chlorinity is a proxy indicator for the presence of gas hydrates. Figure 3.11 (a, b, c) shows the grain-size distributions from sites 994, 995 and 997. 


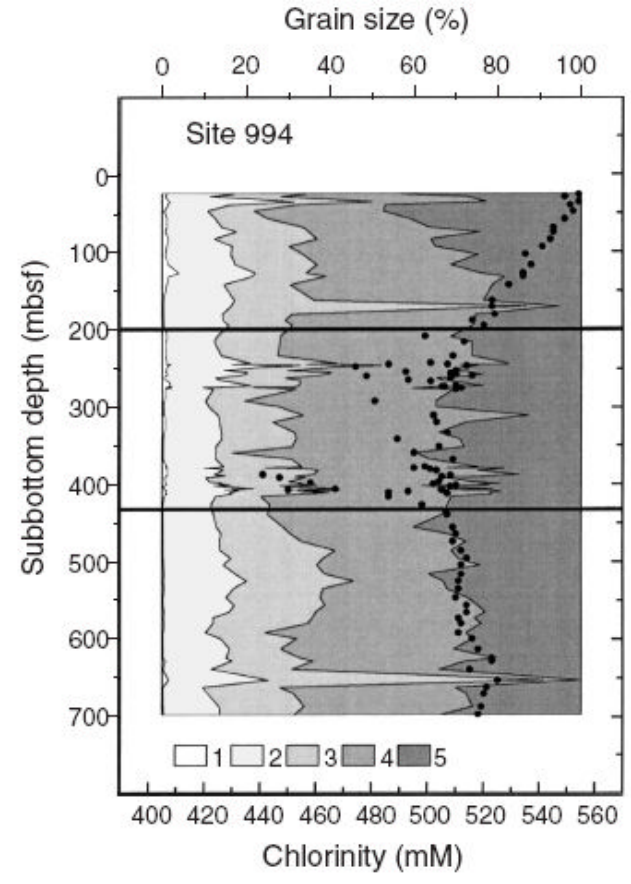

Figure 3.11a - Site 994

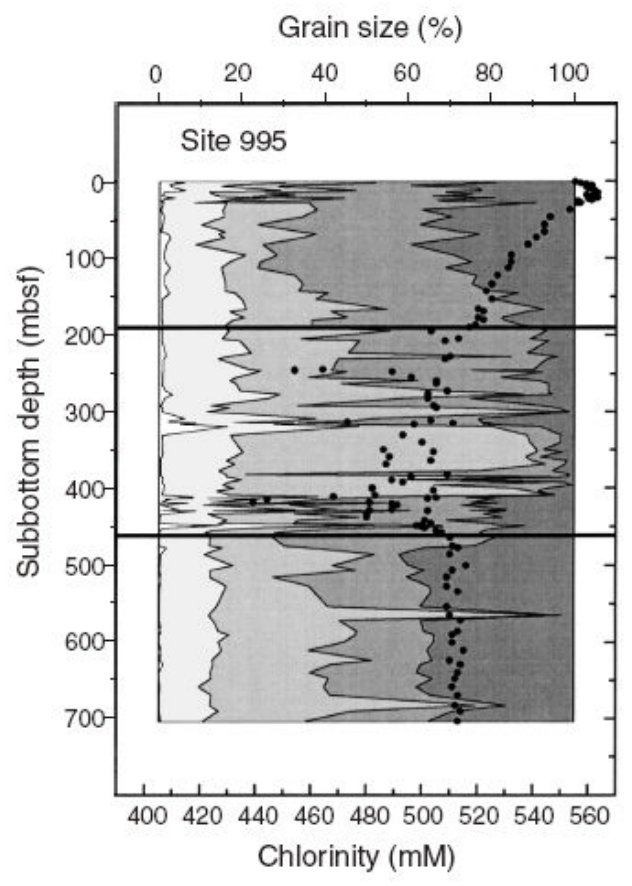

Figure 3.11b - Site 995

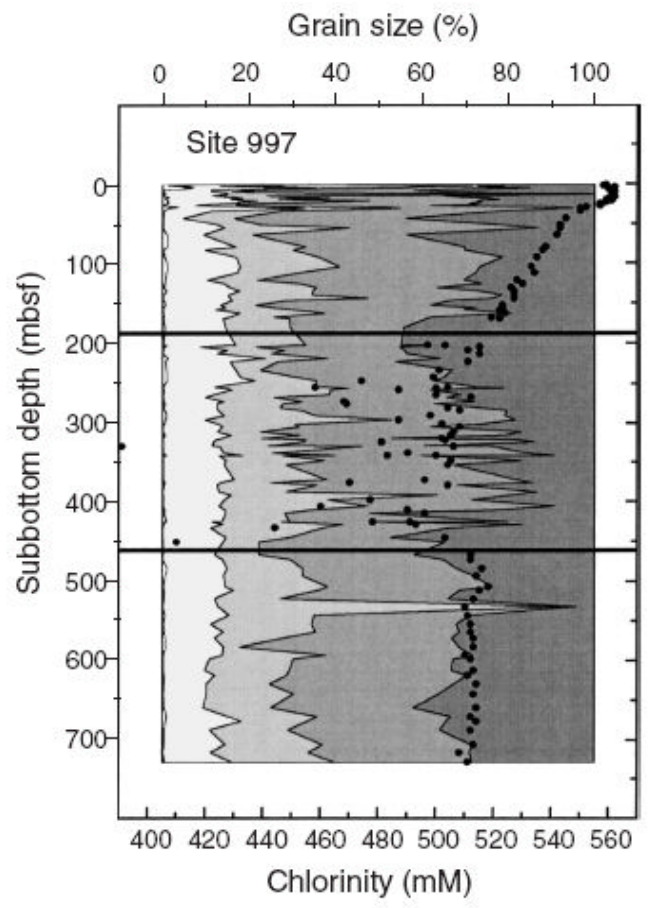

Figure 3.11c - Site 997

Figure 3.11 - Sediment grain size control on gas hydrates (Ginsburg et al. 2000) 


\section{Summary for Blake Ridge}

According to data, the sediment grain size distribution of sediments in the hydrate stability zone ranges from $0.005-0.001 ~ \mathbf{~ m m}$.

Table 3.4 - Major lithology for Blake Ridge

\begin{tabular}{|l|l|l|}
\hline SITE & Major lithology & Other constituents \\
\hline 994 & Clay & Nanofossil, foraminifers \\
\hline 995 & Clay & Nanofossil, foraminifers \\
\hline 996 & Silty-clay & Nanofossil \\
\hline 997 & Clay & Nanofossil, foraminifers \\
\hline
\end{tabular}

Table 3.5 - Mineralogy for Blake Ridge

\begin{tabular}{|l|l|l|l|}
\hline SITE & Clay & Quartz & Calcite \\
\hline 994 & $50-75 \%$ & $5-15 \%$ & $10-30 \%$ \\
\hline 995 & $50-85 \%$ & $5-10 \%$ & $10-30 \%$ \\
\hline 996 & $45-70 \%$ & $10-20 \%$ & $15-35 \%$ \\
\hline 997 & $60-80 \%$ & $<10 \%$ & $15-30 \%$ \\
\hline
\end{tabular}




\section{Cascadia Margin}

Figure 3.12 shows the expeditions performed in the Cascadia Margin, which were ODP Leg 168, 204 and IODP Expedition 311.

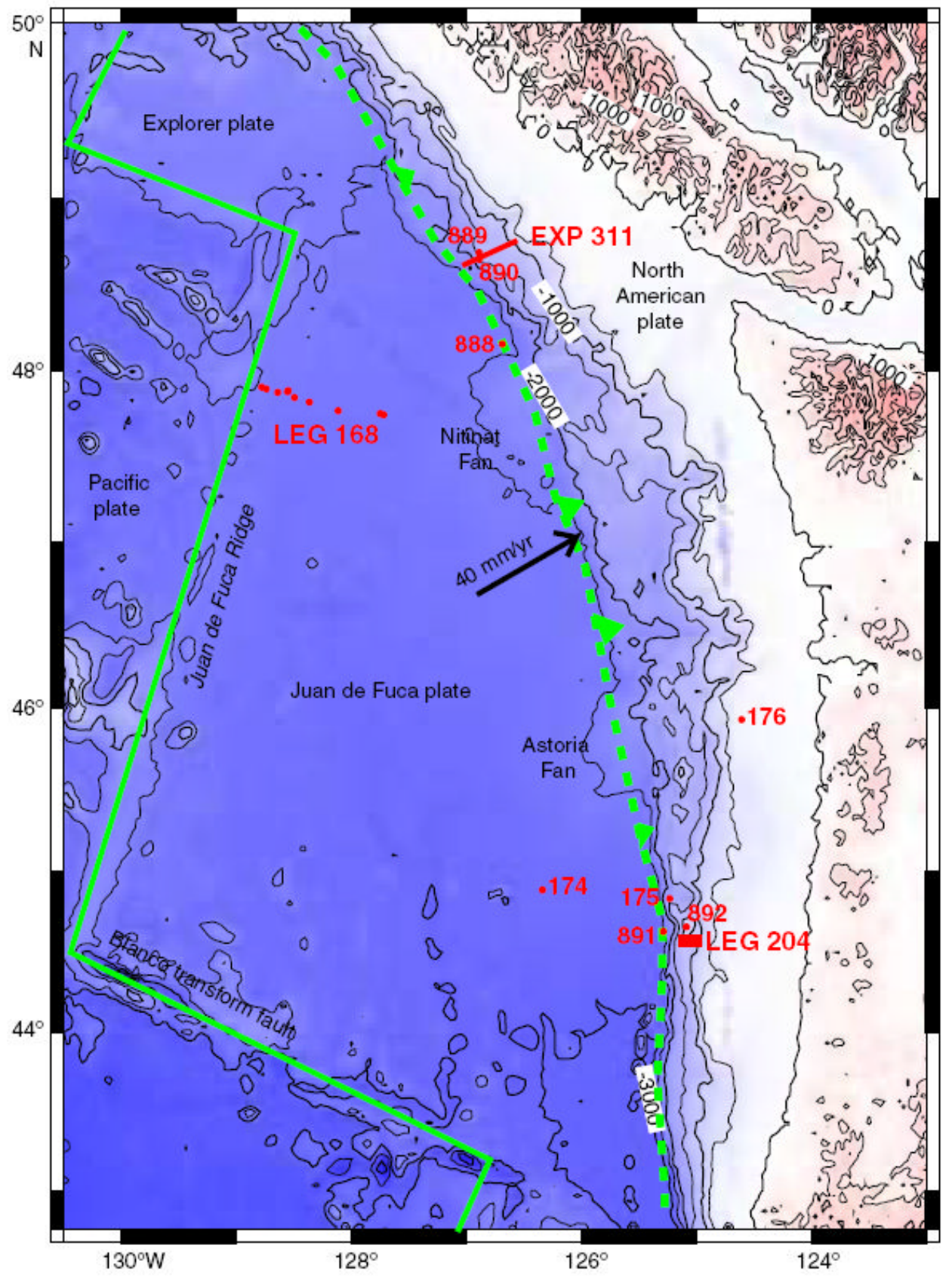

Figure 3.12 - Map of drilling sites at Cascadia Margin (Trehu, Torres et al. 2006) 
ODP Leg 204 and IODP Expedition 311 were the two operations dedicated to the understanding of the gas hydrate processes in marine environments. Leg 311 targeted a segment of northern Cascadia Margin where the sediments were coarser grained. The sediments encountered during the Leg 204 were finer grained. Leg 204 was carried out at Hydrate Ridge.

Hydrate Ridge is a $25-\mathrm{km}$ long and $15-\mathrm{km}$ wide ridge in the Cascadia accretionary complex, formed as Juan De Fuca plate subducts obliquely beneath North America at a rate of $\sim 4.5 \mathrm{~cm} /$ year (Shipboard-Scientists 2003). Sediment on the subducting plate contains large volumes of sandy and silty turbidites. Hydrate Ridge is characterized by a northern summit at a water depth of $\sim 600 \mathrm{~m}$ and a southern summit at a water depth of $\sim 800 \mathrm{~m}$.
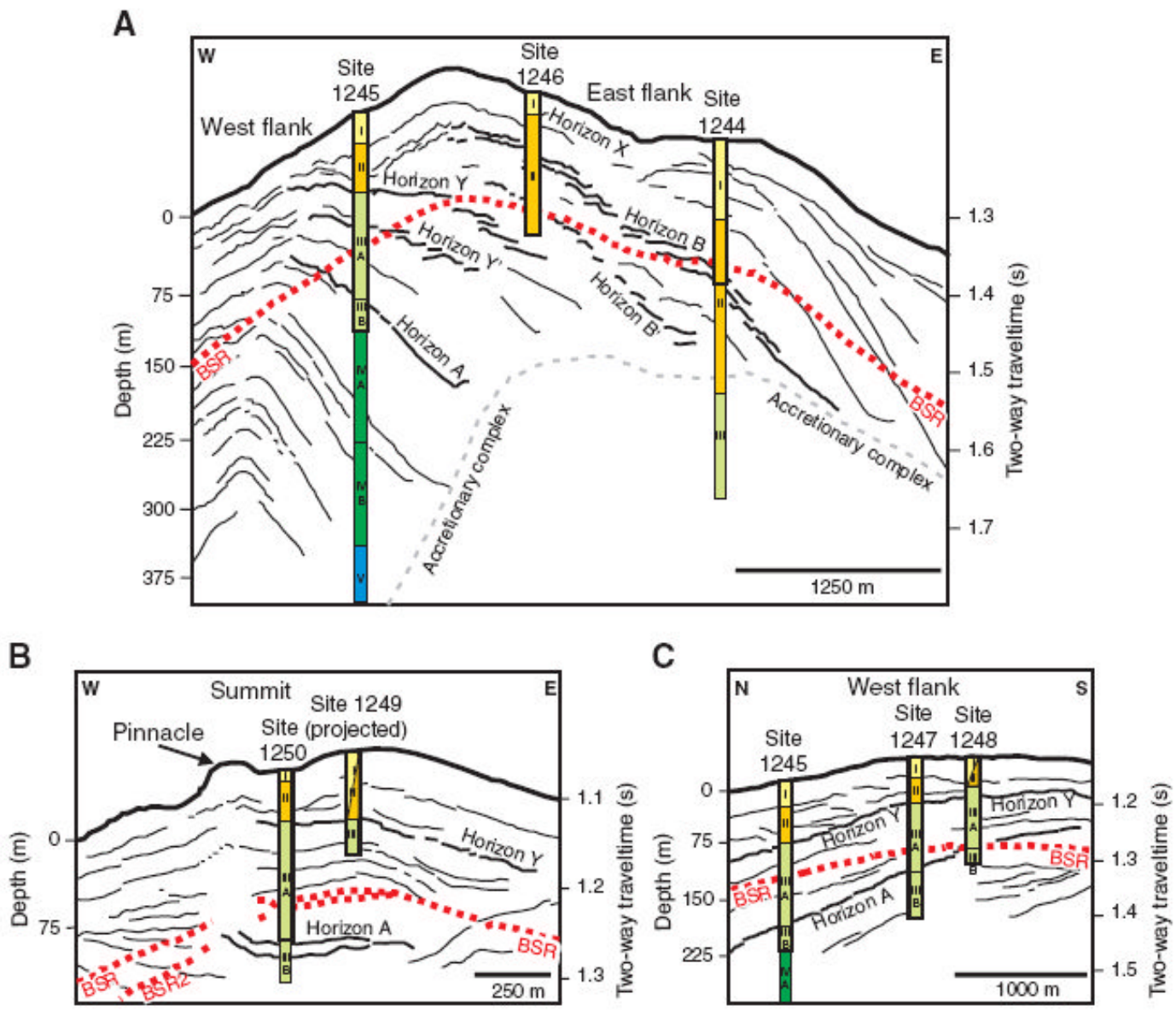

Figure 3.13 - Drilling sites during Leg 204 (Gracia, Martinez-Ruiz et al. 2006) 

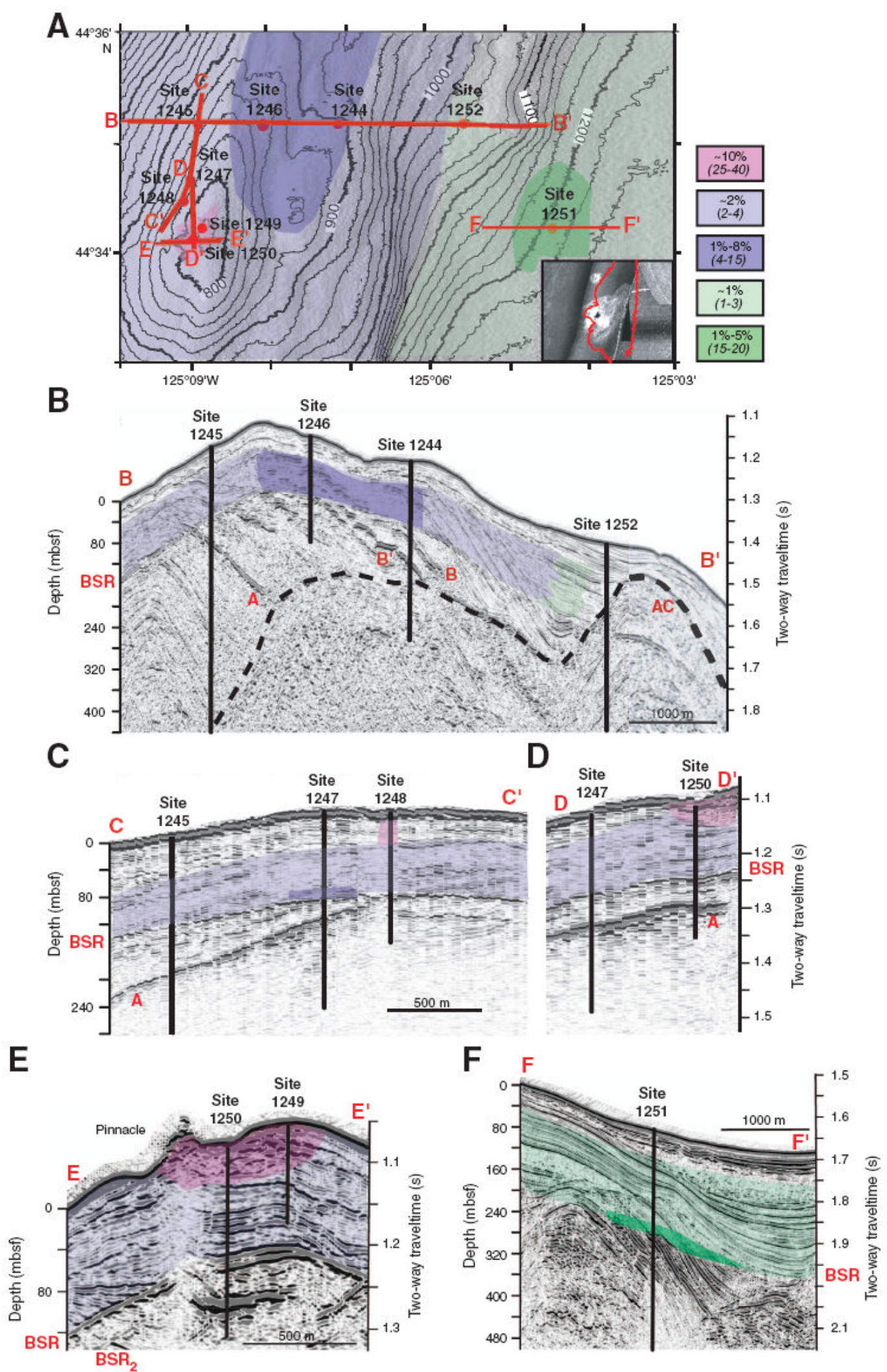

Figure 3.14 - ODP Leg 204 Drill Sites (Trehu, Torres et al. 2006) 


\section{Sediment characteristics and mineralogy}

Gracia et al. (2006) have analyzed the samples from seven Hydrate Ridge sites, and the grain sizes were defined as follows:

- Coarse-grained $(>50 \mu \mathrm{m})$

- Silt and clay $(<50 \mu \mathrm{m})$

Table 3.6 - Sediment Characteristics of Hydrate Ridge

\begin{tabular}{|l|l|l|l|l|}
\hline Site & Major lithology & Clays \% & Silt \% & Sand \% \\
\hline 1244 & Clay/Silty-clay & $60-80$ & $5-30$ & $<5$ \\
\hline 1245 & Clay/Silty-clay & $60-90$ & $0-20$ & $<5$ \\
\hline 1246 & Clay/Silty-clay & $70-80$ & $5-25$ & $<5$ \\
\hline 1247 & Clay/Silty-clay & $70-90$ & $5-30$ & $<10$ \\
\hline 1248 & Clay/Silty-clay & $60-90$ & $5-30$ & $<5$ \\
\hline 1249 & Clay/Silty-clay & $70-90$ & $10-30$ & $<5$ \\
\hline 1250 & Clay/Silty-clay & $70-100$ & $0-20$ & $<5$ \\
\hline 1251 & Clay/Silty-clay & $60-80$ & $15-30$ & $<5$ \\
\hline 1252 & Clay/Silty-clay & $70-95$ & $5-30$ & $<10$ \\
\hline
\end{tabular}

Table 3.7 - Mineralogy of Hydrate Ridge

\begin{tabular}{|l|l|l|l|l|}
\hline Hole & Detrital mica & Smectite & Kaolinite & Chlorite \\
\hline 1244 E & $30-60$ & $5-30$ & $15-30$ & $10-30$ \\
\hline 1250 C & $30-50$ & $10-30$ & $5-15$ & $10-20$ \\
\hline 1245 B & $\sim 50$ & $5-10$ & $10-15$ & $10-30$ \\
\hline
\end{tabular}

Tables 3.8 and 3.9, plus Figures 15 a), 15 b), and 15 c) contain information from the cores from the Cascadia Margin. 
Table 3.8 - Summary of Cascadia Margin Coring Operations

\begin{tabular}{|c|c|c|c|}
\hline Hole & Water Depth (m) & Penetration (m) & Formation \\
\hline $1244 \mathrm{~A}$ & 895 & 0 & \\
\hline $1244 \mathrm{~B}$ & 895 & 53.1 & L U I 0-53.1 mbsf \\
\hline $1244 \mathrm{C}$ & 895 & 334 & LU I: 0-69 mbsf; LU II: 69-245 mbsf: LU III 245-334 mbsf \\
\hline $1244 \mathrm{D}$ & 895 & 380 & LU I: 0-77.6 mbsf; LU II: 77.6-140.69 mbsf: LU III 140.69-380 mbsf \\
\hline $1244 \mathrm{E}$ & 895 & 136 & LU I: 0-77.6 mbsf; LU II: 77.6-140.69 mbsf \\
\hline $1245 \mathrm{~A}$ & 870 & 380 & \\
\hline $1245 \mathrm{~B}$ & 870 & 473.7 & LU I: 0.00-31.50 mbsf, LU II: 31.50-76.00 mbsf, LU III: 76.00-212.70 mbsf, LU IV: $212.70-419.30 \mathrm{mbsf}$, LU V: $419.30-472.88 \mathrm{mbsf}$ \\
\hline $1245 \mathrm{C}$ & 870 & 201.7 & LU I: 0.00-28.50 mbsf, LU II: $28.50-77.00$ mbsf, LU III: $77.00-200.90$ mbsf \\
\hline $1245 \mathrm{D}$ & 870 & 24 & LU I \\
\hline $1245 \mathrm{E}$ & 870 & $473.7-540.3$ & LU V \\
\hline $1246 \mathrm{~A}$ & 850 & 180 & No coring \\
\hline $1246 \mathrm{~B}$ & 850 & 136.7 & LU I: 0.00-21.70 mbsf, 21.70-136.76 mbsf \\
\hline $1247 \mathrm{~A}$ & 835 & 270 & No coring \\
\hline $1247 \mathrm{~B}$ & 835 & 220 & LU I: 0.00-27.00 mbsf, L U II: 27.00-60.00 mbsf, LU III: $60.00-220.62$ mbsf \\
\hline $1248 \mathrm{~A}$ & 830 & 194 & No coring \\
\hline $1248 \mathrm{~B}$ & 830 & 17 & Abandoned at 17 meters \\
\hline $1248 \mathrm{C}$ & 830 & 149 & LU I-II: 0.00-39.00 mbsf, LU III: 39.00-148.33 mbsf \\
\hline $1249 \mathrm{~A}$ & 775 & & No coring \\
\hline $1249 \mathrm{~B}$ & 775 & 74.9 & LU I-II: 29.90-57.62 mbsf, LU III: 57.62-74.90 mbsf \\
\hline $1249 \mathrm{C}$ & 775 & 90 & LU I-II: 0.00-59.30 mbsf. LU III: 59.33-89.50 \\
\hline $1249 \mathrm{D}$ & 775 & 18.5 & LU I-II: 0.00-18.50 mbsf \\
\hline $1249 \mathrm{E}$ & 775 & 11 & LU I-II: $0.00-11.00 \mathrm{mbsf}$ \\
\hline $1249 \mathrm{~F}$ & 775 & 90 & LU I-II: $0.00-51.52 \mathrm{mbsf}$, LU III: $51.52-90.00 \mathrm{mbsf}$ \\
\hline $1249 \mathrm{G}$ & 775 & & \\
\hline $1249 \mathrm{H}$ & 775 & & \\
\hline 1249 I & 775 & & These cores went directly to the pressure vessel and were not described \\
\hline $1249 \mathrm{~J}$ & 775 & & These cores went aireculy to the pressure vessel and were not described \\
\hline $1249 \mathrm{~K}$ & 775 & & \\
\hline $1249 \mathrm{~L}$ & 775 & & \\
\hline $1250 \mathrm{~A}$ & 792 & 210 & No Coring \\
\hline $1250 \mathrm{~B}$ & 792 & 160 & No Coring \\
\hline $1250 \mathrm{C}$ & 792 & 145 & LU I: $0.00-9.50$ mbsf, LU II: $9.50-43.75$ mbsf, LU III: $43.75-145.00$ mbsf \\
\hline $1250 \mathrm{D}$ & 792 & 145 & LU I: 0.00-9.50 mbsf, LU II: 9.50-39.50 mbsf, LU III: 39.50-145.00 \\
\hline $1250 \mathrm{E}$ & 792 & 180 & LU II: 9.50-16.00 mbsf \\
\hline $1250 \mathrm{~F}$ & 792 & 180 & LU I: $0.00-9.50 \mathrm{mbsf}$, LU III: 100.00-180.00 mbsf \\
\hline $1251 \mathrm{~A}$ & 1210 & 380 & No Coring \\
\hline $1251 \mathrm{~B}$ & 1210 & 445.1 & No Coring \\
\hline $1251 \mathrm{C}$ & 1210 & 17.6 & LU I: $0.00-17.60 \mathrm{mbsf}$ \\
\hline $1251 \mathrm{D}$ & 1210 & 230.5 & LU I: 0-130 mbsf, LU II: 130.00-228.50 mbsf \\
\hline $1251 \mathrm{E}$ & 1210 & 9.5 & LU I \\
\hline $1251 \mathrm{~F}$ & 1210 & 9.5 & LU I \\
\hline $1251 \mathrm{G}$ & 1210 & 21 & LU I \\
\hline $1251 \mathrm{H}$ & 1210 & 445 & $\mathrm{~N} / \mathrm{A}$ \\
\hline $1252 \mathrm{~A}$ & 1040 & 260 & LU I: 0-96 mbsf, LU II: 96.4-113.9 mbsf, LU III: 113.9-259.8 mbsf \\
\hline
\end{tabular}




\begin{tabular}{|c|c|c|}
\hline \multirow{4}{*}{ Site } & \multicolumn{2}{|r|}{$\begin{array}{c}\text { Lithological Description } \\
\end{array}$} \\
\hline & Lithostratographic Unit I & $\begin{array}{l}\text { Dark greenish gray clay, scattered thin layers of silty clay and fine silt. } \\
\text { Biogenic content varies from } 5 \% \text { to } 40 \% \\
\text { Sedimentary sequence extensively fractured } \\
\text { Major lithology: } 5 \% \text { quartz, } 10 \% \text { feldspar and } 70 \% \text { clay minerals }\end{array}$ \\
\hline & Lithostratigraphic Unit II & $\begin{array}{l}\text { Dark greenish gray silty clay with increased presence of silty clay } \\
\text { Biogenic components are } 3-8 \% \text { of the sediments } \\
\text { Silt sized grains typically compose the } 10-35 \% \text { of the sediments }\end{array}$ \\
\hline & Lithostratigraphic Unit III & $\begin{array}{l}\text { Composed of hard, indurated silty clay and clayey silt } \\
\text { Major components are primarily clay minerals, quartz and feldspar } \\
\text { Clay size grains typically compose of } 70 \% \text { of the sedimentary components }\end{array}$ \\
\hline 1245 & Lithostratographic Unit I & $\begin{array}{l}\text { Dark greenish gray nannofossil bearing clay to silty clay } \\
\text { Foraminifer bearing zones }\end{array}$ \\
\hline & Lithostratigraphic Unit II & $\begin{array}{l}\text { Dark greenish gray diatom bearing clay and silty clay commonly interbedded with fine to very fine sand layers } \\
78 \% \text { clay, } 19 \% \text { silt and } 3 \% \text { sand } \\
\text { Major minerals are feldspar, quartz and clay } \\
\text { Total biogenic components of the sediments comprise of foraminifers, nannofossils, diatoms, radiolarians }\end{array}$ \\
\hline & $\begin{array}{l}\text { Lithostratigraphic Unit III } \\
\text { Subunit III A }\end{array}$ & $\begin{array}{l}\text { dark greenish gray clay and silty clay to nannofossil-rich and diatom-rich silty clay } \\
\text { major lithology of lithostratigraphic Subunit IIIA is typically composed of } \sim 77 \% \text { clay and } \sim 23 \% \text { silt } \\
\text { Biogenic components (calcareous and opal) vary from } 0 \% \text { to } 25 \% \text { of the total sediments }\end{array}$ \\
\hline & $\begin{array}{r}\text { Lithostratigraphic Unit IV } \\
\text { Subunit IV A } \\
\text { Subunit IV B }\end{array}$ & $\begin{array}{l}\text { primarily composed of dark greenish gray ( } 5 \mathrm{GY} 4 / 1) \text { to very dark gray (N3) indurated claystone and silty claystone } \\
>10 \% \text { biogenic components } \\
<10 \% \text { biogenic components }\end{array}$ \\
\hline & Lithostratigraphic Unit V & $\begin{array}{l}\text { Dark greenish gray claystone and silty claystone } \\
\text { Claystone contains up to } 98 \% \text { clay and the silty claystone up to } 3 \% \text { sand and } 27 \% \text { silt } \\
\text { The major components are quartz, feldspar, muscovite, illite, other clay minerals, and minor amounts of calcite }\end{array}$ \\
\hline 1246 & Lithostratographic Unit I & $\begin{array}{l}\text { Dark greenish gray clay with diatom-rich silty clay and nannofossil and diatom-bearing silty clay } \\
\text { Biogenic components (mainly diatoms and calcareous nannofossils) compose between } 3 \% \text { and } 16 \% \text { of the major and minor lithologies }\end{array}$ \\
\hline & Lithostratigraphic Unit II & $\begin{array}{l}\text { Series of fining-upward sequences of silt to silty clay } \\
\text { Dominant lithology is silty clay with variations in the amount of biogenic opal and few biogenic calcareous components } \\
\text { Silt to silty sand is the typical minor lithology } \\
\text { Calcareous biogenic components consistently compose }<10 \% \text { of the total sedimentary components }\end{array}$ \\
\hline 1247 & Lithostratographic Unit I & $\begin{array}{l}\text { Dark greenish gray hemipelagic clay and silty clay with a low total biogenic content }(<10 \%) \\
\text { The clay content of lithostratigraphic Unit I varies between } 70 \% \text { and } 80 \% \text { in the major lithology } \\
\text { Silt-size components compose the remaining } 20 \%-30 \% \text { of the lithology }\end{array}$ \\
\hline & Lithostratographic Unit II & $\begin{array}{l}\text { Dark greenish gray ( } 5 \mathrm{GY} 4 / 1 \text { ) diatom-bearing to diatom-rich silty clay with graded silt and sand turbidites } \\
\text { The major lithology of lithostratigraphic Unit II is diatom-bearing to diatom-rich silty clay (contains } 20 \%-40 \% \text { silt-size grains) } \\
\text { Mineralogy composed of quartz, feldspar, and opaque and clay minerals } \\
\text { Minor lithologies ranges from clayey silt (containing } 40 \% \text { clay-size grains) to sandy silt (containing } 40 \% \text { sand-size grains) } \\
\text { Biogenic composed of diatoms, siliceous microfossils, calcareous nannofossils, and foraminifers, ranges from } 5 \% \text { to } 35 \% \text { of the total sediments }\end{array}$ \\
\hline & Lithostratigraphic Unit III & Dark greenish gray diatom-bearing to diatom-rich clay and silty clay \\
\hline
\end{tabular}




\begin{tabular}{|c|c|c|}
\hline \multirow{3}{*}{\begin{tabular}{|l} 
Site \\
1248
\end{tabular}} & \multicolumn{2}{|r|}{$\begin{array}{r}\text { Lithological Description } \\
\end{array}$} \\
\hline & Lithostratographic Unit I-II & $\begin{array}{l}\text { Dark greenish gray, homogeneous fine-grained sediments diatom-bearing to diatom-rich clay and silty clay } \\
\text { Authigenic carbonate precipitates related to the presence of gas hydrate are common in the upper part of this unit } \\
\text { Sediments that are typically } \sim 80 \% \text { clay, } \sim 19 \% \text { silt, and } \sim 1 \% \text { sand } \\
\text { The major nonbiogenic components of the unit are quartz, feldspar, and clay and opaque minerals } \\
\text { The biogenic components (mainly siliceous microfossils) compose } 2 \% \text { to } 13 \% \text { of the total sedimentary components }\end{array}$ \\
\hline & $\begin{array}{l}\text { Lithostratigraphic Unit III } \\
\text { Subunit IIIA } \\
\text { Subunit IIIB }\end{array}$ & $\begin{array}{l}\text { Diatom- and nannofossil-bearing silty clay interbedded with thin layers of graded silt and fine sand } \\
\text { Sediment with } \sim 75 \% \text { clay, } 25 \% \text { silt, and }<1 \% \text { sand } \\
76 \% \text { clays, } 24 \% \text { silts, and no sands in major lithology }\end{array}$ \\
\hline \multirow[t]{2}{*}{1249} & Lithostratographic Unit I-II & $\begin{array}{l}\text { Clay and silty clay with a varying biogenic component that ranges from nannofossil- to diatom-bearing and diatom-rich clay } \\
\text { Mineralogic components of lithostratigraphic ranges from clay to silty clay } \\
\text { On average, } ~ 70 \% \text { of the total components are clay and } \sim 30 \% \text { are silt } \\
\text { Biogenic components typically compose } 5 \%-15 \% \text { of the sediments }\end{array}$ \\
\hline & Lithostratigraphic Unit III & Major lithology is diatom-bearing to diatom-rich clay and silty clay with nannofossil-bearing to nannofossil-rich zones \\
\hline \multirow[t]{3}{*}{1250} & Lithostratographic Unit I & $\begin{array}{l}\text { Dark greenish gray diatom-bearing clay to diatom-rich silty clay near its base } \\
\text { dominant lithology of lithostratigraphic Unit I contains } \sim 70 \% \text { clay, } \sim 20 \% \text { silt, and } \sim 10 \% \text { sand } \\
\text { Calcareous components (calcareous nannofossils and foraminifers) are rare }\end{array}$ \\
\hline & Lithostratographic Unit II & sequence of diatom-bearing to diatom-rich silty clay to layers interbedded with thin silt and fine sand \\
\hline & $\begin{array}{l}\text { Lithostratographic Unit III } \\
\text { Subunit IIIA } \\
\text { Subunit IIIB }\end{array}$ & $\begin{array}{l}\text { consists of diatom-bearing to diatom-rich silty clay to nannofossil-rich clay interbedded with abundant layers of silt to fine sand } \\
80 \% \text { clay, } 20 \% \text { silt, and }<1 \% \text { sand } \\
80 \% \text { clay, } 20 \% \text { silt, and }<1 \% \text { sand }\end{array}$ \\
\hline \multirow[t]{3}{*}{1251} & $\begin{array}{l}\text { Lithostratographic Unit I } \\
\text { Subunit I A } \\
\text { Subunit I B } \\
\text { Subunit I C }\end{array}$ & $\begin{array}{l}\text { Silty clay and clay with interlayered sand and silt layers and mud clast deposits } \\
\text { Dark greenish gray }(5 \mathrm{GY} 4 / 1) \text { clay with thin }(1-5 \mathrm{~cm} \text { thick) silt to silty sand turbidites } \\
\text { dominated by zones of convoluted clay with abundant sulfide material containing unsorted clay-rich granules and pebble-sized silty clay clasts } \\
\text { interbedded clays and silty clays, with bioturbation }\end{array}$ \\
\hline & $\begin{array}{c}\text { Lithostratographic Unit II } \\
\text { Subunit IIA } \\
\text { Subunit IIB }\end{array}$ & $\begin{array}{l}\text { composed of silty clay and clay } \\
\text { consists of silty clay, which typically contains } 30 \%-35 \% \text { silt and } 65 \%-70 \% \text { clay } \\
\text { The major lithology contains } 15 \% \text { to } 20 \% \text { silt and } 80 \% \text { to } 85 \% \text { clay }\end{array}$ \\
\hline & Lithostratographic Unit III & $\begin{array}{l}\text { composed of hard indurated clay, silty clay, and claystone with reduced calcareous components } \\
\text { High state of lithification, diatom-rich clay, authigenic carbonate in the clay fraction, carbonate nodules, and increasing scaly clay fabric } \\
\text { Silty claystone contains up to } 5 \% \text { sand and } 30 \% \text { silt } \\
\text { The major components are quartz, feldspar, muscovite, illite, other clay minerals, and calcite in varying amounts } \\
\text { The presence of carbonate nodules is characteristic of lithostratigraphic Unit III }\end{array}$ \\
\hline \multirow[t]{4}{*}{1252} & Lithostratographic Unit I & Dark greenish gray diatom-rich to diatom-bearing homogeneous silty clay \\
\hline & $\begin{array}{l}\text { Subunit IA } \\
\text { Subunit IB-IC }\end{array}$ & $\begin{array}{l}70 \% \text { clay, } 25 \% \text { silt, and }<1 \% \text { sand } \\
\text { The minor lithology is dominated by coarse grains, with an average distribution of } 28 \% \text { silt and } 23 \% \text { sand } \\
\text { consists of homogeneous diatom-bearing to diatom-rich silty clay } \\
69 \% \text { clay, } 30 \% \text { silt, and } 1 \% \text { sand } \\
\text { Biogenic components } \sim 12 \% \text { of sediments } \\
\text { Mud clasts, ranging from } 1 \text { to } 3 \mathrm{~cm} \text { in diameter, are embedded in a clay-rich convoluted matrix } \\
770 \% \text { clay and } 30 \% \text { silt } \\
\text { rich in biogenic components } \\
\text { calcareous components (calcareous nannofossils and foraminifers) typically compose } 3 \%-7 \% \text { of the sedimentary components }\end{array}$ \\
\hline & Lithostratographic Unit II & $\begin{array}{l}\text { primarily composed of foraminifer-rich silty clay } \\
\text { The major sedimentary components of lithostratigraphic Unit II are clay minerals, quartz, and feldspar } \\
\text { Quartz } \sim 10 \% \text { of the coarse fraction } \\
\text { Silt- and sand-size grains compose } 28 \% \text { and } 5 \% \text {, respectively, of the sedimentary components, with the remainder composed of clay-size minerals }\end{array}$ \\
\hline & Lithostratographic Unit III & $\begin{array}{l}\text { The major lithology of the lithostratigraphic unit comprises } 73 \% \text { clay-, } 24 \% \text { silt-, and } 3 \% \text { sand-size grains } \\
\text { The minor lithologies range from clay, composed of } 5 \% \text { silt and } 95 \% \text { clay, to sand-silt-clay, composed of } 40 \% \text { sand, } 30 \% \text { silt, and } 30 \% \text { clay }\end{array}$ \\
\hline
\end{tabular}




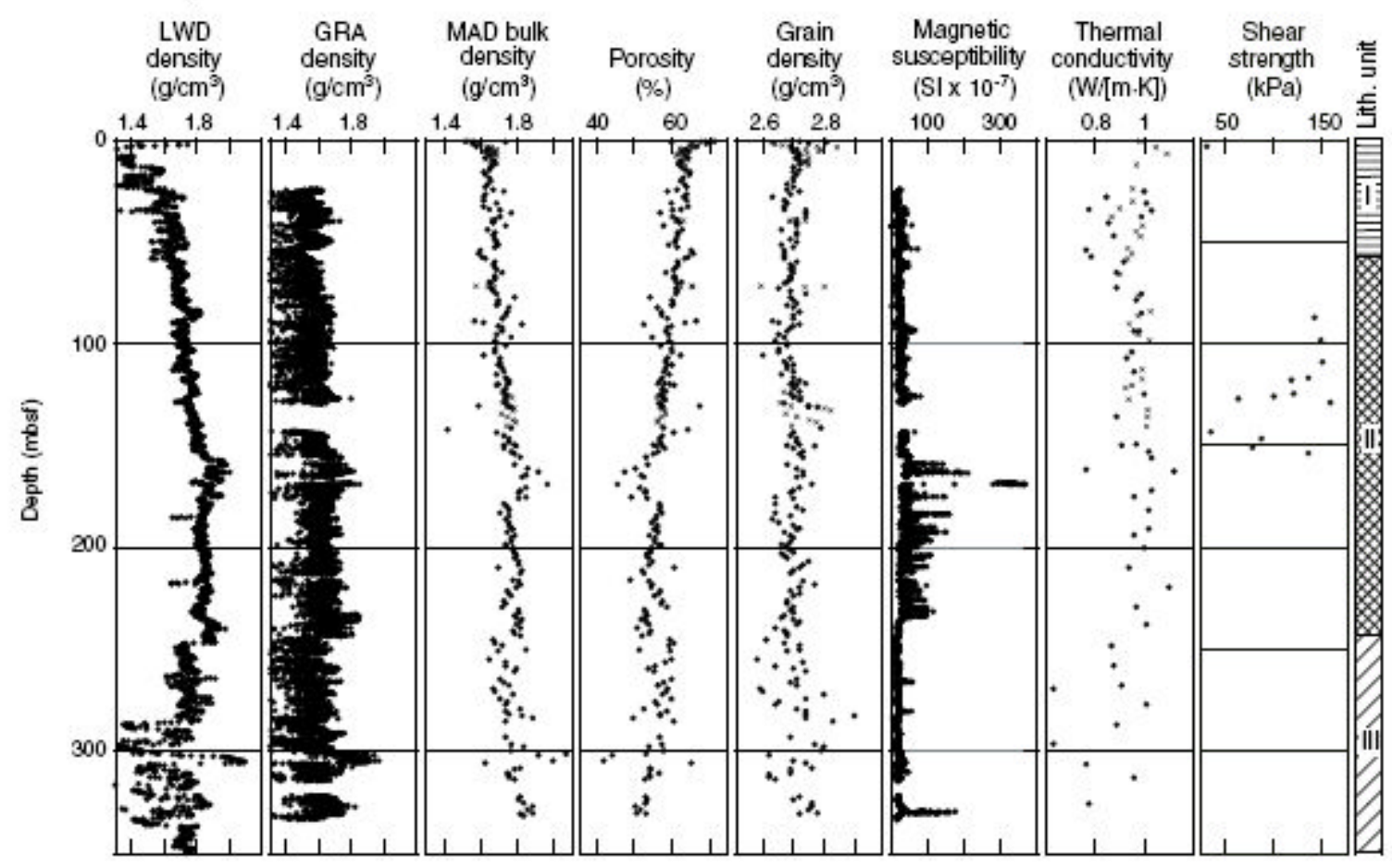

Figure 3.15a - Physical properties of Hole 1244 (Shipboard-Scientists 1996)

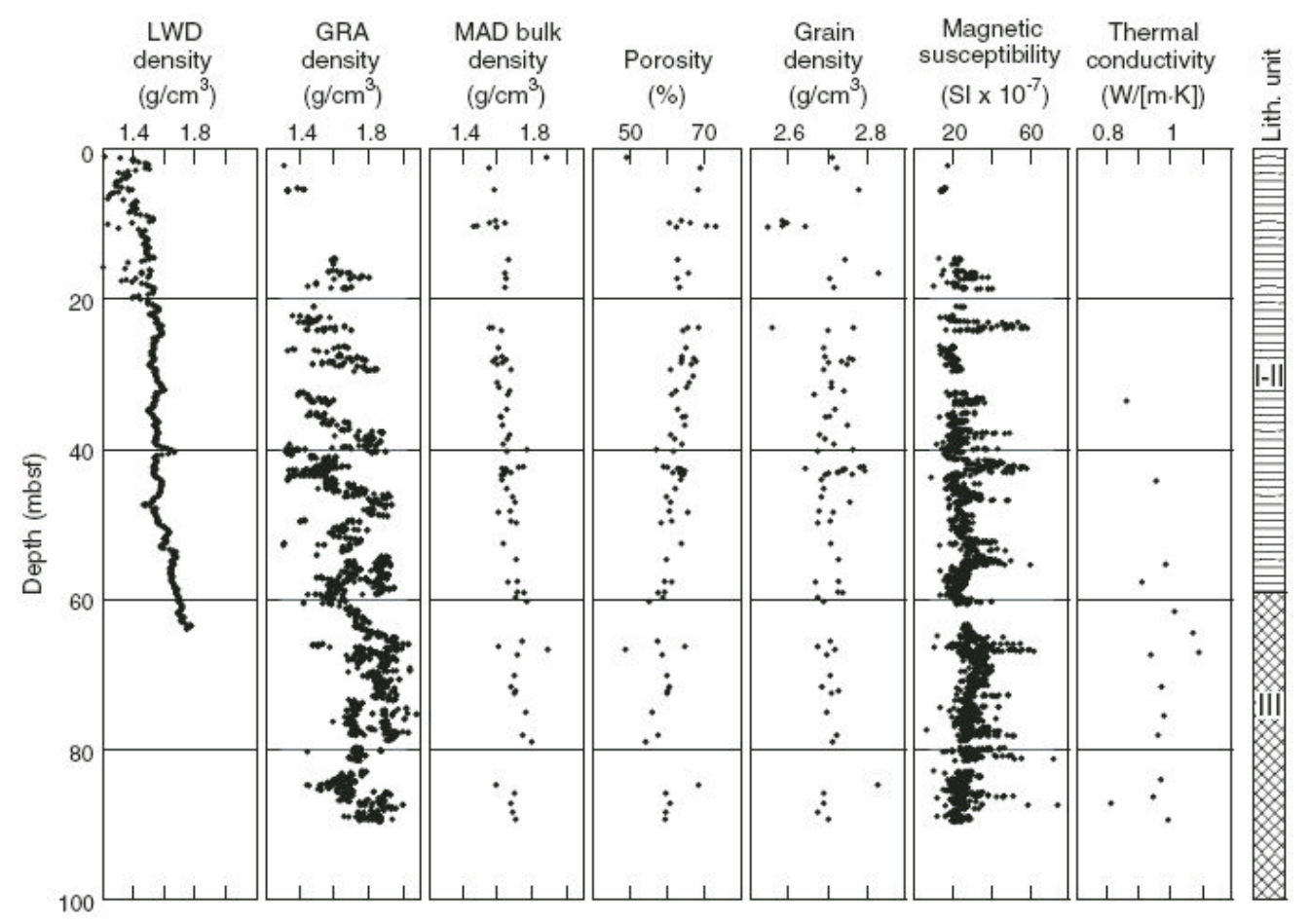

Figure 3.15b - Physical properties of Hole 1249 B, C and F (Shipboard-Scientists 1996) 


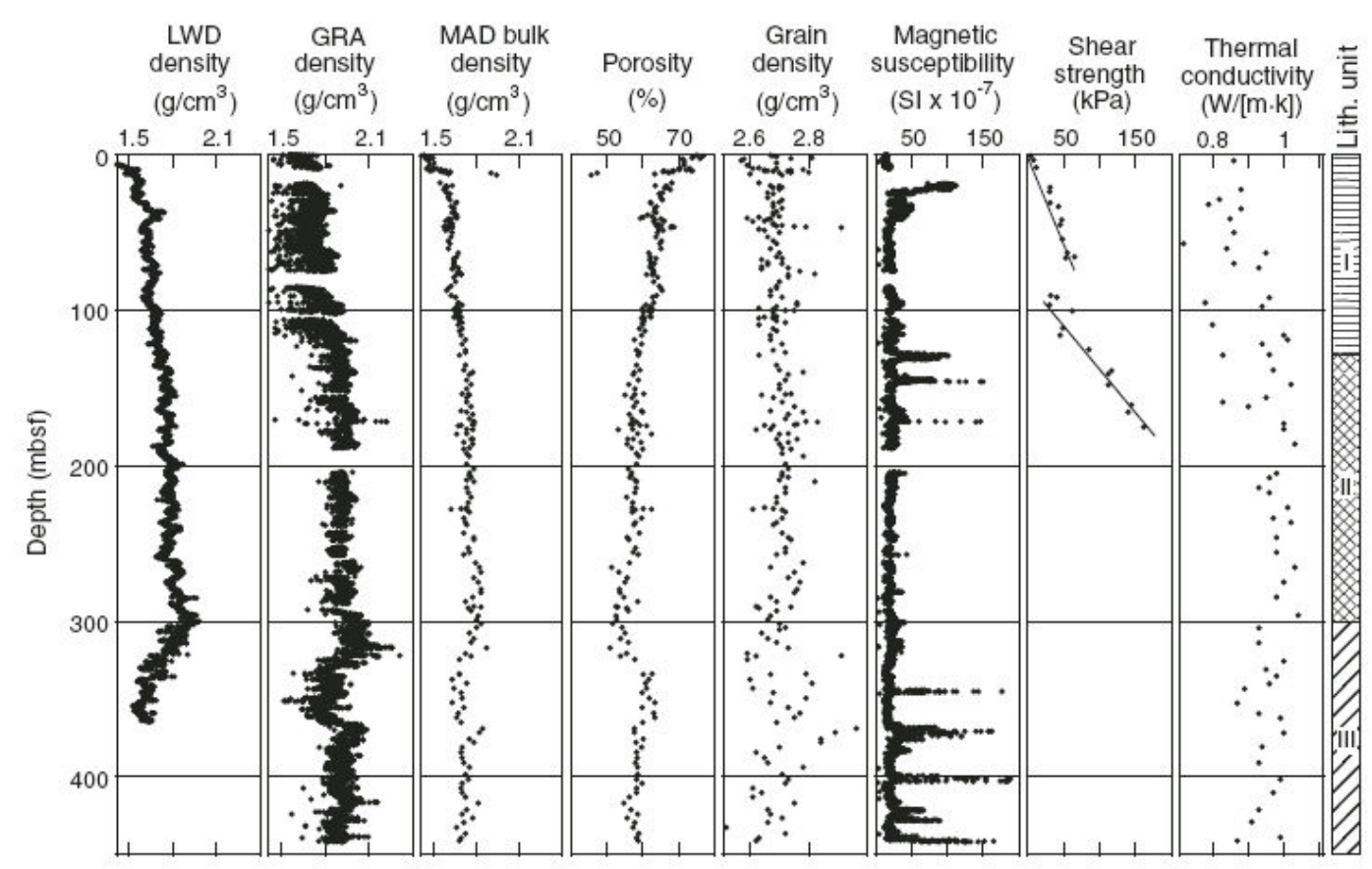

Figure 3.15c - Physical properties of Hole 1251 B (Shipboard-Scientists 1996)

Table 3.9 - Analysis of various samples for the grain sizes in the gas hydrate stability zone (Su, Song et al. 2006)

\begin{tabular}{ccccc}
\hline Site & Location & $\begin{array}{c}\text { Water } \\
\text { depth (m) }\end{array}$ & $\begin{array}{c}\text { BSR depth } \\
\text { (mbsf) }\end{array}$ & $N$ \\
\hline 1244 & $44.586^{\circ} \mathrm{N}, 125.119^{\circ} \mathrm{W}$ & 890 & 125 & 16 \\
1245 & $44.586^{\circ} \mathrm{N}, 125.148^{\circ} \mathrm{W}$ & 870 & 134 & 58 \\
1246 & $44.586^{\circ} \mathrm{N}, 125.135^{\circ} \mathrm{W}$ & 848 & 114 & 50 \\
1248 & $44.574^{\circ} \mathrm{N}, 125.153^{\circ} \mathrm{W}$ & 832 & 124 & 45 \\
1249 & $44.57^{\circ} \mathrm{N}, 125.148^{\circ} \mathrm{W}$ & 778 & 115 & 13 \\
1250 & $44.569^{\circ} \mathrm{N}, 125.149^{\circ} \mathrm{W}$ & 782 & 114 & 42 \\
1251 & $44.57^{\circ} \mathrm{N}, 125.074^{\circ} \mathrm{W}$ & 1216 & 196 & 20 \\
1252 & $44.486^{\circ} \mathrm{N}, 125.094^{\circ} \mathrm{W}$ & 1039 & 170 & 75 \\
\hline
\end{tabular}

$\mathrm{N}$ refers to the number of samples analyzed. 
Figure 3.16 illustrates the location of the cores and the grain size distribution from some of the cores in the Cascadia Margin.
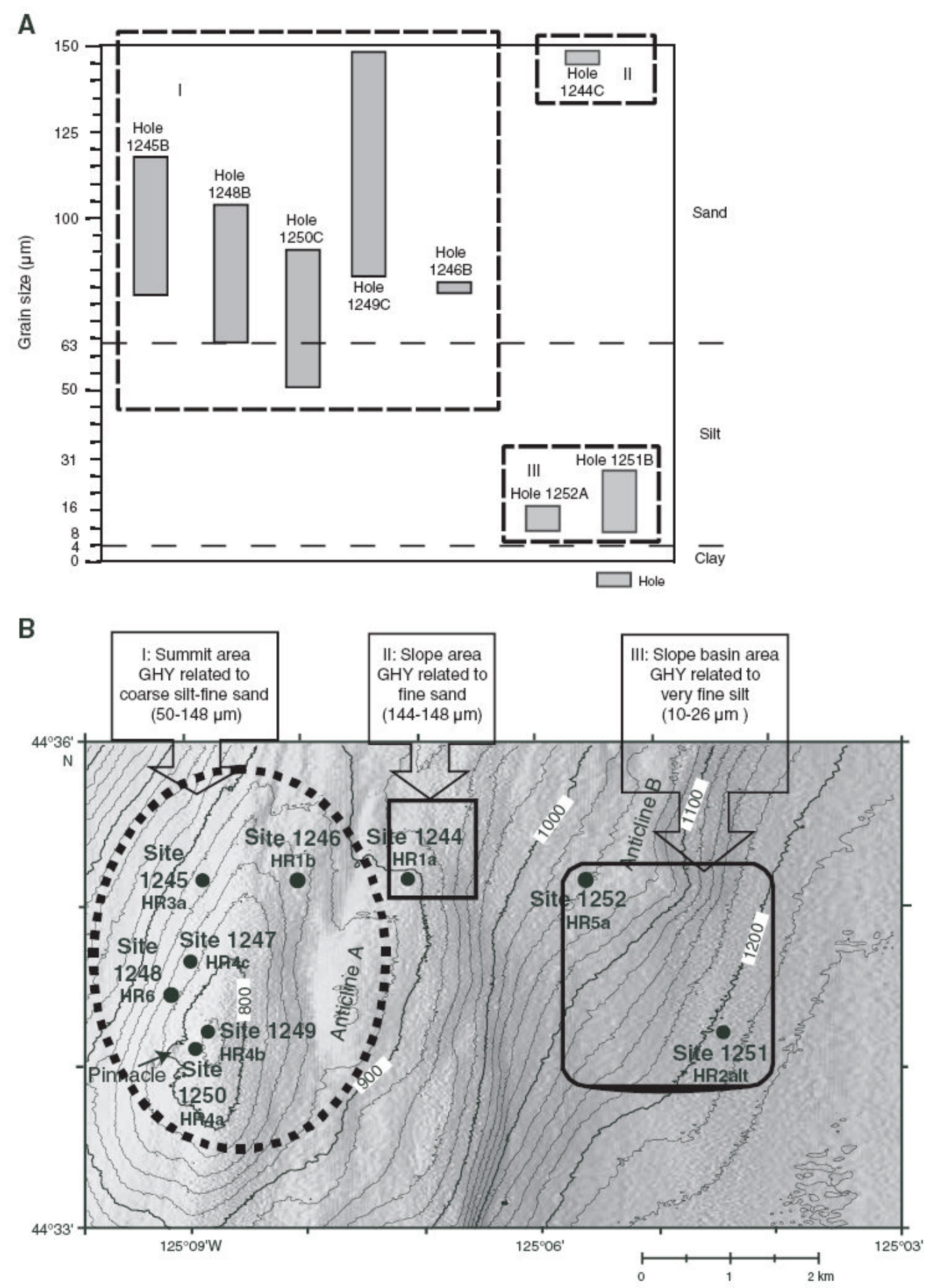

Figure 3.16 - Grain size controls on hydrate distribution (Su, Song et al. 2006) 
Trehu (2006) has summarized the subsurface temperatures and thermal profiles at Hydrate Ridge (See Table 3.10 below).

Table 3.10 - Subsurface temperatures and thermal properties at Hydrate Ridge

\begin{tabular}{|c|c|c|c|c|}
\hline Site & Water depth (m) & $\begin{array}{c}\text { Thermal gradient } \\
\left({ }^{\circ} \mathrm{C} / \mathbf{k m}\right)\end{array}$ & $\begin{array}{c}\text { Average thermal } \\
\text { conductivity } \\
(W / m / K)\end{array}$ & $\begin{array}{l}\text { Heat flow } \\
(\mathrm{mW} / \mathrm{m} 2)\end{array}$ \\
\hline 1244 & 895 & $62 \pm 1$ & $0.93 \pm 0.07$ & $58 \pm 5$ \\
\hline 1245 & 871 & $54 \pm 1$ & $0.98 \pm 0.05$ & $54 \pm 4$ \\
\hline 1246 & 851 & $55 \pm 7$ & $0.93 \pm 0.07$ & $51 \pm 10$ \\
\hline 1247 & 830 & $53 \pm 1$ & $0.96 \pm 0.07$ & $51 \pm 5$ \\
\hline 1248 & 830 & $54 \pm 1$ & $0.98 \pm 0.07$ & $53 \pm 5$ \\
\hline 1249 & 780 & $59 \pm 3$ & $0.93 \pm 0.07$ & $55 \pm 7$ \\
\hline 1249 & 780 & $56 \pm 5$ & $0.93 \pm 0.07$ & $52 \pm 9$ \\
\hline 1250 & 790 & $59 \pm 2$ & $0.94 \pm 0.07$ & $55 \pm 6$ \\
\hline 1250 & 790 & $53 \pm 2$ & $0.94 \pm 0.07$ & $50 \pm 6$ \\
\hline $1249 / 1250$ & & $58 \pm 2$ & $0.94 \pm 0.06$ & $55 \pm 5$ \\
\hline 1251 & 1212 & $54 \pm 1$ & $0.83 / 0.95$ & $52 \pm 8$ \\
\hline 1252 & 1040 & $57 \pm 1$ & $0.84 / 0.93$ & $53 \pm 6$ \\
\hline $1251 / 1252$ & All & $54 \pm 1$ & $0.90 \pm 0.14$ & $49 \pm 11$ \\
\hline $1251 / 1252$ & $<100 \mathrm{mbsf}$ & $58 \pm 2$ & $0.83 \pm 0.07$ & $48 \pm 6$ \\
\hline $1251 / 1252$ & $>100 \mathrm{mbsf}$ & $52 \pm 1$ & $0.94 \pm 0.06$ & $49 \pm 4$ \\
\hline
\end{tabular}

Tan et al. (2006) have described the strength characteristics of the sediments from Site 1244. Table 3.11 is the tabulated form of their results: 
Table 3.11 - Data from sediments recovered at Site 1244 .

\begin{tabular}{|c|c|c|c|c|c|c|c|c|}
\hline Section & $\begin{array}{l}\text { Depth } \\
\text { (mbsf) }\end{array}$ & $\begin{array}{l}w_{n} \\
(\%)\end{array}$ & $\begin{array}{l}m \\
(\%)\end{array}$ & $\begin{array}{l}w_{p} \\
(\%)\end{array}$ & ${ }_{(p)}^{I_{p}}$ & $\begin{array}{c}1 \\
(\%)\end{array}$ & $\begin{array}{l}\mathrm{LOI} \\
(\%)\end{array}$ & $\begin{array}{c}\mathrm{CaCO}_{3} \\
\text { content }(w t \%)\end{array}$ \\
\hline \multicolumn{9}{|l|}{ 204-1244B- } \\
\hline 1H-4WR & 5.70 & 59.90 & 71.00 & 32.00 & 39.00 & 72.00 & 5.89 & \\
\hline $3 \mathrm{H}-3 W R$ & 20.30 & 63.80 & 82.00 & 37.00 & 45.00 & 60.00 & 4.55 & 1.297 \\
\hline $4 \mathrm{H}-6 \mathrm{WR}$ & 32.98 & 62.70 & 87.00 & 42.00 & 45.00 & 46.00 & 5.18 & 1.253 \\
\hline $6 \mathrm{H}-8 \mathrm{WR}$ & 52.81 & 60.05 & 85.00 & 38.00 & 47.00 & 47.00 & 4.93 & 2.357 \\
\hline \multicolumn{9}{|l|}{$204-1244 C$ - } \\
\hline $8 \mathrm{H}-7$ WR & 70.88 & 58.10 & 86.00 & 40.00 & 46.00 & 39.00 & 5.87 & 2.090 \\
\hline $9 \mathrm{H}-5 \mathrm{WR}$ & 79.05 & 54.40 & 83.00 & 38.00 & 45.00 & 36.00 & 7.27 & \\
\hline $13 \mathrm{H}-3 \mathrm{WR}$ & 114.20 & 47.27 & 81.00 & 39.00 & 42.00 & 20.00 & 5.19 & 5.812 \\
\hline $13 \mathrm{H}-3 \mathrm{WR}$ & 114.20 & Oven-dried & 64.00 & 39.00 & 25.00 & & & \\
\hline $17 \mathrm{H}-3 \mathrm{WR}$ & 135.55 & 48.85 & 77.00 & 35.00 & 42.00 & 33.00 & 4.68 & 2.928 \\
\hline
\end{tabular}

The nomenclature used in their report is as follows:

\begin{tabular}{|c|c|c|c|}
\hline Variable & Definition & Dimensions & Sl units \\
\hline A & A-parameter & Dimensionless & - \\
\hline B & B-value & Dimensionless & - \\
\hline $\mathrm{C}_{\mathrm{c}}$ & Compression index & Dimensionless & - \\
\hline $\mathrm{C}_{\mathrm{r}}$ & Recompression index & Dimensionless & - \\
\hline$c_{\mathrm{v}}$ & Coefficient of consolidation & $L^{2} / T$ & $\mathrm{~cm}^{2} / \mathrm{s}$ \\
\hline $\mathrm{G}_{3}$ & Specific gravity & Dimensionless & - \\
\hline$e_{c}$ & Corsolidation void ratio & Dimensionless & - \\
\hline$e_{1}$ & Initial void ratio & Dimensionless & - \\
\hline$I_{1}$ & Liquidity index & Dimensionless & - \\
\hline$I_{p}$ & Plasticity index & Dimensionless & - \\
\hline $\mathrm{K}_{\mathrm{c}}$ & Corsolidation lateral stress ratio & Dimensionless & - \\
\hline $\mathrm{K}_{0}$ & In situ lateral stress ratio & Dimensionless & - \\
\hline $\mathrm{K}$ & Lateral stress ratio & Dimensionless & - \\
\hline$k_{0}$ & In situ hydraulic conductivity & $\mathrm{L} / \mathrm{T}$ & $\mathrm{cm} / \mathrm{s}$ \\
\hline k & Hydraulic conductivity & $\mathrm{L} / \mathrm{T}$ & $\mathrm{cm} / \mathrm{s}$ \\
\hline LOI & Loss on ignition & Dimensionless & - \\
\hline OCR & Overconsolidation ratio & Dimensionless & - \\
\hline$p^{\prime}$ & Mean stress & $\mathrm{M} / \mathrm{LT}^{2}$ & $\mathrm{kgf} / \mathrm{cm}^{2}$ \\
\hline q & Shear stress & $\mathrm{M} / \mathrm{LT}^{2}$ & $\mathrm{kgf} / \mathrm{cm}^{2}$ \\
\hline$S_{1}$ & Initial saturation & Dimensionless & $\%$ \\
\hline$t_{s}$ & Time for secondary compression & $\mathrm{T}$ & $\sec$ \\
\hline 4 & Back pressure & $\mathrm{M} / \mathrm{LT}^{2}$ & $\mathrm{kgf} / \mathrm{cm}^{2}$ \\
\hline $\mathbf{w}_{\mathrm{c}}$ & Water content & Dimensionless & $\%$ \\
\hline$w_{1}$ & Liquid limit & Dimensionless & - \\
\hline$w_{n}$ & Natural water content & Dimensionless & $\%$ \\
\hline$w_{p}$ & Plastic limit & Dimensionless & - \\
\hline$\Delta \mathrm{u}_{\mathrm{a}}$ & Excess pore pressure & $\mathrm{M} / \mathrm{LT}^{2}$ & $\mathrm{kgf} / \mathrm{cm}^{2}$ \\
\hline$\Delta \mathrm{u}_{3}$ & Shear induced pore pressure & $\mathrm{M} / \mathrm{LT}^{2}$ & $\mathrm{kgf} / \mathrm{cm}^{2}$ \\
\hline$\delta_{e} / \delta \mathrm{t}$ & Strain rate & $1 / T$ & $\% / \mathrm{hr}$ \\
\hline$\varepsilon_{\mathrm{a}}$ & Axial strain & Dimensionless & - \\
\hline$\varepsilon_{\mathrm{vol}}$ & Volumetric strain & Dimensionless & - \\
\hline $\mathrm{Pt}$ & Total density & $M / L^{3}$ & $\mathrm{~g} / \mathrm{am}^{3}$ \\
\hline f & Friction angle & Degrees & degrees \\
\hline$\sigma_{1}^{\prime}$ & Initial ffective stress & $\mathrm{M} / \mathrm{LT}^{2}$ & $\mathrm{kgf} / \mathrm{cm}^{2}$ \\
\hline
\end{tabular}

Water content is important parameter because it suggests the available water for the formation of hydrate. 


\section{Gulf of Mexico}

Gas hydrate has been recovered in more than 53 sites in the northwest portion of the Gulf of Mexico (GOM) at water depths of 440-2400 m (Sassen, Joye et al. 1999). According to Krason et al (1985), the total volume of hydrate-bound gas in the GOM is estimated to be between $\sim 0.5-255 \times 10^{12} \mathrm{~m}^{3}$. BSRs are rare in the GOM and no relationship has been observed between the presence of actual hydrates and the geophysical signatures. Sassen et. al. have performed numerous field sample studies from the shallow sediments from the GOM. There have also been two cruises in the GOM, namely Leg 96 of Ocean Drilling Program and the Chevron JIP/DOE work in 2005.

Although the GOM has the origin as a passive continental margin, it is tectonically-active with complex geological features. These features are faults, folds and salt piercements. The main characteristic in the GOM that is different from other continental margins is that hydrates are found in the shallow sediments. In other continental margins (e.g. Blake Ridge, Costa Rica margin, Cascadia margin and Nankai accretionary margin) the top of the GHSZ for methane gas is found from tens to hundreds of meters below seafloor. Milkov and Sassen (2003) have presented the studied areas of Gulf of Mexico, which has been summarized in Table 3.12 and are shown in Figures 3.17 - 3.24.

\section{Table 3.12 - Areas in the Gulf of Mexico Studied by Sassen and Associates}

\begin{tabular}{|c|c|c|c|c|c|c|}
\hline Accumulation & Estimated area & $\begin{array}{l}\text { Water depth } \\
(\mathrm{m})\end{array}$ & Area $\left(\mathrm{m}^{2}\right)$ & $\begin{array}{l}\text { Average thickness } \\
\text { of the GHSZ (m) }\end{array}$ & $\begin{array}{l}\text { Volume of the } \\
\text { GHSZ }\left(\mathrm{m}^{3}\right)\end{array}$ & $\begin{array}{l}\text { Assumed gas hydrate } \\
\text { concentration (vol\%) }\end{array}$ \\
\hline \multirow[t]{2}{*}{ GC 184/185 } & Bush Hill & $540-560$ & 101,300 & 370 & $3.75 \times 10^{7}$ & $5-10$ \\
\hline & Wipe-out zone & $500-650$ & 350,700 & 390 & $1.37 \times 10^{8}$ & $1-5$ \\
\hline GC $234 / 235$ & Faults & $500-670$ & 612,400 & 400 & $2.45 \times 10^{8}$ & $5-10$ \\
\hline \multirow[t]{2}{*}{ GB 388} & Faults & $650-750$ & $3,200,200$ & 495 & $1.58 \times 10^{9}$ & $5-10$ \\
\hline & & & & 130 & $4.16 \times 10^{8}$ & $5-10$ \\
\hline \multirow[t]{2}{*}{ MC 798/842 } & Mound & $807-813$ & 55,600 & 575 & $3.20 \times 10^{7}$ & $5-10$ \\
\hline & Wipe-out zone & $810-820$ & 217,400 & 580 & $1.26 \times 10^{8}$ & $1-5$ \\
\hline GC 204 & Wipe-out zone & $850-1000$ & $26,130,700$ & 640 & $1.67 \times 10^{10}$ & $1-5$ \\
\hline MC 852/853 & Mound & $1080-1120$ & $1,935,500$ & 780 & $1.51 \times 10^{9}$ & $5-10$ \\
\hline AT $425 / 426$ & Mound & $1920-1940$ & $5,650,000$ & 380 & $2.15 \times 10^{9}$ & $5-10$ \\
\hline
\end{tabular}




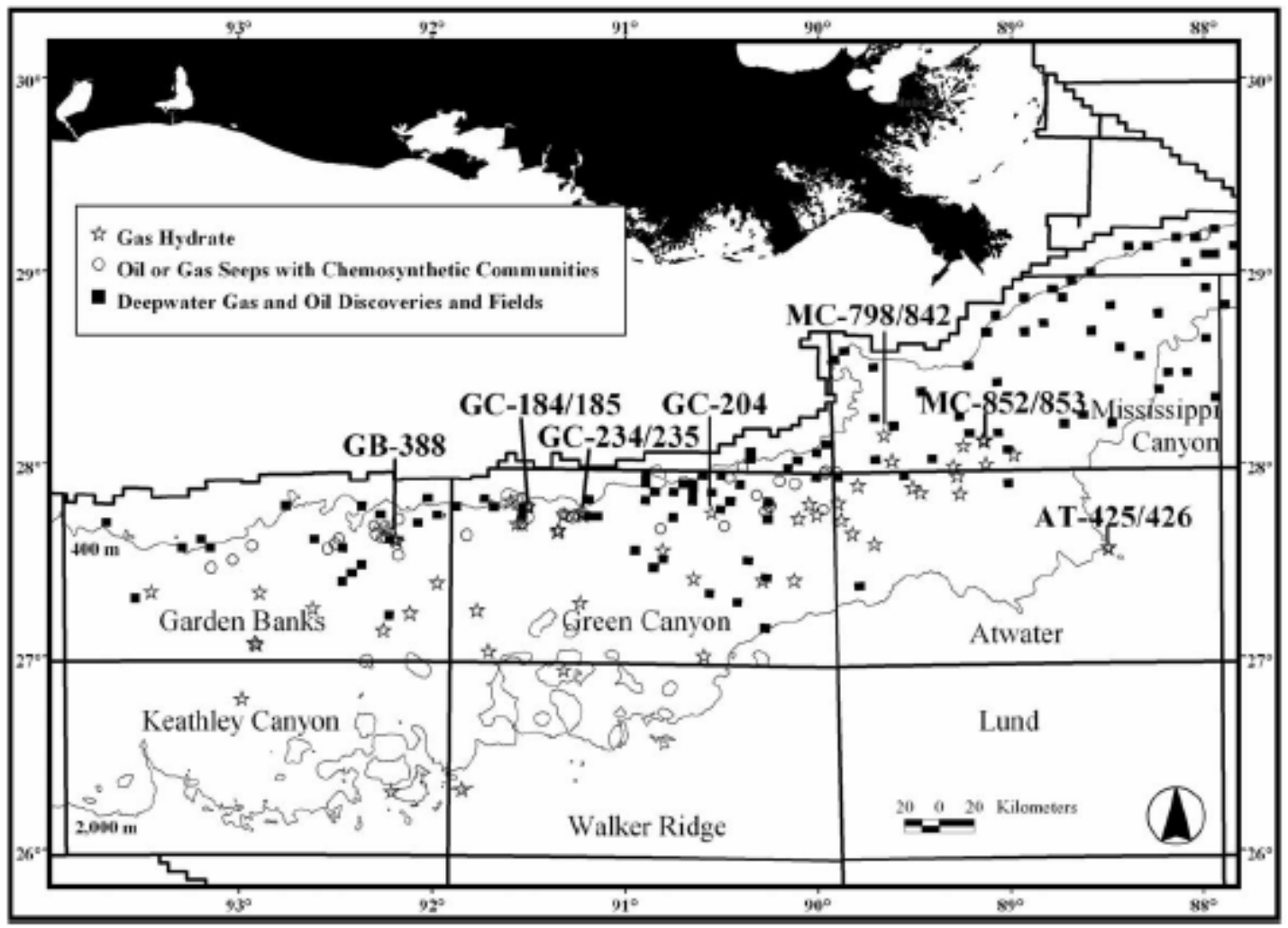

Figure 3.17 - Studied sites at Gulf of Mexico (Milkov and Sassen 2003)

Green Canyon (GC) 184/185:
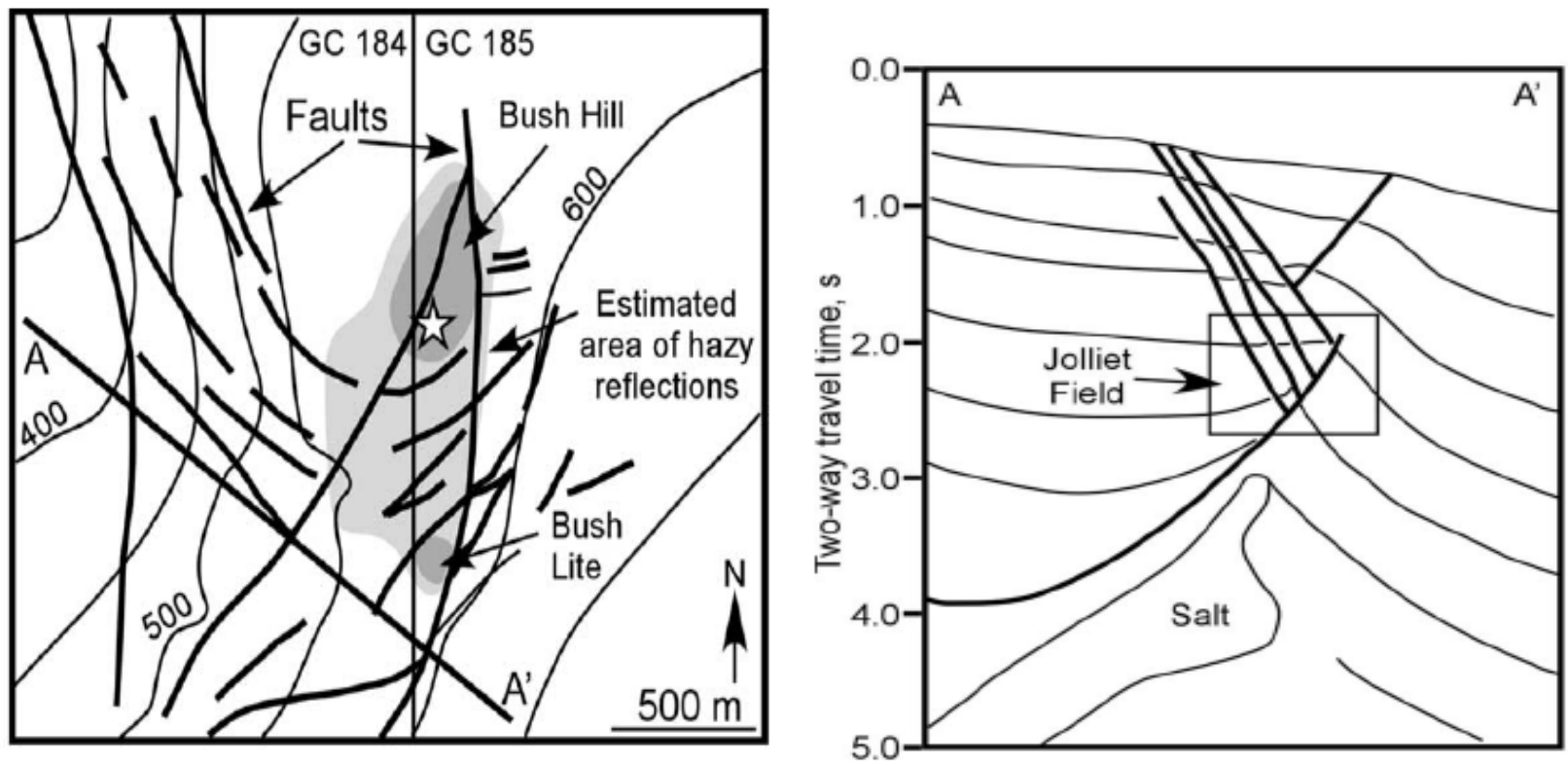

Figure 3.18 - Green Canyon 184/185 map (Milkov and Sassen 2003) 


\section{Green Canyon 234/235}
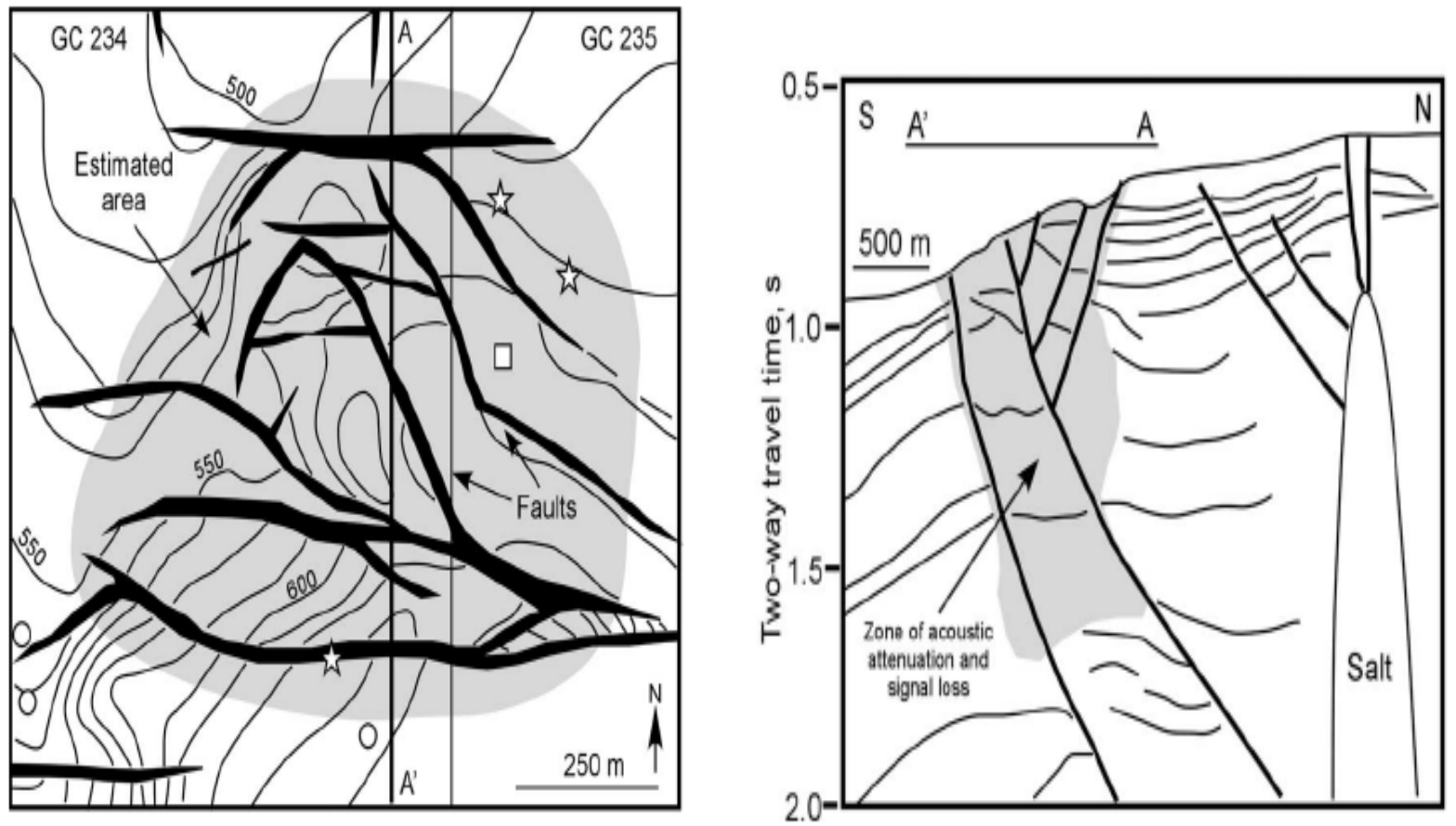

Figure 3.19 - Green Canyon 234/235 map (Milkov and Sassen 2003)

\section{Garden Banks 388}

This is an area of shallow faults located at water depths $650-750 \mathrm{~m}$.
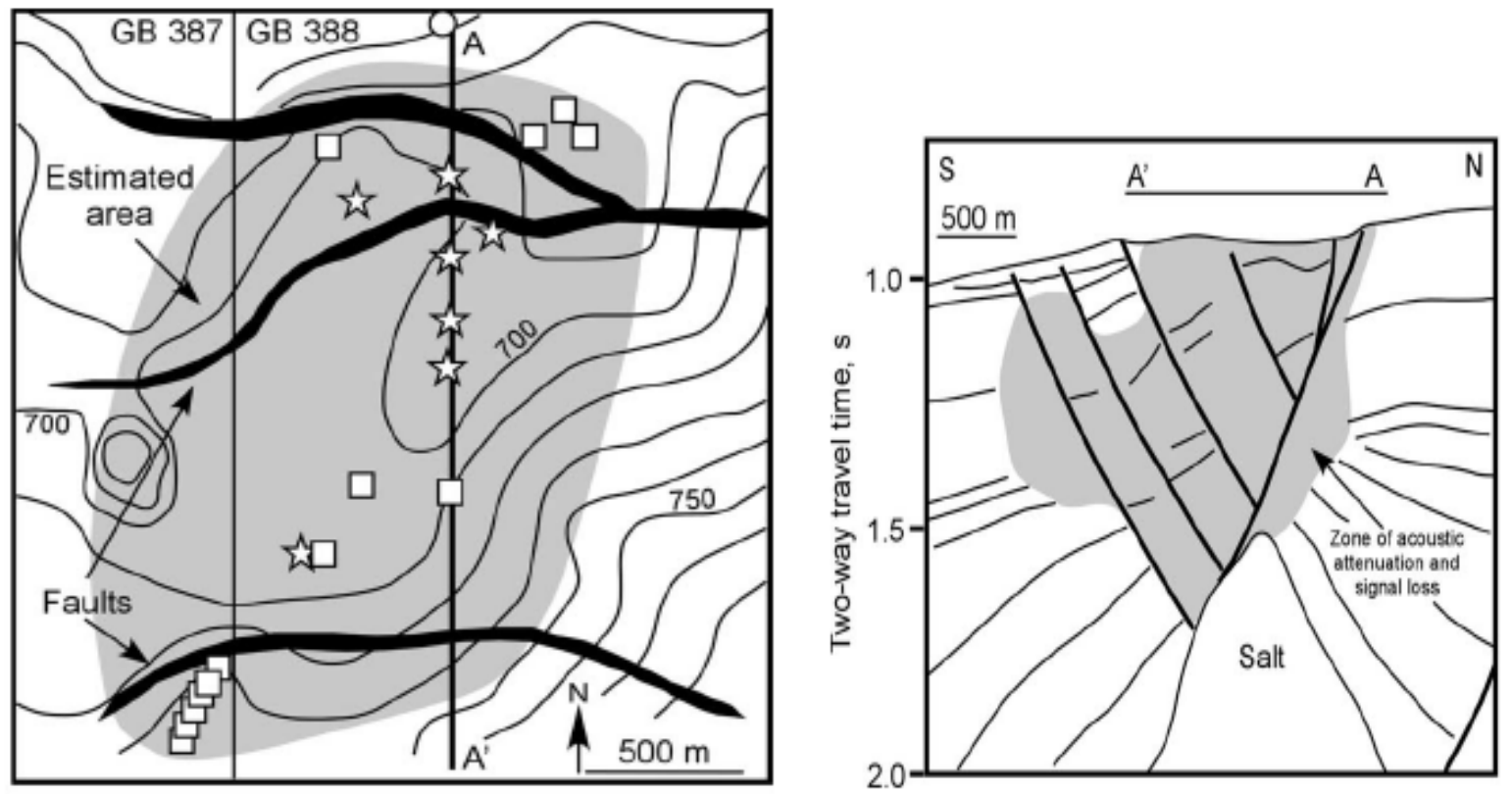

Figure 3.20 - Garden Banks 388 map (Milkov and Sassen 2003) 
Mississippi Canyon 798/842
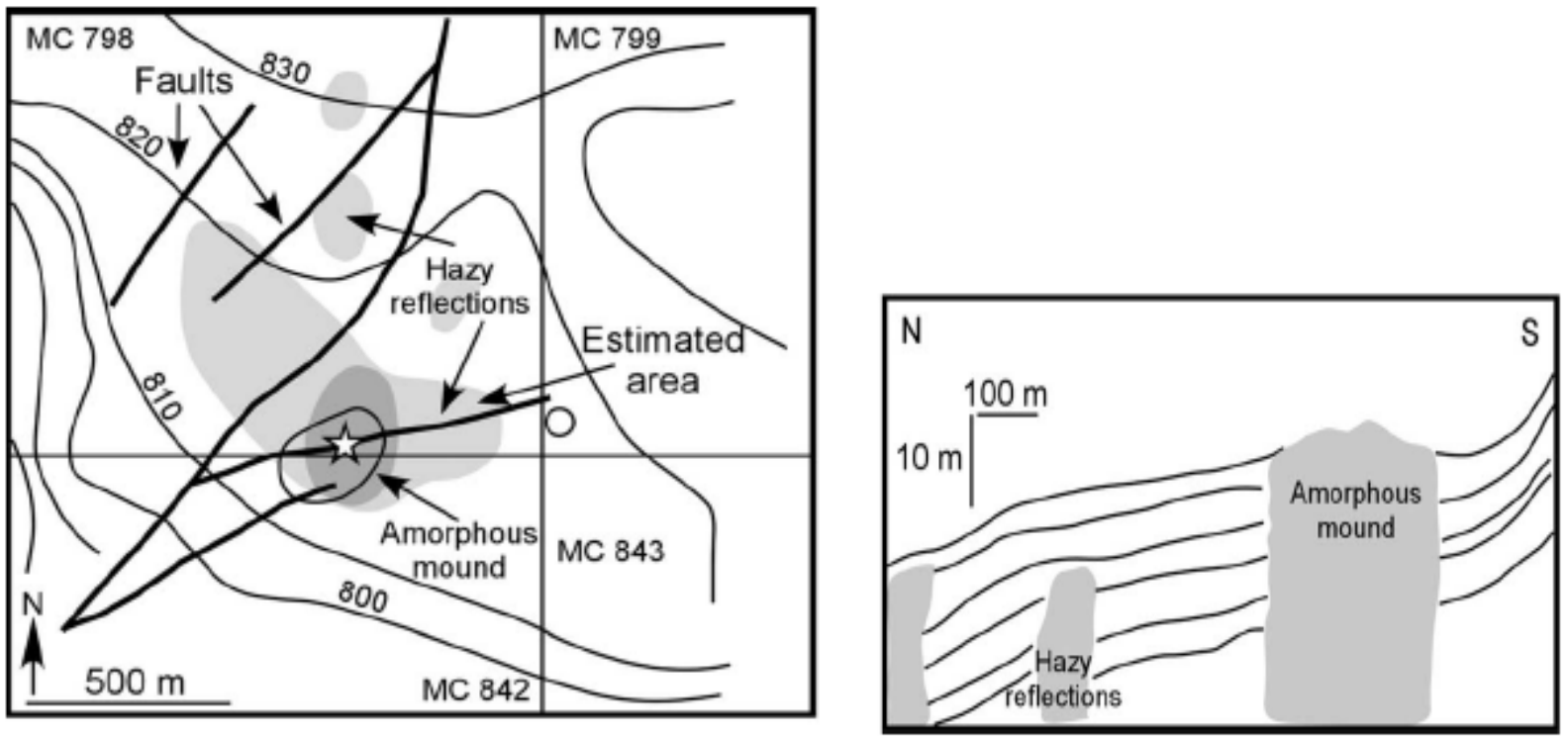

Figure 3.21 - Mississippi Canyon 798/842 map (Milkov and Sassen 2003)

\section{Green Canyon 204}
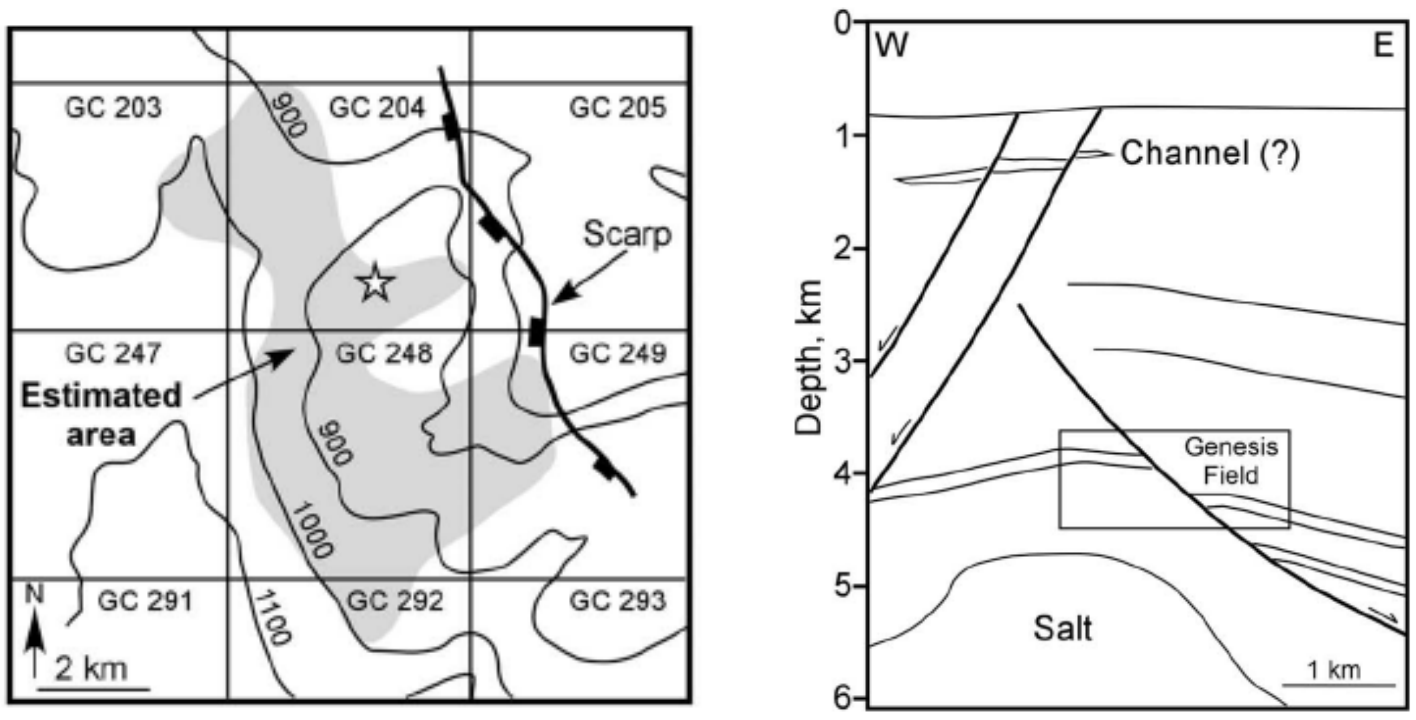

Figure 3.22 - Green Canyon 204 map (Milkov and Sassen 2003) 


\section{Mississippi Canyon 852/853}
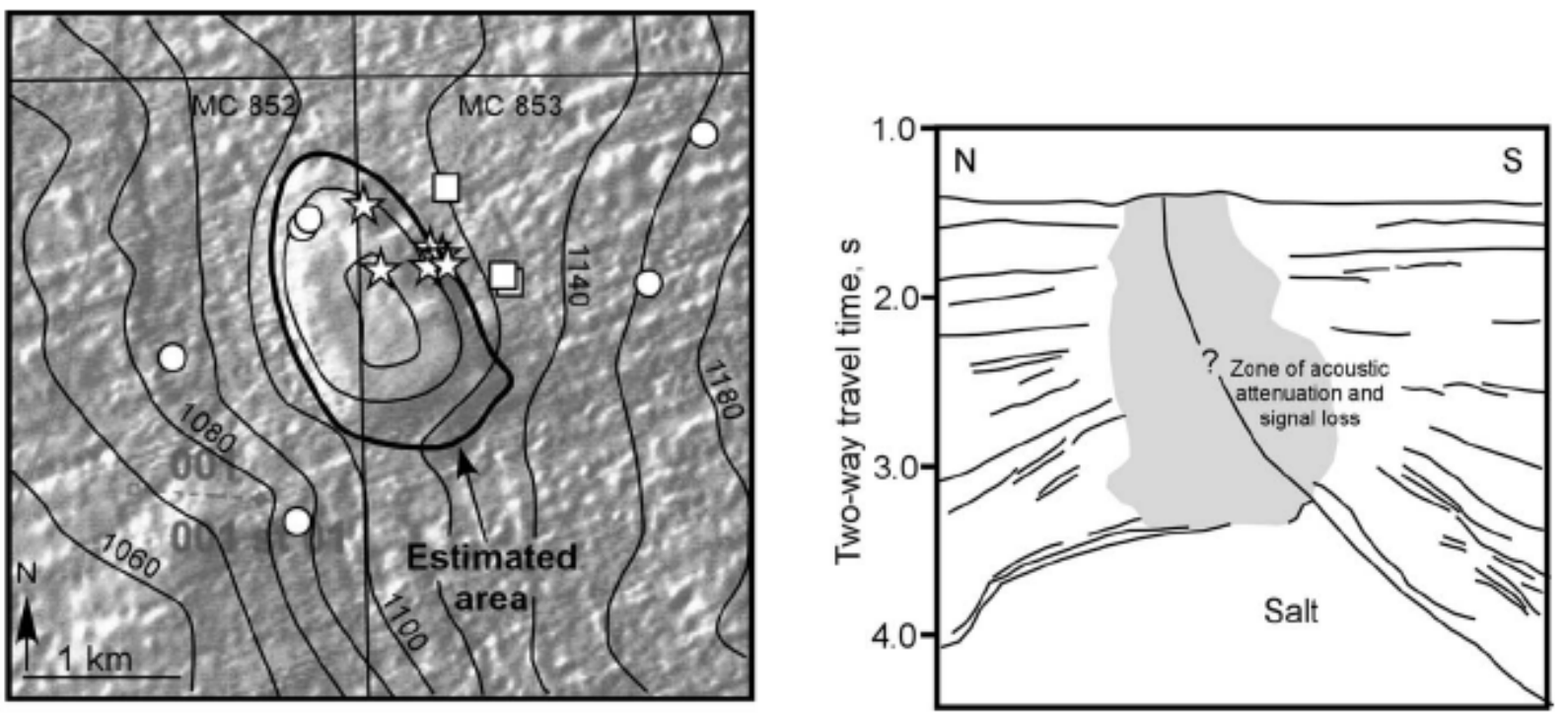

Figure 3.23 - Mississippi Canyon 852/853 map (Milkov and Sassen 2003)

\section{Atwater Valley 425}
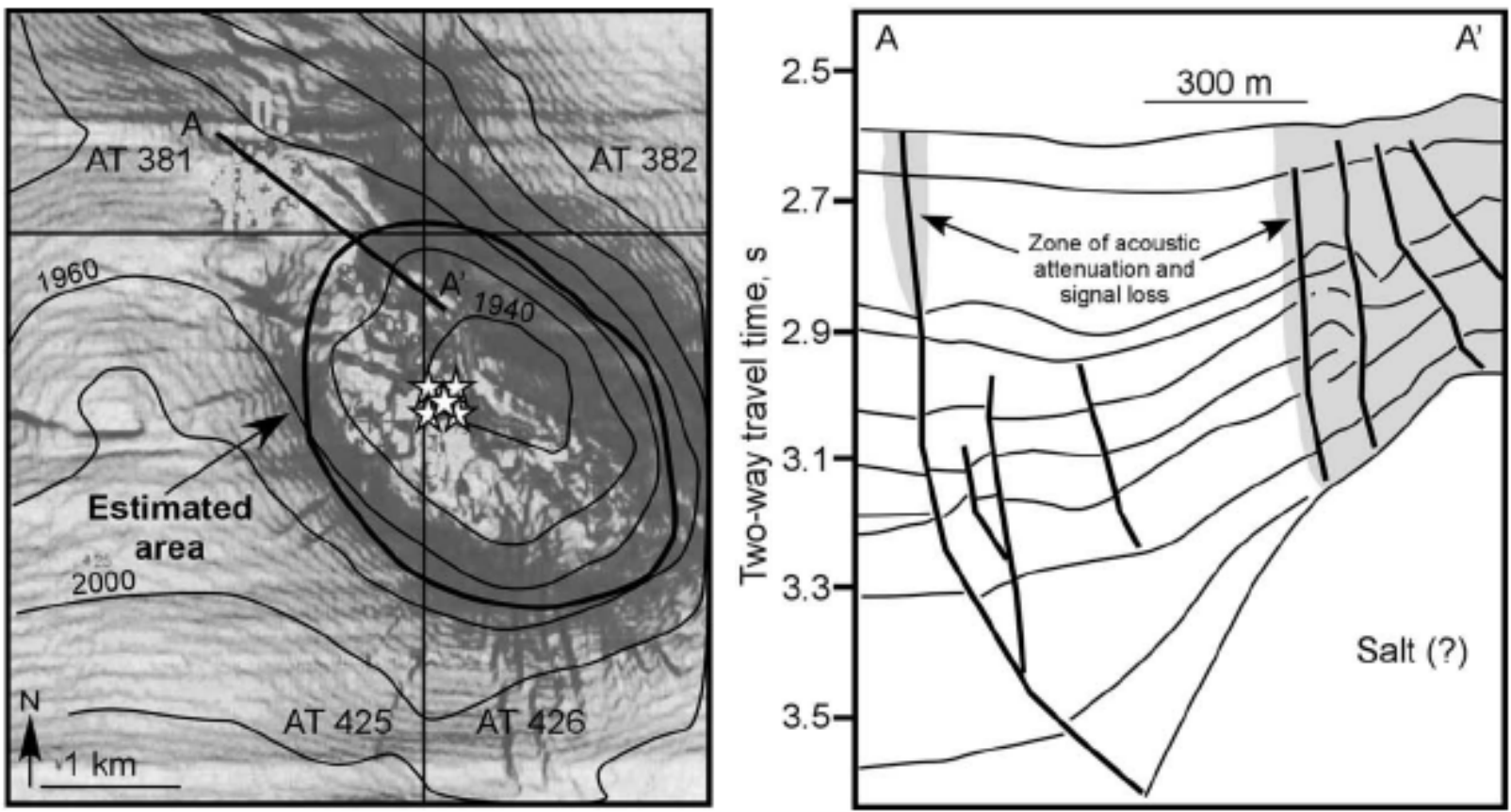

Figure 3.24 - Atwater Valley 425 map (Milkov and Sassen 2003) 
Francisca et al. (2005) have studied the Green Canyon sites and Mississippi Canyon sites in Gulf of Mexico and report the following composition of the sediments:

Table 3.13 - Sediment data from 3 Sites in the Gulf of Mexico

\begin{tabular}{|l|l|l|l|}
\hline \multirow{2}{*}{ Sediment constituents } & \multicolumn{3}{|c|}{ Sites } \\
\cline { 2 - 4 } & GC 185 & GB 425 & MC 852 \\
\hline Sand fraction (\%) & 4.9 & 2.6 & 3.5 \\
\hline Clay fraction (\%) & 55.0 & 52.5 & 48.5 \\
\hline Carbonate range (\%) & $4-55$ & $6-35$ & $7-72$ \\
\hline
\end{tabular}

The data in Table 3.13 indicate that these gas hydrate sediments are silty clay to clay.

Francisca et al. (2005) measured the water content from different sediments and describes them in Figure 3.25.

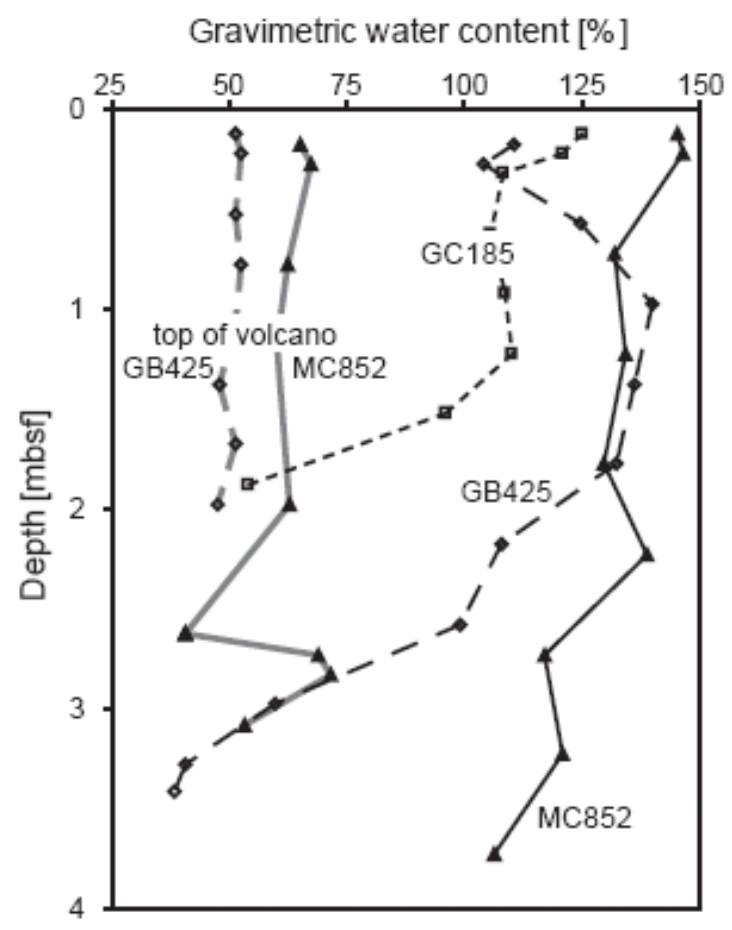

Figure 3.25 - Water content of GOM shallow sediments (Francisca, Yun et al. 2005)

Yun et al. (2007) have measured the physical characterization of core samples recovered from the Atwater Valley and Keathley Canyon drilling sites in Gulf of Mexico. They classified the sediments as high plasticity clays. A more detailed cruise was carried out to study the distribution of gas hydrates in GOM in 2005 with DOE/Chevron JIP. The 
detailed results about mineralogy of the sediments are being published and we will include them when possible.

Figure 3.26 (Yun, Narsilio et al. 2007) shows the water content in the Gulf of Mexico sediments at Atwater Valley, AT-Mound and Keathley Canyon.

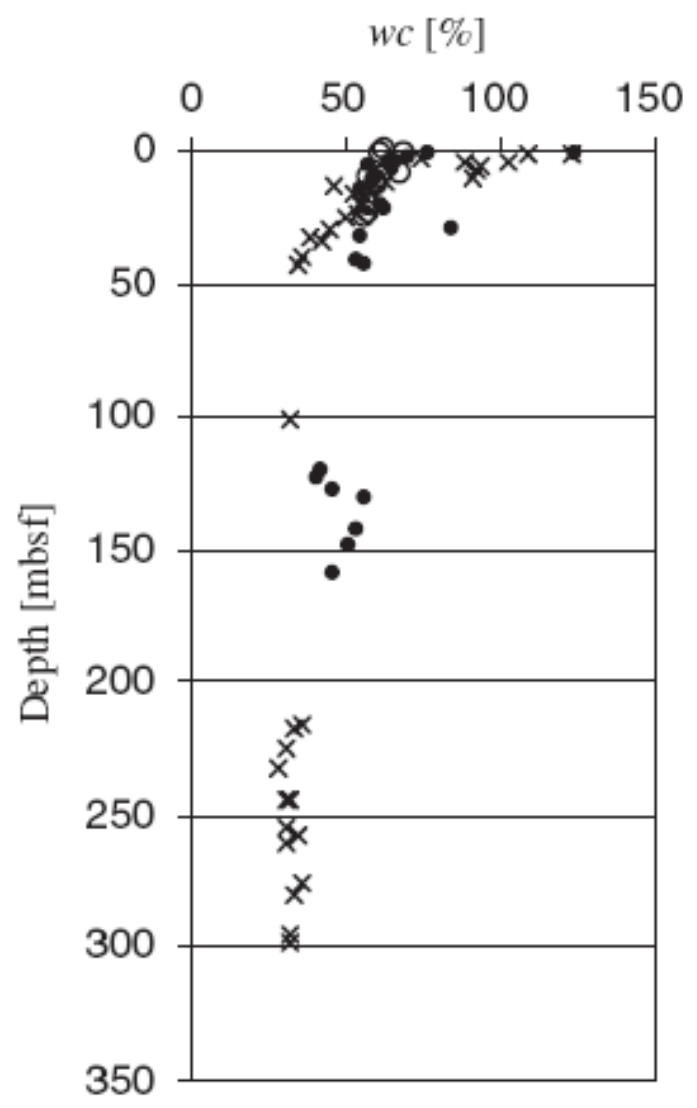

Figure 3.26 - Water content of GOM sediments from conventional piston cores (Yun, Narsilio et al. 2007) AT-Mound (filled circles), Atwater Valley (open circles), Keathley Canyon (cross)

Additional data from the USGS on the Gulf of Mexico is included in Table 3.14. 
Table 3.14 - USGS Open-file Report 96-272 Describing Sites in the GOM

\begin{tabular}{|c|c|c|c|c|c|c|c|c|c|}
\hline Site ID & Water Depth (m) & $\begin{array}{c}\text { Subbottom Depth } \\
(\mathrm{m})\end{array}$ & $\begin{array}{c}\text { Temperature at } \\
\text { Hydrate: Geothermal } \\
\text { Gradient }\end{array}$ & $\begin{array}{l}\text { Estimated Depth } \\
\text { to Phase } \\
\text { Boundary }\end{array}$ & $\begin{array}{c}\text { Observed } \\
\text { Thickness of } \\
\text { Hydrate Zone }(m)\end{array}$ & $\begin{array}{l}\text { Thickness/Size of } \\
\text { Pure Hydrate } \\
\text { Layer/Grains }\end{array}$ & $\begin{array}{l}\text { Habit or Mode of } \\
\text { Occurrence }\end{array}$ & $\begin{array}{l}\text { Sediment } \\
\text { Description }\end{array}$ & $\begin{array}{l}\text { Apparent Origin of } \\
\text { Included Gas }\end{array}$ \\
\hline Site 1 (Orca Basin) (DSDP leg 96, hole 618) & 2400 & 20 & $\begin{array}{c}\text { No temperature data: } \\
\sim 40^{\circ} \mathrm{C} / \mathrm{km} \text { (gradient } \\
\text { extrapolated from } \\
\text { proximal site) } \\
\end{array}$ & $\begin{array}{c}\sim 440 \\
\text { (seawater)C\&K } \\
\sim 480 \text { (pure water)S }\end{array}$ & $\sim 20(20-40)$ & $\begin{array}{l}\text { Typically, } 1-4 \mathrm{~mm} \\
\text { beads; possibly some } \\
\text { up to } 10 \mathrm{~mm} \text { in } \\
\text { diameter } \\
\end{array}$ & $\begin{array}{l}\text { Dispersed white } \\
\text { crystals throughout } 20 \\
m \text { interval }\end{array}$ & Gray mud, sand & Biogenic \\
\hline Site 2 (Green Canyon, Block 184) & 530 & & & & & $\begin{array}{l}\text { Chunks } 1-2 \mathrm{~mm} \text { up to } \\
50 \mathrm{~mm} \text { in diameter }\end{array}$ & $\begin{array}{l}\text { Chunks; larger ones } \\
\text { bulbous, nodular, } \\
\text { spherical }\end{array}$ & $\begin{array}{l}\text { Coarse } \\
\text { sediments; } \\
\text { carbonate } \\
\text { rubble and/or } \\
\text { shell hash }\end{array}$ & Thermogenic \\
\hline Site 3 (Green Canyon, Block 204) & 850 & 1.4 & & & 2.8 & $\begin{array}{l}\text { Chunks } 2-5 \mathrm{~mm} \text { up to } \\
30 \mathrm{~mm} \text { in diameter }\end{array}$ & Chunks, dispersed & $\begin{array}{c}\text { Coarse } \\
\text { sediments; } \\
\text { carbonate } \\
\text { rubble and/or } \\
\text { shell hash }\end{array}$ & Thermogenic \\
\hline Site 4 (Green Canyon, Block 234) & 590 & $\begin{array}{l}\text { Core penetrations } \\
\text { of } 1.2,2.8\end{array}$ & & & & $\begin{array}{c}\text { Core plug }>150 \mathrm{~mm} \text { in } \\
\text { length }\end{array}$ & Massive & $\begin{array}{l}\text { Coarse } \\
\text { sediments; } \\
\text { carbonate } \\
\text { rubble and/or } \\
\text { shell hash }\end{array}$ & Thermogenic \\
\hline Site 5 (Garden Banks, Block 388) & 850 & $2.8,3.8$ & $\begin{array}{c}\text { Est. } 5^{\circ} \mathrm{C}: \text { no gradient } \\
\text { data }\end{array}$ & & $\begin{array}{l}2 \mathrm{~mm}, 10-20 \mathrm{~mm} \\
\text { thick, respectively }\end{array}$ & $2 \mathrm{~mm}$ wide, $10 \mathrm{~mm}$ long & $\begin{array}{l}\text { Small white nodules; } \\
\text { falt, sheet-like layers }\end{array}$ & $\begin{array}{l}\text { Coarse } \\
\text { sediments; } \\
\text { carbonate } \\
\text { rubble and/or } \\
\text { shell hash }\end{array}$ & Biogenic \\
\hline Site 6 (Green Canyon, Block 257) & 880 & $4.2,4.8$ & $\begin{array}{c}\text { Est. } 5^{\circ} \mathrm{C}: \text { no gradient } \\
\text { data }\end{array}$ & & & $\begin{array}{l}3 \mathrm{~mm} \text { wide and } 10 \mathrm{~mm} \\
\text { long }\end{array}$ & $\begin{array}{l}\text { Small white nodules; } \\
\text { flat, sheet-like layers }\end{array}$ & $\begin{array}{l}\text { Sandy muds; } \\
\text { gravel-sized } \\
\text { authigenic } \\
\text { carbonate } \\
\text { particles }\end{array}$ & Biogenic \\
\hline Site 7 (Green Canyon, Block 320) & 800 & 3.2 & $\begin{array}{c}\text { Est. } 5^{\circ} \mathrm{C} \text { : no gradient } \\
\text { data }\end{array}$ & & 0.4 & $2 \mathrm{~mm}$ wide, $10 \mathrm{~mm}$ long & $\begin{array}{l}\text { Small white nodules; } \\
\text { falt, sheet-like layers }\end{array}$ & $\begin{array}{l}\text { Coarse } \\
\text { sediments; } \\
\text { carbonate } \\
\text { rubble and/or } \\
\text { shell hash }\end{array}$ & Biogenic \\
\hline Site 8 (Mississippi Canyon) & 1300 & $\sim 3.8$ & $\begin{array}{c}\text { Bottom water }>=4^{\circ} \mathrm{C}: \\
\sim 37^{\circ} \mathrm{C} / \mathrm{km} \text { (gradient } \\
\text { extrapolated from } \\
\text { proximal site) }\end{array}$ & $\begin{array}{c}\sim 320 \\
\text { (seawater)C\&K } \\
\sim 360 \text { (pure water)S }\end{array}$ & $<5 \mathrm{~cm} ?$ & $\begin{array}{l}<2 \mathrm{~mm} \text { diameter, but } \\
\text { could have partially } \\
\text { decomposed before } \\
\text { size estimates made }\end{array}$ & Small pieces & $\begin{array}{l}\text { Coarse } \\
\text { sediments } \\
\text { implied }\end{array}$ & Thermogenic \\
\hline Site 9 (Bush Hill) & 540 & At sea floor & $\begin{array}{c}7-7.5^{\circ} \mathrm{C}: \text { no gradient } \\
\text { data }\end{array}$ & & & $0.5 \mathrm{~m}$ diameter mound & Large mounds & & Thermogenic \\
\hline
\end{tabular}




\section{Nankai Trough}

The Nankai Trough is a convergent margin offshore south-west Japan. It is situated along the subduction zone between the Philippine Sea Plate and the island arc system of Japan. This area has been the focus of geologic and geophysical investigations for gas hydrates. Convergent margins are the favorable location for the formation of gas hydrates and it is estimated that twothirds of total worldwide marine hydrates are found in these geological structures. According to Krason (1994), total gas resources in the form of gas hydrates in Nankai Trough is around 15 148 Tcf. Figure 3.27 (He, Matsubayashi et al. 2006) describes the geological setting of Nankai Trough.

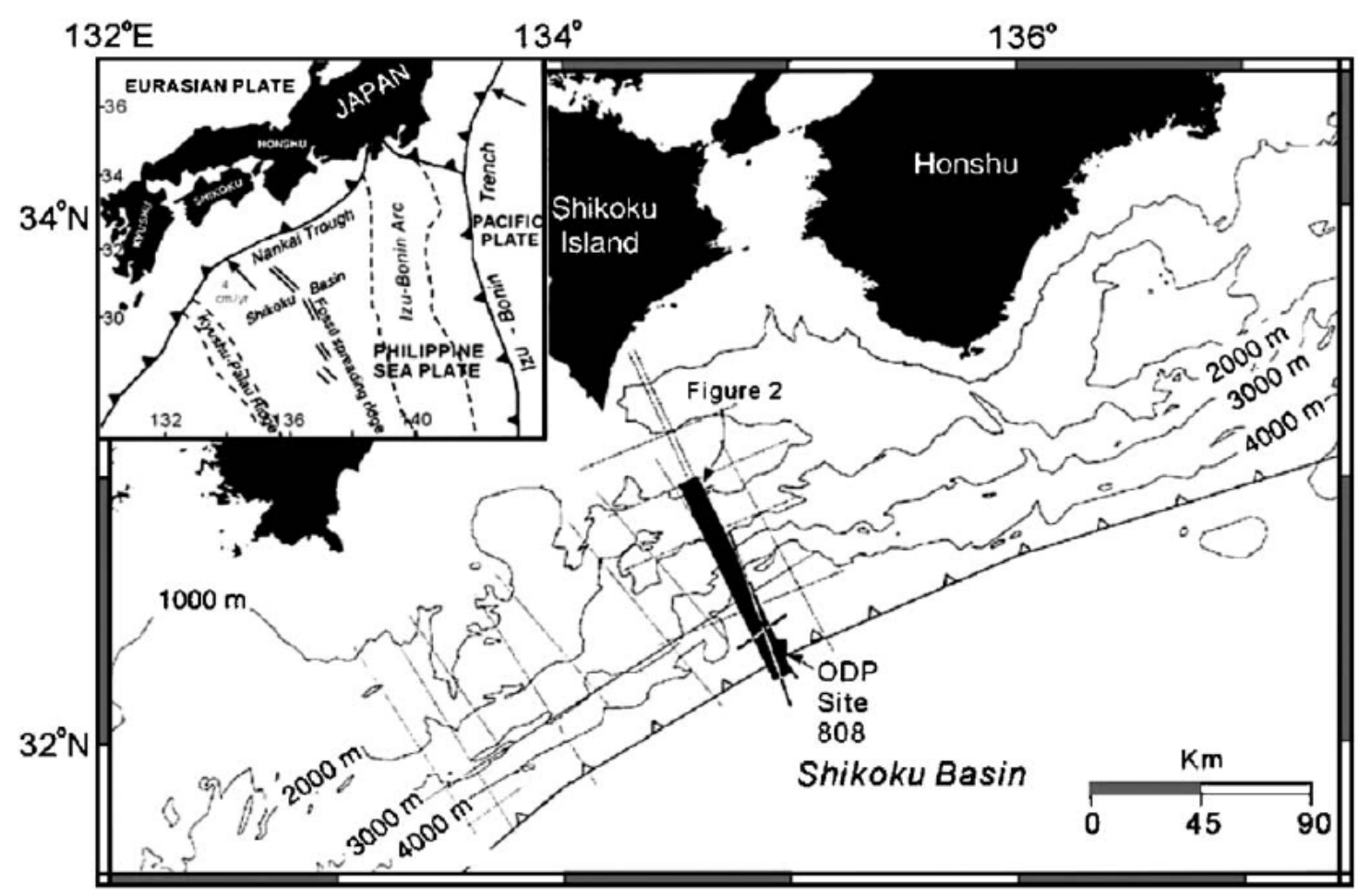

Figure 3.27 - Geological setting of Nankai accretionary prism (He, Matsubayashi et al. 2006)

Gas hydrates were indicated by the detection of BSRs in the early 1980s. However, the first samples of cores containing gas hydrates were collected in 1990 during the ODP Leg 131. During this expedition, hydrates were noted in cores between 90 to 140 meters below the seafloor (mbsf). The methane in the cores was considered to be of biological origin because of the low concentration of higher hydrocarbons. 
The ODP carried out another expedition in Nankai Trough in 2000 and drilled seven holes. Japan National Oil Company and Japan Petroleum Exploration Corporation drilled three boreholes in eastern Nankai Trough as a part of Japan's effort to study the feasibility of gas production from the marine hydrate deposits. The world's first offshore natural hydrate exploratory wells were drilled from November 1999 to February 2000 at a single location at the water depth of 945 meters. Up to about 100 mbsf the sediments are composed of flat-lying mudstonesiltstone with occasional ash beds. Below $100 \mathrm{~m}$, the formation is mudstone and with increasing depth, the number and thickness of sandstone beds increases.

\section{Summary of the Sediments Descriptions Obtained from Core and Log Data \\ Definitions:}

Water content: Ratio of water mass to solid mass in a sediment specimen

Liquid limit: When water content is raised to a point where the mixture of sediment and water behaves like a liquid, it is called liquid limit.

Plastic limit: When there is sufficient water present to allow the particles to slide past each other without developing internal cracks the soil has reached plastic limit.

\section{Blake Ridge}

According to data, the sediment grain size distribution of sediments in the hydrate stability zone is $0.005-0.001 \mathrm{~mm}$.

Table 3.15 - Lithology of Blake Ridge

\begin{tabular}{|l|l|l|}
\hline SITE & Major lithology & Other constituents \\
\hline 994 & Clay & Nannofossils, foraminifers \\
\hline 995 & Clay & Nannofossils, foraminifers \\
\hline 996 & Silty-clay & Nannofossils \\
\hline 997 & Clay & Nannofossils, foraminifers \\
\hline
\end{tabular}

Table 3.16 - Mineralogy of Blake Ridge

\begin{tabular}{|l|l|l|l|}
\hline SITE & Clay & Quartz & Calcite \\
\hline 994 & $50-75 \%$ & $5-15 \%$ & $10-30 \%$ \\
\hline 995 & $50-85 \%$ & $5-10 \%$ & $10-30 \%$ \\
\hline 996 & $45-70 \%$ & $10-20 \%$ & $15-35 \%$ \\
\hline 997 & $60-80 \%$ & $<10 \%$ & $15-30 \%$ \\
\hline
\end{tabular}

Major clay minerals are Illite and Kaolinite. 
(Winters 2000) and (Winters 2000) have described the index properties of the sediments in holes 991, 995 and 997 as follows

Table 3.17 - Index Properties of Sediments in Holes

\begin{tabular}{|c|c|c|c|c|c|c|c|c|}
\hline \multirow[b]{2}{*}{ Site } & \multirow[b]{2}{*}{ Depth (mbsf) } & \multicolumn{3}{|c|}{ Water content $\%$} & \multirow[b]{2}{*}{ Sand \% } & \multirow[b]{2}{*}{ Silt \% } & \multirow[b]{2}{*}{ Clay \% } & \multirow[b]{2}{*}{ Smectite \% } \\
\hline & & dry $23^{\circ} \mathrm{C}$ & dry $60^{\circ} \mathrm{C}$ & dry $120^{\circ} \mathrm{C}$ & & & & \\
\hline \multirow{6}{*}{991} & 5.8 & 70.73 & 73.06 & 74.26 & 2.6 & 65.8 & 31.7 & \\
\hline & 14.96 & 63.96 & 66.46 & 67.68 & 2 & 56.6 & $\overline{41.1}$ & \\
\hline & 24.4 & 52.05 & 54.5 & 55.59 & 5.8 & 65.5 & 28.7 & \\
\hline & 33.3 & 65.94 & 70.16 & 71.8 & 2.4 & 67.1 & 30.5 & \\
\hline & 42.7 & 59.18 & 62.95 & 64.81 & 1 & 66.8 & 32.5 & \\
\hline & 54.1 & 53.16 & 57.88 & 59.57 & 4 & 70.5 & 25.5 & \\
\hline \multirow{8}{*}{995} & 3.09 & 66.54 & 68.71 & 69.56 & 5.6 & 55.2 & $\overline{39.2}$ & \\
\hline & 49.57 & 83.48 & 86.99 & 88.32 & 1.5 & 51.2 & 47.2 & 8 \\
\hline & 148.48 & 57.44 & 61.6 & 62.77 & 0.3 & 61.1 & 38.6 & \\
\hline & 253.4 & 48.09 & 51.68 & 52.67 & 0.4 & 56.6 & 43 & 8 \\
\hline & 350.8 & 40.02 & 43.78 & 44.77 & 0.2 & 53.6 & 46.2 & $\overline{10}$ \\
\hline & 467 & 33.11 & 36.6 & 37.8 & 0.4 & 55.8 & 43.8 & \\
\hline & 546.11 & 45.76 & 49.64 & 50.83 & 1.4 & 49.7 & 49 & 17 \\
\hline & 666.85 & 34.85 & 38.56 & 39.45 & 0.2 & 52.3 & 47.5 & \\
\hline \multirow{6}{*}{996} & 5.35 & 65.93 & 68.52 & 69.68 & 8 & 57.6 & 34.4 & \\
\hline & 11.17 & 43.97 & 45.1 & 45.68 & 6.1 & 56.1 & 37.8 & \\
\hline & 29.63 & 63.57 & 65.81 & 66.75 & 4.5 & 67.9 & 27.7 & \\
\hline & 38.72 & 63.33 & 65.78 & 66.67 & 5.3 & 51.9 & 42.9 & \\
\hline & 49.41 & 67.14 & 69.66 & 70.64 & 5.3 & 68.6 & 26.1 & \\
\hline & 58.53 & 50.23 & 52.5 & 53.37 & 6.8 & 62.5 & 30.7 & \\
\hline
\end{tabular}

Table 3.18 - Index properties for Site 995 cored sediments

\begin{tabular}{|r|r|r|r|r|r|r|}
\hline $\begin{array}{c}\text { Depth } \\
\text { (mbsf) }\end{array}$ & \multicolumn{1}{|c|}{$\begin{array}{c}\text { Water content } \\
\text { (\% dry wt) }\end{array}$} & $\begin{array}{c}\text { Porosity } \\
\text { (\%) }\end{array}$ & $\begin{array}{c}\text { Liquid } \\
\text { limit }\end{array}$ & $\begin{array}{c}\text { Plastic } \\
\text { limit }\end{array}$ & $\begin{array}{c}\text { Liquidity } \\
\text { index }\end{array}$ & $\begin{array}{c}\text { Plasticity } \\
\text { index }\end{array}$ \\
\hline 3.09 & 69.3 & 64.7 & & & & \\
\hline 3.09 & 63 & & 68 & & & \\
\hline 49.57 & 87.9 & 70 & & & & \\
\hline 148.48 & 62.5 & 62.3 & & & & \\
\hline 148.48 & 60 & & 99 & & & \\
\hline 253.4 & 52.4 & 58.1 & & & & \\
\hline 350.8 & 44.5 & 54.1 & & & & \\
\hline 350.8 & 44 & & & & & \\
\hline 467 & 37.5 & 49.9 & & & & \\
\hline 546.11 & 50.5 & 57.2 & & & & \\
\hline 546.11 & 52 & & & & & \\
\hline 666.85 & 39.3 & 519 & & & & \\
\hline
\end{tabular}




\section{Cascadia Margin}

(Gracia, Martinez-Ruiz et al. 2006) have analyzed the samples from seven Hydrate Ridge sites. Grain size was defined as follows:

- Coarse-grained $(>50 \mu \mathrm{m})$

- Silt and clay $(<50 \mu \mathrm{m})$

Table 3.19 - Lithology of Cascadia Margin

\begin{tabular}{|l|l|l|l|l|}
\hline Site & Major lithology & Clays \% & Silt \% & Sand \% \\
\hline 1244 & Clay/Silty-clay & $60-80$ & $5-30$ & $<5$ \\
\hline 1245 & Clay/Silty-clay & $60-90$ & $0-20$ & $<5$ \\
\hline 1246 & Clay/Silty-clay & $70-80$ & $5-25$ & $<5$ \\
\hline 1247 & Clay/Silty-clay & $70-90$ & $5-30$ & $<10$ \\
\hline 1248 & Clay/Silty-clay & $60-90$ & $5-30$ & $<5$ \\
\hline 1249 & Clay/Silty-clay & $70-90$ & $10-30$ & $<5$ \\
\hline 1250 & Clay/Silty-clay & $70-100$ & $0-20$ & $<5$ \\
\hline 1251 & Clay/Silty-clay & $60-80$ & $15-30$ & $<5$ \\
\hline 1252 & Clay/Silty-clay & $70-95$ & $5-30$ & $<10$ \\
\hline
\end{tabular}

Table 3.20 - Mineralogy of Cascadia Margin

\begin{tabular}{|l|l|l|l|l|}
\hline Hole & Detrital mica & Smectite & Kaolinite & Chlorite \\
\hline $1244 \mathrm{E}$ & $30-60$ & $5-30$ & $15-30$ & $10-30$ \\
\hline $1250 \mathrm{C}$ & $30-50$ & $10-30$ & $5-15$ & $10-20$ \\
\hline $1245 \mathrm{~B}$ & $\sim 50$ & $5-10$ & $10-15$ & $10-30$ \\
\hline
\end{tabular}

- Based on Atterberg Limit tests, Hydrate Ridge soil classifies as high plasticity silt

- Clay mineral is composed mainly of Illite 
Index properties (Site 1244) are described as follows:

Table 3.21 - Hole 1244

\begin{tabular}{|r|r|r|r|r|r|r|}
\hline Depth & $\begin{array}{c}\text { Water } \\
\text { content }\end{array}$ & $\begin{array}{c}\text { Liquid } \\
\text { limit }\end{array}$ & $\begin{array}{c}\text { Plastic } \\
\text { limit }\end{array}$ & $\begin{array}{c}\text { Plasticity } \\
\text { index }\end{array}$ & $\begin{array}{l}\text { Liquidit } \\
\mathbf{y} \text { index }\end{array}$ & $\mathbf{C a C O}_{\mathbf{3}}$ \\
$\mathbf{( m b s f )}$ & $\mathbf{( \% )}$ & $\mathbf{( \% )}$ & $\mathbf{( \% )}$ & $\mathbf{( \% )}$ & $\mathbf{( \% )}$ & $\begin{array}{c}\text { content } \\
\text { (wt\%) }\end{array}$ \\
\hline 5.7 & 59.9 & 71 & 32 & 39 & 72 & \\
\hline 20.3 & 63.8 & 82 & 37 & 45 & 60 & 1.297 \\
\hline 32.98 & 62.7 & 87 & 42 & 45 & 46 & 1.253 \\
\hline 52.81 & 60.05 & 85 & 38 & 47 & 47 & 2.357 \\
\hline 70.88 & 58.1 & 86 & 40 & 46 & 39 & 2.09 \\
\hline 79.05 & 54.4 & 83 & 38 & 45 & 36 & \\
\hline 114.2 & 47.27 & 81 & 39 & 42 & 20 & 5.812 \\
\hline 114.2 & $\begin{array}{l}\text { Oven- } \\
\text { dried }\end{array}$ & 64 & 39 & 25 & & \\
\hline 135.55 & 48.85 & 77 & 35 & 42 & 33 & 2.928 \\
\hline
\end{tabular}

\section{Gulf of Mexico}

(Francisca, Yun et al. 2005) studied the Green Canyon and Mississippi Canyon sites in Gulf of Mexico and reported the following composition of the sediments.

Table 3.22 - Green Canyon and Mississippi

\begin{tabular}{|l|l|l|l|}
\hline \multirow{2}{*}{ Sediment constituents } & \multicolumn{3}{|c|}{ Sites } \\
\cline { 2 - 4 } & GC 185 & GB 425 & MC 852 \\
\hline Sand fraction (\%) & 4.9 & 2.6 & 3.5 \\
\hline Clay fraction (\%) & 55.0 & 52.5 & 48.5 \\
\hline Carbonate range (\%) & $4-55$ & $6-35$ & $7-72$ \\
\hline
\end{tabular}

- Major lithology is silty-clay to clay

- High specific surface area suggests that clay is Illite/Montmorillonite 
Index properties at various Gulf of Mexico hydrate sites (Yun, Narsilio et al. 2007)

Table 3.23 - Atwater Valley \#13

\begin{tabular}{|c|c|c|c|}
\hline Depth (mbsf) & Water content \% & Liquid limit & Plastic limit \\
\hline 0.8 & $\begin{array}{r}123.9 \\
\end{array}$ & & \\
\hline 1.8 & 76.5 & & \\
\hline 2.8 & 70.4 & & \\
\hline 3.8 & 67.3 & & \\
\hline 4.8 & 64.3 & & \\
\hline 5.8 & 57.2 & & \\
\hline 7.8 & 65.4 & & \\
\hline 9.8 & 60.7 & & \\
\hline 12.1 & 59.1 & & \\
\hline 14.2 & 55.5 & 74.9 & 27 \\
\hline 20.1 & 61.5 & & \\
\hline 22.5 & 63.1 & & \\
\hline 29.2 & 84.5 & & \\
\hline 32.2 & 54.6 & & \\
\hline 41.1 & 53.5 & & \\
\hline 43.7 & 56 & & \\
\hline 120.5 & 42.9 & & \\
\hline 124.2 & 41.1 & & \\
\hline 127.6 & 46.7 & & \\
\hline 130.8 & 55.9 & & \\
\hline 142.9 & 53.5 & & \\
\hline 148.3 & 51.7 & 77 & 30.5 \\
\hline 158.6 & 46 & & \\
\hline
\end{tabular}


Table 3.24 - Keathley Canyon site 151

\begin{tabular}{|c|c|c|c|}
\hline \begin{tabular}{|l|} 
Depth (mbsf) \\
\end{tabular} & Water content \% & Liquid limit & \begin{tabular}{|l} 
Plastic limit \\
\end{tabular} \\
\hline 0.8 & 122.9 & & \\
\hline 1.8 & 108.9 & & \\
\hline 2.8 & 74.5 & & \\
\hline 3.8 & 102.8 & & \\
\hline 4.8 & 88.1 & & \\
\hline 5.8 & 93.1 & & \\
\hline 6.8 & 92.1 & & \\
\hline 10.3 & 91 & & \\
\hline 12.3 & 62.3 & & \\
\hline 13.3 & 45.8 & & \\
\hline 14.3 & 57.8 & & \\
\hline 15.3 & 57.6 & & \\
\hline 16.2 & 52.2 & & \\
\hline 19.4 & 54.7 & & \\
\hline 21.3 & 55.1 & & \\
\hline 23.4 & 53.2 & 66.6 & 27.7 \\
\hline 25.3 & 50.1 & & \\
\hline 29.5 & 44.6 & & \\
\hline 32.5 & 38.8 & & \\
\hline 34.5 & 42.2 & & \\
\hline 40 & 36 & & \\
\hline 43 & 34.9 & & \\
\hline 102 & 32.5 & & \\
\hline 216.5 & 35.8 & & \\
\hline 217.5 & 33.8 & & \\
\hline 224.8 & 30.3 & 51.2 & 20.7 \\
\hline 227 & & & \\
\hline 231.8 & 28.1 & & \\
\hline 236 & & & \\
\hline 243.8 & 32.2 & & \\
\hline 244.8 & 31.1 & & \\
\hline 254.8 & 31.1 & & \\
\hline 257.8 & 34.1 & & \\
\hline 260.3 & 31 & & \\
\hline 276.2 & 36.1 & & \\
\hline 280.2 & 32.7 & & \\
\hline 294.5 & 31.8 & & \\
\hline 298.5 & 31.6 & & \\
\hline
\end{tabular}

\section{Nankai Trough}

Up to about $100 \mathrm{mbsf}$ the sediments are composed of flat-lying mudstone-siltstone with occasional ash beds. Below $100 \mathrm{~m}$, the formation is mudstone and with increasing depth, the number and thickness of sandstone beds increases. 


\section{Review of the Gas Hydrate Experimental Studies in Porous Media}

The following text briefly describes the experiments and procedures that are in the public literature where porous media have been used to form gas hydrates and then the mixture is tested for various flow, electrical, mechanical or other properties. These publications contain substantially more information than we have summarized in this report. However, the reader can refer to the bibliography at the end of this chapter to find the papers that contain more detail. The examples are described in no particular order of importance.

Example 1 - Decomposition of methane hydrates in sand, sandstone, clays, and glass beads (Uchida, Takeya et al. 2004)

This experiment involve hydrate dissociation in Toyoura sand, Berea sandstone, Kaolinite, Bentonite, Russian clay samples (RUS_KA, RUS_BE) and glass beads.

- The experimental apparatus that was used is shown below.

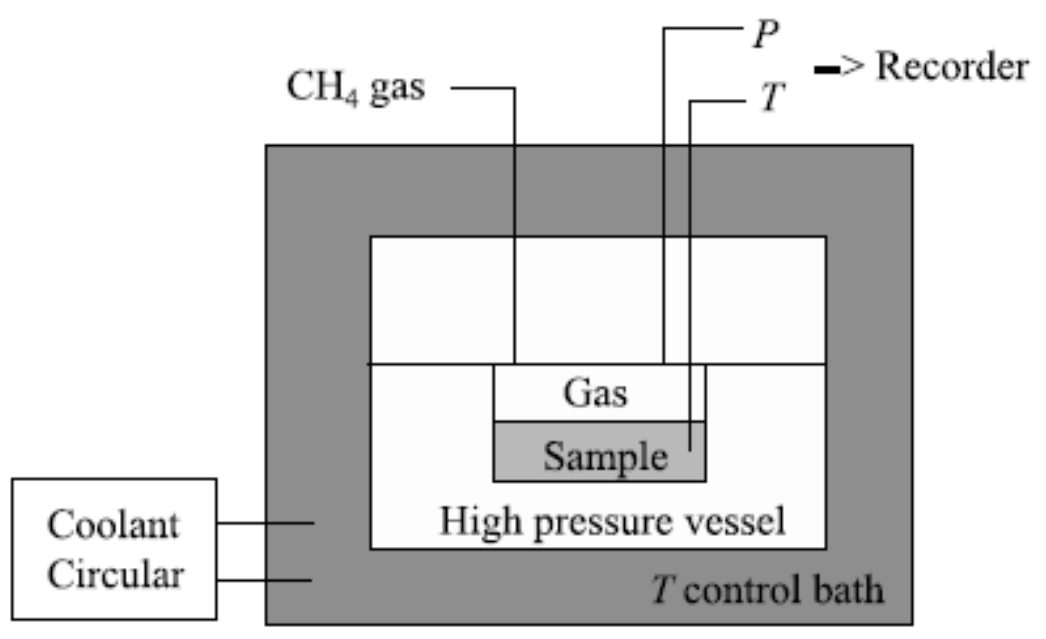

Figure 4.1 - Uchida et al Experimental Set-up 
Example 2 - Thermal diffusivity measurements of porous methane hydrate and hydratesediment mixture (Kumar, Turner et al. 2004)

○ Experiment assembled to measure the thermal diffusivity of hydrate and hydratesand/sediment mixtures.

- Methane hydrate formed directly within the cell from granular ice.

- Blake Ridge (site 996 B) sediments also used in hydrate-sediment experiments. These samples consisted of $75 \%$ clay, $20 \%$ silt and $5 \%$ sand

- Commercially available quartz sand from Platte Valley, CO was used for sand and hydrate-sand experiments.

- Sand and sediment samples were sieved to between 250 and 500 micron grain sizes before use, so that mixture porosities could be easily determined.

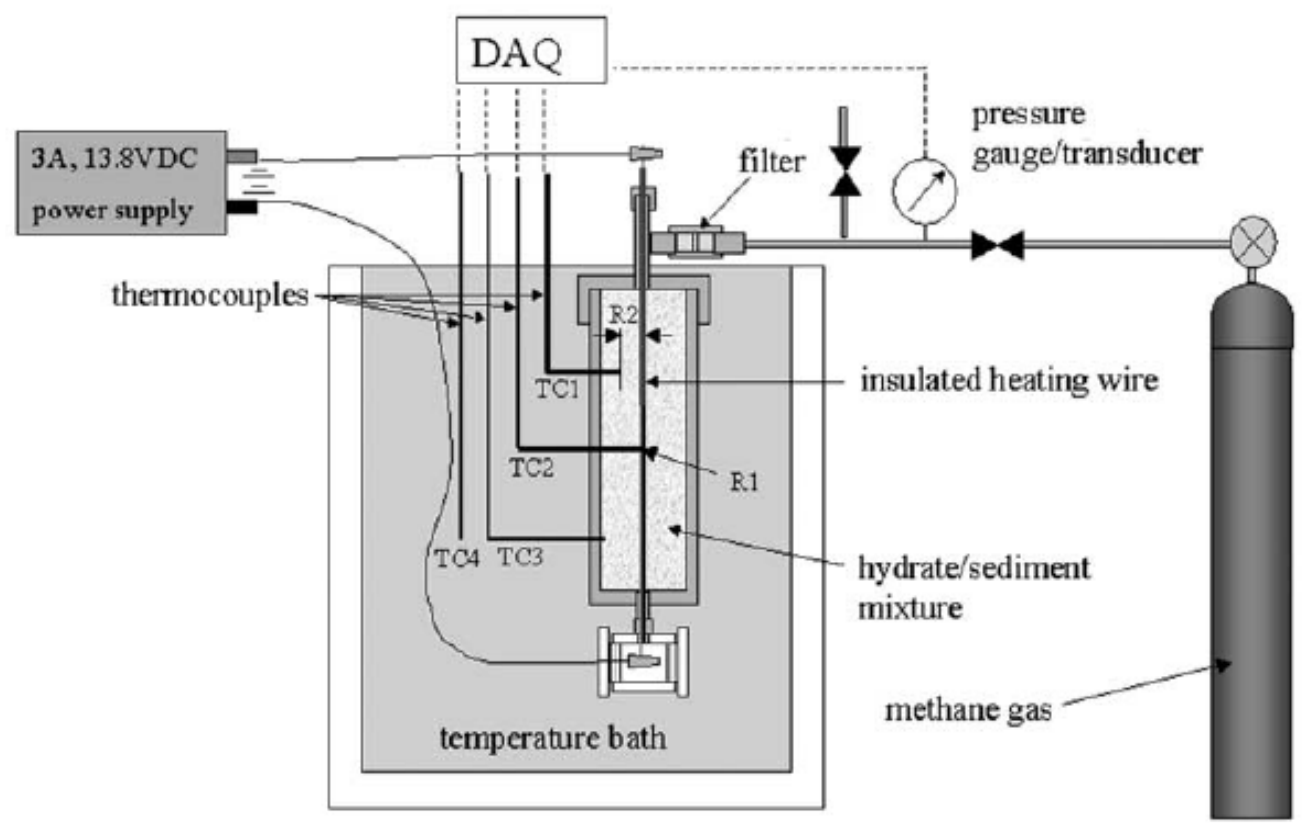

Figure 4.2 - Kumar et al experimental set-up 
Example 3 - Compressional and shear wave velocities in un-cemented sediment containing gas hydrate (Sun, Francisca et al. 2005)

○ Experiments designed specifically to study particle-level processes associated with hydrate formation in porous media.

- Fine grained sand specimens (grain size $120 \mu \mathrm{m}$, specific surface $0.019 \mathrm{~m} 2 \mathrm{~g}-1$, and average porosity 0.37 ) were used in the experiments.

- THF hydrates were formed in the porous media.

Example 4 - Physical properties and rock physics models of sediment containing natural and laboratory-formed methane gas hydrate (Winters, Pecher et al. 2004)

- This paper presents results of shear strength and acoustic (p-wave) measurements performed on specimens (1) from McKenzie Delta that contain natural gas hydrates and (2) of reconstituted Ottawa sand that contain laboratory-formed gas hydrate.

- The tests were done in the equipment called GHASTLI (Gas Hydrate and Sediment Test Laboratory Instrument) at Woods Hole Oceanographic Institute.

Example 5 - Pore space hydrate formation in a glass bead sample from methane dissolved in water (Spanpenberg, Kulenkampff et al. 2005)

- The experiment was designed to form methane hydrate in glass beads.

- The experimental approach described in this work was based on the hydrate formation model that involves upward migration of pore fluid, which is common to ocean environments.

- Methane hydrate is formed by the methane gas dissolved in water and no free gas is supplied.

- Spherical glass beads (250-500 $\mu \mathrm{m}$ in diameter) were used as porous media. The porosity of the sample was $38 \%$ and density $1550 \mathrm{~kg} / \mathrm{m} 3$. 


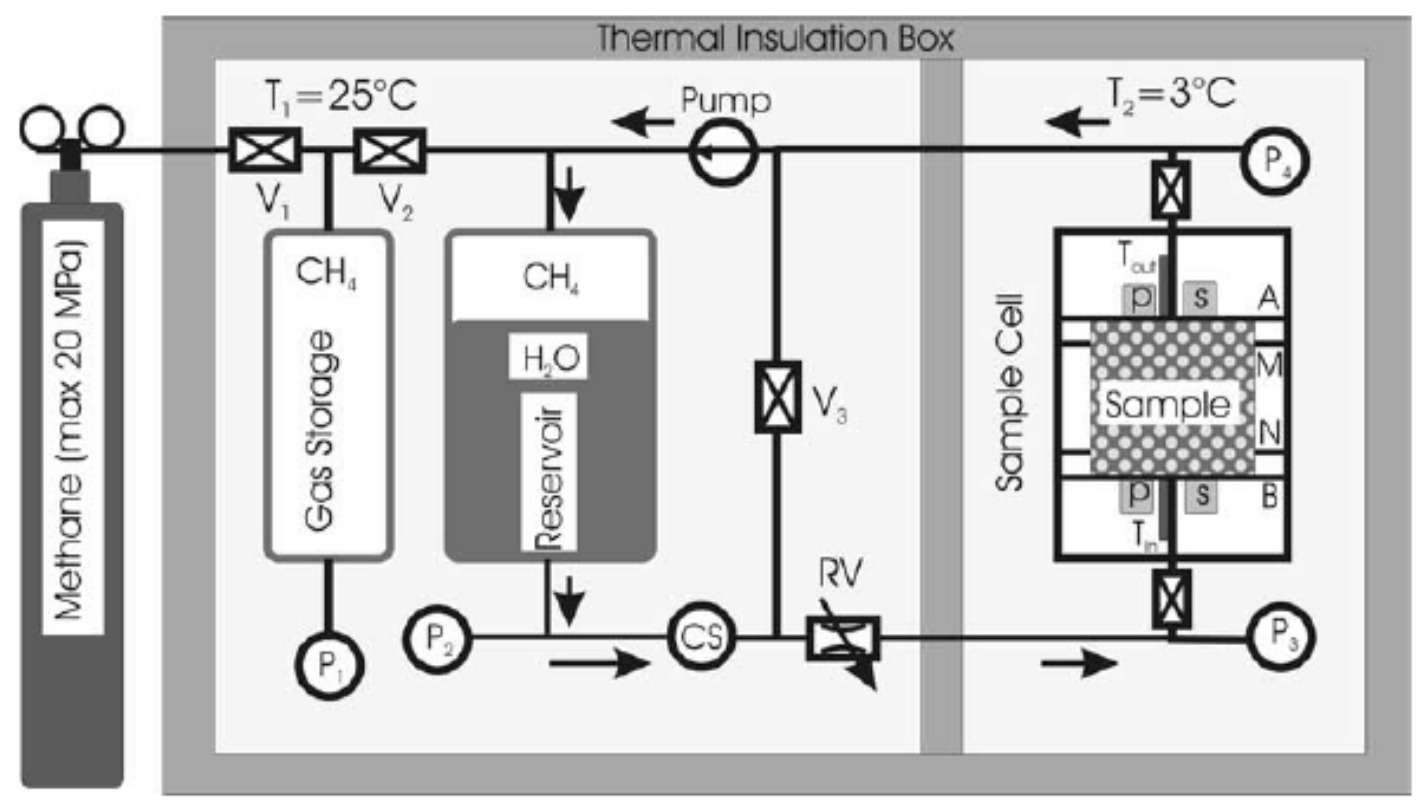

Figure 4.3 - Spanpenberg et al experimental set-up

Example 6 - Mechanical, thermal and electrical properties of hydrate-bearing sediments (Santamarina, Francisca et al. 2004)

- Various cells were used to simulate the stress and strain fields in-situ.

- Four distinct homogeneous sediments for this study were used:

- Ottawa sand,

- precipitated silica flour,

- crushed silica flour (silt), and

- kaolinite (clay).

$\circ$ A wide range of grain sizes were tested i.e. from $120 \mu \mathrm{m}$ sand to $\sim 1 \mu \mathrm{m}$ clay. 
Example 7 - Modeling the heating curve for gas hydrate dissociation in porous media (Dicharry, Gayet et al. 2005)

- A method for modeling the heating curve for gas hydrate dissociation in porous media at isochoric conditions is presented.

- Porous material (called Controlled Pore Glass, CPG) was used. It consisted of a powder of porous silica particles, with mean particle size of 37-74 $\mu \mathrm{m}$.

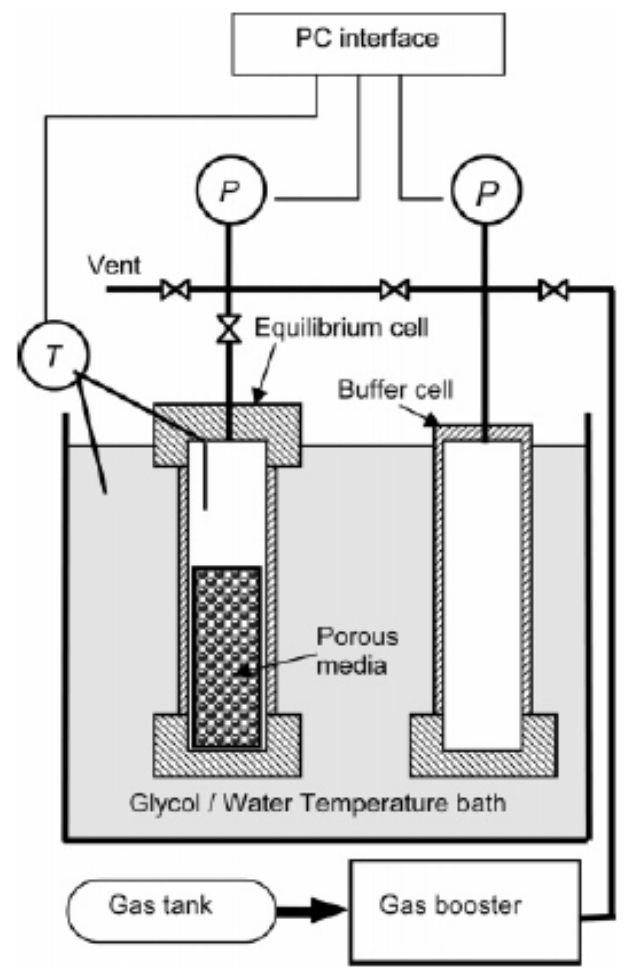

Figure 4.4 - Dicharry et al experimental set-up 
Example 8 - Thermal conductivity measurements in porous mixtures of methane hydrate and quartz sand (Waite, deMartin et al. 2002)

- Methane hydrate was formed in a chamber by slowly heating granular ice in a pressurized methane atmosphere.

○ Quartz sand was used in a mixed proportion with the hydrate to measure thermal conductivity of hydrate-sand mixture.

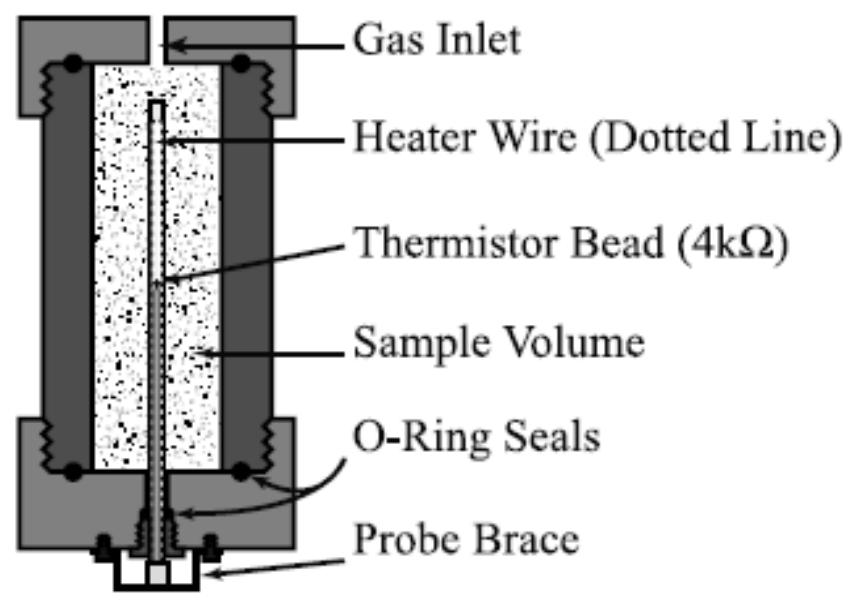

Figure 4.5 - Waite et al experimental set-up

Example 9 - Synthesis of methane gas hydrate in porous sediments and its dissociation by depressurizing (Kono, Narasimhan et al. 2002)

- Experiment designed to measure the kinetics of hydrate dissociation in a sediment

○ Dissociation measured by depressurization method

○ Distilled water and $99.99 \%$ methane was used

- The sediment mixtures which were used were:

- Glass beads $(100 \mu \mathrm{m})$ and synthetic ceramic

- Glass beads $(100 \mu \mathrm{m})$ and glass beads $(5000 \mu \mathrm{m})$

- Glass beads $(100 \mu \mathrm{m})$

- Glass beads $(100 \mu \mathrm{m})$ and glass beads $(5000 \mu \mathrm{m})$ 


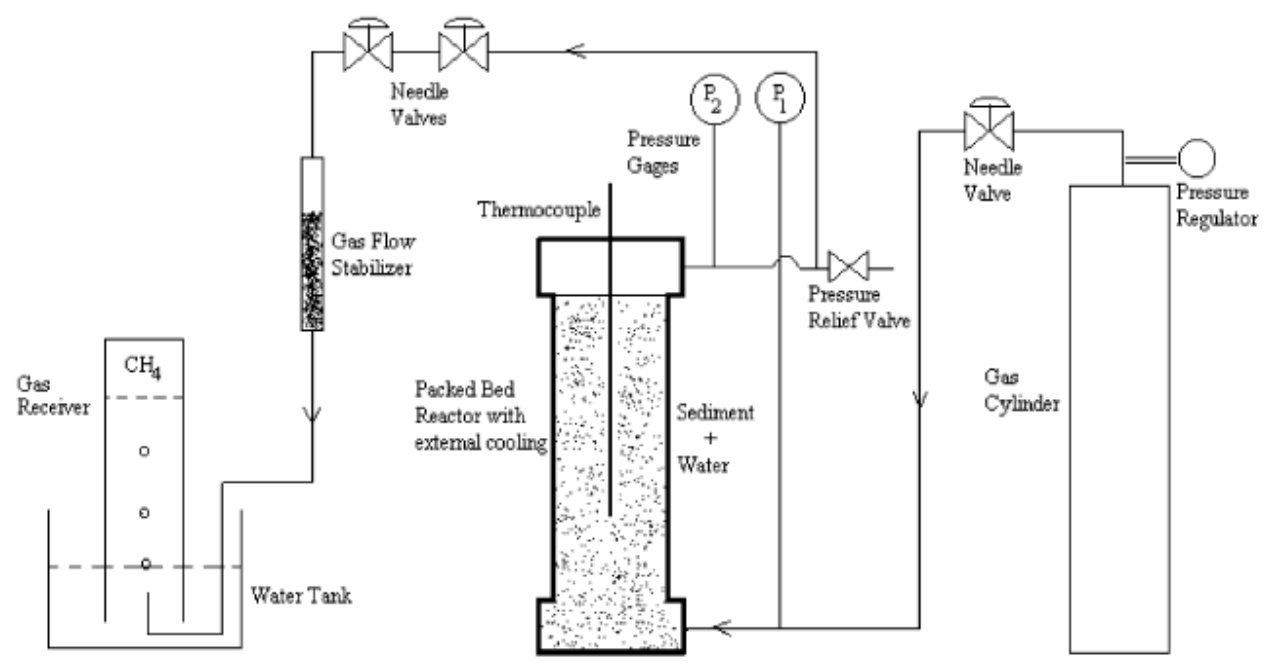

Figure 4.6 - Kono et al experimental set-up

Example 10 - Visual observation of gas-hydrate formation and dissociation in synthetic porous media by means of glass micro-models (Tohidi, Anderson et al. 2001)

○ Porous media (glass micro-models) was used to form the methane hydrate

Example 11 - Thermodynamic properties and dissociation characteristics of methane and propane hydrates in 70 Å radius silica gel pores (Handa and Stupin 1992)

○ Porous silica gel was used as porous media in which hydrates were formed

- Sample was in the form of a fine powder (mesh size 240-425 mesh)

○ $99.99 \%$ methane was used as a hydrate forming gas

○ Distilled water was used

Example 12 - Methane hydrate equilibria in silica gels with broad pore-size distributions (Smith, Wilder et al. 2002)

- Equilibrium pressures were measured for the dissociation of methane hydrates confined in silica gel pores of nominal radii 7.5, 5.0 and 3.0 nm over a wide temperature range. 
Example 13 - Determination of synthetic hydrate content in sand specimens using dielectrics (Kilner and Grozic 2006)

- An experimental analysis of synthetic refrigerant (R-11) hydrates in 20/30 Ottawa sand is discussed

- Hydrate samples were constructed via moist tamped Ottawa sand, purged with carbon dioxide $(\mathrm{CO} 2)$, saturated with de-aerated water and mixed with a known amount of R-11 to produce precise hydrate contents

- A soil specimen was initially constructed at a loose state within the specific apparatus designed for these experiments to emulate a favorable environment for hydrate formation.

- An ample amount of 20/30 Ottawa sand was placed in a mixing bowl and weighed to determine the water requirements for moist tamping method of construction. Distilled water was continually applied to the sand using a spray bottle and thoroughly mixed until $5 \%$ by weight had been added.

- The sand layers were compacted stepwise.

- the first layer was compacted several times,

- the second layer consisted of same amount of soil as first one but the compaction was carried out for two times that of the first layer.

- For the third layer, the numbers of drops were increased three times to ensure thorough compaction.

- Average moisture content of the prepared specimen was determined by collecting three samples of the unused sand mixture, weighing, and oven drying for 24 hours and weighing again after drying. 


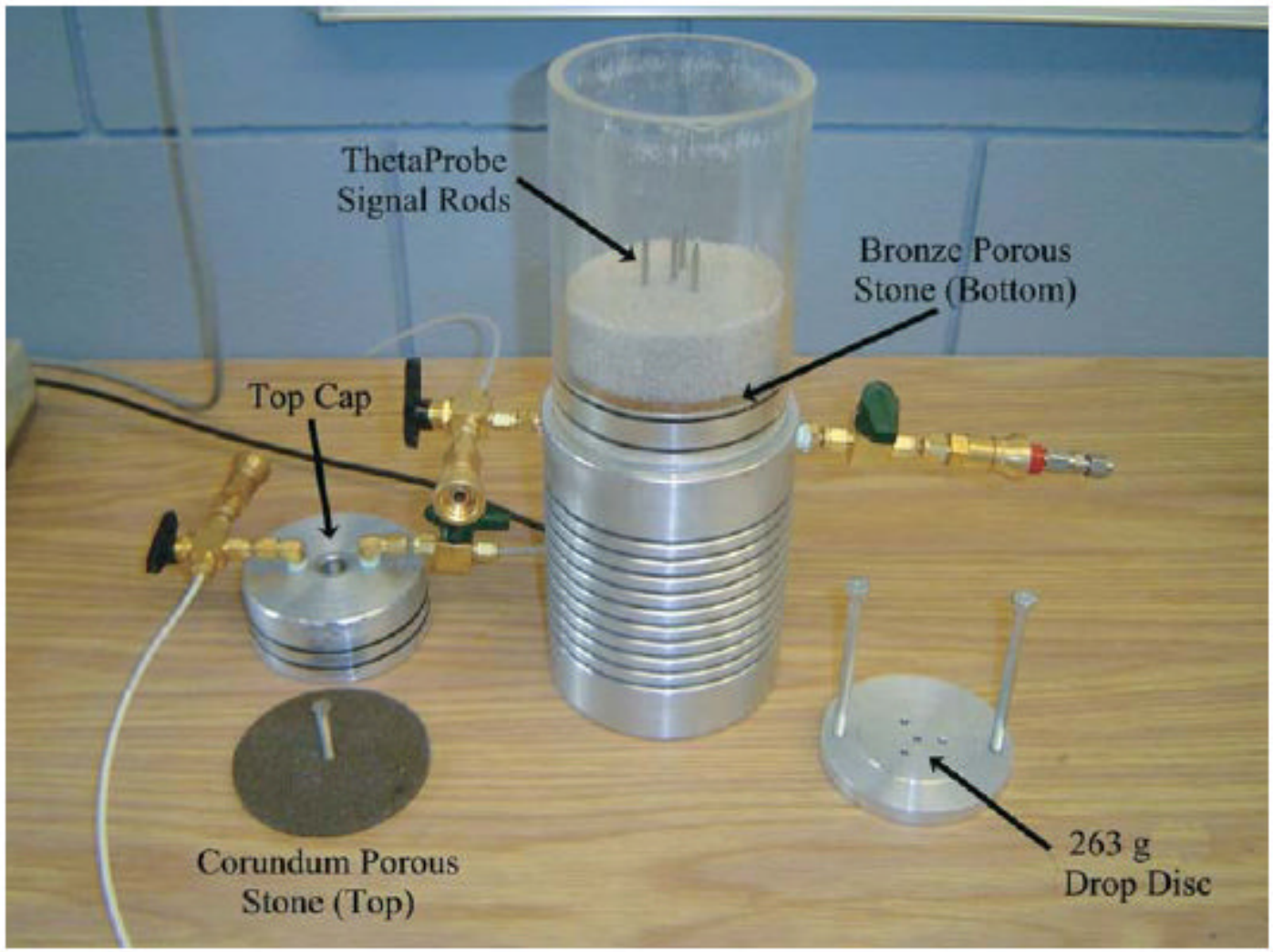

Figure 4.7 - Grozic et al experimental set-up 


\section{Example 14 - Experimental apparatus at Texas A\&M University (Makogon 2006)}

The experimental equipment at Texas A\&M University is unique. Professor Yuri Makogon designed the equipment and the experiments to study the morphology and kinetic behavior of gas hydrates in porous media. Figures 4.8 illustrates the experimental set-up.

Schematic Diagram for study gas hydrates in the cores - (Makogon, 2003)

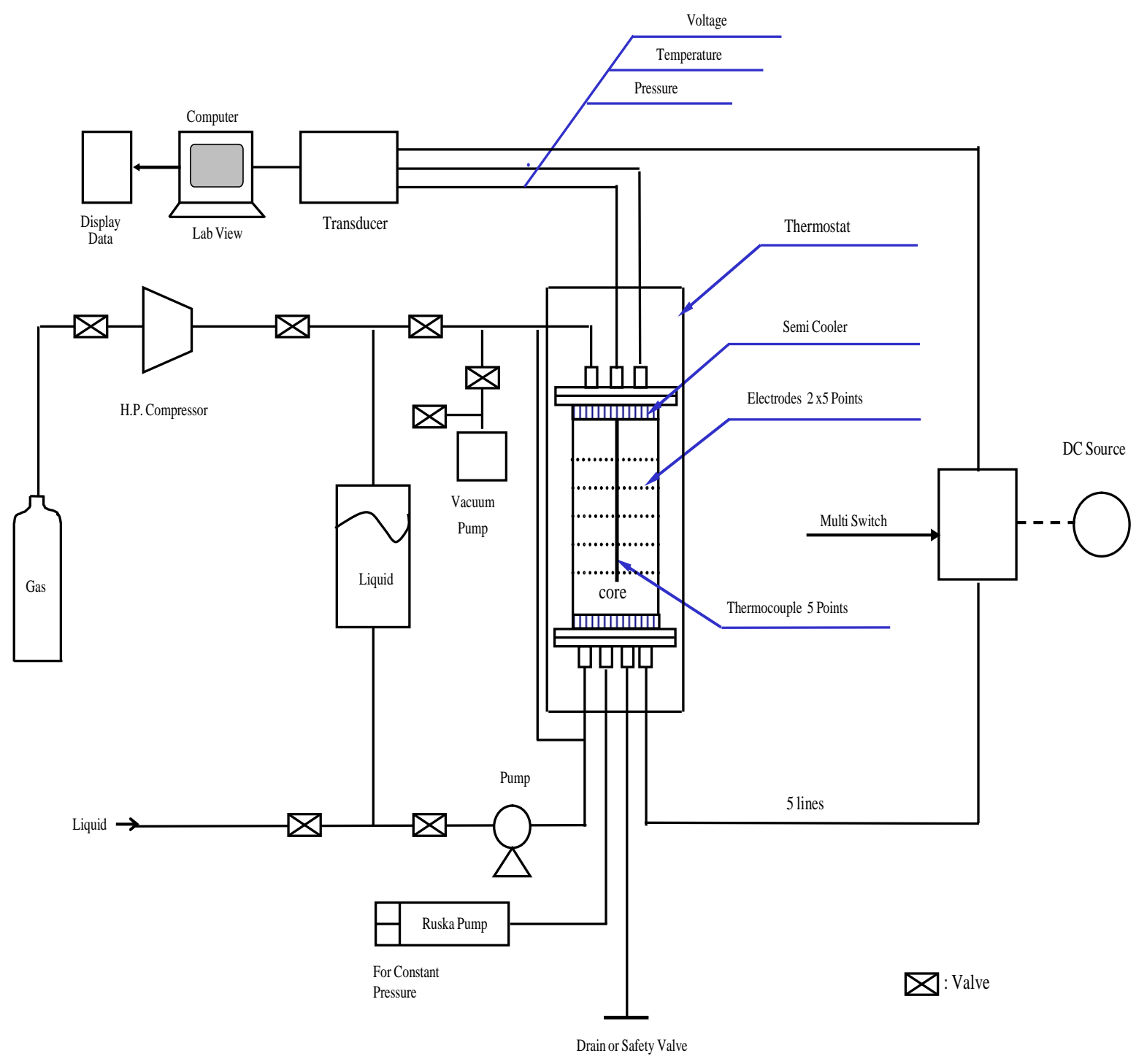

Figure 4.8 - Makogon's experimental set-up, 2003 


\section{Example 15 - Nucleation of CO2-hydrate in a porous medium (Zatsepina and Buffett}

2001)

$\circ$ Lane mountain Sand (Grain size 0.4-0.6 mm) was used in these tests

○ Constant pressure was maintained in a thin layer on top of the cell by gas

- Hydrate formed by the dissolved $\mathrm{CO} 2$ in distilled water

○ Temperature is lowered down at different rates to study hydrate formation rate

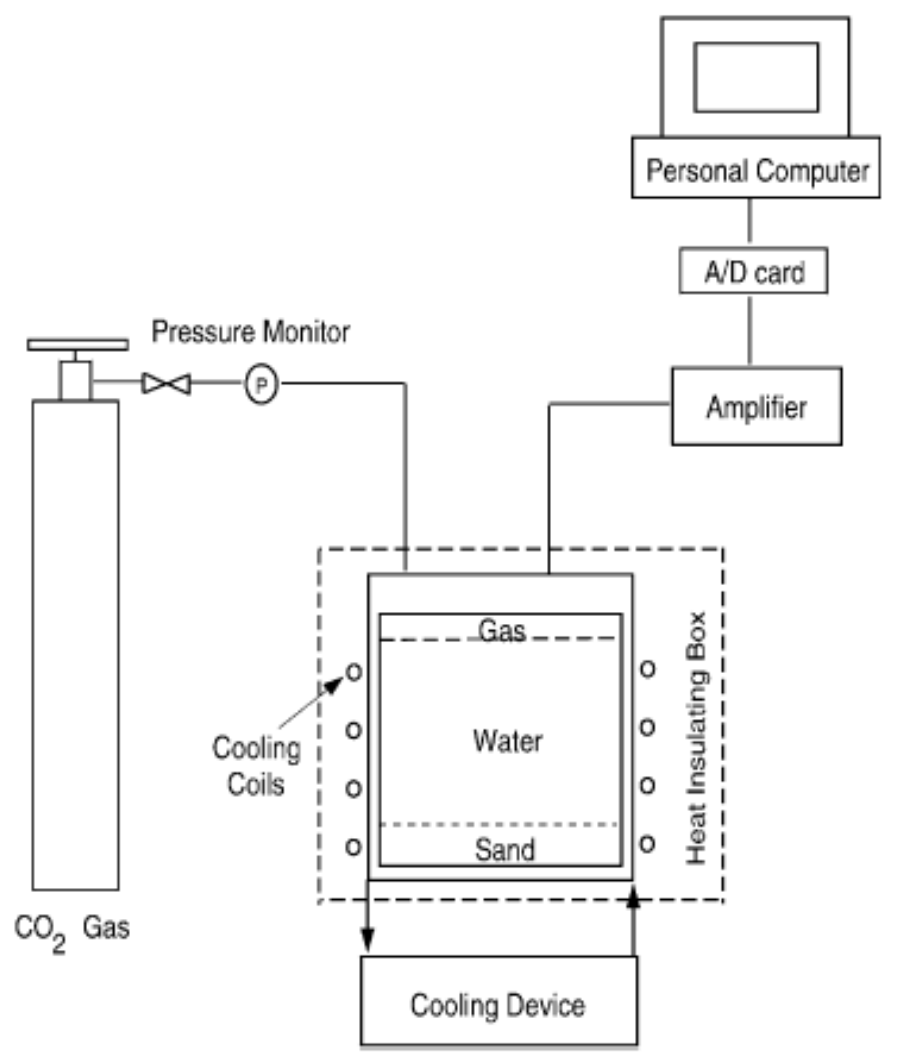




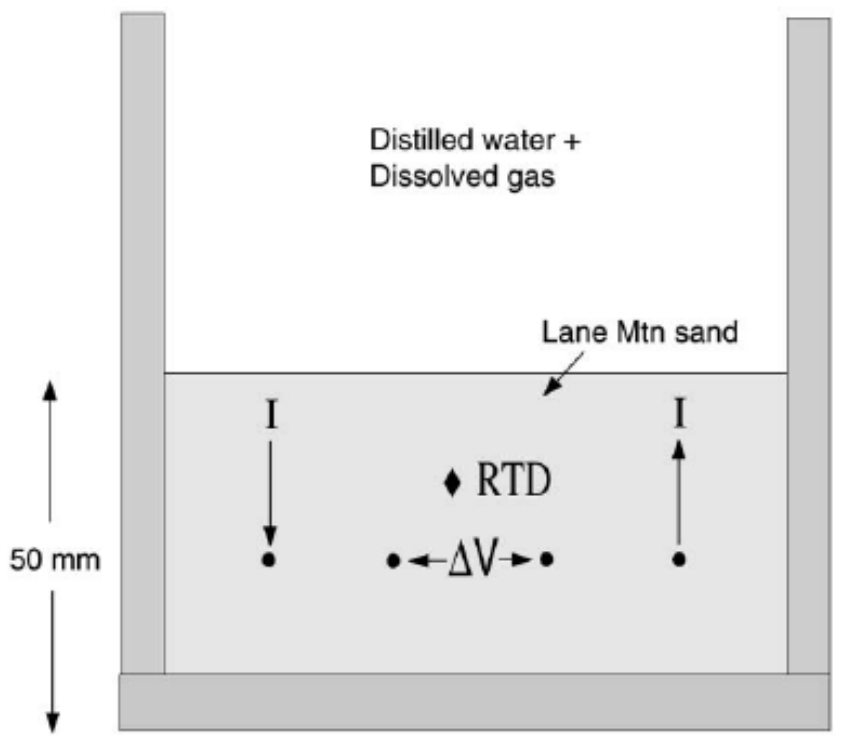

Figure 4.9 - Zatsepina and Buffett experimental set-up

Example 16 - Acoustic laboratory measurements during the formation of a THF hydrate in unconsolidated porous media (Kunerth, Weinberg et al. 2001)

$\circ$ Garnet sand was used (grain size $0.5-0.85 \mathrm{~mm}$ )

○ THF used as the hydrate former

- Mixture of water and THF was cooled from bottom to top to form the hydrate in the sediment

- Purpose of the experiment was to study the acoustic properties in the hydrate saturated sediments 
Example 17 - Experimental and modeling study on decomposition kinetics of methane hydrates in different media(Liang, Chen et al. 2005)

- Methane gas used as hydrate former

○ 20-40 mesh wet activated carbon used as porous media

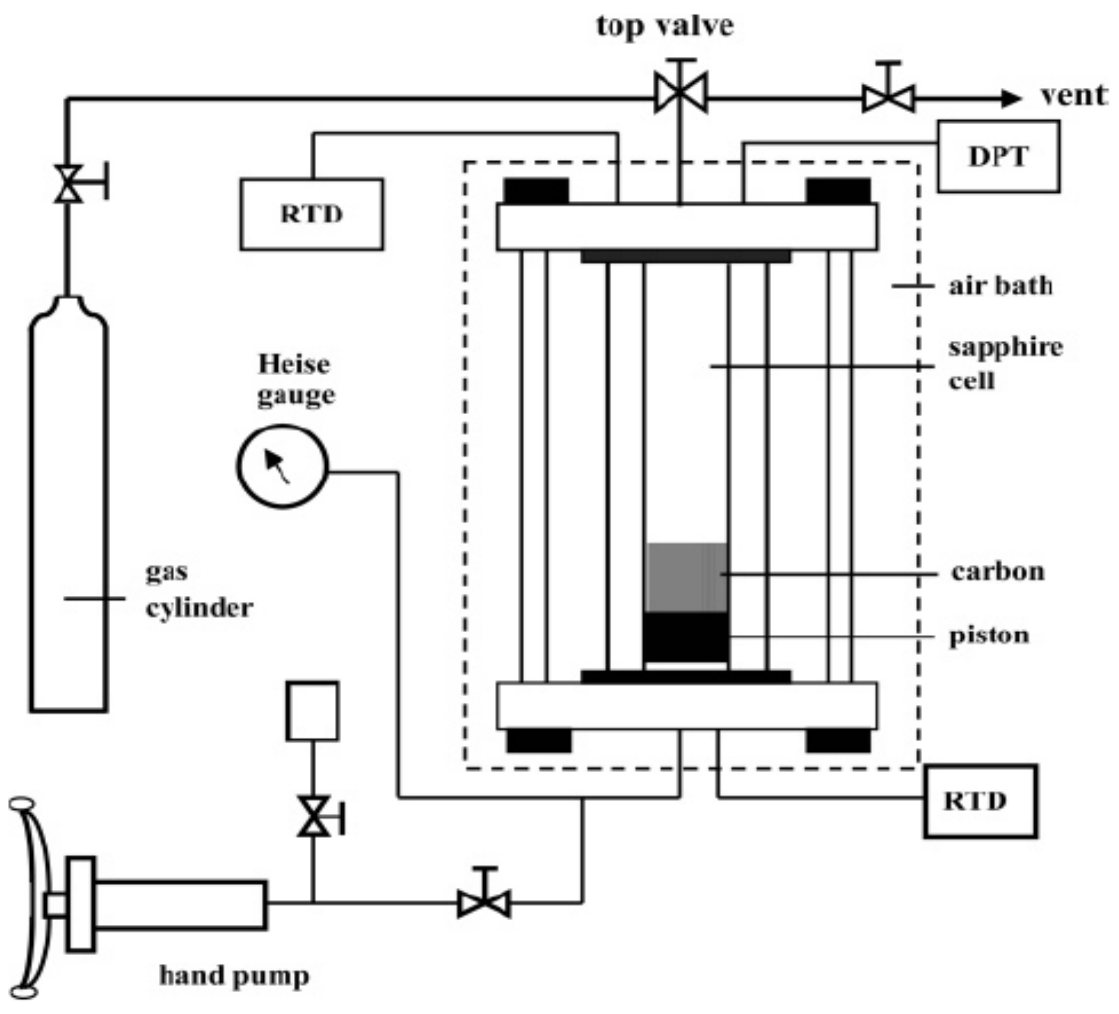

Figure 4.10 - Liang et al set up 


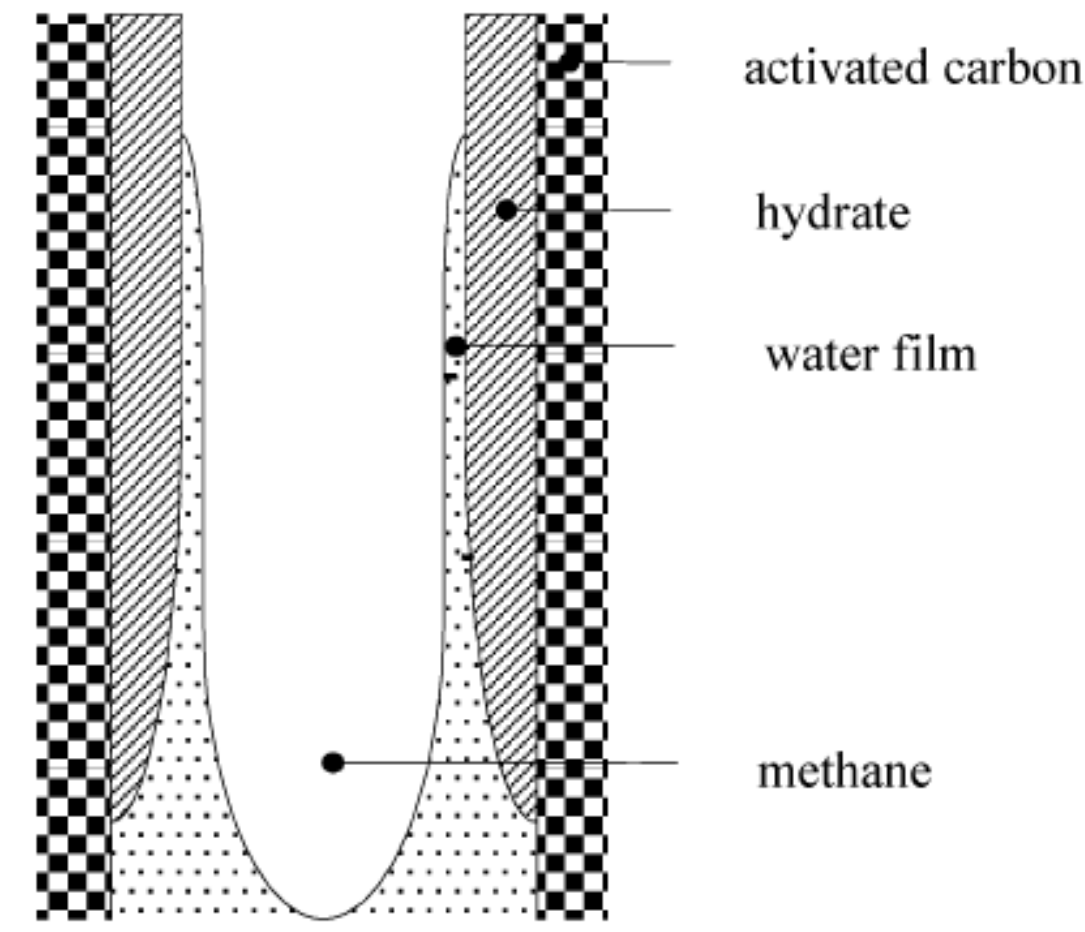

Figure 4.11 - Model for hydrate formation in wet activated carbon (Yan, Chen et al. 2005)

Example 18 - Sensitivity of methane hydrate phase equilibria to sediment pore size (Turner, Cherry et al. 2005)

- Adriatic sandstone sample (pore size $550 \AA$ ) and ceramic core (pore size 5360 A) were used as porous media

- Methane gas was used

○ Hydrate was formed by first saturating the sample with water. Then, the methane gas was supplied under pressure and core was pressurized with methane 


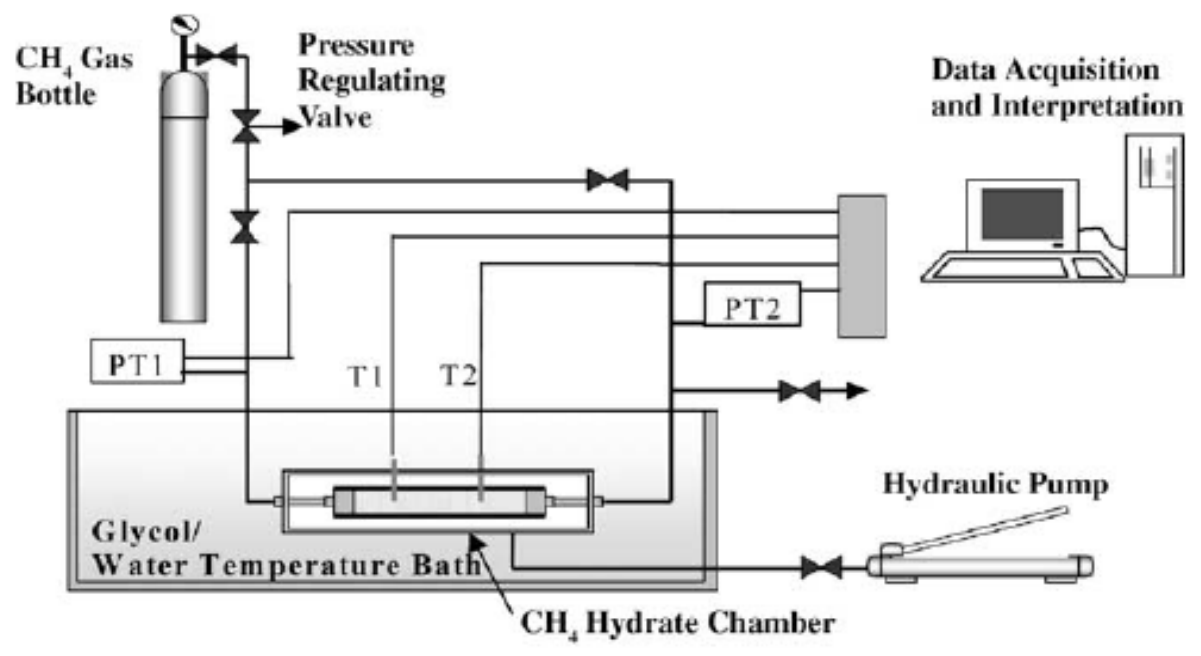

Figure 4.12 - Turner et al experimental set up

Example 19 - Methane gas hydrate effect on sediment acoustic and strength properties (Winters, Waite et al. 2007)

○ GHASTLI is used for experiments

- Methane gas is used as hydrate former

○ Medium sized sandy sediment from McKenzie Delta, Ottawa sand and clayey silt were used as sediments

- Hydrate was formed using two methods:

- Method 1 - Slowly pushing methane gas into an initially water saturated sample. Confining and pore pressures were simultaneously raised to $12 \mathrm{MP}$ and then an additional confining stress was applied to sample exterior. Methane was slowly percolated up through the sediment until a predetermined amount of water, measured by the collector, was pushed out of the sample. Then the temperature of the coolant flowing to the heat exchanger was lowered until P-T conditions were within the gas hydrate stability zone.

○ Method 2 - It started with a specimen initially partially saturated with water. Drainage was not allowed during the specimen pressurization. This was done particularly not to change the water content of the specimen. 


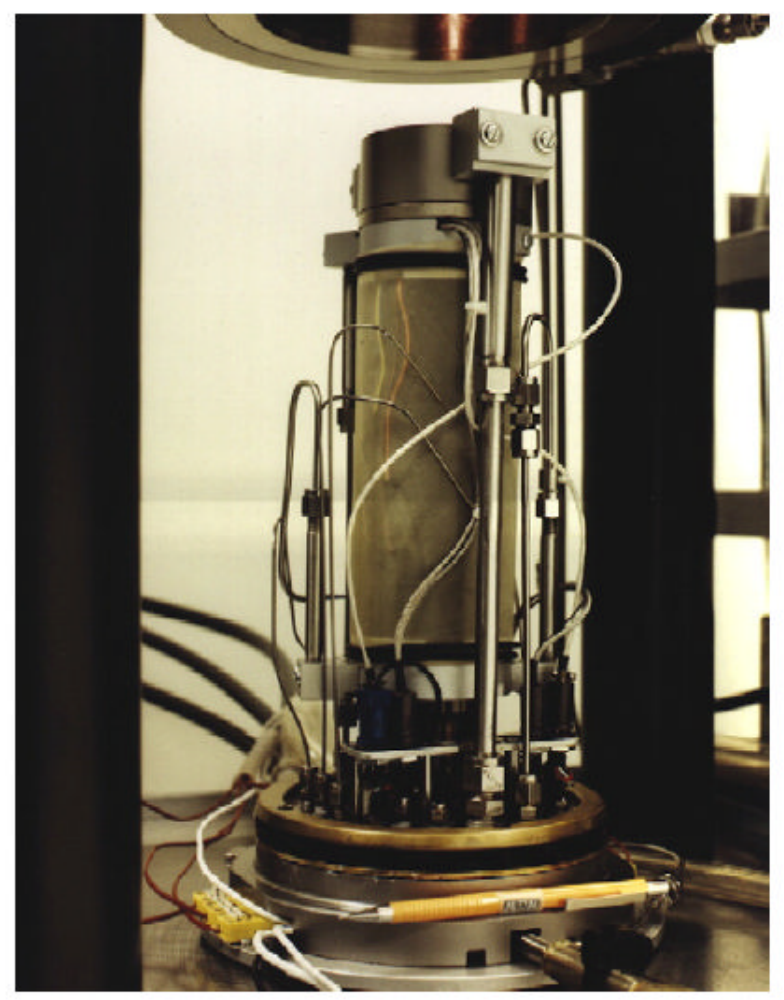

Figure 4.13 - GHASTLI

Example 20 - Methane hydrate formation and dissociation in partially saturated corescale sand sample (Kneafsey, Tomutsa et al. 2007)

○ Foundry 110 sand (US Silica, Berkeley Springs WV) was used

- Sand consists of rounded to sub-angular grains primarily in the 100 to $200 \mu \mathrm{m}$ grain size.

- Sand was moistened in a step-wise manner with distilled, de-ionized water until desired water content was achieved

○ Then the sample was pressurized with methane gas. Hydrate was formed in the pressurized sand pack kept at a temperature of $1.1^{\circ} \mathrm{C}$. 


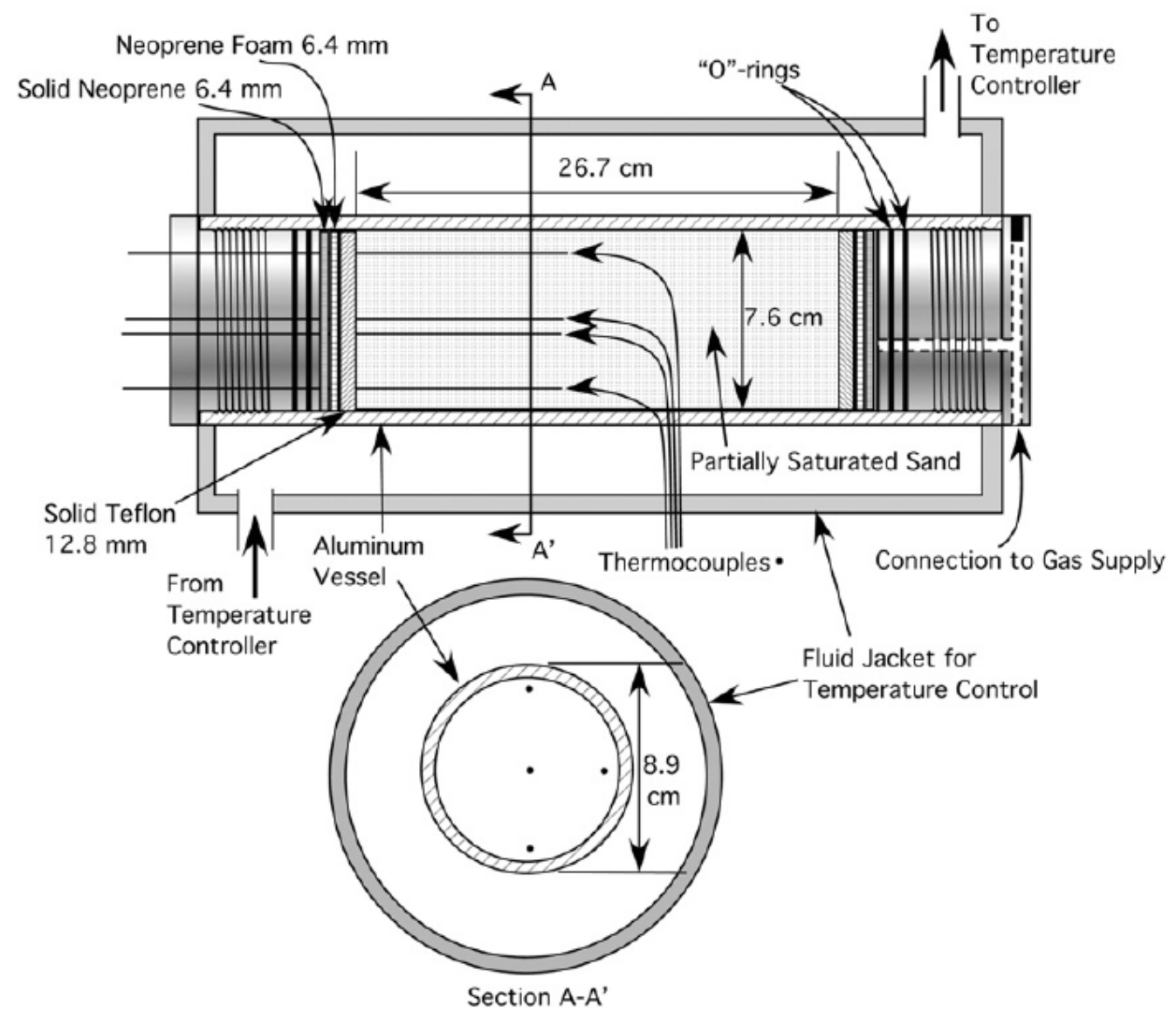

Figure 4.14 - Kneafsey et al experimental set-up 
Example 21 - Measuring and modeling thermal conductivity of gas hydrate bearing sand (Huang and Fan 2005)

- THF and methane were used to form hydrates

○ Construction sand (300-125 $\mu \mathrm{m})$ is used with quartz as the major constituent

- SDS (surfactant) solution was used to enhance hydrate formation

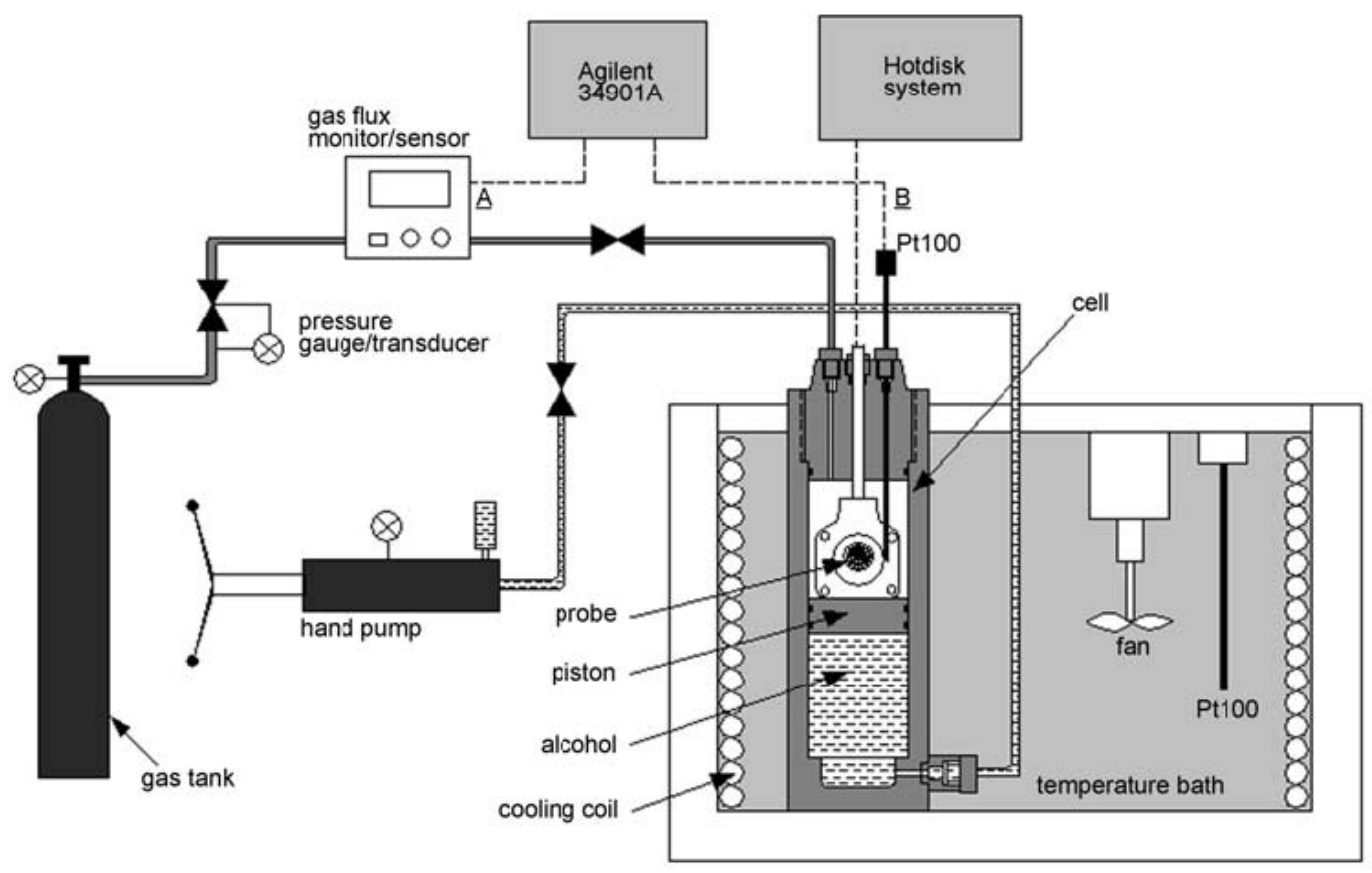

Figure 4.15 - Huang and Fang experimental set-up 
Example 22 - Makogon Measurements and Equipment in 2006

Makogon (2006) has been measuring the dissociation characteristics in porous media. Understanding of this dissociation curve is very important if hydrate deposits are to be understood in detail.

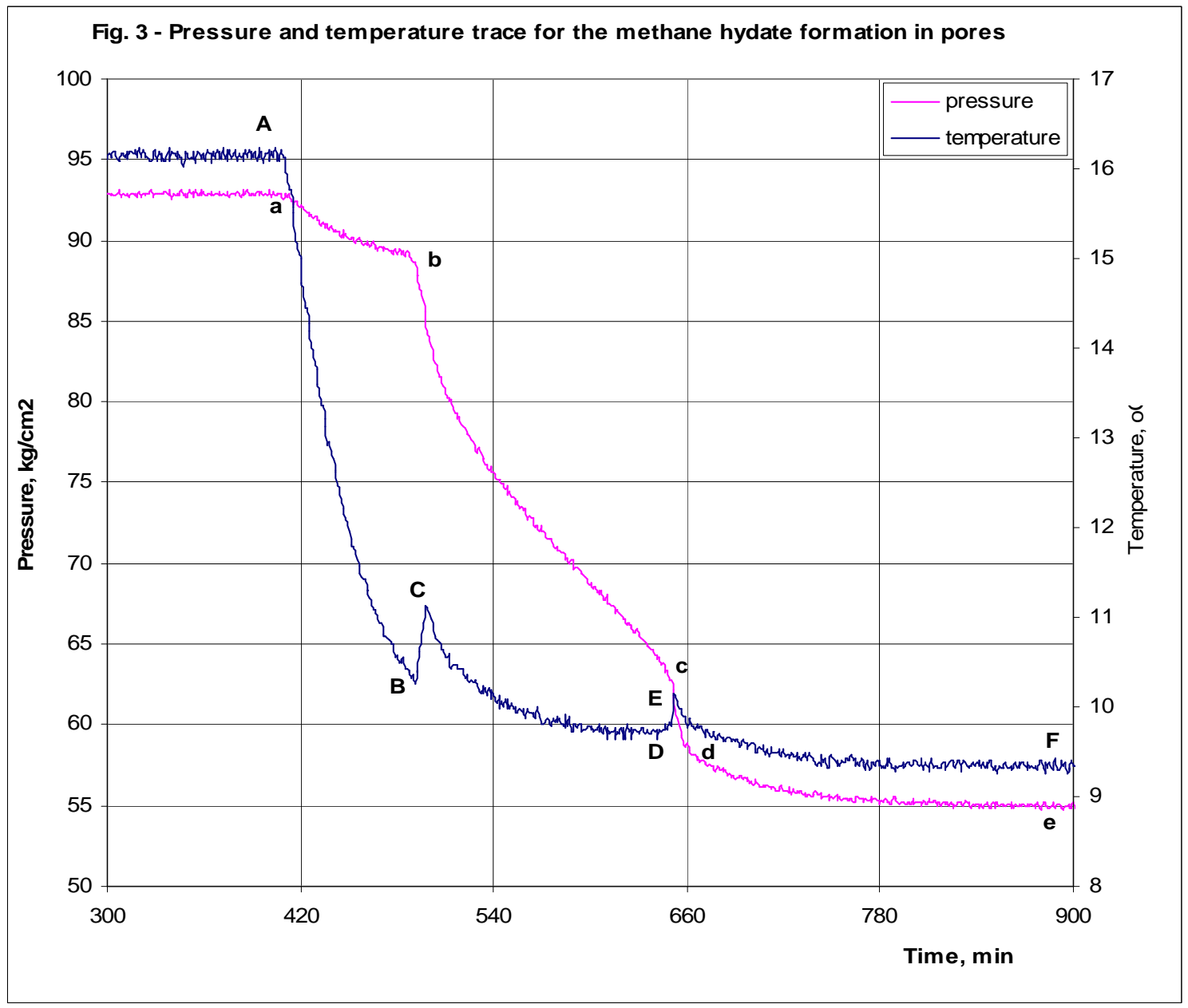

Figure 4.16 - P-T trace for methane hydrate formation in pore space (Makogon 2006) 


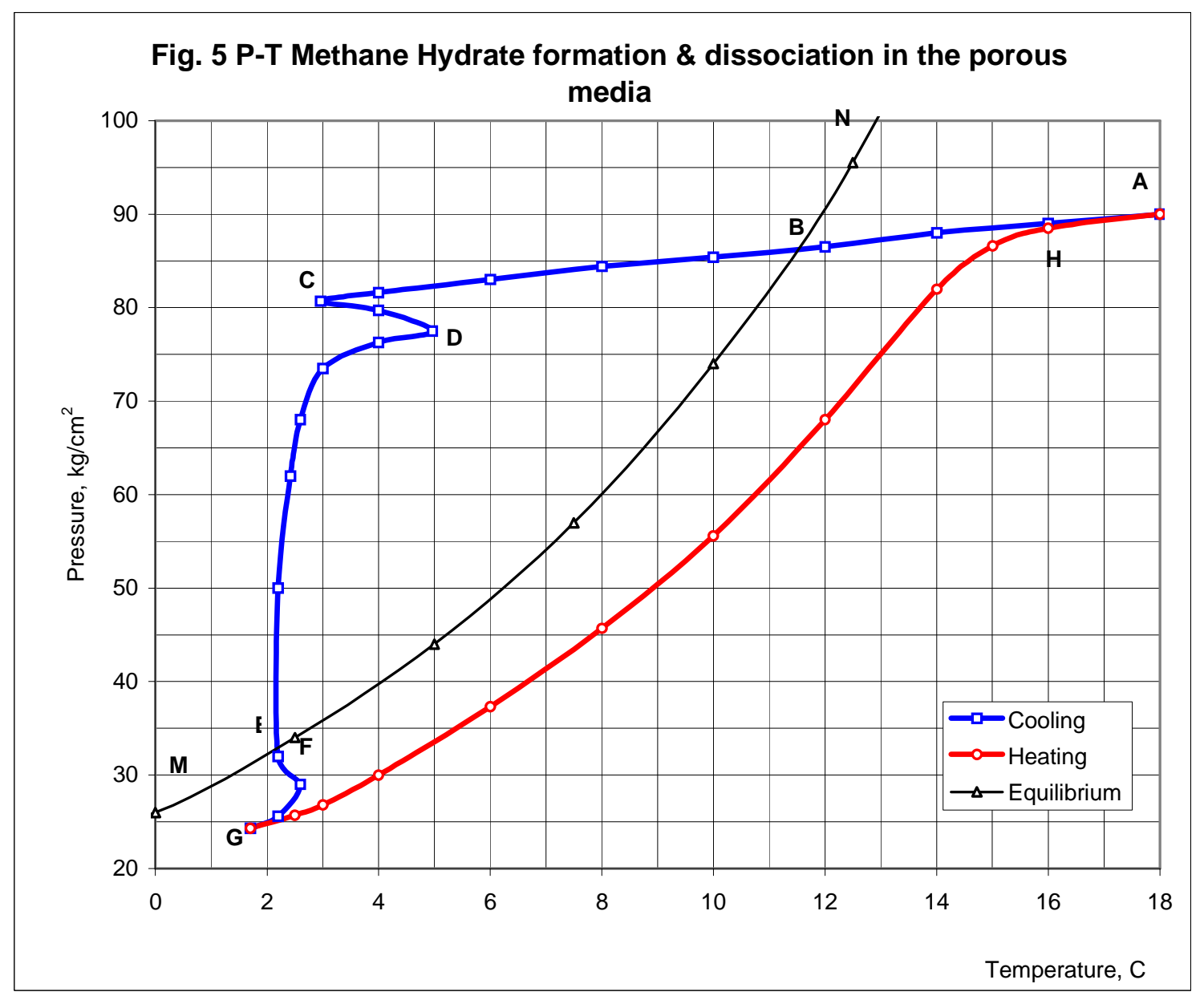

Figure 4.17 - Methane hydrate formation and dissociation in porous media (Makogon 2006)

Makogon (1981) also demonstrated the effect of porous media on the equilibrium curve (P-T curve) of gas hydrates in pore space. The capillary pressure behavior for methane-water system in porous media is important to study the flow characteristics in hydrate bearing sediments. Figure 4.17 shows the variation of capillary pressure with pore radius. The capillary forces become very important in sediments with small pore sizes. 


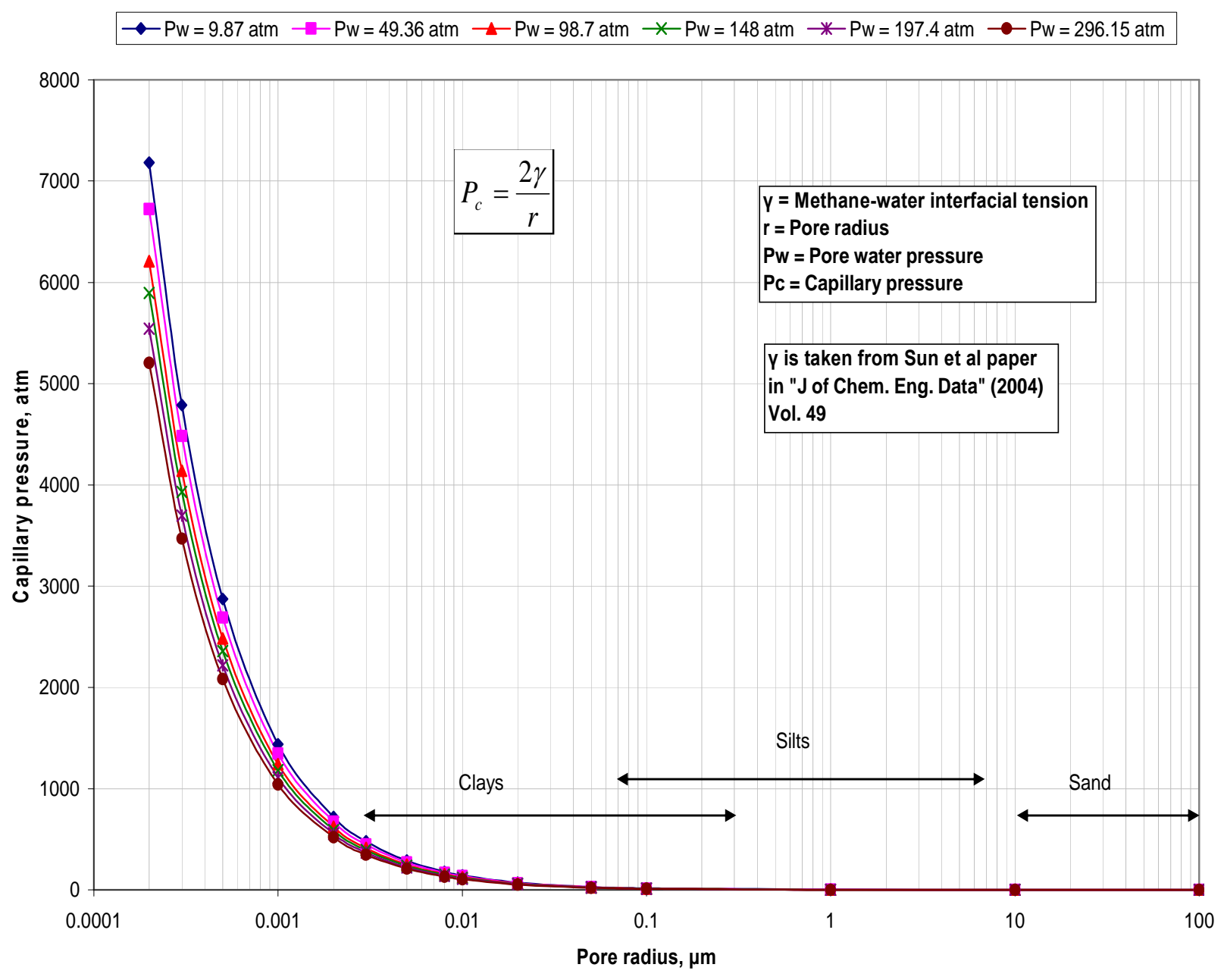

Figure 4.18 - Capillary pressure with pore radius at different pore water pressures. 
During 2006, Makogon has been building equipment to measure kinetic and various properties of cores containing gas hydrates in preparation of continued work in 2007. Below are several pictures of the equipment that has been under construction and is now ready to be used in this project.

Cell for study micro morphology of crystals. $P=350$ bar

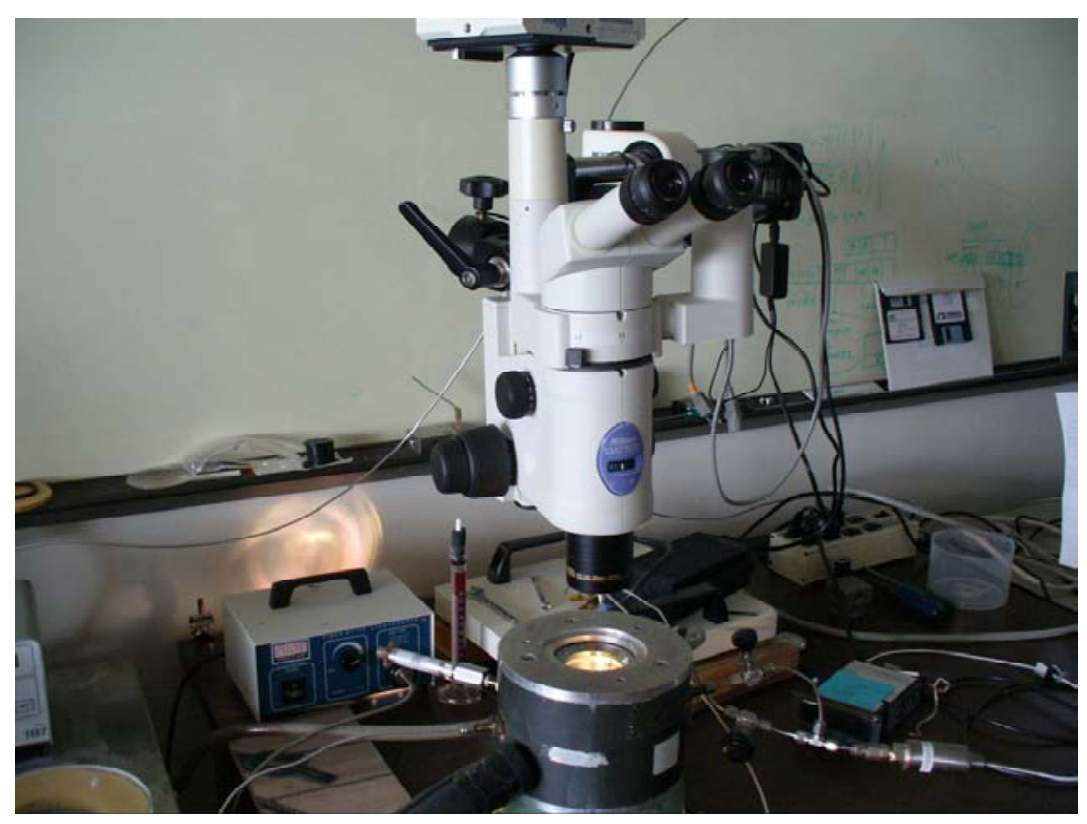

Cell for study hydrates in porous media. $\mathrm{P}=\mathbf{3 0 0}$ bar

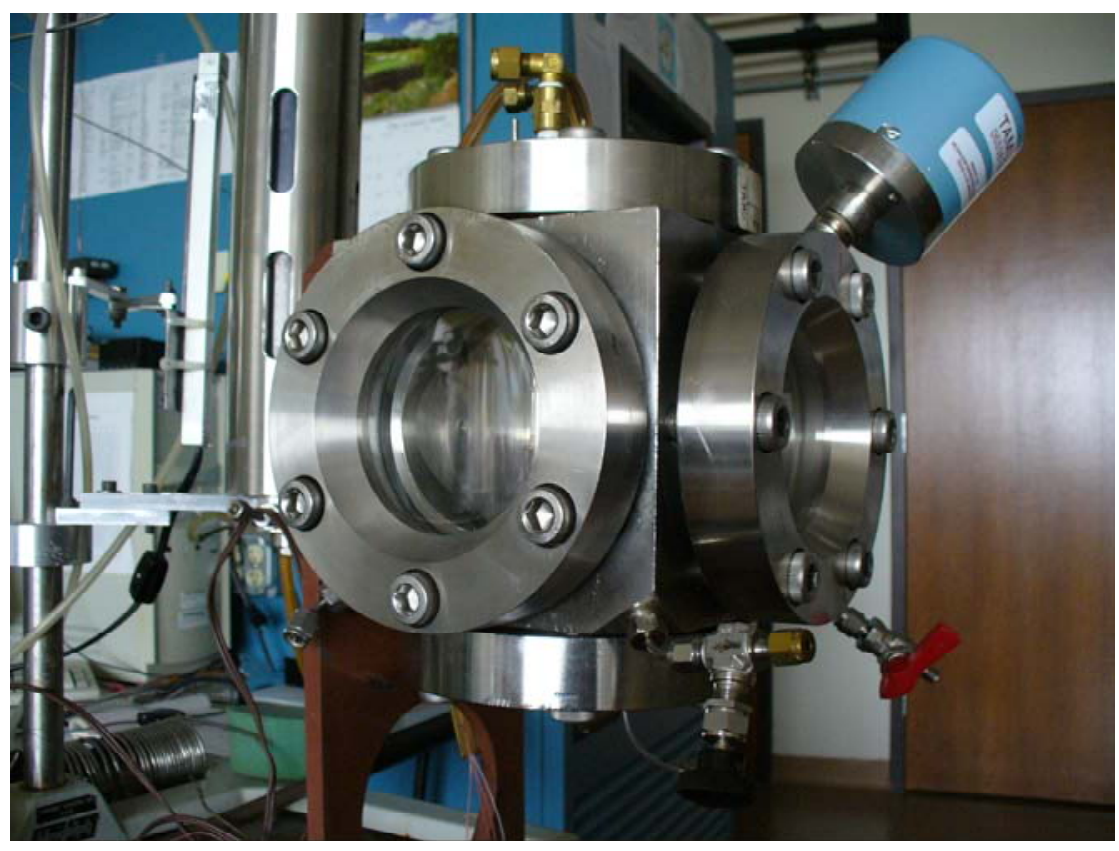




\section{Synthetic Cores in the Laboratory for Gas Hydrate Testing}

Table 5.1 describes various types of sediments used and their grain size/pore size distribution.

Most of the experiments have been done in coarse sediments (sand, glass beads).

Table 5.1 - Summary of Sediments and Grain Sizes

\begin{tabular}{|l|l|l|}
\hline Researcher & Sediment used & Pore size/Grain size \\
\hline $\begin{array}{l}\text { Makogon 1966; Makogon 1974; } \\
\text { Makogon 1981; Makogon 1997) }\end{array}$ & Sands, real cores & Different real \\
\hline (Handa and Stupin 1992) & Porous silica gel & $23-70 \AA$ (pore radii) \\
\hline (Kunerth, Weinberg et al. 2001) & Sand (Garnet sand) & $500-850 \mu \mathrm{m}$ (grain size) \\
\hline (Tohidi, Anderson et al. 2001) & Glass micro-models & $0.094-0.5 \mathrm{~mm}$ (grain size) \\
\hline (Zatsepina and Buffett 2001) & Lane mountain sand & $0.4-0.6 \mathrm{~mm}$ (grain size) \\
\hline (Kono, Narasimhan et al. 2002) & Glass beads & 100 and 5000 $\mu \mathrm{m}$ (grain-size) \\
\hline (Smith, Wilder et al. 2002) & Silica gel & $7.5,5,3 \mathrm{~nm}$ (pore radii) \\
\hline (Uchida, Ebinuma et al. 2002) & Glass beads & $20-200 \mu \mathrm{m}$ (grain size) \\
\hline (Waite, deMartin et al. 2002) & Quartz sand & \\
\hline (Kumar, Turner et al. 2004) & $\begin{array}{l}\text { Platte Valey sand } \\
\text { Blake Ridge sediments }\end{array}$ & $250-500 \mu \mathrm{m}$ (grain size) \\
\hline (Santamarina, Francisca et al. 2004) & Ottawa sand \\
& $\begin{array}{l}\text { Precipitated silica flour } \\
\text { Crushed silica flour }\end{array}$ & $1-120 \mu \mathrm{m}$ (grain size) \\
Kaolinite & \\
\hline (Uchida, Takeya et al. 2004) & Toyoura sand (TS) & $60-150 \mu \mathrm{m}$ (grain size) \\
& Berera sandstone (BS) & $50-200 \mu \mathrm{m}$ (grain size) \\
Clays & $0.1-9 \mu \mathrm{m}$ (grain size) \\
& Glass beads & $20,100 \mu \mathrm{m}$ (grain size) \\
\hline (Winters, Pecher et al. 2004) & $\begin{array}{l}\text { Reconstituted Ottawa } \\
\text { sand }\end{array}$ & \\
\hline (Dicharry, Gayet et al. 2005) & Controlled pore glass & $25-40 \mathrm{~nm}$ (pore diameter) \\
\hline (Huang and Fan 2005) & Sand & $300-125 \mu \mathrm{m}$ (grain size) \\
\hline (Liang, Chen et al. 2005) & Activated carbon & $1.9 \mathrm{~nm}$ (Mean pore diameter) \\
\hline (Spanpenberg, Kulenkampff et al. & Glass bead & $250-500 \mu \mathrm{m}$ (grain size) \\
\hline 2005) & Fine grained sand & $120 \mu \mathrm{m}$ (grain size), average \\
\hline (Yun, Francisca et al. 2005) & Ottawa sand & $20 / 30 \mathrm{mesh}$ size \\
\hline (Kilner and Grozic 2006) & Foundry 110 sand & $100-200 \mu \mathrm{m}$ (grain size) \\
\hline (Kneafsey, Tomutsa et al. In Press) & $\begin{array}{l}\text { Medium sized sand } \\
\text { Clayey silt }\end{array}$ & $0.25 \mathrm{~mm}$ (grain size) \\
& $0.004 \mathrm{~mm}$ (grain size) \\
\hline (Winters, Waite et al. In Press) & & \\
\hline
\end{tabular}


There have been many different methods to form gas hydrates in sediments. The following three methods seem to be the most popular.

In Method 1, the sediment completely saturated with water, is first cooled with liquid nitrogen. The water in the sediment is hence turned into ice. Then the ice and sediment mixture is pressurized with gas. Slowly the temperature is raised above the equilibrium temperature such that the ice is melted and the gas reacts with that water to form the hydrate in the sediment.

In Method 2, the sediment is first fully saturated with water. Gas is pushed through the sediment sample until the known amount of water is displaced. Then the temperature is decreased until the P-T conditions are within the hydrate stability zone.

In Method 3, the sediment is first sprayed with water until the wanted water content has been achieved. The partly saturated sediment is then pressurized with gas. The temperature is decreased until hydrates were formed in the pore space.

\section{Recommendations to Mix Standard Sediments in the Laboratory for Testing in 2007}

We describe here three different types of sediments which can be used in the laboratory.

○ $100 \%$ sand sized particles of average diameter $100 \mu \mathrm{m}$

- $50 \%$ silt sized particles of average diameter $10 \mu \mathrm{m}$ and $50 \%$ clay sized of average diameter $1 \mu \mathrm{m}$

○ $100 \%$ clay sized particles of average diameter $1 \mu \mathrm{m}$

Based on the review of sediment description in various offshore environments, we have divided the sediment composition into three subgroups. For each of the subgroup, a procedure will be outlined to make the sediments in the laboratory. The reason to choose these three compositions of sediments is that these types of sediments are found in nature. For example, in Nankai Trough hydrates are found in the sandstone; at Blake Ridge they are found in silty clay; and at Gulf of Mexico both in silty clay and clay 


\section{Steps for Mixing Sediments in the Laboratory}

The following recipes are for mixing $1 \mathrm{~kg}$ of dry sediment. The mixing rules are fairly straight forward; however, we need to decide the basic soil samples we will use. Different types of clays can be used to represent different clay mineralogies. We will need to decide upon a standard soil type for our experiments. One of the first tasks of Phase II will be to confer with all parties to decide the type of raw materials we will use to mix the soil samples.

\section{Sand}

1. To make $100 \%$ medium sand specimen:

a. Take $1 \mathrm{~kg}$ of sand of average size $100 \mu \mathrm{m}$, sand in this range can be collected using sieves.

b. Measure the water content of the sand specimen according to ASTM D2216 standards.

c. Add salt to the distilled water until the desired salinity value is obtained

d. To increase the water content of the sand specimen, spray water on the sand in steps and mix uniformly. Continue to do so until the required water content is reached.

e. It is important to pack the sand to a porosity that is representative of that of natural sediments. To pack the sand to a particular porosity, the moistened sand should be given a number of blows.

f. Once the desired porosity is reached and water saturation reaches the desired level, the partially saturated sand sample should be pressurized with methane.

g. After pressurization, the temperature is to be lowered down until the hydrate is formed in the pore space. 


\section{Clay}

2. To make high plasticity clay specimen:

a. Take the part of a specified soil sample that is $50 \%$ or more by weight with a nominal diameter smaller than $0.075 \mathrm{~mm}$.

b. The clay should be such that its plasticity index is greater than the " $A$ " line in the plasticity chart (ASTM standard D2487) and liquid limit $>50 \%$

c. Once this clay sample is procured, then the water content can be increased by spraying more water until it reaches the desired water content

\section{Silty Clay}

3. To make the silty-clay specimen:

a. From a specified soil mixture, sort out 750 gm of clay fraction $(<5 \mu \mathrm{m})$ and then using 250 gm of silt sized fraction $(75 \mu \mathrm{m}$ to $5 \mu \mathrm{m})$, mix these two proportions together - different types of clays can be used to represent different clay mineralogies. We will need to decide upon a standard soil type for our experiments.

b. After mixing, then the initial water content should be measured as explained in the ASTM D2216 standard.

c. Add the salt to the distilled water until the salinity reaches the desired value.

d. To increase the water content of the soil specimen, spray water on the sample in steps and mix uniformly. Continue to do so until the required water content is reached.

e. It is important to pack this sediment to a porosity which is representative of that of natural sediments. To pack the sediment to a particular porosity, the moistened sediment should be given a number of blows.

f. Once the desired porosity is reached and water saturation reaches the desired level, the partially saturated sediment sample should be pressurized with methane.

g. After pressurization, the temperature is to be lowered down until the hydrate is formed in the pore space 


\section{Effect of cementation}

The understanding of the cementation of the marine sediments is important because the behavior of hydrate bearing sediments in loose sediment is probably different than in the cemented sediments. This is an important factor for geotechnical studies of the hydrate bearing sediments.

(Molenaar and Venmans 1993) have described a method for producing artificially cemented samples for geotechnical testing and a comparison with natural cementation processes. According to their study " the most important factors controlling calcium carbonate cementation are the chemistry of the seawater, the physical conditions, in terms of hydraulic energy, sedimentary parameters such as permeability, texture and composition of the sand, and an initially stabilizer of the loose sediment."

The mineralogy of the calcium carbonate cement precipitated from seawater is typically aragonite. 
6. Annual Report from University of California at Berkeley 


\title{
Mechanical Properties of Granular Media via Grain-Scale Simulations; Modeling the Mechanics of Hydrate-Bearing Sediments
}

\author{
Annual Report for Phase I \\ Geomechanical Performance of Hydrate-bearing \\ Sediments in Offshore Environments \\ DOE Award Number: DE-FC26-05NT42664 \\ CFDA Number: 81.089 \\ Fossil Energy Research and Development
}

Ran Holtzman, Dmitriy B. Silin, and Tadeusz W. Patzek

February 14, 2007

\section{Introduction}

Knowledge of mechanical properties of hydrate-bearing sediments (HBS) is crucial to offshore production. As hydrates dissociate, the solid water and trapped gas become fluids. Loss of stress support caused by hydrate dissociation may result in a significant reduction of rock strength. The strength of a hydrate-bearing sedimentary formation is a function of the strengths of inter-granular bonds and the interactions between the rock grains and the hydrates in the pore space. A myriad of such bonds and interactions defines the macroscopic rock strength parameters. We expect that the history of hydrate formation has a great impact on the character of hydrate distribution and, consequently, on the possible scenarios of failure of a hydrate-bearing rock. Our work will help to quantify the impacts of offshore platforms, sea-bottom facilities, and oil\&gas extraction on the nearby sediments that contain hydrates.

This report summarizes the results of Phase I, and describes a robust approach to obtaining the mechanical properties of a general granular medium. This approach will be used in Phase II to model HBS.

The existing mechanical descriptions of granular media are far from complete. Mechanical property measurements at small scales are extremely difficult, and direct computations discrete models are cumbersome and expensive. Moreover, little is currently known about the mechanical properties of gas-hydrates and HBS. It is still unclear how hydrates grow within a sediment layer (Sloan, 1998) and what their spatial distribution is. Two extreme modeling approaches might consider hydrates as: (a) solid particles that interact with the 
granular sediment; and (b) a cement that fills the pore space and builds around grain contacts.

Recent works on mechanics of HBS devise analytical bounds on the mechanic properties of these compound materials, e.g., Helgerud et al., 2000 and Jakobsen et al., 2000. These bounds are usually coarse, especially when the pore space is filled with a compressible fluid. In addition, in some cases, these bounds are calculated with models that might be oversimplified with respect to the geometrical features of a real HBS. We propose to extract the effective macroscopic properties using direct calculations from the direct micro- and mesoscale simulations of HBS. Our model of HBS accounts for mechanical interactions among the grains. From an extension of this model, we will derive the continuum scale constitutive models of HBS that will be used in mega-scale numerical simulators of flow and deformation in marine sediments located near offshore platforms.

\section{Approach}

We present the mechanical problem of deformation of granular media. We are interested in describing the macroscopic behavior of a rock mass in response to, e.g., changes in applied stress or imposed displacements. This description will be based on the microscopic response of a pack of grains. Here we formulate a grain-scale model, which accounts for the discrete nature of the problem by simulating interactions of individual grains. We are not interested in a detailed description, such as the shapes of the deformed interfaces, but rather in the displacements of the centers of grain masses caused by local deformations. This approach is consistent with the assumptions used to develop the Hertz-Mindlin contact theories (Hertz, 1882 and Mindlin, 1949).

The individual grain deformations are small and grains are modeled as linear elastic bodies. Each grain is considered to be homogenous and isotropic. The deformations are assumed to be localized around the contact interfaces. Thus, we are able to use Hertz and Mindlin's contact theories (Hertz, 1882 and Mindlin, 1949). In these theories, each grain is approximated by a linear elastic half space. The solution to the continuum problem provides the stresses and strains close to the contact area, from which the resultant forces are calculated.

The simulations are three-dimensional, and the grains are spherical in shape. The grains differ in size and mechanical properties. The granular pack is unstructured: it is a random packing rather than a lattice. The pack is contained within a semi-rigid box, made of elastic planar surfaces which are stiffer than the spheres. At this stage, no adhesion or cementation is considered. Thus, the problem is reduced to a box containing unconsolidated, unsorted round quartz sand, see Figure 1. Our model does not yet include the effects of hydrate dissociation, but the model's microscopic nature provides a robust framework to include these effects in the future.

The process of deformation is considered to be slow relative to the time it takes for the system to reach mechanical equilibrium, so that dynamic effects are neglected at this stage. Thus, the problem is modeled as quasi-static. This means that the deformation process is described as a sequence of equilibrium configurations that represent responses of the system to changing boundary conditions (wall locations), given some initial configuration. These equilibrium configurations, described by the locations of the centers of mass of the spheres 


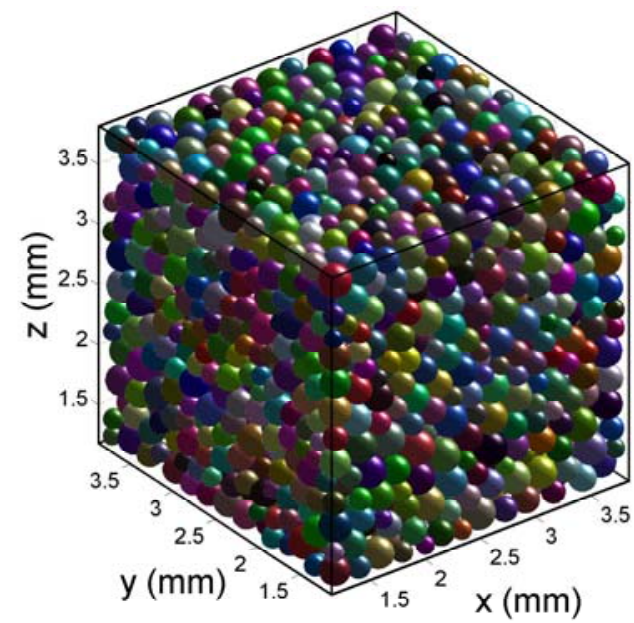

Figure 1: A typical sediment sample made of 2740 grains used in numerical simulations.

and their rotations, are defined by the vanishing sums of forces and moments on each sphere. Thus, equilibrium is expressed by a system of equations of the size equal to the number of degrees of freedom. Direct solution of such a system of nonlinear equations is very expensive for a large number of grains. Thus, we offer a variational formulation, where it becomes an optimization problem, which can be solved iteratively. In other words, the displacements (linear and angular) that minimize the potential energy are the ones that correspond to zero residual forces and moments. Note that the minimum of energy is a local minimum and in general the problem is non-unique.

A crucial consequence of the assumptions above is that the forces and moments are potential, i.e., the residual forces and moments are the gradient of a potential energy. This means that we consider the contacts to be elastic. We neglect energy losses by friction by ignoring slip at the grain contacts. For each pair of grains in contact, the displacement field is continuous from both sides of the interface. This can be visualized as if the grains are "glued" while contact is maintained, and only complete separation is possible. In this work, the tangential forces and torsion are also considered in the construction of the mathematical model, but the simulations are done accounting for normal contact forces only. This type of models is often termed "non-frictional contact". Note that even with this simplification, the force-displacement relation for each pair of grains is non-linear. This is because the contact area is a non-linear function of the displacements.

We will consider two cases, which differ by their initial configuration:

1. Undeformed pack, where the contacts are singular (a point contact), and no stresses or strains exist. For this case, the full non-linear formulation is required.

2. Prestressed pack, where some stresses and deformations already exist, and the pack is in static equilibrium. For this case, one could replace the non-linear problem with a linear approximation by providing a linear relation between the forces and moments with the displacements and rotations. Linear approximation will be often used in this work. 


\section{Model Formulation}

\subsection{The Quasi-Static Problem}

This section describes the forces, moments and potential energies that result from the relative deformations of grains, starting from an unstressed body. These quantities can be calculated from kinematics, i.e., from the geometry of the pack. This section contains explicit formulae for calculating the forces, moments, and energies that will be used to obtain an equilibrium configuration.

A given 3D configuration requires knowing 6 degrees of freedom that describe the location and orientation of each sphere in space. From this knowledge, the displacement of each sphere with respect to its position in the undisturbed configuration can be obtained:

- $\boldsymbol{\delta} \boldsymbol{r}_{i}=\boldsymbol{r}_{i}-\boldsymbol{r}_{0 i}$ is the vector of linear displacements of the grain center with respect to a fixed coordinate system (mutual to all spheres), where $\boldsymbol{r}_{i}$ is the radius vector from a fixed origin of a cartesian coordinate system, see Figure 2, and subscript 0 denotes the initial unperturbed configuration. In this work, "unperturbed" relates to initial configuration which is either undeformed or prestressed. Section 4.3 exploits the fact that the initial configuration is prestressed, the normal force-displacement relation is further away from its highly non-linear part, and the contact area is further away from being a singular point. The total relative displacement of sphere $i$ w.r.t. sphere $j$ is $\boldsymbol{\delta} \boldsymbol{r}_{i j}=\boldsymbol{r}_{i}-\boldsymbol{r}_{0 i}-\left(\boldsymbol{r}_{j}-\boldsymbol{r}_{0 j}\right)$.

- $\boldsymbol{\Omega}_{i}$ is the rotation vector, i.e., rotation of each sphere around its center by a magnitude $\Omega_{i}$ and around an axis in the direction of $\boldsymbol{\Omega}_{i}$ (using the right-hand rule).

For a given configuration, we calculate the relative displacements of sphere $i$ with respect to each of its neighbors. From the displacements, we then calculate the sphere deformations at each contact. These deformations result in stresses. We wish to express the contact forces and moments acting on the spheres as functions of the displacements. Note that if the spheres are not in contact, no forces/moments are assumed to be acting between them, and since there is no deformation, no potential energy is associated with the relative displacements. Additional restrictions will enable us to linearize the relations and obtain a system of linear equations, see Section 4.3.

\subsection{Non-Frictional Contact}

Hertzian contact theory (Hertz, 1882) assumes that each body can be approximated by an elastic half-space. This assumption is based on the fact that the contact area is much smaller than the size of the body and its radius of curvature, and that the deformations are sufficiently small so that linear strain theory can be applied. It is observed that the contact stresses are highly concentrated close to the contact region, and they decrease rapidly in intensity with the distance from the contact area, so that the domain of influence lies close to the contact interface. With these assumptions, the following constitutive relation between the local deformations and the contact force holds (see Figure 3)

$$
\boldsymbol{P}_{i j}=\left[\frac{4}{3} E_{i j}^{*} \sqrt{R_{i j}^{*}} h_{i j}^{\frac{3}{2}}\right] \frac{\boldsymbol{r}_{i j}}{\left\|\boldsymbol{r}_{i j}\right\|}
$$




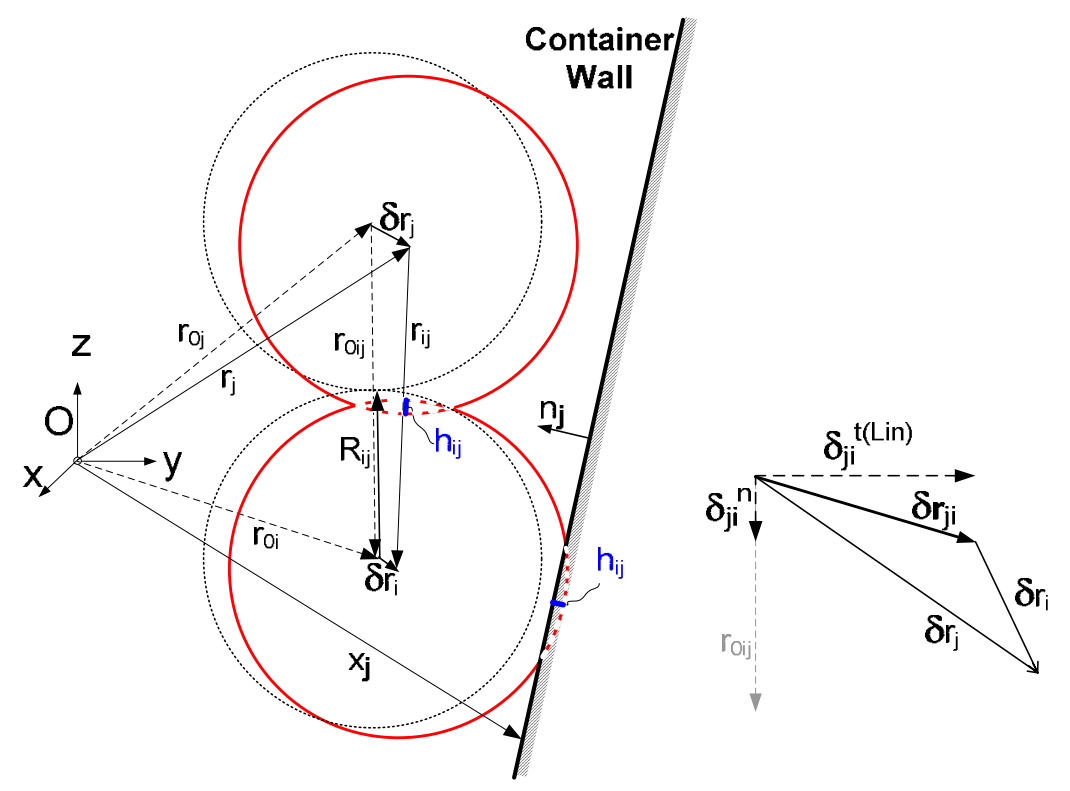

Figure 2: Schematic description of contact of two spherical grains, and a sphere in contact with a planar container wall. Dashed lines represent initial configuration. Left: Absolute displacements. Right: A zoom onto relative displacement components that are resolved into normal and tangential parts.

where $\boldsymbol{r}_{i j}=\boldsymbol{r}_{i}-\boldsymbol{r}_{j}$ is a vector between the center of sphere $j$ towards $i$, in the direction of compressive force on $i$ due to the contact with $j . h_{i j}=R_{i}+R_{j}-\left\|\boldsymbol{r}_{i j}\right\|$ is the mutual approach, i.e. the decrease of distance between the spheres from the state of initial contact at a point. Note that Eq. 1 is accounts only for the compressive force; thus, it is valid for $h_{i j} \geq 0 . R_{i}, E_{i}$ and $\nu_{i}$ are the radius, the Young's modulus, and the Poisson's ratio of grain $i$, respectively. $R^{*}$ and $E^{*}$ contain information about the curvatures and elastic properties of the two bodies in contact, and are defined as

$$
\begin{aligned}
\frac{1}{E_{i j}^{*}} & =\frac{\left(1-\nu_{i}^{2}\right)}{E_{i}}+\frac{\left(1-\nu_{j}^{2}\right)}{E_{j}} \\
\frac{1}{R_{i j}^{*}} & =\frac{1}{R_{i}}+\frac{1}{R_{j}}
\end{aligned}
$$

For the case of a grain in contact with a fixed planar wall (see Figure 2), the force is

$$
\boldsymbol{P}_{i j}=\left[\frac{4}{3} E_{i j}^{*} \sqrt{R_{i j}^{*}} h_{i j}^{\frac{3}{2}}\right] \boldsymbol{n}_{j}
$$

$h_{i j}=R_{i}-\left(\boldsymbol{r}_{i}-\boldsymbol{x}_{j}\right) \cdot \boldsymbol{n}_{j}, \boldsymbol{x}_{j}$ is the radius vector to an arbitrary point on the planar boundary $j$, and $\boldsymbol{n}_{j}$ is a unit inward normal to the container wall $j$, see Figure 2. Note that for a planar boundary, $R_{j} \rightarrow \infty$ so that $R_{i j}^{*} \rightarrow R_{i}$, see Eq. 2 . Hertzian contact theory also provides the radius of the contact area as

$$
a_{i j}=\left(\frac{3 P_{i j} R_{i j}^{*}}{4 E_{i j}^{*}}\right)^{\frac{1}{3}}=\sqrt{R_{i j}^{*} h_{i j}}
$$



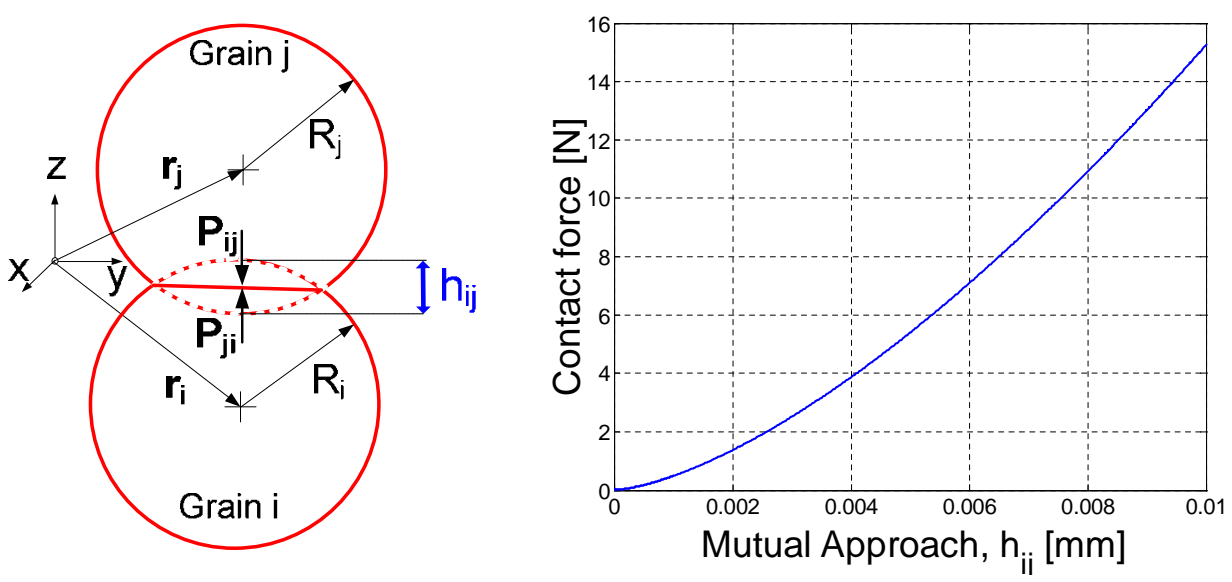

Figure 3: Hertzian model of contact of two spherical grains. The force $\boldsymbol{P}_{i j}$, is acting on grain $i$ at the interface with grain $j$. Left: Schematic description. Right: Force-displacement relation, for identical grains with radii of $0.1 \mathrm{~mm}, E=100 \mathrm{GPa}$ and $\nu=0.15$. Note that the nonlinear relation could be approximated by a linear function for larger displacements.

Since elastic forces are potential, the normal contact force is the gradient of the potential energy $U_{i j}^{n}$ accumulated by the action of that force, $\boldsymbol{P}_{i j}=-\frac{\partial U_{i j}}{\partial \boldsymbol{\delta} \boldsymbol{r}_{i j}}$. Thus, the deformation energy is identical to the work required to move the bodies by a given displacement with a given force. This energy can be calculated by integration of the contact force along the relative displacement (see, e.g. Eq. 9.15 in Landau and Lifshitz, 1986)

$$
U_{i j}^{n}=\int_{\boldsymbol{r}_{0 i j}}^{\boldsymbol{r}_{i j}} \boldsymbol{P}_{i j} \cdot d \boldsymbol{r}_{i j}^{\prime}=\frac{8 E_{i j}^{*} \sqrt{R_{i j}^{*}}}{15}\left(h_{i j}\right)^{\frac{5}{2}}
$$

where $\boldsymbol{r}_{0 i j}$ is the undeformed radius vector connecting center of sphere $j$ to $i$.

\subsection{Frictional Contact}

Since surfaces are never perfectly smooth, friction opposes tangential motion between bodies in contact. This friction causes tangential stresses/twisting moments to develop between the bodies, which in turn cause shear deformations/torsion, see Figure 4. As in the case of normal components, the deformations are considered to be localized, the parts of the bodies away from contact area will not deform and thus will experience tangential rigid displacements. These displacements will be used to calculate the tangential contact forces caused by the elastic deformation in the tangential direction. The formulae below were originally derived by Mindlin, 1949 .

To remain within theory of elasticity we will restrict this discussion to static friction only, where the bodies are stuck and no slip occurs. Singularities of streses/displacements at the edge of the contact area suggest that some slip always occurs. Slip will cause energy losses through friction, and forces can no longer be considered as potential. Thus, the applicability of the following formulae will be limited to small increments of forces/displacements applied to the spheres. This is because the compliance of a pair obtained with the no-slip assumption is identical with the initial compliance obtained from solutions which account for some 


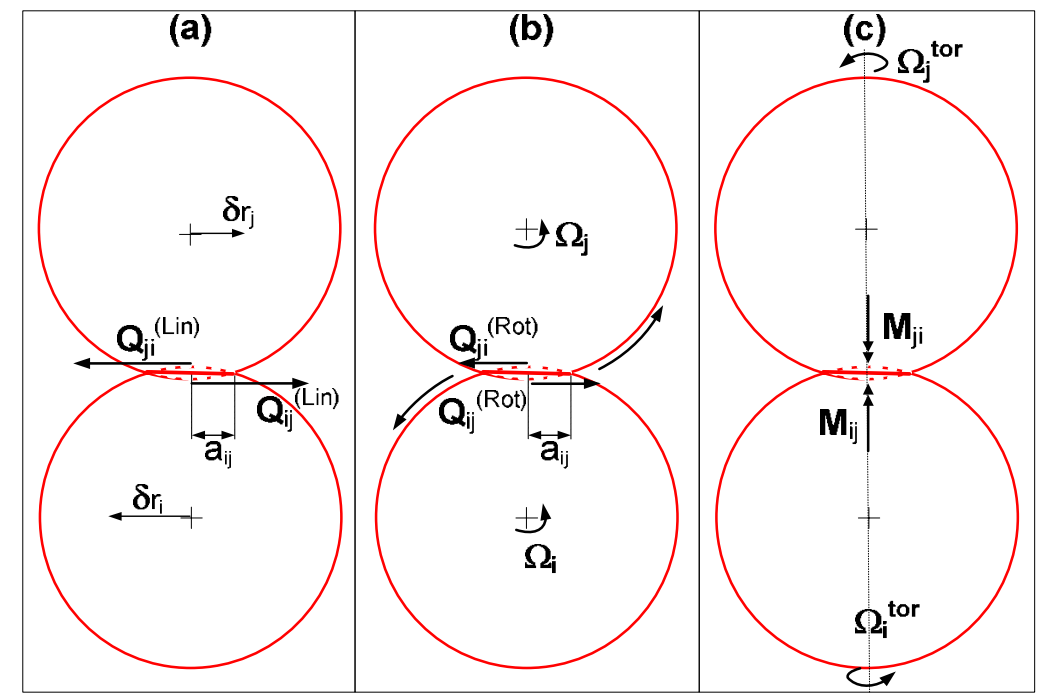

Figure 4: Forces and moments caused by tangential stresses/moments transferred at the contact of two bodies: (a) Relative tangential displacement; (b) Relative rotations around an axis which lies in the contact plane; (c) Relative rotations around an axis perpendicular to the contact plane.

slip (Deresiewicz, 1958). The influence of slip was thoroughly investigated in Mindlin and Deresiewicz, 1953.

The no-slip assumption implies that the shear stresses are everywhere smaller than the limiting friction, which could be determined by, e.g., Amonton's law of friction (Johnson, 1987). Due to symmetry, it is usually assumed (see, e.g. Mindlin, 1949, Mindlin and Deresiewicz, 1953 or Johnson, 1987) that the tangential forces do not have a major influence on the pressure distribution and thus on the contact area. Thus, these forces can still be determined using the contact area derived from the Hertzian contact theory, which is considered fixed with respect to the tangential components. This approximation decouples the normal and tangential components and simplifies the following derivations.

\subsubsection{Tangential Force Due to Relative Tangential Displacements}

This section deals with the symmetrically-distributed tangential stresses that do not cause twisting moments, but rather only moments around an axis parallel to the contact area. Ignoring slip, we assume that the contact surfaces are stuck, thus we approximate the tangential displacements at the interface as uniform. To obtain the tangential stress distribution that gives rise to uniform tangential displacement within the contact area, an analogy with the derivation of equations for the normal stresses leading to a uniform normal displacement (i.e. a rigid punch) is used. With this analogy, for contact of spherical bodies (Mindlin, 1949), the tangential stress $q$ is

$$
q(r)=q_{0}\left(1-r^{2} / a^{2}\right)^{-1 / 2}
$$

where $q$ is directed along the direction of the tangential displacement $u^{t}$ (no stresses appear in the perpendicular tangential direction), $a$ is the radius of the contact area, determined 
by Eq. 4, and $q_{0}$ is the tangential stress at the original contact point. The corresponding tangential displacement at the interface of sphere $i$ is

$$
u_{i}^{t}=q_{0} a \frac{\pi\left(2-\nu_{i}\right)}{4 G_{i}}
$$

where $G_{i}$ is the shear modulus of sphere $i$, or "modulus of rigidity". The pair of resultant tangential forces, $Q_{i j}^{(\operatorname{Lin})}=2 \pi a^{2} q_{0}$, that act on spheres $i, j$ at the contact interface, can be related to the total relative (rigid) displacement $\delta_{i j}^{t(\operatorname{Lin})}=\delta_{i}^{t(\operatorname{Lin})}-\delta_{j}^{t(\operatorname{Lin})}$ as $\delta_{i j}^{t(\operatorname{Lin})}=$ $\frac{Q_{i j}^{(\operatorname{Lin})}}{8 a_{i j}}\left(\frac{2-\nu_{i}}{G_{i}}+\frac{2-\nu_{j}}{G_{j}}\right)$. We may rewrite this expression in vector form:

$$
\boldsymbol{Q}_{i j}^{(L i n)}=-8 a_{i j}\left(\frac{2-\nu_{i}}{G_{i}}+\frac{2-\nu_{j}}{G_{j}}\right)^{-1} \boldsymbol{\delta}_{i j}^{t(\operatorname{Lin})}
$$

where the superscript $(\operatorname{Lin})$ denotes the fact that this tangential force is caused by the linear relative displacements. Another tangential force component can be attributed to relative rotations, and the total tangential force will be the sum of these vectors, see Figure 4.

The relative tangential displacement of sphere $i$ with respect to $j, \boldsymbol{\delta}_{i j}^{t(\operatorname{Lin})}$, which is caused by linear displacements of the two bodies, is obtained by subtracting the normal component of relative displacement from the total relative displacement $\boldsymbol{\delta} \boldsymbol{r}_{i j}$ (see Figure 2),

$$
\boldsymbol{\delta}_{i j}^{t(\operatorname{Lin})}=\boldsymbol{\delta} \boldsymbol{r}_{i j}-\boldsymbol{\delta}_{i j}^{n}
$$

where the normal component of relative displacement between 2 spheres can be found by the projection of $\boldsymbol{\delta} \boldsymbol{r}_{i j}$ along the original normal direction,

$$
\boldsymbol{\delta}_{i j}^{n}= \begin{cases}\left(\boldsymbol{\delta} \boldsymbol{r}_{i j} \cdot \frac{\boldsymbol{r}_{0 i j}}{\left\|\boldsymbol{r}_{0 i j}\right\|}\right) \frac{\boldsymbol{r}_{0 i j}}{\left\|\boldsymbol{r}_{0 i j}\right\|} & \text { for sphere-sphere contact } \\ \left(\left(\boldsymbol{\delta} \boldsymbol{r}_{i}-\boldsymbol{\delta} \boldsymbol{x}_{j}\right) \cdot \boldsymbol{n}_{j}\right) \boldsymbol{n}_{j} & \text { for contact with boundary }\end{cases}
$$

where $\boldsymbol{\delta} \boldsymbol{x}_{j}$ is the displacement of the planar container wall in the direction of its normal. Note that the lower expression in Eq. 10 will be different if the walls are also rotated. The minus sign in Eq. 8 is due to the fact that the tangential force that acts on sphere $i, \boldsymbol{Q}_{i j}^{(\operatorname{Lin})}$, is in the direction opposite to the rigid tangential motion $\boldsymbol{\delta}_{i j}^{t(\text { Lin })}$. The anti-symmetry of $i$ and $j$ in Eq. 8 is expected, since the tangential force that acts on the two spheres (from both sides of the interface) should be equal in magnitude and opposite in direction. Eq. 8 shows a linear relation between the tangential displacement and the force. This is different than the normal loading case, where the nonlinearity is due to the change in contact area with the pressure. Finally, since the stress distribution in Eq. 6 leads to infinite tangential stresses at the edges of the contact area, partial slip at the edges is expected. This slip is ignored in the current formulation.

\subsubsection{Tangential Force Due to Relative Rotation}

Relative rotation with a rotation axis that is parallel to the contact plane, appears as a relative tangential displacement at the contact. This rotation axis is perpendicular to the line adjoining the sphere centers at the initial configuration, see Figure 4. This displacement 
will exert tangential forces on the contact area, which could be estimated by Eq. 8, using the respective $\boldsymbol{Q}$ and $\delta_{i j}^{t}$ caused by this rotation. Note that this is an approximation, since the distribution of tractions will be different in the case of pure rotation around a horizontal axis and relative tangential displacement, even if the tangential resultant force is the same. Moreover, if the contact area is not perfectly planar and orthogonal to the line adjoining the spheres centers, rotation will exert normal tractions. Hertz-Mindlin theory neglects this effect (Mindlin, 1949), since the radius of curvature is much larger than the radius of the contact area, which in turn is considered planar.

Consider a pair of spheres compressed together with a normal force $P$ so that each sphere is rotating around its center. These rotations are characterized by the rotation vectors $\boldsymbol{\Omega}_{i}$ and $\boldsymbol{\Omega}_{j}$, respectively. These rotations are rigid everywhere except a neighborhood of the contact areas. Again, at the contact it is assumed that there is no slip, i.e., the tangential traction is everywhere smaller than the pressure times the limiting friction coefficient. The no-slip assumption implies that the spheres remain "stuck" together at the contact interface, so that the tangential displacements of both spheres are uniform and identical from both sides of the contact area. As before, the contact area is assumed fixed and is calculated using the normal components. The relative tangential component of the elastic displacement at the interface $\boldsymbol{\delta}_{i}^{t(R o t)}$, relative to the center of the contact area, is calculated from the rotation of sphere $i$ by the cross-product:

$$
\left.\boldsymbol{\delta}_{i}^{t(R o t)}\right|_{j=\text { fixed }}=\boldsymbol{\Omega}_{i} \times \boldsymbol{R}_{i j}
$$

where the superscript Rot denotes the fact that this tangential displacement component arises from rotation, and $\boldsymbol{R}_{i j}$ is a vector of magnitude $R_{i}$ (radius of sphere $i$ ) directed along the line from the unperturbed center of sphere $i$ to the center of the contact area with sphere $j$,

$$
\boldsymbol{R}_{i j}= \begin{cases}\boldsymbol{r}_{0 j i} \frac{R_{i}}{R_{i}+R_{j}} & \text { for sphere-sphere contact } \\ R_{i} \boldsymbol{n}_{j} & \text { for contact with boundary }\end{cases}
$$

Note that for rotation vectors that do not lie in the contact plane, torsion will develop at the interface. This torsion is discussed in the next section. However, as this component of rotation is aligned with $\boldsymbol{R}_{i j}$, one can use the total rotation vector in Eq. 11, without decomposing it. The component responsible for torsion will not produce tangential forces, as the cross-product will exclude it.

For the case of contact with a fixed boundary $j, \boldsymbol{\Omega}_{j}=\mathbf{0}$, so that $\boldsymbol{\delta}_{i}^{t(R o t)}$ is the relative rotation with respect to $j$, denoted by $\boldsymbol{\delta}_{i j}^{t(R o t)}$. For the contact of two spheres, one needs to superimpose the effect of the rotations of the two to obtain the total effect. Note that summing up the displacements and obtaining the force is identical to summing the two forces resulting from the rotation of each sphere, while the other sphere is held fixed. Rotation vectors can not be superimposed, in general, as order matters. However, since we are interested in the relative tangential displacement due to these rotations, we can use the fact that linear displacements are cumulative. It is then possible to calculate the tangential displacement of sphere $i$ with respect to $j$ as 


$$
\begin{aligned}
\boldsymbol{\delta}_{i j}^{t(R o t)} & =\boldsymbol{\Omega}_{i} \times \boldsymbol{R}_{i j}-\boldsymbol{\Omega}_{j} \times \boldsymbol{R}_{j i} \\
& =-\frac{1}{R_{i}+R_{j}}\left[\left(R_{i} \boldsymbol{\Omega}_{i}+R_{j} \boldsymbol{\Omega}_{j}\right) \times \boldsymbol{r}_{0 i j}\right]
\end{aligned}
$$

and obtain the tangential resultant force acting on each sphere using $\boldsymbol{\delta}_{i j}^{t(R o t)}$ as the tangential displacement in Eq. 8.

\subsubsection{Total Tangential Force}

To obtain the total tangential displacement, $\boldsymbol{\delta}_{i j}^{t}$, from linear displacement and rotation, the two corresponding tangential displacement vectors should be summed, $\boldsymbol{\delta}_{i j}^{t}=\boldsymbol{\delta}_{i j}^{t(\operatorname{Lin})}+\boldsymbol{\delta}_{i j}^{t(\operatorname{Rot})}$. In the case of a contact of two spheres, this vector is

$$
\boldsymbol{\delta}_{i j}^{t}=\boldsymbol{\delta} \boldsymbol{r}_{i j}-\left(\boldsymbol{\delta} \boldsymbol{r}_{i j} \cdot \frac{\boldsymbol{r}_{0 i j}}{\left\|\boldsymbol{r}_{0 i j}\right\|}\right) \frac{\boldsymbol{r}_{0 i j}}{\left\|\boldsymbol{r}_{0 i j}\right\|}-\frac{1}{R_{i}+R_{j}}\left[\left(R_{i} \boldsymbol{\Omega}_{i}+R_{j} \boldsymbol{\Omega}_{j}\right) \times \boldsymbol{r}_{0 i j}\right]
$$

whereas for the case of contact with a planar boundary, it is

$$
\boldsymbol{\delta}_{i j}^{t}=\boldsymbol{\delta} \boldsymbol{r}_{i}-\left[\left(\boldsymbol{\delta} \boldsymbol{r}_{i}-\boldsymbol{\delta} \boldsymbol{x}_{j}\right) \cdot \boldsymbol{n}_{j}\right] \boldsymbol{n}_{j}+R_{i} \boldsymbol{\Omega}_{i} \times \boldsymbol{n}_{j}
$$

Here, as before, $\boldsymbol{\delta} \boldsymbol{x}_{j}$ is the displacement of the wall in the direction of its normal, and this normal direction is fixed. Rotation of the walls will introduce a different expression than the one in Eq. 15. Using the total tangential displacement in Eq. 8 provides tangential force from relative tangential displacements and rotations:

$$
\boldsymbol{Q}_{i j}\left(\boldsymbol{\delta}_{i j}^{t}\right)=-8 a_{i j}\left(\frac{2-\nu_{i}}{G_{i}}+\frac{2-\nu_{j}}{G_{j}}\right)^{-1} \boldsymbol{\delta}_{i j}^{t}
$$

\subsubsection{Elastic Torsion and Twisting Moments}

Relative rotation around an axis directed along the line connecting the centers induces torsional deformation that exerts a twisting moment, see Figure 2. Note that in this case, only a moment is transferred through the contact area, whereas the resultant force is zero, i.e., we are dealing with a force couple. Similarly to the development of tangential forces, it is assumed that the bodies rotate rigidly everywhere except for a neighborhood of the contact areas, where elastic deformation is assumed. Since it is assumed that there is no slip, and that no normal traction component or distortion in the contact plane results from this rotation (Mindlin, 1949 and Deresiewicz, 1958), these moments will induce only torsion.

Consider a pair of identical spheres with similar elastic properties. The torsional compliance that relates the moment to the rotation angle in the case of twisting couple of magnitude $M_{i j}^{\text {tor }}$ is (Mindlin, 1949)

$$
M_{i j}^{t o r}=\frac{8}{3} G a_{i j}^{3} \Omega_{i j}^{t o r}
$$


where $\Omega_{i j}^{t o r}$ is the relative rotation of the two bodies in a direction normal to the contact surface. It is denoted by the superscript tor. The direction of the moment can be found since the moment opposes the direction of rotation. To obtain the relative rotation, we will use the fact that we eventually deal with the incremental formulation, i.e. small deformations. We consider infinitesimal rotation of the spheres around their centers, $\boldsymbol{\Omega}_{i}$. The component of rotation of each sphere around an axis which is perpendicular to the contact surface would be $\left.\boldsymbol{\Omega}_{i}^{\text {tor }}\right|_{j=\text { fixed }}=\left(\boldsymbol{\Omega}_{i} \cdot \frac{\boldsymbol{r}_{0 i j}}{\left\|\boldsymbol{r}_{0 i j}\right\|}\right) \frac{\boldsymbol{r}_{0 i j}}{\left\|\boldsymbol{r}_{0 i j}\right\|}$. For contact with another sphere, the rotation of that sphere around the same axis is $\left.\boldsymbol{\Omega}_{j}^{\text {tor }}\right|_{i=\text { fixed }}=\left(\boldsymbol{\Omega}_{j} \cdot \frac{\boldsymbol{r}_{0 j i}}{\left\|\boldsymbol{r}_{0 j i}\right\|}\right) \frac{\boldsymbol{r}_{0 j i}}{\left\|\boldsymbol{r}_{0 j i}\right\|}$. Since these rotations are around the same axis, the relative rotation of $i$ with respect to $j$ is obtained by taking the difference, as

$$
\left.\boldsymbol{\Omega}_{i j}^{t o r}=\boldsymbol{\Omega}_{i}^{t o r}-\boldsymbol{\Omega}_{j}^{t o r}=\left[\left(\boldsymbol{\Omega}_{i}-\boldsymbol{\Omega}_{j}\right) \cdot \boldsymbol{r}_{0 i j}\right)\right] \frac{\boldsymbol{r}_{0 i j}}{\left\|\boldsymbol{r}_{0 i j}\right\|^{2}}
$$

where for contact with a fixed plane, $\boldsymbol{\Omega}_{i j}^{t o r}=\left.\boldsymbol{\Omega}_{i}^{t o r}\right|_{j=\text { fixed }}$. For the case of non-uniform elastic properties, the relation in Eq. 17 will transform into (Johnson, 1987)

$$
\boldsymbol{M}_{i j}^{t o r}=-\frac{16}{3} a_{i j}^{3}\left(\frac{1}{G_{i}}+\frac{1}{G_{j}}\right)^{-1} \boldsymbol{\Omega}_{i j}^{t o r}
$$

where $\boldsymbol{M}_{i j}^{\text {tor }}$ is the moment applied on sphere $i$ by sphere $j$ due to a relative rotation of $\boldsymbol{\Omega}_{i j}^{t o r}$.

As in the case of tangential displacements, singularities at the edge of the contact area suggest that some slip in a circumferential direction takes place over an annular area. This restricts the use of Eq. 19 to cases where the limiting friction is large relative to the stresses developed in the contact area. Intuitively, the stresses produced by this motion would be smaller compared with those created by tangential displacements and rotation around horizontal axis; however, twisting has a very important role in determining the strength of contact (Hills, 1986), and should be considered carefully when the model also includes failure of cemented bonds.

\subsubsection{Moments}

Assuming spherical grains simplifies the problem, the normal force induced at the contacts acts along the line connecting the centers, and thus does not affect the moments. Note that we are assuming small deformations so that grains remain spherical, and the center of mass remains at the sphere center. The tangential forces, Eq. 16, however, do create a moment with respect to the center of each sphere. Since the deformations are small, the tangential forces at the contacts can be considered as acting at the center of the contact area, which is the original contact point before perturbation applied. Thus the arm from sphere $i$ to the center of the contact area is described by $\boldsymbol{R}_{i j}$, see Eq. 12. The moments are calculated by the cross product of the arm and the force, so that the moment acting on sphere $i$, produced by the tangential force $\boldsymbol{Q}_{i j}$, is ${ }^{1}$

$$
\boldsymbol{M}_{i j}^{t}=\boldsymbol{R}_{i j} \times \boldsymbol{Q}_{i j}
$$

\footnotetext{
${ }^{1}$ Note that the force is perpendicular to the arm, so that the magnitude of the moment is $\operatorname{simply} R_{i}\left\|\boldsymbol{Q}_{i j}\right\|$. The vectorial notation is needed though for determining the direction of the moment.
} 
Note that this moment is a function of both linear tangential displacements and rotations around an axis parallel to the contact plane. Upon inserting the explicit expressions for $\boldsymbol{R}_{i j}$ and $\boldsymbol{Q}_{i j}$, one could simplify the resulting equation, using the fact that cross products of parallel vectors will vanish. Using the formula for vector triple product (Aris, 1989), $\boldsymbol{A} \times(\boldsymbol{B} \times \boldsymbol{C})=\boldsymbol{B}(\boldsymbol{A} \cdot \boldsymbol{C})-\boldsymbol{C}(\boldsymbol{A} \cdot \boldsymbol{B})$, obtain

$$
\begin{aligned}
\boldsymbol{M}_{i j}^{t}= & -8 a_{i j}\left(\frac{2-\nu_{i}}{G_{i}}+\frac{2-\nu_{j}}{G_{j}}\right)^{-1} \frac{R_{i}}{R_{i}+R_{j}}\left\{-\boldsymbol{r}_{0 i j} \times \boldsymbol{\delta} \boldsymbol{r}_{\boldsymbol{i j}}\right. \\
& \left.+\frac{1}{R_{i}+R_{j}}\left(\left\|\boldsymbol{r}_{0 i j}\right\|^{2}\left(R_{i} \boldsymbol{\Omega}_{i}+R_{j} \boldsymbol{\Omega}_{j}\right)-\boldsymbol{r}_{0 i j}\left[\boldsymbol{r}_{0 i j} \cdot\left(R_{i} \boldsymbol{\Omega}_{i}+R_{j} \boldsymbol{\Omega}_{j}\right)\right]\right)\right\}
\end{aligned}
$$

for the case of sphere-sphere contact, and

$$
\boldsymbol{M}_{i j}^{t}=-8 a_{i j}\left(\frac{2-\nu_{i}}{G_{i}}+\frac{2-\nu_{j}}{G_{j}}\right)^{-1} R_{i}\left[\boldsymbol{n}_{j} \times \boldsymbol{\delta} \boldsymbol{r}_{i}+R_{i} \boldsymbol{\Omega}_{i}-\boldsymbol{n}_{j}\left(\boldsymbol{n}_{j} \cdot R_{i} \boldsymbol{\Omega}_{i}\right)\right]
$$

for the case of sphere-wall contact. Note that $\boldsymbol{M}_{i j}^{t}$ in Eq. 21 and Eq. 22 is calculated with respect to the center of the sphere, so the sum of moments on each sphere with respect to its center, due to tangential loading, is simply the sum of all those moment vectors. The total sum of moments should include the torsional moments (which is a function of relative rotations around an axis perpendicular to the contact plane),

$$
\boldsymbol{M}_{i}=\sum_{j=1}^{N_{c}^{i}}\left[\boldsymbol{M}_{i j}^{t}+\boldsymbol{M}_{i j}^{t o r}\right]
$$

where $N_{c}^{i}$ is the number of contacts for sphere $i$. This sum should be used as the residual moment of each sphere, which in turn will be used to find the equilibrium configuration. Both the residual force and moment acting on each sphere could be used as microscopic measures of equilibrium, i.e. estimating the deviation from the equilibrium, e.g. by summing up the squared norms of these vectors.

\subsubsection{Elastic Strain Energy}

The energy stored in elastic deformations of a neighborhood of a contact is the so-called "strain energy", analogous to the energy stored in a spring. This energy is calculated as work done by the stresses over the strains. Since the forces/stresses change during deformation, obtaining the energy requires evaluation of an integral. Because the elastic forces and moments are considered to be acting in a potential field, a simplified calculation can be done by considering the resultant forces/moments and displacements/rotations at the contact, i.e. by calculating the work done by those.

Assuming quasi-static case, where the kinetic energy can be neglected, the change in potential energy due to such forces/moments applied over an increment of displacement can be calculated by

$$
\delta U=\int_{\boldsymbol{x}_{0}}^{\boldsymbol{x}_{0}+\boldsymbol{\delta} \boldsymbol{x}} \boldsymbol{F}\left(\boldsymbol{x}^{\prime}\right) \cdot d \boldsymbol{x}^{\prime}+\int_{\boldsymbol{\Omega}_{0}}^{\boldsymbol{\Omega}_{0}+\boldsymbol{\delta} \boldsymbol{\Omega}} \boldsymbol{M}\left(\boldsymbol{\Omega}^{\prime}\right) \cdot d \boldsymbol{\Omega}^{\prime}
$$


where $\boldsymbol{x}$ is the radius vector to the center of the spherical grain, $\boldsymbol{\Omega}$ is the rotation around an axis passing through the center, $\boldsymbol{F}$ is the total force acting at that point and $\boldsymbol{M}$ is the moment applied with respect to the center. In the one dimensional case, the energy is $U\left(x^{\prime}\right)=-\int_{0}^{x} F\left(x^{\prime}\right) d x^{\prime}$. The minus sign is omitted in the derivations since the force in the above equation is the external force, while we will use the reaction force due to the elastic deformation in my derivations. The energy stored in the deformations is equal to the work done by the contact force/moment over the corresponding relative displacement/rotation. Keep in mind that the relative displacements/rotation and forces/moments for the two bodies are always equal in magnitude and opposite in sign.

Noting that the dot product is identically zero for a pair of orthogonal vectors, and using the assumption that the tangential and rotational components do not alter the normal pressure or the contact area, the energy related to the normal force is determined by Eq. 5 even when oblique forces/moments are applied at the contact. For the same reason, the change in energy due to tangential forces, produced both by relative tangential displacement and rotations, is decoupled from the energy pertinent to the normal forces, and can be calculated separately. Both these energy increments can be calculated independently of the twisting moment, since this moment and the torsional component of rotation are perpendicular to the component of rotation parallel to the contact area.

Following the above argument, the elastic potential energy related to the tangential forces transmitted through the contact area, is evaluated by integrating dot product of the total tangential force with the linear displacement,

$$
U_{i j}^{t}=\int_{\boldsymbol{r}_{0 i j}}^{\boldsymbol{r}_{i j}} \boldsymbol{Q}_{i j} \cdot d \boldsymbol{r}_{i j}^{\prime}
$$

Note that this displacement and tangential force should include the contribution due to the rotation. Since the work of a potential force is path-independent, one can use any path for the integration. We use a linear path, parameterizing the displacements from $\boldsymbol{r}_{0 i j}$ to $\boldsymbol{r}_{i j}=\boldsymbol{r}_{0 i j}+\delta \boldsymbol{r}_{i j}$ as $\boldsymbol{\delta} \boldsymbol{r}_{i j}(s)=s \boldsymbol{\delta} \boldsymbol{r}_{i j}$, where $s$ is a scalar parameter which varies between 0 and 1. $s=0$ and $s=1$ are the initial and disturbed configuration, respectively. With this, the integration is done over $d \boldsymbol{r}_{i j}^{\prime}=\boldsymbol{\delta} \boldsymbol{r}_{i j} d s$, where only quantities which depend on $\boldsymbol{\delta} \boldsymbol{r}_{i j}$ are functions of $s$ within that integral, i.e.

$$
U_{i j}^{t}=\int_{s=0}^{s=1} \boldsymbol{Q}_{i j}(s) \cdot \boldsymbol{\delta} \boldsymbol{r}_{i j} d s
$$

Because $\boldsymbol{Q}_{i j}$ is linear with respect to the tangential displacement, see Eq. 14, and this displacement is proportional to the total relative displacement, one can use the same parameter $s$ in Eq. 14, replacing $\boldsymbol{\delta} \boldsymbol{r}_{i j}^{t}(s)$ by $s \boldsymbol{\delta} \boldsymbol{r}_{i j}^{t}$. Taking out the constant parts in Eq. 26 and integrating over $s$ from 0 to 1 , we get $U_{i j}^{t}=4 a_{i j}\left(\frac{2-\nu_{i}}{G_{i}}+\frac{2-\nu_{j}}{G_{j}}\right)^{-1} \boldsymbol{\delta}_{i j}^{t} \cdot \boldsymbol{\delta} \boldsymbol{r}_{i j}$. Note that this is only true as a first approximation, since $a_{i j}$ depends on the normal force/displacement. If an exact result rather than approximation is desired, rigorous calculation should be made where $a_{i j}$ is a function of $s$, thus remaining within the integrand. One should always keep in mind that the approximation obtained here applies only to the case of small increments.

Since the dot product eliminates the normal component of the displacement, $\delta r_{i j}$ in the above equation can be replaced with $\boldsymbol{\delta}_{i j}^{t}$. This will make the equation quadratic with respect 
to $\delta_{i j}^{t}$ :

$$
U_{i j}^{t}\left(\boldsymbol{r}_{i}, \boldsymbol{r}_{j}, \boldsymbol{\Omega}_{i}, \boldsymbol{\Omega}_{j}\right)=4 a_{i j}\left(\frac{2-\nu_{i}}{G_{i}}+\frac{2-\nu_{j}}{G_{j}}\right)^{-1}\left\|\boldsymbol{\delta}_{i j}^{t}\right\|^{2}
$$

Since $\boldsymbol{\delta}_{i j}^{t}$ includes both linear and angular relative displacements, it is a function of $\boldsymbol{r}_{i}, \boldsymbol{r}_{j}, \boldsymbol{\Omega}_{i}, \boldsymbol{\Omega}_{j}$. Using the same reasoning, the energy associated with the torsion, calculated as the integral of the moment along the rotation angle, is

$$
U_{i j}^{t o r}=\frac{8}{3} a_{i j}^{3}\left(\frac{1}{G_{i}}+\frac{1}{G_{j}}\right)^{-1}\left\|\Omega_{i j}^{t o r}\right\|^{2}
$$

where $\left\|\boldsymbol{\Omega}_{i j}^{\text {tor }}\right\|$ is the magnitude of the relative torsional rotation between the spheres, see Eq. 18. Note that because the contact area affects both the the tangential force and moments, and thus the associated energy (Eq. 27 and Eq. 28), those quantities are explicit functions of the normal component. As a technical note, using Eq. 27 and Eq. 28 within the computations should be done only for the case of bodies in contact.

\section{Solving for Equilibrium Configuration}

\subsection{Variational Formulation}

The elastic potential energy associated with elastic deformations is the sum of contributions required for the normal and tangential displacements (including the rotation parallel to the contact area), torsion, and gravitational potential energy. Equilibrium configuration is obtained when the following two quantities vanish on each sphere: (a) the sum of forces, and (b) the sum of moments. To use the potential energy to obtain equilibrium configuration, we will minimize a functional which includes the total potential energy of the pack: the sum of energies associated with all spheres/contacts. These quantities are a function of the relative linear displacements and rotations, thus $\Pi=\Pi\left(\boldsymbol{r}_{1}, \boldsymbol{r}_{2}, \ldots, \boldsymbol{r}_{N N}, \boldsymbol{\Omega}_{1}, \boldsymbol{\Omega}_{2}, \ldots, \boldsymbol{\Omega}_{N N}\right)$, as

$$
\Pi=\frac{1}{2} \sum_{i j=1}^{N_{c s}}\left[U_{i j}^{n}+U_{i j}^{t}+U_{i j}^{t o r}\right]+\sum_{i w=1}^{N_{c w}}\left[U_{i w}^{n}+U_{i w}^{t}+U_{i w}^{t o r}\right]-\sum_{i=1}^{N} m_{i} g \boldsymbol{\delta}_{i} \cdot\left(-\hat{\boldsymbol{e}}_{z}\right)
$$

where $i j$ and $i w$ denotes the contact between sphere $i$ and sphere $j$ /boundary $w$, respectively. There are $N_{c s}$ grain-grain contacts, and $N_{c w}$ grain-wall contacts. $N$ is the total number of grains, $m_{i}$ is the mass of grain $i, g$ is the gravitational acceleration, and $\hat{\boldsymbol{e}}_{z}$ is a unit vector pointing upwards (opposite to the gravitational acceleration). The minus sign in the last term is due to the fact that the work done by the weight is done by the sphere itself, i.e., it reduces the potential energy of the sphere. The factor of $1 / 2$ arises because summing over all contacts of all spheres results in counting each sphere-sphere contact twice. Using $\boldsymbol{r}_{1}, \boldsymbol{r}_{2}, \ldots, \boldsymbol{r}_{N}, \boldsymbol{\Omega}_{1}, \boldsymbol{\Omega}_{2}, \ldots, \boldsymbol{\Omega}_{N}$ as generalized coordinates, and minimizing $\Pi$ with respect to these coordinates, is equivalent to solving the system of force and moment equilibrium equations, 2 vectorial equations for each grain, i.e., $N \times 6$ in three dimensions.

An important observation is that in the Hertz-Mindlin theory, the normal force components and the respective stored energy $\left(U_{i j}^{n}\right)$ are known at every configuration, even if the 
undeformed configuration is unknown. This is because for normal components only the distance matters, and the undeformed distance is the sum of the radii, which is known. However, for the tangential components, one needs to know the undeformed configuration. Thus, it becomes "path-dependent", in the sense that one needs to know what was the undeformed state. This will pose a problem in accounting for the frictional contacts in a prestressed pack, where the undeformed state is not known.

\subsection{Incremental Case}

To consider deformations of granular materials during hydrate dissociation, we now address the case of a prestressed pack. For example, consider a rock or unconsolidated sediment prestressed by the weight of the overburden layers above. For this problem, one needs to determine a new equilibrium configuration after a small perturbation has been introduced starting from some "undisturbed" or "prestressed" equilibrium. The case of a prestressed pack is treated differently than the case an undeformed pack, as the displacement history, which is needed to obtain the tangential/rotationl components, is unknown. To obtain the

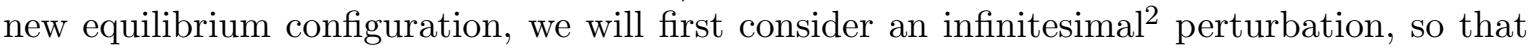
the resulting displacements are infinitesimal as well. Resorting to the incremental formulation allow us to use linearized constitutive relations. The equilibrium configuration associated with the perturbation will be found by minimizing the change in energy from its initial state.

Applying a sequence of such incremental changes and integrating provides an equilibrium configuration associated with the final finite change. Note that it may be that some other equilibrium configuration with lower energy may be attained by applying the change at once. However, since we only seek for local minimum, this is not a problem. Even though at the undisturbed configuration the tangential forces, moments, and associated energies are unknown, its equilibrium energy is a minimum, and the next equilibrium corresponding to the minimal energy of the perturbed configuration is attained when the increment of energy is also minimal. Equivalent argument is that since at equilibrium the sum of forces and moments on each grain is zero, the residuals could be calculated from the increments of forces and moments.

\subsection{Linear Formulation}

In this section we linearize the relations which are involved in calculating the forces and energies with respect to small increments of the parameters $\boldsymbol{r}_{i}, \boldsymbol{\Omega}_{i}(i=1,2, . ., N)$, i.e., with the linear and rotational displacements. The linearization is justified by using small increments, and because the force-displacement relation for the normal component is approaching a linear function as the contact area gets larger, see Figure 3. Let $U_{0}$ be the potential energy of some initial, stressed configuration. Due to a perturbation in the boundary conditions (walls placements), the pack will transform to a new configuration, whose energy is $U=U_{0}+\delta U$. The new equilibrium configuration is characterized by the minimum of the increment $\delta U$. Assuming that the perturbation is small, we can express $\delta U$ as a quadratic function of the increment of the grain positions. To obtain a quadratic expression, we need to linearize the

\footnotetext{
${ }^{2}$ Infinitesimal in this context means that it is small enough for the linear theory to apply within certain accuracy.
} 
force-displacement and moment-displacement/rotation relations.

Noting that tangential forces and moments are linear with tangential displacements and rotations, it is necessary to use the assumption of decoupled tangential-normal components. With this assumption, as the contact area is calculated from the normal contact force, and is assumed to be fixed for every increment, one obtains a linear relation (and quadratic expression for the energy). However, we still need to linearize the normal components. The linearization is done by expanding the expression for normal forces as a function of location near an undisturbed reference configuration. This results in an approximation for the increment in the energy associated with normal components, which is accurate up to quadratic terms.

This procedure is sensible only for a prestressed configuration, where for all contacts the contact area is assumed to be far enough from being singular, see Figure 3. There might be a small number of grains with small contact areas, which might lose contact due to a small incremental displacement. In that case, the values of forces, moments and potential energies associated with those particular contacts should be identically zero, and not calculated using the linear formulae. Other new contacts might form due to the incremental displacement, and the forces there should be calculated using the full nonlinear formulation, as in Section 3.1. Note that if losses/gains of contacts will happen to a relatively small number of grains in the pack, the overall effect on the calculations should be small. Due to the multiplicity of the contacts in granular media, it becomes a statistical issue to determine how many of the contacts need to be in such state for this approximation to be valid.

Starting with the normal components, it is necessary to linearize the forces and energy with respect to the position vectors. Noting that rotation vector does not affect the normal components, the force will be expressed as a linear function of the displacements. Note that both the direction and the magnitude of the force vector in Eq. 1 depends on the displacement, so both will be linearized by

$$
\boldsymbol{P}_{i j}\left(\boldsymbol{r}_{0 i j}, \boldsymbol{\delta} \boldsymbol{r}_{i j}\right) \approx \boldsymbol{P}_{0 i j}\left(\boldsymbol{r}_{0 i j}\right)+\boldsymbol{\delta} \boldsymbol{P}_{\boldsymbol{i j}}\left(\boldsymbol{r}_{0 i j}, \boldsymbol{\delta} \boldsymbol{r}_{i j}\right)=\boldsymbol{P}_{0 i j}+\left.\nabla \boldsymbol{P}_{i j}\right|_{\boldsymbol{\delta} \boldsymbol{r}_{i j}=0} \cdot \boldsymbol{\delta} \boldsymbol{r}_{i j}
$$

where $\boldsymbol{P}_{0 i j}$ is obtained by using the undisturbed geometry, i.e., $\boldsymbol{r}_{0 i j}$ in Eq. 1, and the gradient tensor is defined by $\left.\nabla \boldsymbol{P}_{i j}\right|_{\delta \boldsymbol{r}_{i j}=0}=\left.\frac{\partial \boldsymbol{P}_{0 i j}}{\partial \boldsymbol{\delta} \boldsymbol{r}_{i j}}\right|_{\boldsymbol{\delta} \boldsymbol{r}_{i j}=0}$. For a sphere-sphere contact, this gradient is given by

$$
\left.\nabla \boldsymbol{P}_{i j}\right|_{\delta \boldsymbol{r}_{i j}=0}=\frac{4}{3} E_{i j}^{*} \sqrt{R_{i j}^{*}}\left\{\frac{\left(h_{0 i j}\right)^{\frac{3}{2}}}{\left\|\boldsymbol{r}_{0 i j}\right\|} \mathbf{1}-\frac{\sqrt{h_{0 i j}}}{\left\|\boldsymbol{r}_{0 i j}\right\|^{3}}\left(\frac{3}{2}\left\|\boldsymbol{r}_{0 i j}\right\|+h_{0 i j}\right)\left(\boldsymbol{r}_{0 i j} \otimes \boldsymbol{r}_{0 i j}\right)\right\}
$$

where $\mathbf{1}$ is the unit tensor, i.e., the second order diagonal tensor with 1 s along the diagonal, and $h_{0 i j}=R_{i}+R_{j}-\left\|\boldsymbol{r}_{0 i}-\boldsymbol{r}_{0 j}\right\|$ is the undisturbed mutual approach. The dot product of this expression with $\boldsymbol{\delta} \boldsymbol{r}_{i j}$ (see Eq. 30) provides the linear increment in force,

$$
\boldsymbol{\delta} \boldsymbol{P}_{\boldsymbol{i} \boldsymbol{j}}=\frac{4}{3} E_{i j}^{*} \sqrt{R_{i j}^{*}}\left\{\frac{\left(h_{0 i j}\right)^{\frac{3}{2}}}{\left\|\boldsymbol{r}_{0 i j}\right\|} \boldsymbol{\delta} \boldsymbol{r}_{i j}-\frac{\sqrt{h_{0 i j}}}{\left\|\boldsymbol{r}_{0 i j}\right\|^{3}}\left(\frac{3}{2}\left\|\boldsymbol{r}_{0 i j}\right\|+h_{0 i j}\right)\left(\boldsymbol{r}_{0 i j} \cdot \boldsymbol{\delta} \boldsymbol{r}_{i j}\right) \boldsymbol{r}_{0 i j}\right\}
$$


For a contact between a sphere and a planar boundary, we note that the mutual approach is already linear with respect to the displacement of the sphere, see Eq. 3. Then, for a fixed orientation of the boundary $\left(\boldsymbol{n}_{j}\right)$, the increment in force simplifies to

$$
\boldsymbol{\delta} \boldsymbol{P}_{\boldsymbol{i j}}=-2 E_{i j}^{*} \sqrt{R_{i j}^{*} h_{0 i j}}\left(\left(\boldsymbol{\delta} \boldsymbol{r}_{i}-\boldsymbol{\delta} \boldsymbol{x}_{j}\right) \cdot \boldsymbol{n}_{j}\right) \boldsymbol{n}_{j}
$$

To express $U_{i j}^{n}$ as a quadratic function of the displacements, it will be calculated by integrating the linear force (Eq. 30) along the relative displacement, see Eq. 5:

$$
\delta U_{i j}^{n}=\int_{\boldsymbol{r}_{i j}}^{\left(\boldsymbol{r}_{i j}+\boldsymbol{\delta} \boldsymbol{r}_{i j}\right)}\left(\boldsymbol{P}_{0 i j}+\boldsymbol{\delta} \boldsymbol{P}_{\boldsymbol{i j}}\right) \cdot d \boldsymbol{r}_{i j}^{\prime}
$$

As before, the integration can be simplified upon parameterizing the displacements as $\boldsymbol{\delta} \boldsymbol{r}_{i j}(s)=s \boldsymbol{\delta} \boldsymbol{r}_{i j}$ where $s$ is a scalar which varies from 0 to 1 , such that $s=0$ and $s=1$ are the initial (prestressed) and disturbed configuration, respectively. Taking out the constant parts and integrating over $s$ from 0 to 1 , get

$$
\delta U_{i j}^{n}=\left(\boldsymbol{P}_{0 i j}+\frac{1}{2} \boldsymbol{\delta} \boldsymbol{P}_{\boldsymbol{i j}}\right) \cdot \boldsymbol{\delta} \boldsymbol{r}_{i j}
$$

The first term in Eq. 35 is linear in $\boldsymbol{\delta} \boldsymbol{r}_{i j}$, whereas the second one is quadratic. Thus, the respective minimization problem admits a unique solution. The tangential force is nonzero only if the contact area is nonzero. Thus, it is linear with respect to the relative tangential displacement $\delta_{i j}^{t}$. The latter, in turn, is linear with respect to small translations and rotations. The contact area $a$, which appears in Eq. 16, is nonlinear with respect to grain translation. It can be linearized as

$$
a_{i j} \approx \underbrace{\sqrt{R_{i j}^{*} h_{0 i j}}}_{a_{0 i j}}+\frac{1}{2} \sqrt{\frac{R_{i j}^{*}}{h_{0 i j}}} \delta h_{i j}
$$

However, as we seek a linear approximation, the product of second term in Eq. 36 with the incremental relative displacement $\delta_{t(i j)}$ can be neglected. The zero-order, constant approximation of the contact area is equal to its value in the prestressed configuration, $a_{0 i j}$.

Within this approximation, the tangential forces/moments are linear with respect to the relative displacements/rotations. The energy associated with those deformations will be quadratic with respect to them, see Eq. 27. Keep in mind that the calculated $U_{i j}^{t}$ (e.g. in Eq. 27) is the increment of energy, ignoring the amount stored in the undisturbed configuration. This increment will be denoted by $\Delta U_{i j}^{t}$. Note that ignoring the tangential stresses in the initial configuration, is equivalent to assuming they have been dissipated by creep. This seems to be a reasonable assumption for layers which are formed over geological times. 


\section{$5 \quad$ Numerical Simulations}

In this section, we discuss the results of numerical computations simulating a compression test on non-frictional grain pack. The simulations are done in the following way:

- An initial pack is obtained from a different code/data set. This pack is placed in a rectangular container in such a way that the walls touch the outermost spheres with no strains.

- By moving the container walls closer together, the pack is tightened, initially with no apparent stresses, by rearrangements of grains only.

- The loading is further continued by moving the walls even closer, so that stresses develop, due to the contact forces of the outermost grains with the walls.

- Using Hooke's law with the calculated macroscopic stresses and strains, the elastic moduli are found for different segments of the experiment.

- Several loading/unloading cycles are simulated.

\subsection{Mechanical Properties of the Grains}

The properties assigned for all simulations were the following: The grains were assigned a range of elastic properties, designated by $E$, Young's modulus and $\nu$, Poisson's ratio. These values are normally distributed with mean values of $E=100 \mathrm{GPa}$ and $\nu=0.15$, with standard deviation of $10 \%$ from the mean, using a random number generator, see Figure 5 . Mean values were obtained from reports of physical experiments on quartz sand grains (e.g., Yong, 1975, Hart and Wang, 1995). The density of the sand grains was taken to be $2.65 \mathrm{~g} / \mathrm{cm}^{3}$ (Yong, 1975). This density was used in calculating both the forces and the energy due to gravity field with the acceleration of $9.81 \mathrm{~m} / \mathrm{s}^{2}$. In most simulations reported here, the pack contained 2740 grains. The radii were uniformly distributed between 0.07 and $0.13 \mathrm{~mm}$.
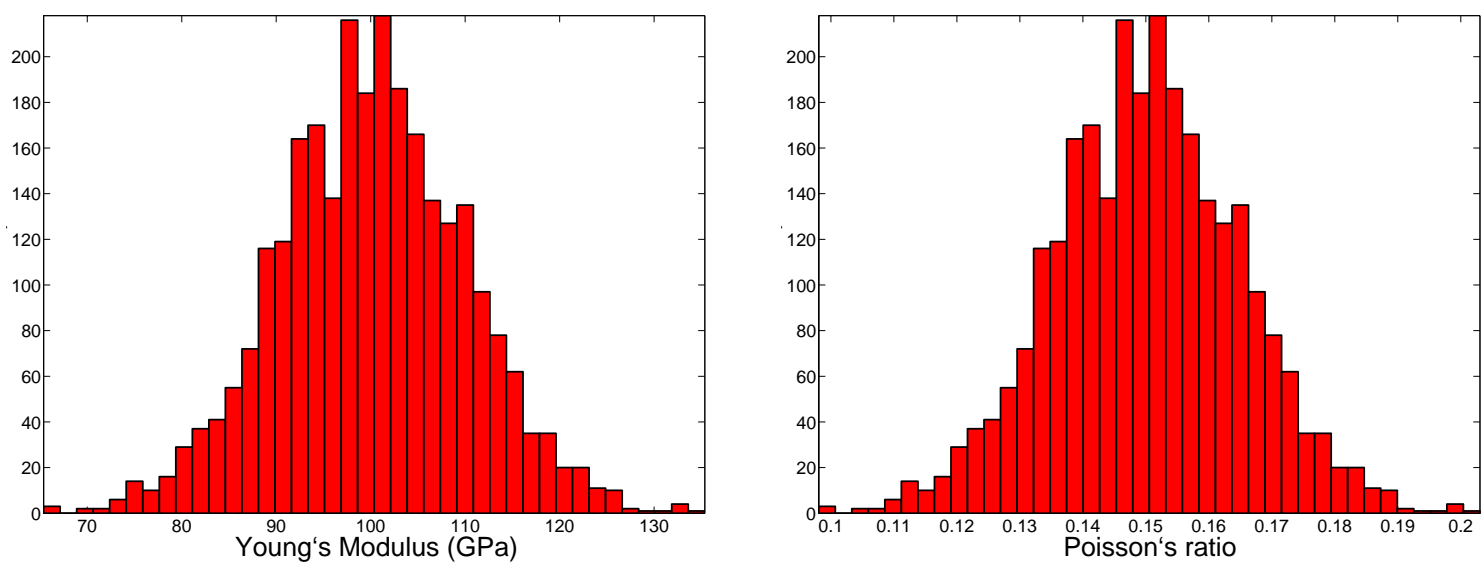

Figure 5: Distributions of Young's modulus and Poisson's ratio of the grains used in the simulations. 


\subsection{Macroscopic Parameters}

\subsubsection{Porosity}

The porosity of the sample was calculated from the ratio of the volume occupied by the solid to the total volume. The total volume is easy to calculate since the sample boundaries are planar and perpendicular to each other. The solid volume is calculated as the sum of spherical volumes minus the sum of overlapping volumes due to deformations. These overlaps are calculated as the sum of two spherical caps, one for each contacting sphere (one cap only in case of contact with a boundary, since the boundaries are semi-rigid). These caps are separated by an imaginary plane which is the so-called "contact plane", as it is defined in the contact theories of Hertz and Mindlin.

Due to the boundary effects, the described-above calculation overestimates the porosity of a small pack comprised of a few hundreds of grains. This is because many voids near the boundaries are not "available" for deformation, and thus the "effective" porosity for comparison of mechanical properties is higher than the one calculated above. This artifact of calculations could be corrected by selecting an inner part of the sample. Obviously, such boundary effects are less significant in larger packs.

\subsubsection{Stress and Strain}

The sum of all individual contact forces on each wall divided by the area of the is the macroscopic stress. The normal force components produce the normal stresses, whereas the tangential components produce the shear stresses.

The normal strains are calculated as the normalized displacements, i.e., the changes in the length relative to an initial state, divided by the initial value for that interval. Note that the definition of strains as a differential quantity implies that the initial value should be chosen from the interval itself. However, the initial value was chosen as the value at the unstressed configuration (first appearance of stresses), as it is done in experiential literature. Using a normalized displacement is an appropriate approximation only under the assumption

of uniform deformation, where the differential is similar to the slope of a straight line. This approximation is used here since we would like to obtain the bulk properties of the sample, ignoring the details inside it.

\subsubsection{Elastic Moduli}

As compaction continues, the mere rearrangements of the grains can no longer accommodate the macroscopic compaction imposed by walls displacements. Consequently, the grains start to deform and produce contact forces. The latter produce macroscopic stresses. The elastic moduli are obtained from Hooke's law for an isotropic body:

$$
\sigma_{i j}=\lambda \epsilon_{k k} \delta_{i j}+2 G \epsilon_{i j}
$$

where $\lambda$ is Lame's constant. Inverting Eq. 37 provides another form of Hooke's law,

$$
\epsilon_{i j}=\frac{1+\nu}{E} \sigma_{i j}-\frac{\nu}{E} \sigma_{k k} \delta_{i j}
$$


Note that elastic properties change during compaction because of the increasing confining stresses. Therefore, to obtain the elastic moduli, these properties are calculated on a small stress-strain interval.

\subsection{Types of Numerical Experiments}

To mimic physical compression experiments, several different types of numerical experiments have been carried out. One numerical experiment performed is the hydrostatic compression, which is usually used to obtain the bulk modulus, $K$. In such an experiment, equal normal stresses are applied from three perpendicular directions, with no shear stresses. For an isotropic medium, one expects to obtain equal normal strains, with no shear. This provides a single equation, from which $\mathrm{K}$ is obtained. Using Eq. 38, denoting the increment in pressure applied on each direction by $p$, the stresses are simply written as $\sigma_{i j}=-\delta_{i j} p$, and thus the strains are $\epsilon_{i j}=-\delta_{i j} \frac{1-2 \nu}{E} p$. From this, one obtains $p=-K \epsilon_{v}$ where $K=\frac{E}{3(1-2 \nu)}$ is the bulk modulus, and $\epsilon_{v}=\epsilon_{k k}$ is the volumetric strain. Therefore, the bulk modulus is the slope of the pressure vs. volumetric strain curve.

In another simulated experiment the sample is deformed in one direction only, termed "axial", with no shear strains. This provides a set of 2 equations, from which 2 elastic moduli can be extracted. From Eq. 37 it is easy to see that the slope of the axial stress vs. axial strain curve provides an estimate for $\lambda+2 G$, while each of the slopes of the lateral stress vs. the lateral strain curves provides the value of $\lambda$. There are two such slopes, as there are two lateral directions. Note that according to isotropic linear elasticity, the two lateral stresses should be equal to each other. This equality is not exactly satisfied in small packs, due to the small number of grains with different properties, which can develop directionality due to their positioning. A mean value of $\lambda$ was then obtained from the 2 slopes of the 2 lateral components. The arithmetic mean value is equivalent to a least-square fit.

A third type of numerical experiment simulates a triaxial test, in which three different normal stresses are applied in three orthogonal directions. Such a test yields three different equations. Since isotropic, homogeneous, linear elastic model requires two coefficients only, the system is over-determined. Note that as the pack gets smaller, the assumption of isotropic response is less likely because the directions on individual contact forces dominate. However, one can use these excess data to verify the validity of the isotropic assumption, and the accuracy of the values obtained from a subset of 2 equations.

\subsection{Results}

\subsubsection{Initial Sample}

The initial sample used in the reported simulations was obtained by cutting a portion of a large sphere pack, constructed to mimic sedimentation of heterogenous grains, by Jin, 2006. This process was modeled using the Distinct Elements Method (DEM) dynamic simulations. The dynamic simulations were stopped when equilibrium was reached. Rigourously speaking, this equilibrium can only be attained approximately, so one has to pick a numerical threshold defining the equilibrium. The selection of this criterion is somewhat arbitrary and may result in gaps or overlaps in the final equilibrium pack. 


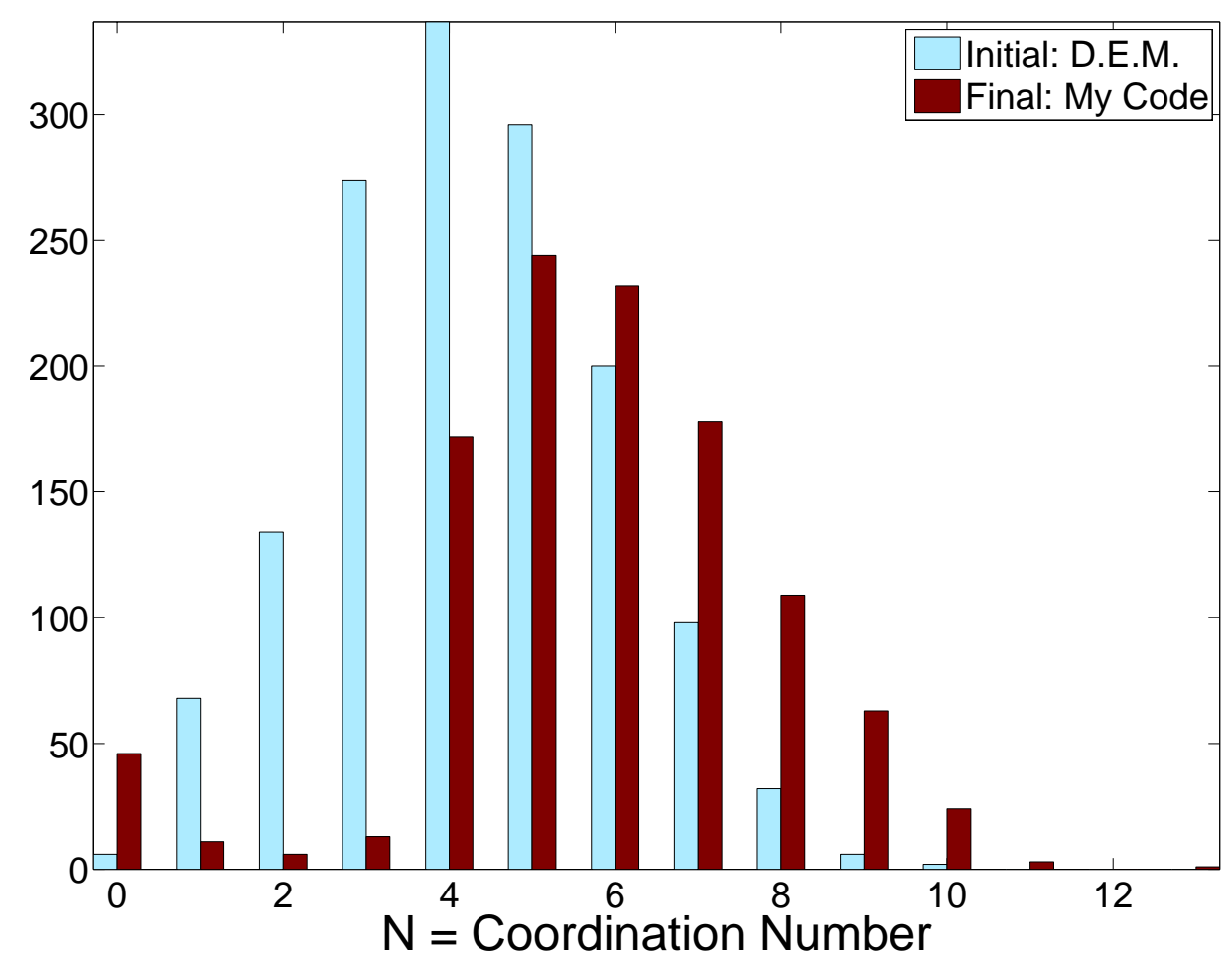

Figure 6: Distribution of the coordination number of internal grains for two unstressed configurations. First one (light blue) is a result of DEM simulations, and the second (dark red) is after reduction of $\sim 1 \%$ porosity using current algorithm.

In 3D, it takes more than 3 contacts to support a grain and at least 4 contacts are needed to fix it in space. The first (light blue) configuration in Figure 6 is the result of DEM simulations. It is obvious from Figure 6 that for this configuration many of the grains are not physically supported even if they are in apparent equilibrium. For example, a grain can have no contacts with neighboring grains when its own weight is so small that for a reasonable numerical threshold it may seem that the sphere is in equilibrium. With that in mind, at first one needs to create a tighter pack by a mere rearrangement of the grains. The latter pack will be the tightest possible, given the initial configuration, and with no internal stresses applied, i.e. with no grain deformations. To improve this initial unstressed configuration, we used our algorithm to compact the pack by moving the outer walls until appreciable stresses were produced. The second configuration in Figure 6, in dark red, is the result of this compaction with no grain deformations.

Note that macroscopic strains have to be counted only after nonzero stresses have been produced. Otherwise, calculations will produce erroneous moduli, as the grains are free to rearrange upon compaction of a loose pack.

\subsubsection{Bulk Modulus}

The bulk modulus measures a pressure response to a change in relative volume, essentially measuring the resistance to uniform compression. This modulus is usually obtained from a hydrostatic compression test. It is well known that because of the complex nature of a granular material, this parameter will vary with the material density, i.e, the amount of compaction 
(Qubain et al., 2003). In addition, due to irreversible rearrangements of grains, the process is irreversible, and the material will display different loading/unloading behaviors. These phenomena are captured with the suggested non-frictional model, even though the grains are perfectly elastic and the tangential forces are neglected, see Figures 8 and 9. Obviously, the values of $K$ also depend on the mean stress applied, which is affecting the amount of compaction.
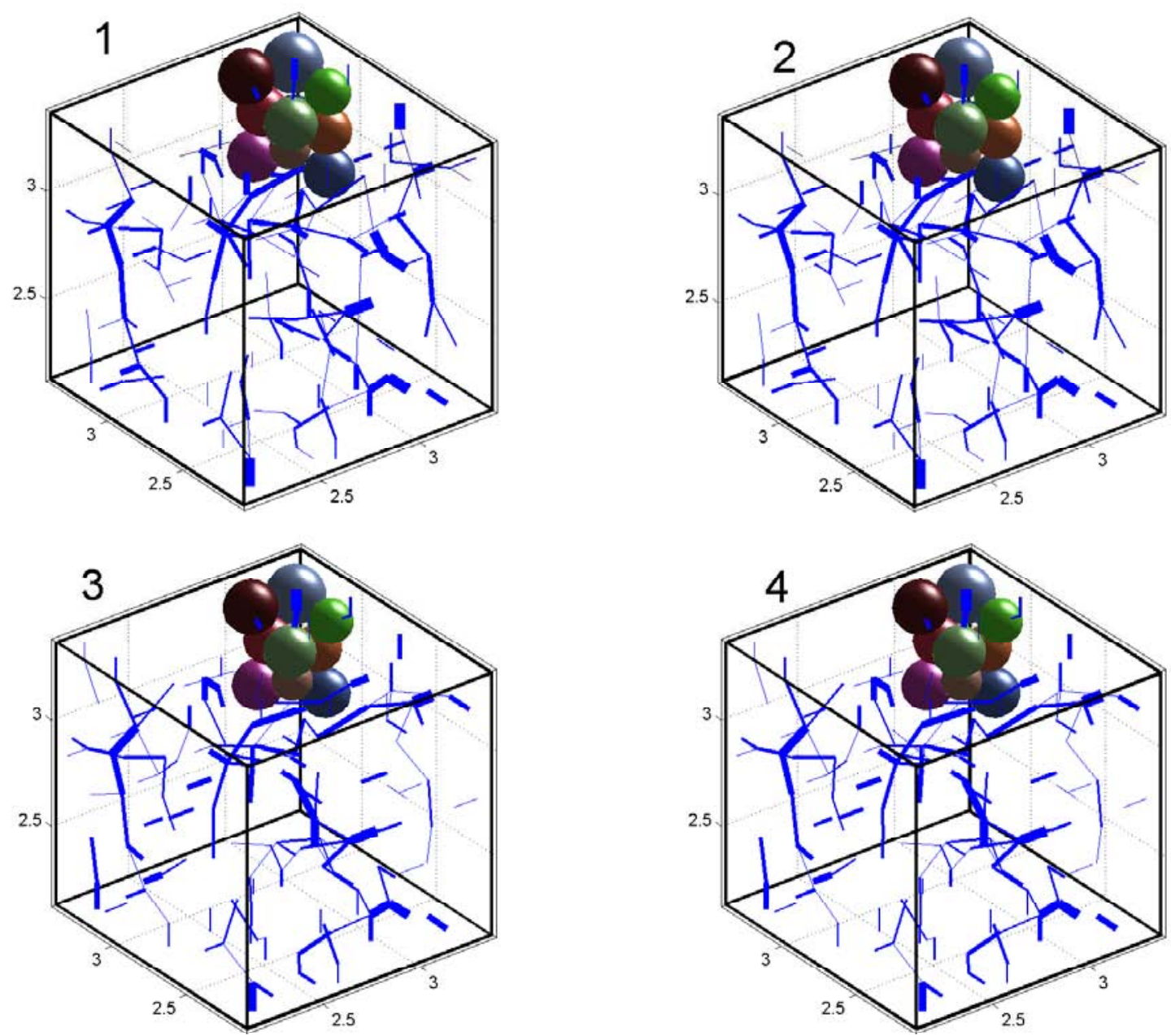

Figure 7: An abrupt local change in force chains and configuration, affecting the overall response of a small pack (306 grains). The plot shows 4 consecutive configurations (marked 14), where the macroscopic strains applied in each step are similar. In each plot the maximum (top 10\%) force vectors are plotted with the line width proportional to the contact force magnitude. Also shown is a cluster of grains. Note the abrupt change from 2 to 3, e.g. as the grain colored in brown is squeezed through a constriction formed by the green and blue grains. The changes from $1 \rightarrow 2$ and $3 \rightarrow 4$ are much smaller.

It may seem odd that a "microscopically" (referring to grain-scale) elastic model predicts non-elastic behavior at macroscopic scale. This is explained by the changes in the number 
of contacts, i.e., by the making and breaking of contacts. If all contacts remain intact, the relative displacements of each pair correspond directly to the elastic strain energy stored in the deformation of that pair. However, if two grains lose contact, their relative displacement does not alter the stored energy, even though it may affect the macroscopic strain. Thus, returning to the same strain level by moving the walls back to their original position, might not correspond to the same energy stored in the pack, and thus might exhibit different macroscopic stresses than that original state.

This nonlinear behavior is most pronounced when a "catastrophic" event occurs, such as breakage of a cluster of grains and the ensuing large displacements of individual grains, which alter multiple grain contacts. Such an event can be seen in Figure 7, where local changes in both the force chains ${ }^{3}$ and configuration are evident. Such events are more pronounced as the number of grains in the packs decreases. One can see that this events are local in nature, even for a small pack, as some of the macroscopic features, e.g. as can be predicted from the force chains, are almost unaltered (see Figure 7).

These events, which appear as "jumps" on the stress-strain curves (see, e.g. Figure 8), can be considered as local macroscopic failures, where the stiffness of the pack decreases abruptly. This is because the increment of stress required for compaction which is mainly due to rearrangements is lesser that a corresponding stress required to do so with smaller amount of rearrangements. Following such events, the pack becomes stiffer, which appears as an increase of the slope of the stress-strain curve, This is somewhat similar effect to strainhardening. This stiffening could be explained initially by increase in the number of contacts, and later on as the by increasing strains in the contacts, which will inhibit further rearrangements.

Figure 9 shows that the values of the bulk modulus increase with compaction from about 1.9 GPa to 3.1 GPa, which corresponds to dense sand (Qubain et al., 2003). However, these values are obtained using higher mean stress; this is likely due to the lack of tangential forces, which requires larger normal forces to hold the pack intact. A more comprehensive answer will be obtained as sufficient statistics of simulations including tangential forces will be acquired.

\subsubsection{Poisson's Ratio}

The values of Poisson's ratio obtained from the simulations are relatively high (over 0.4), higher than the values reported in literature for dry sand, of $\sim 0.17$ (e.g., Yong, 1975, Hart and Wang, 1995). The range of values increases as more complex scenarios are examined, such as saturation with water or gases (e.g. Dvorkin, 2006, Mallick and Dutta, 2002), where values can get close to 0.5. Large Poisson's ratio can be visualized, referring to uniaxial compression test, as the amount of lateral bulging in response to axial compression. The large Poisson's ratio in our simulations can be attributed to the lack of tangential forces at the contacts; those forces will prohibit rearrangements, reducing the amount of lateral bulging. Thus, addition of frictional contacts is expected to improve the future predictions of this ratio.

\footnotetext{
${ }^{3} \mathrm{~A}$ force chain is a graphical description of the contact force vectors (their direction and magnitude), thus showing how these forces are distributed and transferred through the pack.
} 


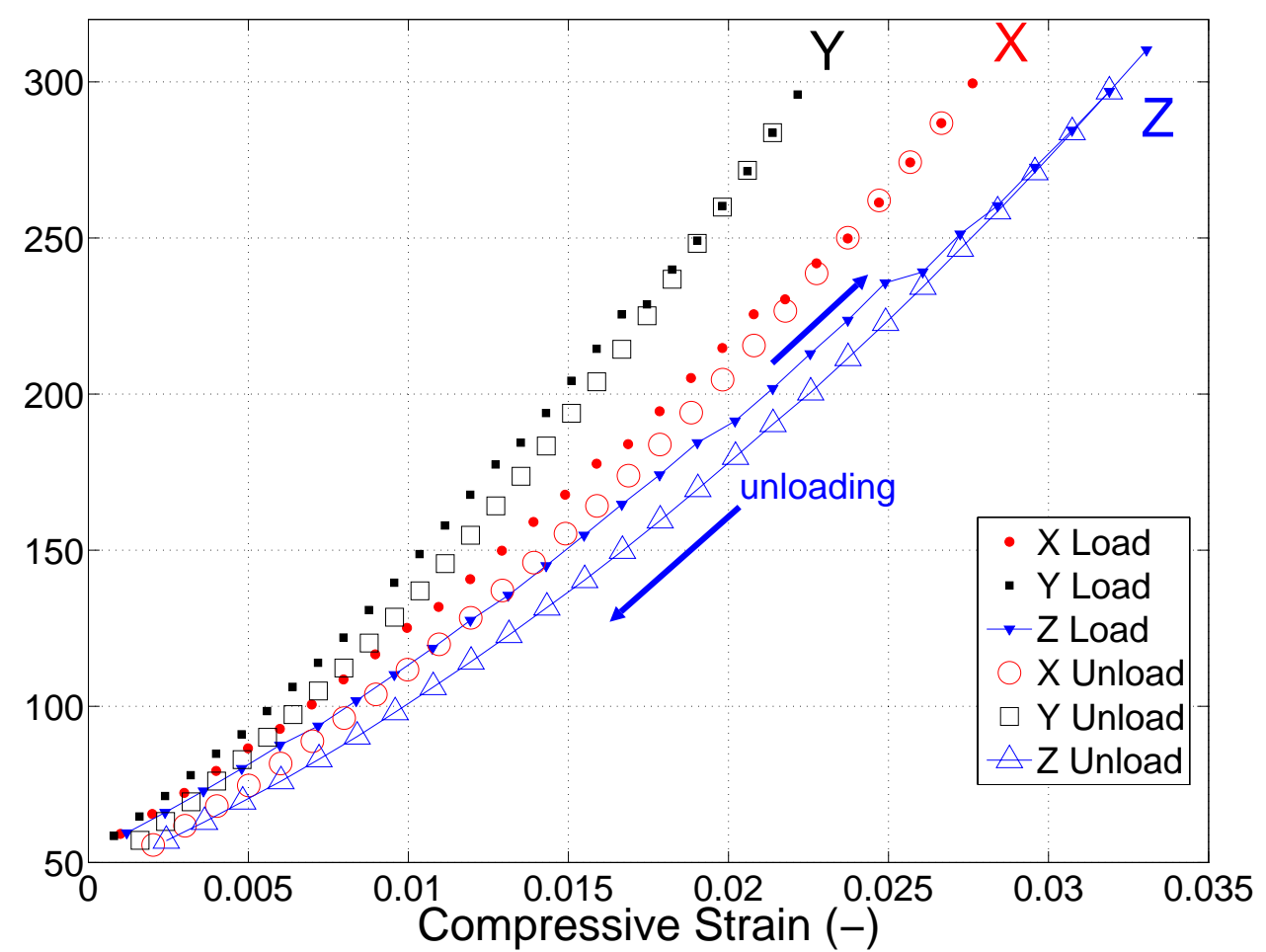

Figure 8: Loading/unloading cycle showing irreversibility due to localized macroscopic failures.

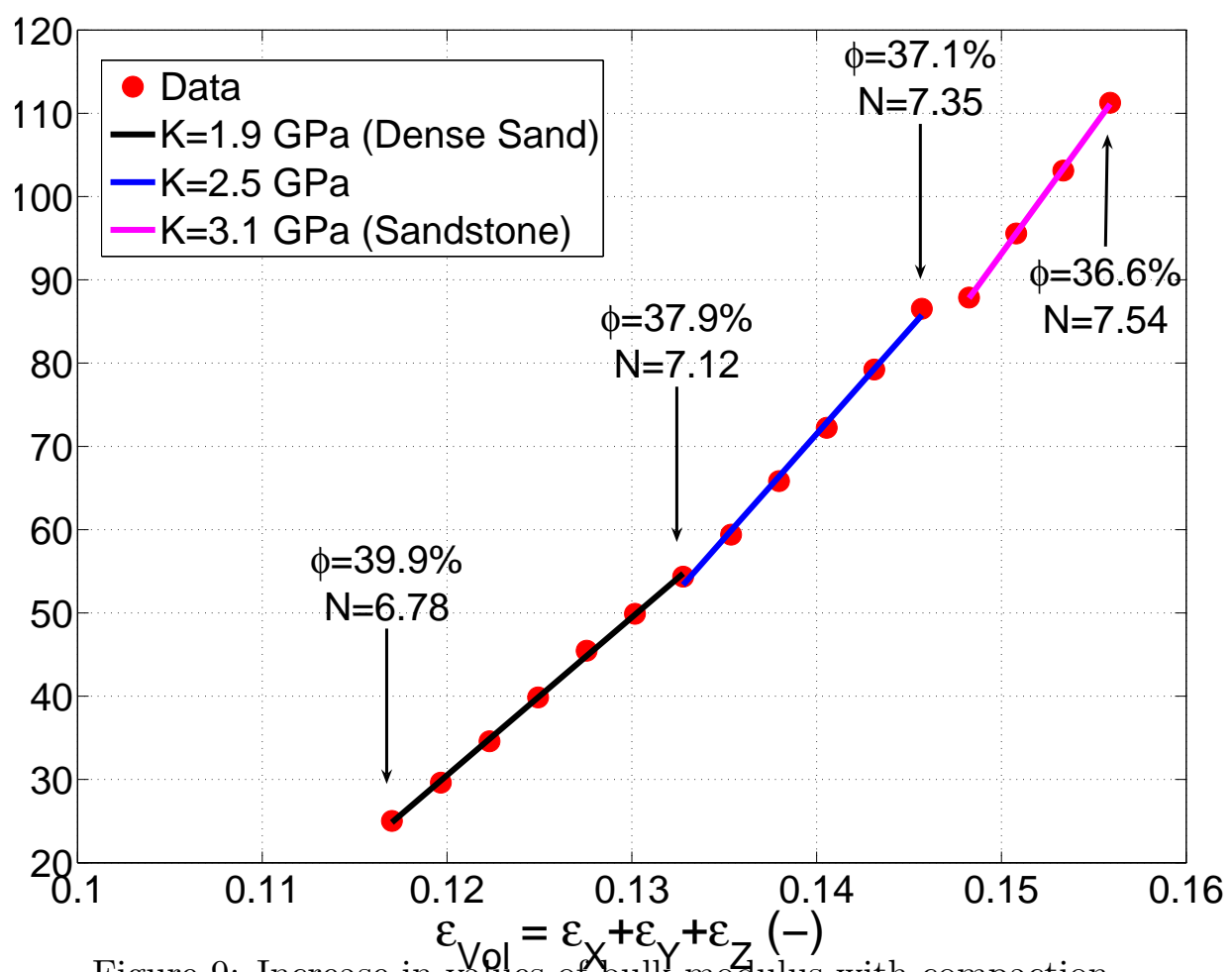

Figure 9: Increase in values of bulk modulus with compaction. 


\section{Summary and Conclusions}

The pipelines lifting the recovered fluids to an oil platform can cause gas hydrate dissociation in the hydrate-bearing layers. The resulting gas release will increase the pore pressure and decrease the effective stress. In addition, the loss of strength by hydrate melting can significantly weaken the rock. The objective of this study is to develop the methods and tools for predicting the change of the strength and failure of HBS caused by hydrate dissociation. The macroscopic rock properties are estimated through grain-scale simulations of deformations in granular media. The input parameters are distributions of grain sizes and elastic moduli. The output includes estimates of effective/macroscopic mechanical properties of the bulk heterogeneous grain pack. Our approach is capable of tracking variations of elastic moduli and propagation of rock damage under changing load conditions. The obtained estimates and constitutive relationships will be used in reservoir-scale poroelastic simulations predicting stability of the sloping sea-bottom sediments in offshore oil production.

The model presented here is founded on basic principles. Although relatively simple, it retains the most important features of a heterogenous granular medium. It utilizes variational approach and incorporates the Hertz-Mindlin contact theory. The developed iterative solution scheme is based on the conjugate gradient method. It is fast and robust.

The principle results of Phase I are: (i) The development of a conceptual model of granular porous media, (ii) derivation of the governing equations, and (iii) implementation of the resulting algorithms in computer codes. The quality of agreement between the numerical simulations of a normally-stressed grain pack and the published laboratory tests on quartz sands and sandstones is encouraging.

Next, we will incorporate into our model the inter-granular adhesive forces, cementation and cement bond failures, and non-spherical grains. Implementation of these steps will make it possible to adequately describe the mechanical implications of hydrate dissociation in HBS. The results obtained thus far encourage us to claim that Phase II of this project will equally successful. 


\section{Future Work - Phase II}

Simulations using the codes developed in Phase I capture most of the mechanical processes in a layer of dry grains. We successfully estimate the the bulk modulus of a grain pack, as it evolves with compaction. However, further work is needed to adequately simulate the mechanics of HBS. The objective of Phase II is further theoretical and computational development of a comprehensive grain-scale model of hydrate-bearing rock. It includes the following tasks:

Tangential contact stresses. Incorporation of tangential stresses is more tricky than that of normal stresses and requires several steps. The current model includes the local deformation and is good for estimation of elastic properties of the rock. A more comprehensive approach requires to keep track of the deformation history over a large range of strain. Even in the case of elastic deformations it results in increasing the amount of computer memory used. Therefore, the efficiency of computations and data storage will have to increase accordingly. Non-spherical grain shapes would introduce additional moments and may be needed to model anisotropic rocks.

Cementation, adhesion and bond failure. The experience acquired in Phase I suggests that a basic-level inclusion of adhesion into the contact model is relatively simple. Moreover, adhesion should reduce the changes in contacts during macroscopic deformations and, therefore, will stabilize the computations. However, modeling the complex geometry of cement around the grains is not obvious. One also should note that not all of the cement is load-bearing, depending on its position relative to the contacts. Cement will still decrease porosity, and thus will change the flow properties of the medium. Different grain configurations will cause different parts of the cement to have different roles in bearing loads. Inclusion of cement will be accompanied by a failure criterion for the bonds between the grains.

Hydrates in the pore space. Hydrates could be considered either as solid grains, or as cementing material in the matrix pores. In either case, the dissociation of hydrates will melt part of the solid skeleton, and thus will have a significant effect on the mechanical behavior. The gas release will increase the pore pressure and reduce the macroscopic effective stress. Both processes have a strong impact on the strength of HBS and must be parts of the model.

REV and ensemble averaging. Reliable estimation of the moduli will require additional statistical analysis and/or calibration from experiments. This includes ensembleaveraging over samples of similar sizes. The study of sensitivity of the estimates with respect to the sample size will determine an appropriate representative volume (REV). Ensembleaveraging will be preformed through numerical experiments, repeated on different packs which have similar distributions of geometrical and physical grain properties. The sample size effects could be examined by tracking the evolution of the total energy of the pack per unit volume, and the elastic moduli, vs. the size of the sample.

Model verification. To be efficient, the model must be simple and adequate. Model verification against available laboratory and field data is a part of this project. Additional features will be added if the existing model becomes insufficient for some types of sediments. 


\section{Appendix: Algorithm for Computations}

In this section, a brief overview of the methods used to solve for the equilibrium configuration is presented, together with a note on the implementation of these methods. The simplest method which is presented in the steepest descent, while the method chosen was the conjugate gradient, which has proven to converge within finite number of iterations for linear systems.

\subsection{Contact Detection Algorithm}

For the initial configuration, i.e. before any displacements occur, the current distances between the surfaces of all possible pairs of spherical grains are calculated by, e.g., calculating the parameter $h_{i j}$. Note that although this is a simple calculation, it is performed about $N^{2}$ times; thus, for a large number of grains it is expensive. For each sphere, a list is generated which includes the possible neighbors. This list includes not just the grains in current contact with the sphere, but also those which are closer than a criterion which is proportional to the radii of the grains. For a sphere-sphere pair, it is $C_{\max }\left(R_{i}+R_{j}\right)$, while for a sphere-wall contact it is $C_{\max } R_{i}$. The tolerance-of-distance parameter $C_{\max }$ is a constant which can be chosen arbitrarily. This tolerance allows relative motion of each pair by $C_{\max }$ before the list is updated.

Choosing a large $C_{\max }$ will minimize the number of times the update procedure is repeated. On the other hand, there is a trade-off since the list will be larger, depending on the tolerance of distance criterion $C_{\max }$. In every iteration $k$, the cumulative relative displacement vectors $\boldsymbol{\delta} \boldsymbol{r}_{i j}^{k}$ for each pair in the list are stored in memory. If, for a single pair, they exceed the specified tolerance specified above, the list is updated. Note that this is a list of possible contacts, i.e. the distance $h_{i j}$ should still be calculated at each step for each pair in the list, to see if contact is maintained. This distance is used to determine contact forces, and considered to be known.

Efficiency of the contact detection algorithm and bookkeeping method depends not just on the number of grains, but also on how many contacts are expected to change. For example, in a tight pack where a small perturbation is applied, one may expect a small number of contacts to change, whereas in the case of a loose pack with a large perturbation, many contacts can be lost/formed. For very large systems with loose packing, if computational power rather than memory is an issue, one could use a dual list. The first list will have a relatively small tolerance, and will be used in computations in every iteration. A second, more tolerant list, which includes many more possible neighbors, will be used in refreshing of the first one if needed, eliminating the need to run over all possible pairs more than once.

\subsection{Steepest Descent Method}

The starting point of the iterative procedure is an initial configuration, i.e., a set of linear and rotational displacements with respect to an undisturbed equilibrium state. For example, one could take the undisturbed configuration, i.e., zero displacements/rotations, as the initial guess. From the corresponding relative displacements the normal and tangential forces, moments, and energies are calculated (see Section 3.1). The sum of forces and the sum of 
moments are the residuals, which will be identically zero in equilibrium.

Energy minimization is done by displacing the spheres in the anti-direction of the residuals, with some coefficient. Note that in general this coefficient does not have to be a single scalar, for example it could be different for linear and rotational displacements. The steepestdescent algorithm requires the value of the coefficient to be such that the energy is minimized the most when the residuals are in the direction of the steepest descent. Finding these coefficients requires minimization of function $\Pi$ with respect to them; thus, the more a coefficient is used the higher the cost for this minimization. There is a tradeoff between using more coefficients and the time it takes to find them, and one should choose the most efficient way. Here we use a single scalar coefficient for all variables.

To use a single coefficient, one needs to make sure that the units and scales of the parameters updated by that coefficient are similar. Consider a coefficient that is relating the linear displacements (units of length $[\mathrm{L}]$ ) and residual forces. It should have units of $[\mathrm{L}] /[\mathrm{F}]$. Relating the rotation (dimensionless) to the moments, the coefficient must have units of $1 /([\mathrm{F}][\mathrm{L}])$. Assuming that the tangential and normal forces are of the same order, since the moments are the sum of tangential forces times the sphere radius $R_{i}$, the moments are about $R_{i}$ larger than the sum of forces. In addition, the linear displacements should be of order of rotations times $R_{i}$.

To obtain a similar order, preconditioning is needed. Consider the variables to be the linear displacements, $\boldsymbol{\delta}_{i}$, and the arc length vector, $R_{i} \boldsymbol{\Omega}_{i}$, and - in addition - we update the arc length variable by the sum of moments times the coefficient divided by $R_{i}$,

$$
\begin{array}{r}
\boldsymbol{\delta}_{i}^{k+1}=\boldsymbol{\delta}_{i}^{k}-\alpha^{k} \boldsymbol{f}_{i}^{k} \\
R_{i} \boldsymbol{\Omega}_{i}^{k+1}=R_{i} \boldsymbol{\Omega}_{i}^{k}-\frac{\alpha^{k}}{R_{i}} \boldsymbol{M}_{i}^{k}
\end{array}
$$

The choice of variables will become clear when we discuss the application of the conjugate gradient method.

\subsection{Conjugate Gradient Method}

\subsubsection{General Algorithm}

The classical conjugate gradient method was developed for numerical solution of one of two equivalent problems: a system of linear equations

$$
A \mathbf{x}=\mathbf{b}
$$

or minimization of a quadratic criterion

$$
J(\mathbf{x})=\frac{1}{2} A \mathbf{x} \cdot \mathbf{x}-\mathbf{b} \cdot \mathbf{x}
$$

Here $b$ is a known column-vector of dimension $N$, and $A$ is a symmetric positive-definite $N \times N$ matrix. The gradient $J^{\prime}(\mathbf{x})$ of $J(\mathbf{x})$ is

$$
J^{\prime}(\mathbf{x})=A \mathbf{x}-\mathbf{b}
$$


Hence, Eq. 40 is equivalent to $J^{\prime}(\mathbf{x})=0$. The solution $\mathbf{x}_{*}$ to the system in Eq. 40 is the minimum of function in Eq. 41, and vice versa.

Conjugate gradient method is an iterative procedure where starting from some $\mathbf{x}_{0}$, a step from $\mathbf{x}_{n}$ ( $n$ is the iteration index) to $\mathbf{x}_{n+1}$ is performed by the following formula

$$
\mathbf{x}_{n+1}=\mathbf{x}_{n}-\alpha_{n} \mathbf{p}_{n}
$$

The step-size coefficient $\alpha_{n}$ is selected to minimize $J\left(\mathbf{x}_{n}-\alpha_{n} \mathbf{p}_{n}\right)$ (the potential energy in this case) for a given $\mathbf{x}_{n}$ and $\mathbf{p}_{n}$. Note that one could possibly choose it to be different for each sphere, making it a vector and not a scalar. Selection of $\alpha$ in the case of a scalar, reduces to a minimization problem of a function of one variable, which is easily solved by methods such as the golden section. At the minimum,

$$
\left.\frac{d}{d \alpha} J\left(\mathbf{x}_{n}-\alpha \mathbf{p}_{n}\right)\right|_{\alpha=\alpha_{n}}=\left(A\left(\mathbf{x}_{n}-\alpha_{n} \mathbf{p}_{n}\right)-\mathbf{b}\right) \cdot \mathbf{p}_{n}=\left(A \mathbf{x}_{n+1}-\mathbf{b}\right) \cdot \mathbf{p}_{n}=0
$$

Therefore,

$$
\alpha_{n}=\frac{\mathbf{r}_{n} \cdot \mathbf{p}_{n}}{A \mathbf{p}_{n} \cdot \mathbf{p}_{n}}
$$

where

$$
\mathbf{r}_{n}=A \mathbf{x}_{n}-\mathbf{b}
$$

is the gradient of the energy in this case, as defined in Eq. 42. Note that Eq. 43 and Eq. 44 imply that

$$
\mathbf{r}_{n+1} \cdot \mathbf{p}_{n}=0
$$

Also, from Eq. 43

$$
-\alpha_{n} A \mathbf{p}_{n}=A \mathbf{x}_{n+1}-A \mathbf{x}_{n}=\left(A \mathbf{x}_{n+1}-\mathbf{b}\right)-\left(A \mathbf{x}_{n}-\mathbf{b}\right)=\mathbf{r}_{n+1}-\mathbf{r}_{n}
$$

hence

$$
A \mathbf{p}_{n}=\frac{1}{\alpha_{n}}\left(\mathbf{r}_{n}-\mathbf{r}_{n+1}\right)=\frac{1}{\alpha_{n}}\left(J^{\prime}\left(\mathbf{x}_{n}\right)-J^{\prime}\left(\mathbf{x}_{n+1}\right)\right)
$$

Since $\mathbf{x}_{*}$ is the solution to the system $A \mathbf{x}=\mathbf{b}$, Eq. 44 implies

$$
\left(A \mathbf{x}_{*}-\mathbf{b}\right) \cdot \mathbf{p}_{n}=0
$$

Thus far, all calculations are valid for an arbitrary choice of vectors $\mathbf{p}_{n}$. Let the vector, $\mathbf{p}_{0}$, be the gradient of the criterion 41 at some initial guess $\mathbf{x}=\mathbf{x}_{0}$ :

$$
\mathbf{p}_{0}=A \mathbf{x}_{0}-\mathbf{b}=J^{\prime}\left(\mathbf{x}_{0}\right)
$$

Note that due to Eq. 46,

$$
\mathbf{p}_{0}=\mathbf{r}_{0}
$$

Clearly, vector $-\mathbf{p}_{0}$ points in the direction of fastest rate of decay of the criterion Eq. 41 . Thus, from Eq. 47, 


$$
\mathbf{r}_{0} \cdot \mathbf{r}_{1}=J^{\prime}\left(\mathbf{x}_{0}\right) \cdot J^{\prime}\left(\mathbf{x}_{1}\right)=0
$$

Eq. 50 and Eq. 44 at $n=0$, in particular, imply that both $\mathbf{x}_{1}$ and $\mathbf{x}_{*}$ are in the same plane orthogonal to $\mathbf{p}_{0}$. Therefore, one can constrain further iterations to this plane only. This means that we select a direction $\mathbf{p}_{1}$, which is orthogonal to $\mathbf{p}_{0}$. To do so, we put $\mathbf{p}_{1}$ equal to a projection, in some sense, of the gradient of function Eq. 41 on this plane. namely, we subtract from the gradient $\mathbf{p}_{0}$ with an appropriate coefficient $\beta_{1}$. So, put

$$
\mathbf{p}_{1}=J^{\prime}\left(\mathbf{x}_{1}\right)-\beta_{1} \mathbf{p}_{0}
$$

Or, equivalently,

$$
\mathbf{p}_{1}=\left(A \mathbf{x}_{1}-\mathbf{b}\right)-\beta_{1} \mathbf{p}_{0}=\mathbf{r}_{1}-\beta_{1} \mathbf{p}_{0}
$$

The dot product $A \mathbf{p}_{1} \cdot \mathbf{p}_{0}$ must vanish,

$$
A \mathbf{p}_{1} \cdot \mathbf{p}_{0}=0
$$

Hence,

$$
\beta_{1}=\frac{A \mathbf{r}_{1} \cdot \mathbf{p}_{0}}{A \mathbf{p}_{0} \cdot \mathbf{p}_{0}}=\frac{\left(A \mathbf{x}_{1}-\mathbf{b}\right) \cdot A \mathbf{p}_{0}}{A \mathbf{p}_{0} \cdot \mathbf{p}_{0}}
$$

The coefficient $\beta_{1}$ has been chosen in such a way that for any coefficient $\alpha$, the vector $\mathbf{x}_{1}-\alpha \mathbf{p}_{1}$ is in the same plane defined by Eq. 50 at $n=0$ :

$$
\left(A\left(\mathbf{x}_{1}-\alpha \mathbf{p}_{1}\right)-\mathbf{b}\right) \cdot \mathbf{p}_{0}=0
$$

After some algebra, it can be shown that for $i, j$ not exceeding 2 , we have

$$
\begin{gathered}
A \mathbf{p}_{i} \cdot \mathbf{p}_{j}=0, \quad i \neq j \\
\mathbf{r}_{i} \cdot \mathbf{r}_{j}=0, \quad i \neq j
\end{gathered}
$$

and

$$
\mathbf{r}_{i} \cdot \mathbf{p}_{j}=0, \quad i>j
$$

A general step of the algorithm is as follows: After $\mathbf{x}_{i}$ and $\mathbf{p}_{i}$ have been computed for $i=0,1, \ldots, n$ along with the coefficients $\alpha_{i}$ and $\beta_{i}$ for $i<n$, relationships 59-61 hold true for appropriate $i, j$ not exceeding $n$. The next iteration $\mathbf{x}_{n+1}$ is computed using Eq. 43 and Eq. 45. Next direction is computed using

$$
\mathbf{p}_{n+1}=\mathbf{r}_{n+1}-\beta_{n+1} \mathbf{p}_{n}
$$

where $\beta_{n+1}$ is selected to provide for

$$
A \mathbf{p}_{n+1} \cdot \mathbf{p}_{n}=0
$$

That is,

$$
\beta_{n+1}=\frac{A \mathbf{r}_{n+1} \cdot \mathbf{p}_{n}}{A \mathbf{p}_{n} \cdot \mathbf{p}_{n}}
$$

Using relationships Eq. 59-Eq. 61, the latter equation can be modified:

$$
\beta_{n+1}=\frac{\mathbf{r}_{n+1} \cdot\left(\mathbf{r}_{n}-\mathbf{r}_{n+1}\right)}{\left(\mathbf{r}_{n}-\mathbf{r}_{n+1}\right) \cdot \mathbf{p}_{n}}=-\frac{\mathbf{r}_{n+1} \cdot \mathbf{r}_{n+1}}{\mathbf{r}_{n} \cdot \mathbf{p}_{n}}=-\frac{\mathbf{r}_{n+1} \cdot \mathbf{r}_{n+1}}{\mathbf{r}_{n} \cdot\left(\mathbf{r}_{n}-\beta_{n} \mathbf{p}_{n-1}\right)}=-\frac{\mathbf{r}_{n+1} \cdot \mathbf{r}_{n+1}}{\mathbf{r}_{n} \cdot \mathbf{r}_{n}}
$$

By virtue of Eq. 42,

$$
\beta_{n+1}=\frac{\left(J^{\prime}\left(\mathbf{x}_{n+1}\right)-J^{\prime}\left(\mathbf{x}_{n}\right)\right) \cdot J^{\prime}\left(\mathbf{x}_{n+1}\right)}{\left(J^{\prime}\left(\mathbf{x}_{n+1}\right)-J^{\prime}\left(\mathbf{x}_{n}\right)\right) \cdot \mathbf{p}_{n}}=-\frac{\left\|J^{\prime}\left(\mathbf{x}_{n+1}\right)\right\|^{2}}{\left\|J^{\prime}\left(\mathbf{x}_{n}\right)\right\|^{2}}
$$




\subsubsection{Implementation in Granular Media}

Since the conjugate gradient method was developed for linear systems, or the quadratic energy $J(\mathbf{x})$, some modifications are needed to enable its use for nonlinear problems. Renouf and Alart, 2005 proposed the use of conjugate gradient for granular media, using two-dimensional disks and accounting for friction with Coulomb's law, thus leaving the normal components as the parameters. For the three-dimensional case we are considering, we suggest the following way of implementation.

After picking an initial guess, the first step is done using the steepest descent method, Eq. 51. In this case, we choose the initial guess for the first iteration to be the undeformed configuration. For all iterations, $\alpha_{n}$ is chosen such that it minimizes the energy. Then, the next iterations are done as conjugate gradient steps, computing $\beta_{n+1}$ using expression in Eq. 64. For example, after sufficiently many iterations, the direction $\mathbf{p}_{n+1}$ computed by Eq. 62 may point not in the direction of decay of function $J(\mathbf{x})$. To circumvent such problems, one can refresh the procedure by enforcing $\beta_{n+1}=0$, i.e. performing a steepest descent step. The frequency of such an operation was determined empirically, by trial and error. Note that if the conjugate gradient algorithm is restarted at every iteration, it becomes equivalent to the steepest descent method.

When performing numerical experiment, one needs to ensure physical behavior of the system. For a computer-generated pack of granular media, i.e. for a list of centers and radii together with grain physical properties, it may be that permutations of grains will improve the packing by reducing the potential energy, allowing the pack to be more compact for the same external stresses. Thus, since the algorithm is driven by minimization of energy, it is possible that at some iteration, choosing a relatively large $\alpha$ such permutation will occur. Obviously, such process is not physical, as a single grain cannot penetrate another. This is equivalent to taking the pack apart and reassembling it, i.e. constructing a different pack, which is undesired. To prohibit such events, we chose to restrict the values of $\alpha$, such that the relative displacement of each pair of bodies does not exceed a small portion of their radii. This will result in extremely large contact forces in the case a grain attempts to penetrate another body. Since such forces result in large potential energies, the process will be prohibited by the energy minimization.

\subsubsection{Implementation in Prestressed Pack with Frictional Contacts}

To determine the variables used in the conjugate gradient method, which in turn will determine the form of the gradient vector, we first write the explicit expressions for the energy. Since they are uncoupled, we will write the different components of the energy separately. The normal contribution is 


$$
\begin{aligned}
\delta U_{i j}^{n}= & {\left[\boldsymbol{P}_{0 i j}+\frac{2}{3} E_{i j}^{*} \sqrt{R_{i j}^{*}}\left\{\frac{\left(h_{0 i j}\right)^{\frac{3}{2}}}{\left\|\boldsymbol{r}_{0 i j}\right\|} \boldsymbol{\delta} \boldsymbol{r}_{i j}-\frac{\sqrt{h_{0 i j}}}{\left\|\boldsymbol{r}_{0 i j}\right\|^{3}}\left(\frac{3}{2}\left\|\boldsymbol{r}_{0 i j}\right\|+h_{0 i j}\right)\left(\boldsymbol{r}_{0 i j} \cdot \boldsymbol{\delta} \boldsymbol{r}_{i j}\right) \boldsymbol{r}_{0 i j}\right\}\right] \cdot \boldsymbol{\delta} \boldsymbol{r}_{i j} } \\
= & \boldsymbol{P}_{0 i j} \cdot \boldsymbol{\delta} \boldsymbol{r}_{i j}+\frac{2}{3} E_{i j}^{*} \sqrt{R_{i j}^{*}} \frac{\left(h_{0 i j}\right)^{\frac{3}{2}}}{\left\|\boldsymbol{r}_{0 i j}\right\|}\left\|\boldsymbol{\delta} \boldsymbol{r}_{i j}\right\|^{2}-\frac{2}{3} E_{i j}^{*} \sqrt{R_{i j}^{*}} \frac{\sqrt{h_{0 i j}}}{\left\|\boldsymbol{r}_{0 i j}\right\|^{3}}\left(\frac{3}{2}\left\|\boldsymbol{r}_{0 i j}\right\|+h_{0 i j}\right)\left(\boldsymbol{r}_{0 i j} \cdot \boldsymbol{\delta} \boldsymbol{r}_{i j}\right)^{2} \\
= & \boldsymbol{P}_{0 i j} \cdot\left(\boldsymbol{\delta} \boldsymbol{r}_{i}-\boldsymbol{\delta} \boldsymbol{r}_{j}\right)+\frac{2}{3} E_{i j}^{*} \sqrt{R_{i j}^{*}} \frac{\left(h_{0 i j}\right)^{\frac{3}{2}}}{\left\|\boldsymbol{r}_{0 i j}\right\|}\left\|\left(\boldsymbol{\delta}_{i}-\boldsymbol{\delta} \boldsymbol{r}_{j}\right)\right\|^{2} \\
& -\frac{2}{3} E_{i j}^{*} \sqrt{R_{i j}^{*}} \frac{\sqrt{h_{0 i j}}}{\left\|\boldsymbol{r}_{0 i j}\right\|^{3}}\left(\frac{3}{2}\left\|\boldsymbol{r}_{0 i j}\right\|+h_{0 i j}\right)\left(\boldsymbol{r}_{0 i j} \cdot\left(\boldsymbol{\delta} \boldsymbol{r}_{i}-\boldsymbol{\delta} \boldsymbol{r}_{j}\right)\right)^{2}
\end{aligned}
$$

The energies associated with the tangential and rotational displacements are

$$
U_{i j}^{t}=4 a_{i j}\left(\frac{2-\nu_{i}}{G_{i}}+\frac{2-\nu_{j}}{G_{j}}\right)^{-1}\left\|\boldsymbol{\delta}_{i j}^{t}\right\|^{2}
$$

and

$$
U_{i j}^{t o r}=\frac{8}{3} a_{i j}^{3}\left(\frac{1}{G_{i}}+\frac{1}{G_{j}}\right)^{-1}\left\|\boldsymbol{\Omega}_{i j}^{t o r}\right\|^{2}
$$

where the norm squared in the above 2 equations is

$$
\begin{aligned}
\left\|\boldsymbol{\delta}_{i j}^{t}\right\|^{2}= & \left\|\boldsymbol{\delta} \boldsymbol{r}_{i j}-\left(\boldsymbol{\delta} \boldsymbol{r}_{i j} \cdot \frac{\boldsymbol{r}_{0 i j}}{\left\|\boldsymbol{r}_{0 i j}\right\|}\right) \frac{\boldsymbol{r}_{0 i j}}{\left\|\boldsymbol{r}_{0 i j}\right\|}-\frac{1}{R_{i}+R_{j}}\left[\left(R_{i} \boldsymbol{\Omega}_{i}+R_{j} \boldsymbol{\Omega}_{j}\right) \times \boldsymbol{r}_{0 i j}\right]\right\|^{2} \\
= & \left\|\boldsymbol{\delta} \boldsymbol{r}_{i j}\right\|^{2}+\frac{1}{\left\|\boldsymbol{r}_{0 i j}\right\|^{2}}\left(\boldsymbol{\delta} \boldsymbol{r}_{i j} \cdot \boldsymbol{r}_{0 i j}\right)^{2}+\frac{1}{\left(R_{i}+R_{j}\right)^{2}}\left\|\left(R_{i} \boldsymbol{\Omega}_{i}+R_{j} \boldsymbol{\Omega}_{j}\right) \times \boldsymbol{r}_{0 i j}\right\|^{2} \\
& -2 \frac{1}{\left\|\boldsymbol{r}_{0 i j}\right\|^{2}}\left(\boldsymbol{\delta} \boldsymbol{r}_{i j} \cdot \boldsymbol{r}_{0 i j}\right)^{2}-2 \frac{1}{R_{i}+R_{j}}\left[\left(R_{i} \boldsymbol{\Omega}_{i}+R_{j} \boldsymbol{\Omega}_{j}\right) \times \boldsymbol{r}_{0 i j}\right] \cdot \boldsymbol{\delta} \boldsymbol{r}_{i j} \\
& +2 \frac{1}{R_{i}+R_{j}} \frac{1}{\left\|\boldsymbol{r}_{0 i j}\right\|^{2}}\left(\boldsymbol{\delta} \boldsymbol{r}_{i j} \cdot \boldsymbol{r}_{0 i j}\right) \boldsymbol{r}_{0 i j} \cdot\left[\left(R_{i} \boldsymbol{\Omega}_{i}+R_{j} \boldsymbol{\Omega}_{j}\right) \times \boldsymbol{r}_{0 i j}\right]
\end{aligned}
$$

Upon using the triple product $\boldsymbol{r}_{0 i j} \cdot\left[\left(R_{i} \boldsymbol{\Omega}_{i}+R_{j} \boldsymbol{\Omega}_{j}\right) \times \boldsymbol{r}_{0 i j}\right]=\left[\boldsymbol{r}_{0 i j} \times \boldsymbol{r}_{0 i j}\right] \cdot\left(R_{i} \boldsymbol{\Omega}_{i}+R_{j} \boldsymbol{\Omega}_{j}\right)=0$ to eliminate the last term, and adding similar terms, obtain

$$
\begin{gathered}
\left\|\boldsymbol{\delta}_{i j}^{t}\right\|^{2}=\left\|\boldsymbol{\delta}_{i j}\right\|^{2}-\frac{1}{\left\|\boldsymbol{r}_{0 i j}\right\|^{2}}\left(\boldsymbol{\delta} \boldsymbol{r}_{i j} \cdot \boldsymbol{r}_{0 i j}\right)^{2}+\frac{1}{\left(R_{i}+R_{j}\right)^{2}}\left\|\left(R_{i} \boldsymbol{\Omega}_{i}+R_{j} \boldsymbol{\Omega}_{j}\right) \times \boldsymbol{r}_{0 i j}\right\|^{2} \\
-2 \frac{1}{R_{i}+R_{j}}\left[\left(R_{i} \boldsymbol{\Omega}_{i}+R_{j} \boldsymbol{\Omega}_{j}\right) \times \boldsymbol{r}_{0 i j}\right] \cdot \boldsymbol{\delta} \boldsymbol{r}_{i j} \\
\left.\left\|\boldsymbol{\Omega}_{i j}^{t o r}\right\|^{2}=\frac{1}{\left\|\boldsymbol{r}_{0 i j}\right\|^{2}}\left[\left(\boldsymbol{\Omega}_{i}-\boldsymbol{\Omega}_{j}\right) \cdot \boldsymbol{r}_{0 i j}\right)\right]^{2}
\end{gathered}
$$

First, consider the variables to be the generalized coordinates $\boldsymbol{r}_{i}, \boldsymbol{\Omega}_{i}(i=1, \ldots, N$ where $N$ is the number of spheres). Writing them as a column vector, of $6 N$ rows, and taking the 
partial derivatives of the total energy with respect to this vector, we obtain the components of the gradient vector $(1 \times 6 N)$. The components of this vector are: the sum of the normal forces and tangential (including effect of rotation) forces as the component of linear coordinates, and the moments as the components of the rotations.

To make the units and the order of the terms in the vector consistent, consider the following preconditioning: multiply the rotation vectors by the corresponding sphere radius, i.e. use $\boldsymbol{R}_{i} \Omega_{i}$ instead of $\boldsymbol{\Omega}_{i}$. This will result in obtaining the moments divided by the respective radius, $\boldsymbol{M}_{i} / R_{i}$ as the rotational components of the gradient. This procedure generates a better conditioned matrix, since it will reduce the difference between the eigenvalues while keeping the units identical: length for the variables, and force for the gradient vector. Furthermore, the use of a single coefficient $\alpha$ in the update is now possible, whereas otherwise one might have different coefficients for the two types of displacements with different units. 


\section{Conclusions from Phase I}

On the basis of the work performed during Phase I of this project, the following summaries and conclusions are presented.

- We have developed a technique for estimating the elastic moduli of a heterogeneous grain pack by modeling mechanical interactions among the grains. Each grain is elastic, and the contact deformations are modeled using Hertz and Mindlin theories. We model the deformation of a grain pack as a sequence of static equilibrium configurations. Each configuration is sought by minimization of the potential energy of the pack. For a loose configuration, our algorithm produces a more realistic tighter pack than other methods. We capture and analyze hysteretic events, such as different loading and unloading responses or abrupt breakage of grain clusters. The computed bulk modulus estimates match experimental values reported in literature. The current progress has been presented at two conferences.

- We chose discrete modeling of heterogeneous assemblies of grains packed randomly, but having a prescribed distribution of sizes and moduli. To keep the model simple, we chose spherical grains, each of which is linearly elastic, homogeneous, and isotropic. Furthermore, we chose quasi-static simulations, where the equilibrium configurations are solved for at the end of each deformation increment.

- We simulated deformations of several heterogeneous grain packs, containing up to $\sim 3,000$ grains with properties of quartz sand. We were able to capture and analyze hysteretic events, such as different loading and unloading responses, or abrupt breakage of grain clusters. The computed bulk modulus estimates matched experimental values reported in literature.

- The difficulty of modeling a granular material arises at two levels: for each grain pair, and for an assembly of grains. Modeling of the contact interaction of a pair of grains, solved by Mindlin (1949), is the first difficulty, as it involves nonlinearity, hysteresis, and 
path-dependence. To overcome this difficulty, we have simplified Mindlin's model by linearizing grain-contact compliances and displacements. This approximation is easily incorporated in simulations of large packs. The second difficulty is in obtaining the forces and displacements in a pack. It has been resolved using a conjugate gradient algorithm, minimizing the total potential energy of the pack. The effective elastic moduli for the pack are obtained from Hooke's law, using the calculated macroscopic stress-strain.

- Initially, we have modeled smooth grains with non-frictional contacts. This model accounts for normal contact forces only, using Hertz theory. This kind of contact model for a grain pair is nonlinear, but path-independent. However, for a heterogeneous, random pack it shows hysteretic effects, due to the complex nature of the contact geometry, and its variability. This model is also used to create a tight pack from a loose random configuration, obtained from other codes, in particular a DEM simulator. Dynamic codes, such as DEM, often suffer from lack of convergence for loose packs, which is resolved elegantly by our model. The frictionless contact model underestimates shear moduli.

- To remedy this deficiency, we are currently developing and testing a frictional contact model. At this stage, neglecting slip, we restrict its applicability to small deformations. With these restrictions, we were able to calculate realistic values of both the bulk and the shear modulus. In addition, we are incorporating hydrates, currently as clusters of smaller grains in the void spaces, and adding cement to the contacts. The current progress has been presented at two conferences.

- We have coupled the TOUGH+/HYDRATE code with FLAC3D, which is a commercial code that is widely used in soil and rock mechanics engineering, and for scientific research in academia. TOUGH+/HYDRATE allows the study of flow and transport of fluids and heat in hydrate deposits, and accurately describes the thermodynamics of hydrates as they are distributed among fifteen possible states. The coupled model, TH+/FLAC is the first of its kind. The model can be used for the analysis of hydraulic, thermal, flow and geomechanical behavior in HBS, and is a unique tool for the analysis of the effect of 
hydrate dissociation processes on the structural stability and possible displacement of HBS and of their overburden materials.

- We have completed a comprehensive literature review to characterize the sediments containing hydrates that have been recovered from scientific cruises. The various regions that have been explored for gas hydrates and were reviewed in our work include Blake Ridge (Offshore South Carolina), Gulf of Mexico, Offshore Oregon (Cascadian Margin and Hydrate Ridge), Nankai Trough (Offshore Japan), Offshore Peru and various other regions explored by the Ocean Drilling Program (ODP). After analyzing all the sediments, we have recommended that three sediment mixtures that we can use for mechanical properties testing in Phase II of this project.

- We have been developing a method to use Petrel as a platform for entering geologic and reservoir data into the TOUGH+-FLAC3D model when it is completed. There are two requirements for using Petrel to populate FLAC3D with geological surfaces and rock properties. One is to demonstrate that FLAC3D can import surfaces and properties from Petrel. The other is to verify that Petrel can generate the geologic structures characteristic of the hydrate zone offshore. We are also working to characterize geologic structure from 2D seismic lines crossing the hydrate zone in the Gulf of Mexico so we can use that information in our modeling efforts. 


\section{References}

Aladko, E. Y., Y. A. Dyadin, V. B. Fenelonov, E. G. Larionov, M. S. Mel'gunov, A. Y. Manakov, A. N. Nesterov, and F. V. Zhurko, 2004, Dissociation conditions of methane hydrate in mesoporous silica gels in wide range of pressure and water content: Journal of Physical Chemistry B, v. 108, p. 16540-16547.

Brooks, J. M., H. B. Cox, W. R. Bryant, M. C. Kennicutt, R. G. M. II, and T. J. McDonald, 1986, Association of gas hydrates and oil seepage in the Gulf of Mexico: Organic Geochemistry, v. 10, p. 221-234.

Brooks, J. M., M. C. Kennicutt, R. R. F. II, T. J. McDonald, and R. Sassen, 1984, Thermogenic gas hydrates in the Gulf of Mexico: Science, v. 225, p. 409-411.

Clennell, M. B., M. Hovland, and J. S. Booth, 1999, Formation of natural gas hydrates in marine sediments 1 . Conceptual model of gas hydrate growth conditioned by host sediment properties: Journal of Geophysical Research, v. 104.

Dicharry, C., P. Gayet, G. Marion, A. Graciaa, and A. N. Nesterov, 2005, Modeling heating curve for gas hydrate dissociation in porous media: Journal of Physical Chemistry B, v. 2005, p. 17205-17211.

Ecker, C., J. Dvorkin, and A. Nur, 2000, Estimating the amount of gas hydrates and free gas from marine seismic data: Geophysics, v. 65, p. 565-573.

Ginsburg, G., V. Soloviev, T. Matveeva, and I. Andreeva, 2000, Sediment grain-size control on gas hydrate presence, Sites 994, 995 and 997: Ocean Drilling Program, Scientific Results, v. 164, p. 237-245.

Gracia, E., F. Martinez-Ruiz, E. Pinero, J. C. Larrasoana, A. Vizcanio, and G. Ercilla, 2006, Data Report: Grain-size and bulk and clay mineralogy of sediments and the presence of gas hydrate in Hydrate Ridge: Ocean Drilling Program, Scientific Results, v. 204.

Handa, Y. P., and D. Stupin, 1992, Thermodynamic properties and dissociation characteristics of methane and propane hydrates in $70 \AA$ radius silica gel pores Journal of Physical Chemistry, v. 96, p. 8599-8603.

He, L., O. Matsubayashi, and X. Lei, 2006, Methane hydrate accumulation model for the Central Nankai accretionary prism: Marine Geology, v. 227, p. 201-214.

Huang, D., and S. Fan, 2005, Measuring and modeling thermal conductivity of gas hydrate bearing sand: Journal of Geophysical Research, v. 110.

Itasca-Consulting-Group, 2002, FLAC3D, Fast LaGrange analysis of continua in 3 dimensions, Minneapolis, Minnesota.

Kilner, J. R., and J. L. H. Grozic, 2006, Determination of synthetic hydrate content in sand specimens using dielectrics Canadian Geotechnical Journal, v. 43, p. 551-562.

Kneafsey, T. J., L. Tomutsa, G. J. Moridis, Y. Seol, B. M. Friefeld, C. E. Taylor, and A. Gupta, In Press, Methane hydrate formation and dissociation in a partially saturated core-scale sand sample: Journal of Petroleum Science and Engineering, In Press

Kono, H. O., S. Narasimhan, F. Song, and D. H. Smith, 2002, Synthesis of methane gas hydrate in porous sediments and its dissociation by depressurizing Powder Technology, v. 122, p. 239-246.

Kumar, P., D. Turner, and E. D. Sloan, 2004, Thermal diffusivity measurements of porous methane hydrate and hydrate-sediment mixtures: Journal of Geophysical Research, v. 109.

Kunerth, D. C., D. M. Weinberg, J. W. R. III, C. L. Scott, and J. T. Johnson, 2001, Acoustic laboratory measurements during the formation of a THF hydrate in unconsolidated porous 
media Journal of Seismic Exploration, v. 9, p. 337-354.

Liang, M., G. Chen, C. Sun, L. Yan, J. Liu, and Q. Ma, 2005, Experimental and modeling study on decomposition kinetics of methane hydrates in different media: Journal of Physical Chemistry B, v. 109, p. 19034-19041.

Makogon, Y. F., 1965, Hydrate formation in gas bearing beds under permafrost conditions: Gazovaia Promyshlennost, p. 14-15.

Makogon, Y. F., 1965, Some problems regarding distribution, exploration and exploitation of natural gas deposits under permafrost conditions: Neft i' gas, p. 24-28.

Makogon, Y. F., 1966, Specialties of exploitation of the natural gas hydrate fields in permafrost conditions: VNII-GAZPROM.

Makogon, Y. F., 1966, Study of gas hydrate formation and dissociation in a pore space.

Makogon, Y. F., 1974, Hydrates of natural gases, NEDRA, Moscow.

Makogon, Y. F., 1981, Hydrates of natural gases, PennWell, Tulsa.

Makogon, Y. F., 1997, Hydrates of hydrocarbons, PennWell, Tulsa.

Makogon, Y. F., 2006, Personal Communication.

Masui, A., H. Haneda, Y. Ogata, and K. Aoki, 2005, The effect of saturation degree of methane hydrate on the shear strength of synthetic methane hydrate sediments, Proceedings of Fifth International Conference on Gas Hydrates, Trondheim, Norway.

Molenaar, N., and A. A. M. Venmans, 1993, Calcium carbonate cementation of sand: A method for producing artificially cemented samples for geotechnical testing and comparison with natural cementation processes: Engineering Geology, v. 35, p. 103-122.

Moridis, G. J., 2003, Numerical studies of gas production from methane hydrates: SPE Journal, v. 32, p. 359-370.

Moridis, G. J., 2004, Numerical studies of gas production from Class 2 and Class 3 hydrate accumulations at the Mallick Site, McKenzie Delta, Canada: SPE Reservoir Evaluation and Engineering, v. 7, p. 175-783.

Moridis, G. J., M. Kowalsky, and K. Pruess, 2005, TOUGH-Fx/HYDRATE v1.0 User's Manual: A code for the Simulation of System Behavior in Hydrate-Bearing Geologic Media, LBNL.

Rutqvist, J., Y. S. Wu, C. F. Tsang, and G. Bodvarsson, 2002, A modeling approach for analysis of coupled multiphase fluid flow, heat transfer, and deformation in fractured porous rock: International Journal of Rock Mechanics and Mining Sciences, v. 39, p. 429-442.

Santamarina, J. C., F. M. Francisca, T. S. Sun, J. Y. Lee, A. I. Martin, and C. Ruppel, 2004, Mechanical, thermal, and electrical properties of hydrate bearing sediments, AAPG Hedberg Conference, Vancouver, BC, Canada, AAPG.

Sassen, R., S. Joye, S. T. Sweet, D. A. DeFreitas, A. Milkov, and I. R. MacDonald, 1999, Thermogenic gas hydrates and hydrocarbon gases in complex chemosynthetic communities, Gulf of Mexico continental slope: Organic Geochemistry, v. 30, p. 485-497.

Shipboard-Scientists, 1996, ODP- Leg 164: Proceedings of Ocean Drilling Program - Initial Reports.

Shipboard-Scientists, 2003, Leg 204 Summary: Proceedings of Ocean Drilling Program - Initial Reports, v. 204.

Sloan, E. D., 1998, Clathrate hydrates of natural gases, Marcel Dekker, Inc.

Smith, D. H., J. W. Wilder, and K. Seshadri, 2002, Methane hydrate equilibria in silica gels with broad pore-size distributions AIChE Journal, v. 48, p. 393-400. 
Spanpenberg, E., J. Kulenkampff, R. Naumann, and J. Erzinger, 2005, Pore space hydrate formation in a glass bead sample from methane dissolved in water: Geophysical Research Letters, v. 32.

Su, X., C. B. Song, and N. Q. Fang, 2006, Relationship between sediment granulometry and the presence of gas hydrate on Hydrate Ridge: ODP Proceedings, Scientific Results, v. 204, p. 130 .

Subramanian, S., R. A. Kini, S. F. Dec, and E. D. Sloan, 2000, Evidence of structure II hydrate formation from methane+ethane mixtures: Chemical Engineering Science, v. 55, p. 19811999.

Sun, C.-Y., G.-J. Chen, and L.-Y. Yang, 2004, Interfacial tension of methane+water with surfactant near the hydrate formation conditions: Journal of Chemical Engineering Data, v. 49, p. 1023-1025.

Tan, B., J. T. Germaine, and P. B. Flemings, 2006, Data Report: Consolidation and strength characteristics of sediments from ODP Site 1244, Hydrate Ridge, Cascadia continental margin: ODP Proceedings, Scientific Results, v. 204.

Tohidi, B., R. Anderson, M. B. Clennell, R. W. Burgass, and A. B. Biderkab, 2001, Visual observation of gas hydrate formation and dissociation in synthetic porous media by means of glass micromodels: Geology, v. 29, p. 867-870.

Trehu, A. M., 2006, Subsurface temperatures beneath Southern Hydrate Ridge: ODP Proceedings, Scientific Results, v. 204.

Trehu, A. M., M. E. Torres, G. Bohrmann, and F. S. Colwell, 2006, Leg 204 Synthesis: Gas hydrate distribution and dynamics in the Central Cascadia Accretionary Prism Complex: Ocean Drilling Program, Scientific Results, v. 204.

Turner, D. J., R. S. Cherry, and E. D. Sloan, 2005, Sensitivity of methane hydrate phase equilibria to sediment pore size: Fluid Phase Equilibria, v. 228-229, p. 505-510.

Uchida, T., T. Ebinuma, S. Takeya, J. Nagao, and H. Narita, 2002, Effects of pore sizes on dissociation temperatures and pressures of methane, carbon dioxide, and propane hydrates in porous media: Journal of Physical Chemistry B, v. 106, p. 820-826.

Uchida, T., S. Takeya, E. M. Chuvilin, R. Ohmura, J. Nagao, V. S. Yakushev, V. A. Istomin, H. Minagawa, T. Ebinuma, and H. Narita, 2004, Decomposition of methane hydrates in sand, sandstone, clays and glass beads: Journal of Geophysical Research, v. 109.

Waite, W. F., B. J. deMartin, S. H. Kirby, J. Pinkston, and C. D. Ruppel, 2002, Thermal conductivity measurements in porous mixtures of methane hydrate and quartz sand: Geophysical Research Letters, v. 29.

Winters, W. J., 2000, Data Report: Effects of drying methods and temperatures on water content and porosity of sediment from the Blake Ridge: Ocean Drilling Program, Scientific Results, v. 164, p. 431-434.

Winters, W. J., 2000, Stress history and geotechnical properties of sediment from the Cape Fear Diapir, Blake Ridge Diapir and Blake Ridge: Ocean Drilling Program, Scientific Results, v. 164, p. 421-429.

Winters, W. J. W., William F; Mason, David H, 2006, Effects of Methane Hydrate on Physical Properties of Sediment: Personal Communication.

Winters, W. J., I. A. Pecher, W. F. Waite, and D. H. Mason, 2004, Physical properties and rock physics models of sediment containing natural and laboratory-formed methane gas hydrate American Mineralogist, v. 89, p. 1221-1227. 
Winters, W. J., W. F. Waite, D. H. Mason, L. Y. Gilbert, and I. A. Pecher, In Press, Methane gas hydrate effect on sediment acoustic and strength properties: Journal of Petroleum Science and Engineering.

Yan, L., G. Chen, W. Pang, and J. Liu, 2005, Experimental and modeling study on hydrate formation in wet activated carbon: Journal of Physical Chemistry B, v. 109, p. 6025-6030.

Yun, T. S., F. M. Francisca, J. C. Santamarina, and C. Ruppel, 2005, Compressional and shear wave velocities in uncemented sediment containing gas hydrate: Geophysical Research Letters, v. 32.

Zatsepina, O. Y., and B. A. Buffett, 2001, Experimental study of the stability of CO2 hydrate in a porous medium: Fluid Phase Equilibria, v. 192, p. 85-102. 